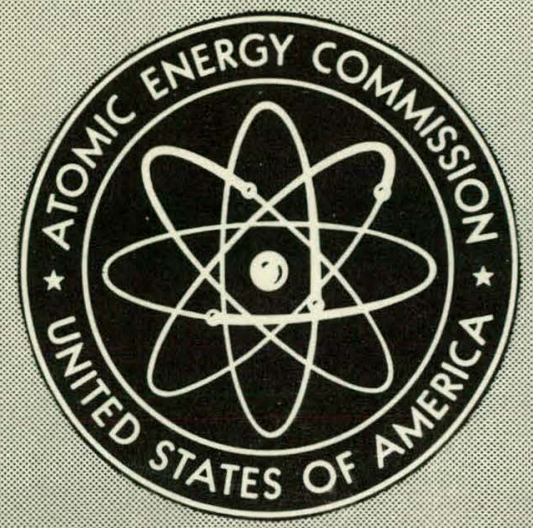

BAW - 393- 7

EVALUATION OF THORIUM FUELS FOR THE HEAVY WATER ORGANIC COOLED REACTOR

July 1966

Atomic Energy Division

The Babcock \& Wilcox Company

Lynchburg, Virginia 


\section{DISCLAIMER}

This report was prepared as an account of work sponsored by an agency of the United States Government. Neither the United States Government nor any agency Thereof, nor any of their employees, makes any warranty, express or implied, or assumes any legal liability or responsibility for the accuracy, completeness, or usefulness of any information, apparatus, product, or process disclosed, or represents that its use would not infringe privately owned rights. Reference herein to any specific commercial product, process, or service by trade name, trademark, manufacturer, or otherwise does not necessarily constitute or imply its endorsement, recommendation, or favoring by the United States Government or any agency thereof. The views and opinions of authors expressed herein do not necessarily state or reflect those of the United States Government or any agency thereof. 


\section{DISCLAIMER}

Portions of this document may be illegible in electronic image products. Images are produced from the best available original document. 


\section{LEGAL NOTICE}

This report was prepared as an account of Government sponsored work. Neither the United States, nor the Commission, nor any person acting on behalf of the Commission:

A. Makes any warranty or representation, expressed or implied, with respect to the accuracy, completeness, or usefulness of the information contained in this report, or that the use of any information, apparatus, method, or process disclosed in this report may not infringe privately owned rights; or

B. Assumes any liabilities with respect to the use of, or for damages resulting from the use of any information, apparatus, method, or process disclosed in this report.

As used in the above, "person acting on behalf of the Commission" includes any employee or contractor of the Commission, or employee of such contractor, to the extent that such employee or contractor of the Commission, or employee of such contractor prepares, disseminates, or provides access to, any information pursuant to his employment or contract with the Commission, or his employment with such contractor.

This report has been reproduced directly from the best available copy.

\section{$\not 2$}

Printed in USA. Price $\$ 0$. Available from the Clearinghouse for Federal Scientific and Technical Information, National Bureau of Standards, U. S. Department of Commerce, Springfield, Virginia 22151. 


\title{
CPSTI PUCES
}

xe. $\frac{3,00}{201} \cdot 65$

\author{
EVALUATIION OF THORIUM FUELS \\ for the
}

HEAVY WATER ORGANIC COOLED REACTOR

Approved by $\frac{\text { W. M. Vannoy, Jr. }}{\text { Project Manager }}$

July 1966

AEC Contract No. AT(38-1)-393

B\&W Contract No. 59-3098

Submitted to

THE UNITED STATES ATOMIC ENERGY COMMISSION

by

THE BABCOCK \& WILCOX COMPANY

Atomic Energy Division

Lynchburg, Virginia 


\section{THIS PAGE}

\section{WAS INTENTIONALLY \\ LEFT BLANK}




\title{
ACKNOW LEDGMENT
}

This report was prepared by the following members of the HWOCR Thorium Project:

\author{
M. W. Croft \\ L. B. Gross \\ F. M. Alcorn \\ C. A. Burkart \\ T. C. Engelder \\ H. Honig \\ J. W. Merchent \\ E. C. Moncrief \\ D. C. North \\ S. W. Spetz \\ W. M. Vannoy
}




\section{THIS PAGE}

\section{WAS INTENTIONALLY \\ LEFT BLANK}




\section{ABSTRACT}

This report summarizes the results of work done by The Babcock \& Wilcox Company to evaluate thorium fuels for the Heavy Water Organic Cooled Reactor (HWOCR). This work is a part of the USAEC's overall program to develop ecconomical heavy water reactors having optimum fuel utilization. The long-range objective of the thorium fuel cycle development is the proof of performance of thorium fuel elements in an HWOCR environment.

The primary effort to date has been related to the selection of a thorium fuel element for future development. Three types of fuel elements were studied in detail: thorium metal nested cylinders, thorium oxide clustered pins, and thorium monocarbide clustered pins. On the basis of extensive parameter studies an optimum design of each type was selected for final evaluation. The economics and fuel utilization of the three fuel element types were evaluated for use in a 1000-MWe HWOCR. Technical feasibility and development costs were also considered in the selection process. A test program was planned in conjunction with the optimization studies to define key technical problems and the development required.

On the basis of the comparative evaluation it is recommended that both the oxide and the metal fuel elemcnts be carried through several phases of irradiation testing before a final selection is made. Priority should be given to the development of the $\mathrm{ThO}_{2}$ fuel element. The initiation of test work as soon as it is practical will give substance to the continued effort toward achieving the long-range objectives of the HWOCR Program. 


\section{THIS PAGE}

\section{WAS INTENTIONALLY LEFT BLANK}




\section{CONTENTS}

Page

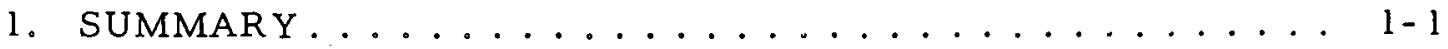

2. $1000 \mathrm{MWe}$ THORIUM HWOCR DESIGNS........... 2-1

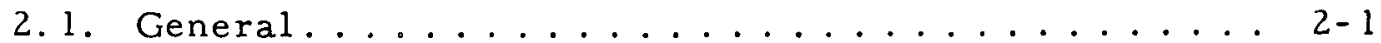

2.2. Overall Plant Design................ 2-1

2.3. Thorium Metal Core Designs............. 2- 3

2.4. Thorium Oxide Core Designs........... 2-23

2.5. Thorium Carbide Core Design............ 2-37

3. HWOCR THORIUM FUEL CYCLE DEVELOPMENT

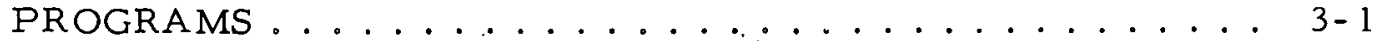

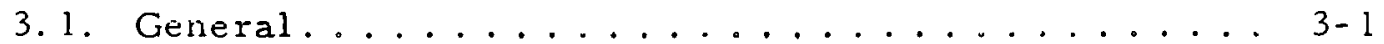

3.2. Thorium Metal Fuel Element Test Program....... 3-2

3.3. Thorium Oxide Fuel Element Test Program....... 3-24

3.4. Thorium Monocarbide Euel Element Test Program... 3-41

3. 5. Additional R\&D Required for Commercial Acceptance...................... 3-52

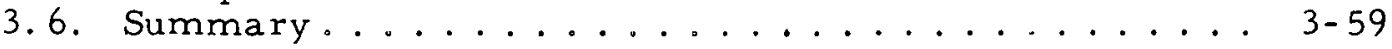

4. COMPARATIVE EVALUATION OF THORIUM EUELS ... 4-

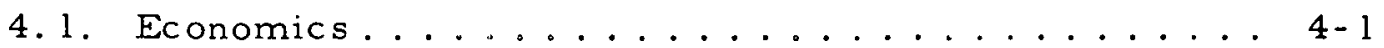

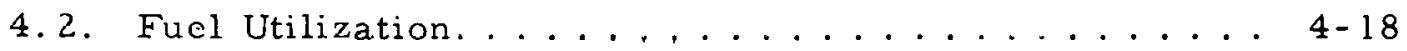

4.3. Compatibility of Thorium Fuel Elements With AI-CE HWOCR .................... 4-... 22

4.4. Technical Feasibility............... 4-... 23

4.5. Saftety ......................... $4-27$

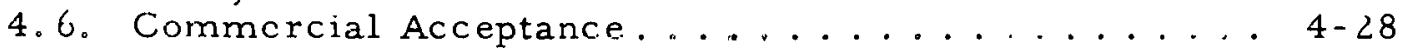

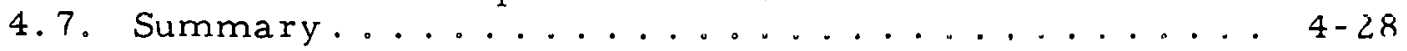

5. RECOMMENDATION ..................... $5-\ldots$

\section{List of Tables}

Table

1-1. 1000 MWe Thorium HWOCR Design Data Summary.... 1-5

2-1. Core Design Data for Four-Cylinder Thorium Metal Fuel Element (With Center Moderator) in a 5.0-Inch-ID Pressure Tube ................... 2-... 43 
Table

2-2. Core Design Data for Five-Cylinder Thorium Metal Fuel Element in a 4.030-Inch-ID Pressure Tube (AI-CE) . . 2-52

2-3. Core Design Data for 37-Pin $\mathrm{ThO}_{2}$ Fuel Element in a 4.030-Inch-ID Pressure Tube ........... 2-58

2-4. Core Design Data for 55-Pin Thorium Oxide Fuel Element in. a 4.030-Inch-ID Pressure Tube ...... 2-66

2-5. Core Design Data for 37-Pin Thorium Carbide Fuel Element in a 4.030 -Inch-ID Pressure Tube ...... 2-72

3-1. Chemical and Metallurgical Uncertainties in ThoriumUranium Fuel Processing.............. 3-60

3-2. Uncertainties in Design of Thorium-Uranium Fuel Processing Equipment................ 3-61

4-1. 30-Year Levelized Fuel Cycle Cost, U-235 Startup Fuel. . 4-29

4-2. 30-Ycar Levelized Fuel Cycle Cost, Plutonium Startup and Recycle..................... 4-29

4-3. Capital, $\mathrm{D}_{2} \mathrm{O}$, and Operation and Maintenance Cost 1000-MWe Thorium-Optimized Designs ......... 4-... 30

4-4. Batch "Idealized" Cycle Fuel Cycle Costs.......... 4-31

4-5. Comparative Unit Processing Costs for Thorium-

Optimized HWOCR Fuel Elements ............ 4-32

4-6. Comparis on of Dynamic Fuel Utilization.......... 4-32

4-7. Fuel Element Test Program Preliminary Cost Estimate

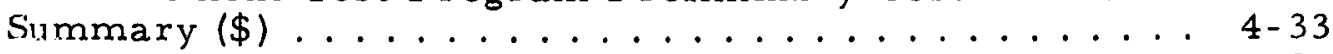

5-1. Evaluation of Alternate Courses of Action......... $5-3$

\section{List of Figures}

Figure

2-1. HWOCR 4-Cylinder Thorium Metal Fuel Element (With

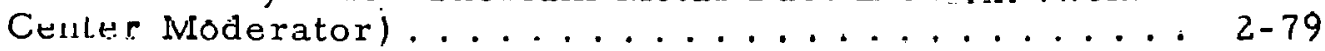

$2-2$. Bow Condition Between Two Adjacent Cylinders...... $2-81$

2-3. Gross Axial Power Distribution ............ 2-82

2-4. Radial Power Distribution (Three Equal Volume

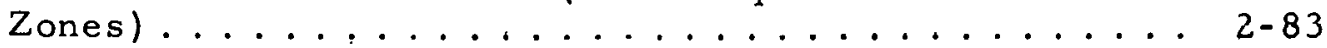

2-5. Axial Local Power Peaking ( $P / \bar{P})$ in Nested-Cylinder

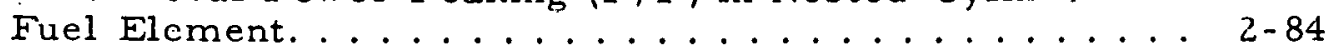

2-6. Coolant, Cladding, and Fuel Temperatures Vs Active Fuel Length (Hottest Cylinder and Coolant Channel -

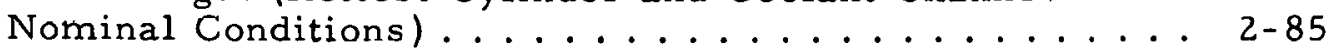

2-7. Coolant, Cladding, and Fuel Temperature Vs Active Fuel Length (Hottest Cylinder and Coolant Channel Hot Channel Factors) .............. 2-86

2-8. Ratio of Burnout Heat Flux to Actual Heat Flux, Based on Constant Saturation Temperature of $850 \mathrm{~F} \ldots \ldots$. . 2-87

2-9. Five-Cylinder Thorium Metal Fuel Element, Cross Section..................... 2-88 
Figure

2-10. Coolant, Cladding, and Fuel Temperatures Vs Active Fuel Length (Hottest Cylinder and Coolant Channel Nominal Conditions)................. 2-89

2-11. Coolant, Cladding, and Fuel Temperatures Vs Active Fuel Length (Hottest Cylinder and Coolant Channel Hot Channel Factors)............... 2-... 90

2-12. Ratio of Burnout Heat Flux to Actual Heat Flux, Based on Constant Saturation Temperature of $850 \mathrm{~F} . \ldots 2-91$

2-13. HWOCR 37-Pin $\mathrm{ThO}_{2}$ Fuel Element.......... 2-93

2-14. Axial Local Power Peaking $(P / \bar{P})$ in Clustered-Pin

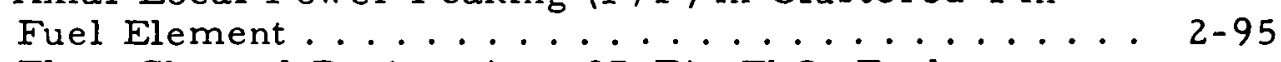

2-15. Flow-Channel Designation, 37-Pin $\mathrm{ThO}_{2}$ Fuel

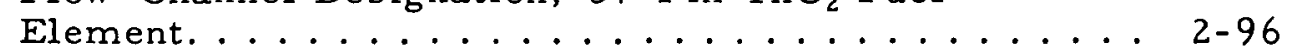

2-16. Hot Channel Coolant and Cladding Surface Temperature Vs Active Fuel Length ................ 2-. 297

2-17. Hot Fuel Pin Temperatures Vs Active Fuel Length ... 2-98

2-18. Ratio of Burnout Heat Flux to Actual Flux, Based on Constant Saturation Temperature of $850 \mathrm{~F} \ldots \ldots$ 2-... . . 99

2-19. Fission Gas Pressure in Hot Pin Vs Full Power

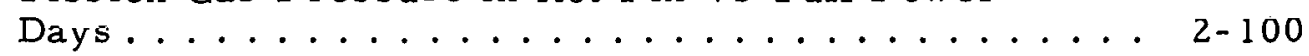

2-20. 55-Pin $\mathrm{ThO}_{2}$ Fuel Element, Cross Section....... 2-101

2-21. Coolant and Cladding Temperatures Vs Active Fuel Length, 55-Pin $\mathrm{ThO}_{2}$ Fuel Element in 4.030-Inch-ID

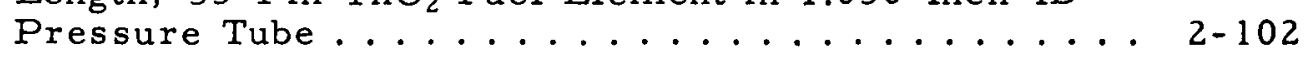

2-22. Ratio of Burnout Flux to Actual Flux, Based on Constant Saturation Temperature of $850 \mathrm{~F} \ldots \ldots 2-103$

2-23. Flow-Channel Designation, 37-Pin Thorium Carbide

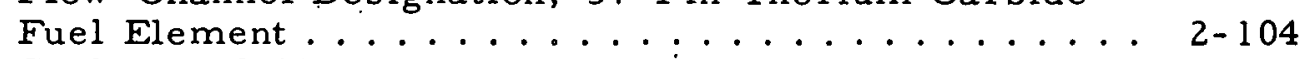

2-24. Coolant and Cladding Temperatures Vs Active Fuel Length, Thorium Carbide Fuel Element ........ 2-105

2-25. Ratio of Burnout Flux to Actual Flux, Based on Constant Saturation Temperature of $850 \mathrm{~F} \ldots \ldots . .2-106$

4-1. Fuel Cycle Cost Vs Fuel Exposure............. 4-34

4-2. Fuel Cycle Cost Vs Plutonium Value (Oxide Core)... 4-35

4-3. Effect of Allowable Cladding Surface Temperature on Core Pressure Drop and Coolant Outlet Temperature ....................... 4-35

4-4. Thorium Fuel Elements: Conversion Ratio Factor Vs Fuel Volume Fraction .................... 4-36

4-5. Preliminary Schedule for Thorium Metal Nested-

Cylinder Fuel Element Test Program......... 4-37

4-6. Preliminary Schedule for Thorium Oxide Clustered-

4-7. Preliminary Schedule for Thorium Monocarbide .... 4-38 Clustered-Pin Fuel Element Test Program ....... 4-39 


\section{SUMMARY}

The primary effort of the Commission's Heavy Water Program, under a contract with AI-CE, is the development of the HWOCR to operate on the uranium fuel cycle. A secondary effort, under a contract with $B \& W$, is the development of the thorium fuel cycle for the HWOCR. At minimum incremental R\&D expense, the HWOCR will have the fuel cycle flexibility to enable the efficient use of our thorium resources when technical and economic factors favor the integration of the thorium fuel cycle into the nuclear economy. Adaptation of thorium fuel to the AI-CE design will also permit proof of performance in an HWOCR environment and/or the near-term construction of a Thorium HWOCR for special applications, such as the development of a nuclear power industry in a nation having large thorium resources.

The HWOCR Thorium Program overall plan has two major phases: Phase I, Evaluation and Planning; Phase II, Thorium Fuel Cycle Development. This report summarizes the results of work done in Phase I, which covers the period of January 1965 through June 1966. The objectives of the Phase I work program were to select a reference thorium fuel element and to prepare a test program plan for the development of this fuel element under Phase II. Three basic types of fuel elements were studied:

\begin{tabular}{lcl} 
Thorium form & Fuel cladding & \multicolumn{1}{c}{ Geometry } \\
\cline { 3 - 3 } Metal & Zircaloy & Nested cylinders \\
Oxide & SAP & Clustered pins (finned) \\
Monocarbide & SAP & Clustered pins (finned)
\end{tabular}

The economics and fuel utilization of these fuel elements were evaluated for a $1000 \mathrm{MWe}$ thorium-optimized HWOCR and for the $1000 \mathrm{MWe}$ AI-CE design. The comparison of the thorium-optimized reactor and 
the thorium-fueled $A I-C E$ reactor shows that the two systems are basically compatible. The design of the thorium-optimized reactor was carried out as an independent effort by $B \& W$. In such areas as refueling and pressure tube design there were basic differences between the uranium and thorium designs. However, since compatibility was demonstrated, the AI-CE reactor arrangement was adopted for the thorium core.

The evolution of a near-optimum design for each type of fuel element involved the evaluation of a number of designs encompassing a broad range of parameters, which significantly affect power costs and fuel utilization. ORNL evaluated thorium metal and thorium oxide designs submitted in November 1965. This evaluation confirmed that more extensive optimization would be required before a valid comparison with alternate concepts could be made. The information developed by ORNL proved valuable to $B \& W$ in continuing the design optimization. The optimization studies led to the $1000 \mathrm{MWe}$ Thorium HWOCR designs described in section 2. A design data summary is given in Table $1-1$.

The relative performance of the $1000 \mathrm{MWe}$ thorium-optimized HWOCR's is indicated by the following summary:

Costs, mills/kwhr

\begin{tabular}{|c|c|c|c|c|c|}
\hline \multirow[b]{3}{*}{$\begin{array}{l}1000 \text { MWe HWOCR } \\
\text { conceptual design }\end{array}$} & \multicolumn{4}{|c|}{ Costs, mills/kwhr } & \multirow[b]{3}{*}{$\begin{array}{l}\text { Conversion ratio } \\
\text { (equilibrium cycle) }\end{array}$} \\
\hline & \multicolumn{2}{|c|}{ Fuel } & \multicolumn{2}{|c|}{ Power } & \\
\hline & $\begin{array}{c}\text { Investor - } \\
\text { owned } \\
\text { utility } \\
\end{array}$ & $\begin{array}{c}\text { Publicly- } \\
\text { owned } \\
\text { utility } \\
\end{array}$ & $\begin{array}{c}\text { Inve stor - } \\
\text { owned } \\
\text { utility } \\
\end{array}$ & $\begin{array}{c}\text { Publicly- } \\
\text { owned } \\
\text { utility } \\
\end{array}$ & \\
\hline Thorium metal & 1.19 & 0.94 & 3.54 & 2.40 & 0.86 \\
\hline Thorium oxide & 1.23 & 0.95 & 3.73 & 2.49 & 0.87 \\
\hline Thorium carbide & 1.23 & 0.99 & 3.71 & 2.52 & 0.87 \\
\hline
\end{tabular}

Fuel cycle costs for the three designs are about equal. The nested-cylinder design shows a slight advantage in power costs, primarily due to lower capital costs resulting from higher power per pressure tube. The cost differences are probably within the uncertainty band; therefore, factors other than economics must also be carefully evaluated.

As indicated above, the three designs have approximately the same conversion ratio. Also, the Dynamic Utilization does not show 
any significant fuel utilization advantage for any design. The similar performances may indicate that economic optimization leads to about the same fuel utilization characteristics. Higher values of conversion ratio can be achieved at the expense of economics by increasing the fuel volume fraction within the pressure tube.

Each of the three fuel element types is adaptable to the AI-CE HWOCR. The ThC fuel element is identical for the thorium-optimized and the AI-CE HWOCR designs and has basically the same configuration as the 37-pin UC fuel element. The Th-U nested-cylinder fuel element is capable of more power output per unit volume than the UC fuel element; therefore, the Th-U core offers a potential "stretch" position for the AI-CE HWOCR. The $\mathrm{ThO}_{2}$ fuel element has a lower pin heat rating $(\mathrm{kw} / \mathrm{ft}$ ) than the UC fuel element and requires 55 pins instead of 37 to achieve the same power output. The smaller diameter pins in the 55pin element increase fabrication costs by about $0.1 \mathrm{mill} / \mathrm{kwhr}$.

Fuel element test programs were planned for each type of fuel element. The key problems to be investigated for the nested-cylinder design are the fabrication tolerances of large-diameter (up to about 5 inches), thin-wall, closely packed cylinders and the dimensional stability of these cylinders under long-term irradiation (20,000 MWD/T average) in an HWOCR environment. The principal limitation on the performance of the $\mathrm{ThO}_{2}$ fuel element is the fission gas pressure buildup in the low-ductility SAP cladding with low (approximately 300 psi or less) external pressure. There is a gross lack of data for ThC, but it is known that $\mathrm{ThC}$ is highly reactive with moisture in air. Before other development tasks can be undertaken, a fuel composition that is resistant to attack by moisture must be developed.

The preliminary cost estimates for the fuel element test programs (outlined in section 3) are summarized below:

$\begin{array}{lr}\text { Thorium metal } & \$ 7,366,300 \\ \text { Thorium oxide } & 5,005,300 \\ \text { Thorium monocarbide } & 7,123,800\end{array}$

In addition, it is anticipated that a supporting experimental physics program will be conducted at SRL at an additional cost of about $\$ 1.8$ million, without much cost variation for the different fuel element types. Not estimated on an absolute basis is the development of recycle technology 
required to achieve large-scale production capability. On a relative basis, it is estimated that $\mathrm{ThO}_{2}$ would require only about one-third as much development as either Th-U. or ThC.

The comparative evaluation of thorium fuels for the HWOCR is discussed in detail in section 4 . On the basis of this evaluation, it was concluded that there is little incentive to develop ThC since the economic and fuel utilization performance is no better than the performance of $\mathrm{ThO}_{2}$ and the technical obstacles to successful development of $\mathrm{ThC}$ are much greater. It is recommended that both $\mathrm{Th}-\mathrm{U}$ and $\mathrm{ThO}_{2}$ be carried through several phases of irradiation testing. After sufficient data have been obtained on the dimensional stability of the nested cylinders and on the fission gas limits of the SAP-clad $\mathrm{ThO}_{2}$.pins, the correct decision can be made with a high degree of confidence. If practical considerations require the selection of a single fuel element, $\mathrm{ThO}_{2}$ is the recommended choice. $\mathrm{ThO}_{2}$ provides the shortest and cheapest route to the successful development of a thorium fuel element for the HWOCR. The $\mathrm{ThO}_{2}$ design and the production processes have flexibility for adapting to changing technical and economic conditions that may favor the large-scale application of the HWOCR thorium fuel cycle. 


\begin{tabular}{|c|c|c|c|}
\hline Parameter & $\begin{array}{c}\mathrm{ThO}_{2} \\
\text { clustered-pin } \\
\text { design } \\
\end{array}$ & $\begin{array}{c}\text { ThC } \\
\text { clustered-pin } \\
\text { design } \\
\end{array}$ & $\begin{array}{c}\text { Th- U } \\
\text { nested-cylinder } \\
\text { design } \\
\end{array}$ \\
\hline \multicolumn{4}{|l|}{ Material } \\
\hline Fuel & $\mathrm{ThO}_{2}$ & ThC & Th-U metal \\
\hline Cladding & SAP & SAP & $\mathrm{Zr}-4$ \\
\hline Coolant & $\begin{array}{l}\text { Santowax OM, } \\
10 \% \mathrm{HB}\end{array}$ & $\begin{array}{l}\text { Santowax OM, } \\
10 \% \mathrm{HB}\end{array}$ & $\begin{array}{l}\text { Santowax OM, } \\
10 \% \mathrm{HB}\end{array}$ \\
\hline Moderator & $\mathrm{D}_{2} \mathrm{O}$ & $\mathrm{D}_{2} \mathrm{O}$ & $\mathrm{D}_{2} \mathrm{O}$ \\
\hline \multicolumn{4}{|l|}{ Power } \\
\hline Reactor power, MWt & 3100 & 3151 & 3187 \\
\hline Power to coolant, MWt & 2936 & 2984 & 3019 \\
\hline Power to moderator, $\mathrm{MWt}$ & 157 & 157 & 158 \\
\hline Net electric output, $\mathrm{MWe}$ & 1076 & 1076 & 1076 \\
\hline $\begin{array}{l}\text { Power/pressure tube, } \\
\text { MWt (max) }\end{array}$ & 4.53 & 6.37 & 10.9 \\
\hline $\begin{array}{l}\text { Power/pressure tube, } \\
\text { MWt (avg) }\end{array}$ & 4.09 & 5.75 & 9.8 \\
\hline $\begin{array}{l}\text { Specific power, w/gm } \\
\text { (avg) }\end{array}$ & 25.8 & 32.0 & 32.0 \\
\hline \multicolumn{4}{|l|}{ Reactor } \\
\hline $\begin{array}{l}\text { Number of pressure } \\
\text { tuhes }\end{array}$ & 758 & 548 & 324 \\
\hline Presoure tube ID, in. & 4.03 & 4.03 & 5.00 \\
\hline Pressure tube pitch, in. & 9.5 & 11.0 & 11.6 \\
\hline $\begin{array}{l}\text { Moderator tank diameter, } \\
\text { ft-in. }\end{array}$ & $26-7$ & $26-3$ & $21-7$ \\
\hline $\begin{array}{l}\text { Moderator tank height, } \\
\text { ft-in. }\end{array}$ & 20 & 20 & $21-4$ \\
\hline Active core length, ft-in. & $17-9.4$ & $17-9.4$ & $18-9$ \\
\hline \multicolumn{4}{|l|}{ Thermal-hydraulic } \\
\hline Stearin temp, $F$ & 675 & 675 & 675 \\
\hline $\begin{array}{l}\text { Steam pressure at turbine, } \\
\text { psia }\end{array}$ & 900 & 900 & 900 \\
\hline Reactor inlet temp, $F$ & 560 & 560 & 560 \\
\hline Reactor outlet temp, $F$ & 721.4 & 716.2 & 708 \\
\hline $\begin{array}{l}\text { Coolant flow rate, } 1 \mathrm{~b} / \mathrm{hr} \\
\times 10^{6}\end{array}$ & 107 & 113 & 119 \\
\hline Core presoure drop, poi & 92 & 153 & 185 \\
\hline $\begin{array}{l}\text { Surface temp excluding } \\
\text { fouling allowances, F }\end{array}$ & 830 & 830 & 820 \\
\hline Max heat flux, Btu/hr $-\mathrm{ft}^{2}$ & 223,000 & 313,000 & 400,000 \\
\hline Core inlet pressure, poia & 229 & 292 & 322 \\
\hline Core outlet pressure, poia & 137 & 137 & 137 \\
\hline \multicolumn{4}{|l|}{ Nuclear } \\
\hline $\begin{array}{l}\text { Fuel loading }(U+T h \\
\text { metal), } \mathrm{kg}\end{array}$ & 119,700 & 98,900 & 98,800 \\
\hline Avg fuel burnup. $M W D / T$ & 20,000 & 20,000 & 20.000 \\
\hline $\begin{array}{l}\text { Initial U-235 enrichment, } \\
\text { wt } \%\end{array}$ & 2.31 & 2.32 & 2.40 \\
\hline $\begin{array}{l}\text { Equilibrium cycle conver- } \\
\text { sion ratio }\end{array}$ & 0.87 & 0.87 & 0.86 \\
\hline $\begin{aligned} \text { Fuel management: on-line } \\
\text { adjacen }\end{aligned}$ & $\begin{array}{l}\text { tinuous refu } \\
\text { anncls }\end{array}$ & , countercus & in \\
\hline
\end{tabular}




\section{1000 MWe THORIUM HWOCR DESIGNS}

\subsection{General}

To provide bases for evaluating thorium fuels for HWOCR use, conceptual designs were evolved for (1) a 1000-MWe thorium-optimized HWOCR and (2) a thorium core for the uranium-optimized 1000-MWe HWOCR designed by AI-CE. A number of designs were evaluated in optimization studies that preceded the selection of a near-optimum design for each type of fuel element. (The design evolution is discussed in technical progress reports. ${ }^{1-3}$ ) Detailed calculations have been made for the selected designs, and the resultant conreptual designs are described in this section. These designs provide the bases for defining key technical problems to be investigated in the test programs (outlined in section 3) and for the comparative evaluation of the thorium fuels (presented in section 4 ).

\subsection{Overall Plant Design}

In accordance with Commission objectives, $B \& W$ has concentrated on the reactor core and relied on the AI-CE plant design effort, with the exception of some work in the area of reactor internals to guide and support the optimization of the thorium cores. Thus the overall plant design for the thorium cores is basically identical to the HWOCR plant design described in AI-CE-MEMO-25,4 except that the design power is $1076 \mathrm{MWe}$, and different numbers of pressure tube assemblies are required depending on the fuel material. Operating parameters also differ slightly, but these can be adjusted to conform to the HWOCR plant values by relatively minor modifications to the fuel element design.

The reactor complex for each of the three reference thorium cores consists of pressure tube assemblies arranged vertically in a calandria vessel which contains the heavy water moderator. Each pressure tube assembly consists of a SAP pressure tube and a zirconium alloy calandria tube that surrounds the pressure tube and separates it 
from the moderator, forming an insulating annulus filled with $\mathrm{CO}_{2}$. Each pressure tube contains a stack of five fuel element assemblies. Two shield plug assemblies at each end of the fuel column hold the fuel elements in the core and prevent radiation streaming from the channel. Santowax-OM coolant enters and leaves through tee connections and "pigtail" piping which connects the process tubes to the inlet and outlet headers at the top and bottom of the reactor. The cylindrical calandria vessel contains the $\mathrm{D}_{2} \mathrm{O}$ moderator and surrounds the fuel channel as semblies to provide a 12 -inch reflector in both axial and radial directions outside of the core. The heat generated in the moderator heats the boiler feedwater. Integral end shields provide radiation protection. The concrete radial biological shield supports the reactor and end shields.

Refueling is performed with the reactor at power by two refueling machines located above and below the reactor structure. The machines are supported vertically from rail structures by carriages which position them opposite the ends of any fuel channel.

The core has one-pass, bi-directional coolant flow with bi-direclional, on-power refueling. The coolant flows in opposite directions in adjacent process tubes to maintain flow in the same direction as the fuel movement. This arrangement results in lower coolant temperatures in the higher power regions of the core and thus improves thermal performance. Process tubes are orificed to match coolant flow rates to the basic radial power distribution so that the coolant temperaturc rise is approximately the same across all the pressure tubes.

Three primary soolant loops aic pruvided; each consists of a tur bine-driven circulating pump and evaporator, superheater, and reheater sections with interconnecting piping. At design power, organic coolant is circulated at the rate of about $115 \times 10^{6} \mathrm{lbs} / \mathrm{hr}$, varying slightly with the different fuel materials. The pressure at the outlet mixing tank is controlled at 100 psia. Coolant is heated in the core from 560 to approximately $705 \mathrm{~F}$, absorbing about $3000 \mathrm{MWt}$. The heat is used to generate superheated steam at $925 \mathrm{psig}$ and $675 \mathrm{~F}$ and to reheat this steam after it leaves the high-pressure section of the steam turbine. More specific operating parameters are detailed under each core description. 
The reactor and moderator systems and the refueling machine are housed in a cylindrical pressure containment building. All other plant systems and components, including the steam generators, are located outdoors or are housed in conventional buildings appropriately grouped around the reactor building. The main coolant piping is equipped with double shut-off valves where it penetrates the reactor building.

\subsection{Thorium Metal Core Designs}

\subsubsection{Thorium-Optimized Core}

\subsubsection{Core Description}

The design of a low-enriched thorium metal nested-cylinder core for the 1000-MWe Thorium HWOCR is described in this section. Design parameters are listed in Table 2-1. The reactor has 324 pressure tubes on an 11.6-inch square pitch, surrounded by $\mathrm{D}_{2} \mathrm{O}$ in a 21 -foot, 4-inch-ID moderator tank. Each pressure tube has a 5-inch ID and contains five fuel elements stacked axially to form an active fuel length of 18 feet, 9 inches. Coolant flow and refueling are bi-directional. The coolant flows in opposite directions in adjacent pressure tubes and in the same direction as the fuel movement.

The Santowax coolant flow rate through the reactor is $119 \times 10^{6} \mathrm{lb} / \mathrm{hr}$ at a header-to-header pressure drop of $239 \mathrm{psi}$. The total system pressure drop is $339 \mathrm{psi}$. The coolant transports 3019 MW of heat while increasing its temperature from 560 to $708 \mathrm{~F}$. In addition to the heat transported by the coolant, the reactor generates 158 $\mathrm{MWt}$ in the moderator and $10 \mathrm{MWt}$ in the shield for a total output of 3187 MWt. This output will produce $1076 \mathrm{MWe}$ at a net plant efficiency of $33.8 \%$ 。

The fuel element is an assembly of four fuel tubes arranged concentrically around a central moderator can to form annular coolant channels (Figure 2-1). The coolant gap between adjacent tubes is $0.150 \mathrm{inch}$, the exterior coolant channel is 0.110 inch wide, and the coolant channel between the moderator can and the inner fuel cylinder is a 0.110 -inch gap. The can is orificed to restrict bypass flow. The 46.3-inch length of the fuel element includes 45 inches of active fuel in cylinders 1,2 , and 3 , and 44.55 inches of active fuel in cylinder 4 . 
The annular geometry allows optimum thermal conditions for each cylinder and flow channel, so that an average of 9.3 MWt can be removed from each pressure tube without exceeding conservative design limits.

Conversion of Th-232 to U-233 is enhanced by continuous refueling, since the use of poisons to hold down excess reactivity is minimized. With an initial enrichment of $\approx 2.4$ wt $\% \mathrm{U}-235$, the equilibrium conversion ratio is about 0.86 at $20,000 \mathrm{MWD} / \mathrm{T}$ burnup.

A pre-fouling maximum surface temperature of $820 \mathrm{~F}$ has been selected for this design to avoid excessive decomposition and fouling of the coolant or hydriding of the cladding. Protuber ances on the heated surface of the fuel cylinders (such as local spacers) are avoided to prevent local coolant stagnation. This prevents coolant charring, which could lead to progressive fouling and flow blockage. The rate of hydriding of Zircaloy has been shown to bc strongly temperature-dependent. Central fuel temperature is limited to about $1000 \mathrm{~F}$ by accelerated irradiation growth rates; however, this temperature is not reached in the fuel because of the surface temperature limit and the good thermal conductivity of the metal fuel.

\subsubsection{Mechanical Design}

'l'he tuel cylinders are made by a coextrusion process in which the Zircaloy cladding (0.025-inch thick) is bonded to the low-enriched thorium metal. The cylinders are extruded in long lengths and then cut to the required length. The fucl is tapered at either end of the cylinder as a result of the extrusion process, and the end sap is extruded as an integral part of the cylinder. Sealing with end rings, with associated problems of machining, brazing, and welding, is eliminated by this process. More importantly, it reduces the axial peaking between elements. The use of the extruded end cap depends upon the success of the development program outlined in section 3.2 .

The coextrusion fabrication process has been developed by NMI, SRL, and PNL, using both thorium and uranium metal. The process is adaptable to remote fabrication and recycle of the U-233 produced in the reactor. ${ }^{5}$

Figure 2-1 illustrates the assembly of the fuel element. The four fuel cylinders are supported and pinned (to eliminate 
all welding at final assembly) to the base plate, which is a rim attached to a center hub with six radial spokes. A comb effect is incorporated in each spoke to pin and locate the plates for accurate control of the coolant channels. The fuel cylinders are assembled to the comb by line drilling to receive the six 0.188-inch-diameter Zircaloy pins. Since the pins are captured within the fuel element and the pressure tube, no tack welding is needed. The base plate is designed so that the outer rim will accept refueling equipment. The top end cap of the outer cylinder has the same geometry to permit handling at that end. This design is adaptable to an AI-CE refueling scheme. Cylinder 1 has two raised lugs at the top that fit into two mating slots in the lower end cap of the axially adjacent cylinder to prevent rotation of one element with respect to the other.

The flow area in the base plate is greater than that within the fuel element to minimize entrance effects on flow distribution. Six full-length straight spacer ribs on each cylinder will maintain adequate flow channels. The most promising method of attaching the ribs appears to be coextruding a butt rib with the basic cylinder; the remainder of the rib is electron-beam welded to the butt. The spacers are than machined to a finished diameter consistent with assembly requirements. However, NMI believes it may be possible to extrude full-height ribs.

Five elements are stacked axially in a reactor pressure tube to form a fuel column. During its lifetime in the reactor, each fuel element occupies successive positions in the fuel channel; thus the burnup in each fuel element is the same in a given pressure tube at the end of life. Axial loads due to pressure, drag, and weight are imposed on the fuel elements and are taken through the cylinders. Differential axial growth between cylinders will be accounted for by machining the length of each cylinder to agree with its axial growth.

An analysis indicates that vibration of the cylinders is insignificant. The cylinders are short and rigid and could conceivably vibrate as a body, causing wear on the surface of the fuel channel. Although this is not considered to be a problem, since numerous full-length spacers are provided to minimize local contact, further 
design analysis and flow tests will be required to determine the nature and magnitude of vibrations, if they exist.

Zircaloy has been selected as the cladding for the metallic fuel, and it is expected to perform satisfactorily if the concentration of hydrides does not exceed an allowable limit. For design purposes, an upper limit of $500 \mathrm{ppm}$ was selected. Several courses of action can extend the design life of Zircaloy: use of improved zirconium alloys, development of barriers, reduced operating temperature, addition of hydride sinks, and increased clad thickness. It is likely that the spacer ribs will provide an effective hydrogen sink.

\section{A first-order estimate of hydride rate was}

made using the hydride pickup in 300 days for each refueling cycle. Then, assuming the hydride rate is linear with time, the time to reach $500 \mathrm{ppm}$ in five cycles (corresponding to the successive positions in the core) was obtained by calculation using a simple proportion: The following tabulation lists the hot channel surface temperature (including flux tilt factor) of the downstream (hot) end of the fuel cylinder for each position and the hydride pickup in 300 days at that temperature. The total is the hydride pickup in 1500 days. The number of days to reach 500 ppm and the corresponding average burnup a re 695 days and 21,800 $\mathrm{MWD} / \mathrm{T}$.

\begin{tabular}{|c|c|c|}
\hline Location & Temp, F & $\begin{array}{c}\text { Hydrogen, } \\
\text { ppm }\end{array}$ \\
\hline $\begin{array}{l}1 \\
2 \\
3 \\
4 \\
5\end{array}$ & $\begin{array}{l}740 \\
765 \\
788 \\
815 \\
758\end{array}$ & $\begin{array}{l}145 \\
185 \\
242 \\
330 \\
175\end{array}$ \\
\hline Total $\mathrm{H}_{2}$ & 0 days) & 1077 \\
\hline
\end{tabular}

Zircaloy -4 has a better hydride rate than Zircaloy -2 and is more readily available than zirconium-niobium alloys. The slight superiority of the zirconium-niobium hydride behavior lover that of Zircaloy-4) does not warrant the extra cost at this time.

Zircaloy and thorium metals are compatible and do not form objectionable intermetallic compounds at the fuel-clad 
interface. Aluminum cladding (metal or SAP) is not suitable for the metal fuel, because aluminum forms brittle intermetallic compounds, and because thorium diffuses into aluminum. Aluminum metal is also unsuitable because of its low melting point. Stainless steel cladding was not considered because of its high neutron cross section.

The thermal expansion coefficient of the Zircaloy cladding is less than that of thorium. In operation, this difference will cause thermal strain within the cylinder, but this is not expected to be a problem because thermal cycling will be minimal with on-line refueling. Analysis and testing will be required, however, to establish allowable design limits (see section 3.2).

Several fuels have been developed and tested for the nested-cylinder configuration for various reactor designs and concepts. Powdered ceramics have been tried in thin-walled clad cylinders, uranium and thorium alloys have been co-extruded with Zircaloy cladding, and attempts have been made to cast carbide rings. For this reference design, the use of thin-walled nonbonded cladding has been discarded because the thin-walled cladding would not withstand the pressure buildup caused by fission gas release from oxides, carbides, etc. Metallic thorium fuel is more stable than uranium, is compatible with Zircaloy, and can be bonded with the Zircaloy cladding. Therefore, thorium alloys are more desirable for the nested-cylinder configuration, and better developed, than are oxides and carbides.

The irradiation behavior of thorium fuel's is reviewed in detail in section 3.2. In the metal fuels, fission products are not released, as they are in ceramic fuels, to cause fission gas pressurc in the cladding; instead they are retained within the metal, causing changes in the density and dimensions of the fuel.

The effect of fuel growth on the fuel cylinder geometry may be complex, making predictions of dimensional changes difficult. Thorium cylinders tested at Savannah River experienced some gruwth of the outer cladding and very little change in the inner cladding. ${ }^{6}$ Uranium cylinders, however, experienced buckling of the inner cladding. If the fuel cylinder were allowed to grow unrestrained by the cladding, the cylinder would expand in the same manner as a tube which is heated and expands thermally. In this case, both OD and ID would increase 
proportionately. Cladding restraint, however, may cause the highertemperature fuel to flow along the path of least resistance. It is expected that the initial effect of growth will be to stretch the outer cladding, an effect experienced with thorium cylinders at SRL, with relatively small changes in diameter. Very large growth or swelling would probably cause distortion, as experienced with uranium cylinders. The dimensional changes are expected to vary, depending on cladding thickness, cylinder geometry, burnup, and fuel temperature. No generalizations can be made, therefore, except that available irradiation data for thorium cylinders show promise of acceptable performance.

Fuel growth was calculated based on a peak burnup of $38,000 \mathrm{MWD} / \mathrm{T}$, a growth rate of $2 \%$ volume change per atomic $\%$ burnup, and the assumption that the growth will stretch the outer cladding without changing the inner cladding. The results of this calculation show a change in flow channel thickness of 7 mils at the time the fuel as sembly is discharged from the reactor. The effect of growth on flow channel thickness is included in the thermal and hydraulic calculations.

Fabrication tolerances were also studied. The

dimensional variations of thin-walled tubing increase when the wall-todiameter ratio decreases. For the larger-diameter cylinders, the wall thickness was limited to 0.100 inch or larger. The 5-inch-diameter cylinders are larger than any experimental cylinders made to date; consultation with personnel from NMI, SRL, and PNL indicates that extrusion of cylinders of this size appears to be feasible. With respect to fabrication tolerances, thrcc general areas of variations in fuel dimensions are of primary concern: fuel, rladiding, and coolant chaniiels. The following values were used in design analyses:

\section{Fuel Variations}

Core thickness/fuel tube

Local

Avg thickness/fuel cylinder length

Fissile fuel uniformity/fuel tube, local
Nominal $\pm 5 \%$ Nominal $+3 \%$

Nominal $\pm 5 \%$

The variation affecting heat transfer to the coolant is significantly reduced by integration over the length of five elements in a fuel channel. For design purposes, a value of $\pm 5 \%$ in the average fuel variation in a fuel channel was used. 


\section{Cladding Variations}

Cladding thickness/fuel tube

Local

Avg thickness/fuel cylinder length

$0.025 \pm 0.005$

$0.025 \pm 0.003$

Coolant Channel Variations

(mechanical tolerances only)

Tolerance in nested cylinders with straight ribs was studied. On the basis of discussions with NMI, SRL, and PNL personnel, a straightness of $0.010 \mathrm{in./ft}$ (for the basic cylinder) was used in arriving at these tolerances. Of all the tolerances considered, straightness has the greatest effect on channel variation. The straightness achieved in practice is indicated below:

PNL

SRL - as extruded

SRL - after straightening (enriched U-Th)

SRL - after straightening (natural U-Th)

$$
\begin{aligned}
& 0.015 \mathrm{in} . / \mathrm{ft} \\
& 0.938 \mathrm{in} . / 12 \mathrm{ft} \\
& 0.015 \mathrm{in} . / \mathrm{ft} \\
& 0.010 \mathrm{in} . / \mathrm{ft}
\end{aligned}
$$

Figure 2-2 shows the bow condition. The following factors were assumed in the tolerance analysis:

1. ID clad \pm 0.005 in.; OD clad \pm 0.005 in.

2. OD ribs \pm 0.003 in.

3. Coextruded cylinders resized and straightened to achieve required diameter and straightness tolerances.

4. Bow $0.010 \mathrm{in.} / \mathrm{ft}$.

5. Six straight ribs electron-beam welded to coextruded stubs, cylinder machined on $O D$ of ribs to \pm 0.003 in. (when mounted) to eliminate bow on the ribs.

6. Assembly clearance between cylinders 0.007 in. on the diameter.

A typical calculation for cylinder $1-2$ produced

the following results (all units in inches):

$$
\begin{array}{ll}
\text { ID of cyl } 2 & \begin{array}{l}
2.970 \\
\text { OD of ribs, cyl 1 }
\end{array} \\
\text { Basic rib height }= & 2.936 \pm 0.003 \\
& 0.133 \pm 0.006
\end{array}
$$


Side "A" Channel (100\% tolerance stack-up)

\begin{tabular}{lc}
\hline Basic rib height & $0.133 \pm 0.006$ \\
Max channel & 0.158 \\
Min channel & 0.108 \\
Avg channel & 0.133 \\
Variation $=$ & \pm 0.025 \\
Side "A" Channel & $(80 \%$ tolerance stack-up) \\
\hline Variation $=$ & $0.80 \times 0.025= \pm 0.020$
\end{tabular}

The $\pm 0.020 \mathrm{in}$. figure is the maximum variation in one channel for one element at the $80 \%$ tolerance stack-up. This considers the maximum adverse bow position for both cylinders. In traversing the length of the fuel channel, the average size variation of the chan$\mathrm{nel}$ is much less than the local variations. A variation of $\pm 0.010 \mathrm{inch}$ in the average channel size is allowed for fabrication tolerances in thermal and hydraulic calculations.

\subsubsection{Nuclear Design}

Nuclear calculations were made to obtain power distributions and data for fuel cycle cost calculations. Continuous refueling is simulated by doubling the lifetime of a batch-loaded core (as described in BAW-393-21). Since this technique approximates the approach to equilibrium rather poorly, a more accurate but time-consuming backup calculation was run to verify the equilibrium cycle obtained from the double-batch recycle. In this calculation, the core is loaded initially to run as a true batch core for about $8000 \mathrm{MWD} / \mathrm{T}$, at which point "continuous" fueling is initiated by refueling $1 / 5$ of the core at a time, at intervals so that discharge burnup is the same as in the doublebatch case $(20,000 \mathrm{MWD} / \mathrm{T})$. Fuel added to the reactor each time is sufficient to keep the reactor $k_{e f f}$ at an average of 1.000 over the next time interval. In principle, this calculation is very similar to the TONG code used at ORNL except that, because of automation, TONG can refuel a much smaller fraction of the core at a time. The time-consuming nature of the calculation prevented recycling completely to equilibrium, but results indicate that the equilibrium cycle computed with the double-batch lifetime recycle method is in good agreement with the more refined continuous refueling model. The results of the nuclear calculations are 
given in Table 2-1, part IV. Part IV contains mass balance data from the U-235 double-batch recycle calculation and results through the third complete recycle of all fuel from the continuous refueling case. All masses are reported on a basis of one pressure tube. Each batch is representative of the entire reactor in the double-batch case and of $1 / 5$ of the reactor in the continuous refueling case. Protactinium decay of 180 days was allowed, along with $1.5 \%$ total losses during reprocessing and refabrication. A minimum holdup of one year was assumed before recycle fuel could re-enter the reactor. Subsequent information indicates that this can be reduced to less than 300 days, which would reduce the out-of-pile inventory considerably.

Calculations were also run for plutonium as an alternate startup fuel. Results of the double-batch recycle calculation based on recycle of bred plutonium fuel are included in part IV of Table 2-1. The plutonium mixture used for startup and feed is that computed by ORNL as being discharged from the Uranium HWOCR.

$\begin{array}{lr}\mathrm{Pu}-239 & 52.8 \% \\ \mathrm{Pu}-240 & 28.8 \% \\ \mathrm{Pu}-241 & 12.7 \% \\ \mathrm{Pu}-242 & 5.7 \%\end{array}$

U-233 idealized-cycle calculations were done for the 4-cylinder design for comparison with previous analyses by the same method. The idealized cycle has a representative fuel loading of $94.5 \%$ U-233 and 5.5\% U-234. This particular fuel combination was chosen arbitrarily for parameter studies and design evaluation on a consistent basis without requiring recycle calculations. Results of the idealized-cycle calculations are included in Table 2-1, part IV, along with the neutron balances for the idealized-cycle, U-235-recycle, and plutonium-recycle cases.

Reactor power distribution is broken down into four components for heat transfer calculations: gross radial, gross axial, local radial, and local axial. All but the local radial are independent of the nested-cylinder radii. The local radial is an uutgrowth of the nuclear-thermal iterations used to size the cylinders for maximum performance. A discussion of each component follows. 
The gross axial peaking factor was computed with a three-dimensional synthesis calculation which accounts for countercurrent fuel movement. This method, derived completely in BAW-393-2,1 produced a peaking factor of 1.33 for a clustered-pin design with a conversion ratio of 1.016 . Since conversion ratio directly affects the distribution of fissionable material along the fuel channel, it was conceivable that the axial peaking would be tied strongly to the conversion ratio. A second synthesis case, using equilibrium cycle data for a similar design with a 0.72 conversion ratio, showed that power peaking is not strongly dependent on the conversion ratio. The axial power distributions (Figure 2-3) deviate from a chopped cosine, but the magnitude of the peak-toaverage power ratio is relatively unaffected. This comparison indicates that counter-current fuel movement has a stabilizing effect on the gross axial power distribution. Since the 4-cylinder thorium metal design has a conversion ratio of 0.86 , the gross axial peaking factor will probably fall between the two curves shown in Figure 2-3. A value of 1.30 was selected.

\section{Gross Radial $\mathrm{P} / \overline{\mathrm{P}}=1.17$}

The core will be zone-loaded in three radial zones to achieve power flattening. A small differential in en richment will suffice to produce the large degree of power flattening desired. Calculations made with the U-233 idealized cycle indicate that a difference of less than 10\% between maximum and minimum enrichment will provide a peak of less than 1,17. This applies equally to the nectod-cylinder ard clustered-pin cores. Exact enrichments have not been computed for the final design, but the increased reactor leakage due to zone loading has been accounted for in the lifetime calculations. Figure 2-4 shows the predicted radial power shape.

\section{Local Axial $P / \bar{P}=1.10$}

Local axial peaking arises because thc fuelbearing section is not continuous over the entire length of the element. Peaking factors as high as 1.7 to 1.8 occur on the innermost cylinders. The simplest way to combat this is to taper the ends of the cylinders in such a way that the heat flux resulting from the peaking is not excessive. 
Each cylinder will be tapered differently in proportion to its peaking. Proper use of the taper should hold the heat flux peaking factor below 1.10. Figure 2-5 shows the actual peaking from PDQ calculations before the taper is introduced.

\section{Local Radial}

Local radial peaking is unique to each design and each fuel material. It results from nuclear-thermal iterations in which the cylinder radii are variables. Optimum performance is obtained if the power distribution within the element is constant during life, since each ring can be sized for the maximum peaking.

Initial fueling with U-233 (the idealized cycle) does indeed produce this behavior-a near-constant power shape with life; however, U-233 is unavailable for fueling, and the use of U-235 for startup produces a total swing in peaking (for any given ring) of about $12 \%$ between cycle 1 and equilibrium. The cylinders can be sized, as a compromise between the two distributions, with a total reduction in element power of only about $6 \%$. Local zone-loading may further alleviate. this.

Plutonium presents a greater problem. Initial peaking is $25 \%$ higher than for U-235, and the total swing over life is about $48 \%$. Methods to counter this change have not been developed, and at this stage, it appears that U-235 will perform better in the nestedcylinder design.

Local radial peaking factors are tabulated below. The cylinder configuration used in this comparison of peaking factors was optimized on the basis of idealized-cycle calculations. Nuclearthermal iterations could size the cylinders to get about the same power at time zero in each case without appreciable changes in other characteristics. The change in peaking as a function of time is the important characteristic to be noted. 
Local Radial Peaking $(\mathrm{P} / \overline{\mathrm{P}})$

Fuel

\begin{tabular}{|c|c|c|c|c|c|}
\hline \multicolumn{2}{|c|}{$\mathrm{U}-235$} & \multicolumn{2}{|c|}{ Plutonium } & \multicolumn{2}{|c|}{$\begin{array}{c}\mathrm{U}-233 \\
\text { (idealized) }\end{array}$} \\
\hline Cycle 1 & Equilibrium & Cycle 1 & Equilibrium & BOL & EOL \\
\hline $\begin{array}{l}0.58 \\
0.71 \\
1.09 \\
1.80\end{array}$ & $\begin{array}{l}0.65 \\
0.77 \\
1.06 \\
1.61\end{array}$ & $\begin{array}{l}0.47 \\
0.54 \\
1.05 \\
2.28\end{array}$ & $\begin{array}{l}0.69 \\
0.74 \\
1.01 \\
1.65\end{array}$ & $\begin{array}{l}0.65 \\
0.77 \\
1.09 \\
1.64\end{array}$ & $\begin{array}{l}0.69 \\
0.79 \\
1.07 \\
1.58\end{array}$ \\
\hline
\end{tabular}

\subsubsection{Thermal Design}

The hottest pressure tube in the core has a nominal power output to the coolant of $10.9 \mathrm{MWt}$, and the average fission power per pressure tube is $9.8 \mathrm{MWt}$. The temperature of the coolant at the outlet of the hot pressure tube is $708 \mathrm{~F}$. The distribution of coolant flow to the 321 pressure tubes is controlled by orifices sized according to the radial power distribution to provide a mixed-mean reactor outlet temperature of $708 \mathrm{~F}$.

A computer program, TANC (described briefly in BAW-393-2 and detailed in BAW-290), was used to evaluate the performance of the nested-cylinder core. ${ }^{1,7}$ This code determines the heat split in each cylinder of the element, calculated maximum fuel and surface temperatures, and the coolant temperature rise in each channel.

The thorium metal nested-cylinder thermal and hydraulic analysis is hased on the hot chamiel cuncept to àssure adequate cooling of the fuel elements under the most adverse conditions. The hot channel is defined as the channel with the poorest heat transfer capability, the largest effective stack-up of tolerances, and the highest power generation. In determining hot channel factors, specification of too-optimistic conditions indicates performance beyond the true reactor capability. On the other hand, consideration of thc most-adverse local conditions is also misleading, since channel size averaged over the length of five separate elements stacked axially in the pressure tube is the effective parameter that retards coolant flow and increases coolant temperature rise. These and other similar factors were considered in specifying the 
variations from the nominal conditions given in section 2.3 .1 .2 and used in the hot channel analysis.

Since the input data to the TANC code allows dimensional and power variations, the hot channel geometry and heat generation were "mocked up" to simulate actual operating conditions more accurately than by use of hot channel factors. The power output of the hottest fuel cylinder was increased by an additional 5\%, and the thickness of the adjacent coolant channels was decreased to reflect the most-adverse manufacturing tolerances and fuel growth. In essence, this method imposes a coolant temperature rise hot channel factor of 1.16 on the channel enclosed by the two highest-power cylinders. Figures 2-6 and 2-7 show the nominal and most-severe operating conditions. The burnout ratio as a function of length (Figure 2-8) shows that the minimum burnout ratio is about 2.5. Other significant parameters are included in Table 2-1, part III.

2. 3.2. AI-CE Design With Thorium Metal Fuel Elements 2.3.2.1. Core Description

This section contains the results of a preliminary effort to define the characteristics of a thorium metal nested-cylinder element for operation in a 1000-MWe Uranium HWOCR. Design parameters are listed in Table $2-2$.

Two difficulties are immediately encountered: the 1000-MWe uranium plant is not defined, and the power capabilities of the UC pin and thorium metal nested-cylinder elements are different. Since current design information is unavailable for the 1000-MWe uranium plant, it was assumed that, basically, the core internals correspond to those of the 500-MWe Uranium Demonstration Plant described in AI-CE-MEMO- $25 ;^{4}$ the nominal 1000-MWe (1076-MWe actual) plant was defined by extrapolation, keeping the maximum power per pressure tube and the net plant efficiency constant. The larger core consists of 548 pressure tubes or fuel chamlels on a oquare pitch of 11.0 inches. Each pressure tube assembly has an ID of 4.030 inches and contains five fuel elements stacked axially to form an active fuel length of $17 \mathrm{ft}, 9.3$ inches. The Zircaloy outer tube forms a $\mathrm{CO}_{2}$ insulating annulus in combination with the SAP inner tube and is surrounded by the $\mathrm{D}_{2} \mathrm{O}$ moderator, which is contained in a $26 \mathrm{ft}, 3$-inch-diameter moderator tank. 
A one-pass, bi-directional coolant system is utilized with coolant flow in the direction of fuel movement. Bi-directional on-line refueling is accomplished by two refueling machines located at'the top and bottom of the core with fuel movement in opposite directions in adjacent pressure tubes.

As mentioned earlier (and shown in Table 2-2) the power capability of the nested-cylinder element is about 30 to $35 \%$ higher than that of the UC pin-type element described in AI-CE-MEMO25.4 This high power capability is an inherent characteristic of the nested-cylinder geometry (see section 2.3.3). While favorable from an economic standpoint, the higher power capability leads to some difficulty in adapting the design for operation in the 1000-MWe Uranium HWOCR. For example, with a fixed geometry either the core must operate at its potential and produce a significantly higher power output, which is incompatible with the secondary side equipment, or it must operate at a specific power far below its capability, which penalizes the economic performance. Naturally, if excess capacity could be assumed in the secondary side equipment, the power costs would be reduced by about 30 to $35 \%$ because of the extra power produced, but this assumption would be unrealistically favorable to the thorium-fueled HWOCR. Rather than adapt either of these assumptions, the economic performanre of the noctcd cylinder core was based on operation of the element at its predicted capability in the number of 4.03-inch-ID pressure tubcs required to achieve 1076-MWe, to illustrate its potential more accurately. The excess pressure tubes in the AI-CE plant would not be utilized for power production.

As shownin in l'able $2-\overline{2}, 414$ pressure tubes or fuel channel assemblies are required. At the average fission power of $7.76 \mathrm{MWt}$ per pressure tube, the reactor produces $3209 \mathrm{MWt}$, of which $3039 \mathrm{MWt}$ are transferred to the coolant and $170 \mathrm{MWt}$ are generated in the moderator or other structures. Santowax coolant enters the core at $560 \mathrm{~F}$, flowing at the rate of $119 \times 10^{6} \mathrm{lb} / \mathrm{hr}$, and exits at $711 \mathrm{~F}$. The total system pressure drop is 400 psi with 300 psi differential from header to header across the core. Since pressure differentials, inlet and outlet temperatures, etc., do not match those of the 500-MWe Uranium Demonstration Plant, relatively minor adjustments to coolant channel sizes would be required if the 500-MWe plant characteristics are main- 
tained in the revised 1000-MWe design. These adjustments, together with final thermal-nuclear iterations to produce a fully optimized element, could lead to a four-cylinder element similar to that for the 5inch-ID pressure tube.

\subsubsection{Mechanical Design}

Fuel Element Description

The basic cross section of the element is shown in Figure 2-9. It is an assembly of five fuel tubes arranged concentrically to form annular coolant channels with a flow blocker in the center of the element. The coolant gap between adjacent fuel cylinders is 0.125 inch, the exterior coolant channel is 0.100 inch, and the channel between the center flow blocker and cylinder 1 is $0.110 \mathrm{inch}$. The fuel thicknesses are $0.284,0.240,0.175,0.126$, and 0.090 inch for cylinders $1,2,3$, 4 , and 5, respectively. The fuel element is 43.96 inches long, of which 42.66 inches is active fuel in cylinders $1,2,3$, and 4 , and 42.21 inches is active fuel in cylinder 5 .

Metallic thorium alloyed with about $2.4 \mathrm{wt} \%$ uranium is used in the fuel tubes. The fuel cylinders are made by the process used in the four-cylinder design. The general description of the four-cylinder center moderator design (in section 2.3.1.2) applies to this element except as noted previously.

\subsubsection{Nuclear Design}

Physics calculations for the AI-CE pressure tube were confined to the usual nuclear-thermal iterations to size the cylinders, followed by a running of U-233 idealized-cycle data for cost comparison with the thorium-optimized core. Nuclear characteristics are nearly identical to those of the thorium-optimized design, i.e., conversion ratio, specific power, and enrichment.

Table 2-2 summarizes the U-233 idealizedcycle data for the nested-cylinder design in the AI-CE pressure tube. Local radial peaking data are also included in the table. The other three components of the power distribution (gross axial, gross radial, and local axial) are the same as those described for the thorium-optimized 1000-MWe HWOCR. 


\subsection{4. Thermal and Hydraulic Characteristics}

The hottest pressure tube in the core has a nominal power output to the coolant of $8.6 \mathrm{MWt}$, and the average fission power per pressure tube is $7.76 \mathrm{MWt}$. The temperature of the coolant at the outlet of the hot pressure tube is $711 \mathrm{~F}$. The distribution of coolant flow to the 414 pressure tubes is controlled by orifices sized according to the radial power distribution to provide a mixed-mean reactor outlet temperature of $711 \mathrm{~F}$.

The calculation methods and computer programs used to determine the thermal and hydraulic characteristics are the same as those used on the four-cylinder element. Figures 2-10 and 2-11 show the nominal and most-severe operating conditions; Figure 2-12 shows that the minimum burnout ratio is about 2.5. Other significant parameters are listed in Table $2-2$.

\subsubsection{Evaluation of Thorium Metal Core Design}

The design optimization studies have shown consistently that the thorium metal nested-cylinder cores have an economic advantage over other types. This advantage is directly related to the predicted performance capability, which depends partly on the design criteria or technical limits imposed on the design and partly on the inherent characteristics involved. Since absolute values on allowable operating conditions or limits are unknown in many instances, engineering judgment must be used. Thus in comparative evaluations, all criteria and assumptions utilized in each design must be examined carefully to avoid undue optimism or pessimism in establishing the performance criteria, and the technical uncertainties must be minimized as much as possible.

The inherently favorable characteristics of the thorium metal cores are attributed more to their adaptability to annular geometry than to the nuclear characteristics of the fuel material. A high-performance, relatively high-burnup, nested-cylinder fuel element that can be fabricated at relatively low cost is more feasible with thorium metal than with oxide or carbide. The relatively simple coextrusion process which bonds the fuel and cladding, together with the high conductivity of the fuel material, results in. low fuel temperatures. The low fuel temperature, in turn, improves the irradiation stability and minimizes swelling of the 
fuel material, so that relatively high burnups should be achievable. The low fuel temperature and the fuel-clad bond therefore preclude the problem of internal fission gas pressure that is likely to limit the performance of oxide or carbide fuels in low-pressure reactors.

The nested-cylinder geometry that evolves from these considerations is ideally suited to a pressure tube reactor. The circular configuration prevents excess bypass flow, which can present a design problem when clustered-pin elements are placed in the round pressure tube. The elimination of excess flow reduces the amount of coolant (which acts as a poison) in the core and increases the reactor outlet temperature, which in turn.improves plant thermal efficiency. The coolant channels between adjacent fuel cylinders can be varied to maintain coolant outlet temperature from all channels at the maximum value, regardless of the radial power variation across the element. The fuel cylinder thicknesses can also be varied to adjust the radial power distribution, which permits the designer to optimize for the maximum allowable surface heat flux on all cylinders and to reduce the amount of surface or cladding material in the core. In other words, the thermal and hydraulic design flexibility of the nested-cylinder geometry permits each cylinder to be designed for maximum power generation, maximum surface heat flux, and maximum cladding temperature. Concurrently, each channel can be designed for maximum outlet temperature at a minimum core pressure drop. These characteristics produce a high power per pressure tube, high reactor outlet temperature, and minimum reactor flow rate to reduce plant capital and operating costs.

The flexibility of the nested cylinder design enhances one of the basic advantages of organic coolants - high coolant temperatures at low operating pressure. Conversely, the use of organic coolant enables the use of thorium metal, since the metal is not highly reactive with the organic, as it is in the case with water.

The characteristics of the nested-cylinder fuel element favor low capital costs in conjunction with the potential for low fuel cycle costs. A successful fabrication development program should result in low manufacturing costs because of the small number of massive cylinders per fuel element. Similarly, the fabrication component of the fuel cycle cost can be reduced by achieving a potentially high burnup, which prorates 
the fabrication cost over a larger amount of power and income. The thorium metal has a high density which, along with the low clad-to-fuel and coolant-to-fuel ratios, favors a high conversion ratio and a low fuel burnup expense. The optimum use of surface area and the higher allowable heat fluxes (because of favorable hydraulic characteristics) contribute to an increase in specific power and a reduction in fuel inventory cost. Finally, the higher plant efficiency attainable with the high reactor outlet temperatures and the adaptability of the nested-cylinder element to larger-diameter pressure tubes lead to a reduction in the number of pressure tubes, the amount of $\mathrm{D}_{2} \mathrm{O}$ required, and the plant capital cost.

The nested-cylinder fuel element, therefore, does have inherent characteristics which, in theory, give it performance and economic advantages over alternate designs. The extent to which these advantages can be realized in practice depends on the compatability of the element with the HWOCR environment, the irradiation and operational stability, and the validity of the design assumptions and cost estimates. Since data are not available at projected operating conditions, extrapolations involving judgment and estimates are unavoidable, and the associated uncertainties should be examined carefully.

One area of concern is the dimensional variations of the fuel, cladding, and coolant channels caused by fabrication tolerances, fuel swelling, and operational distortions. Information on all these aspects is available from reports on development programs at PNL, NMI, and SRL (discussed in section 3.2), but irradiation tests were limited to small-diameter, single-cylinder plements. In addition, projected fuel burnup and clad surface temperatures are greater than the values associated with test conditions; however, the maximum fuel temperature is below the corresponding values in test elements. Although extending the results to large, closely-spaced tubes involves some extrapolation, the results from these programs are favorable in all areas of concern. For example, the PNL experiment at about 13,000 MWD/T burnup indicates a swelling rate near $1 \%$ /atomic \% burnup, whereas $2 \%$ was used as a design basis.

Assuming that the projected burnup can be achieved without affecting the structural integrity of the element, the primary effects 
of fuel swelling or operational distortions are reflected in the thermalhydraulic characteristics. Higher core pressure differentials will be required to maintain the specified cladding surface temperatures on the cylinder adjacent to a deviated channel. Consequently, flow rates in nominal pressure tubes are higher, and the coolant outlet temperatures are lower. Both changes affect the net plant efficiency adversely and thereby alter the economic performance. Other variables that play a significant role in determining power cost, such as specific power, would not be altered significantly by reasonable changes in channel dimensions.

The thermal-hydraulic analyses of all nested-cylinder cores have been based on an average coolant channel variation of \pm 13 mils. This variation is a significant percentage of the nominal coolant channel. Allowance for this change reduces the coolant temperature rise about $16 \%$, and to some extent negates the potentially superior thermal performance of the nested-cylinder geometry.

Development and test results will be required to further define the fabrication tolerances that can be held at reasonable cost, as well as the changes in fuel element dimensions caused by irradiation. Assessment of possible adverse results indicates that the power cost increases about 0.003 mills per 0.001 inch change from nominal channel dimensions. Correspondingly, an improvement in dimensional control could improve the performance.

Another uncertainty is the hydriding of the cladding. The practicality of successfully operating Zircaloy-4-clad tubes in organic coolant for the two-year period required to achieve the design burnup has not been clearly demonstrated. However, the performance of zirconium alloys in organic coolants has been investigated by AECL since early 1961, and the basic compatibility of the materials has been established. Zirconium-clad pins are currently in operation in the WR-1.

The economic effect of excessive hydride buildup would probably be reflected in reduced burnup limits, which would increase power cost at $0.015 \mathrm{mills} / \mathrm{kwhx}$ per $1000 \mathrm{MWD} / \mathrm{T}$ reduction. Naturally, if burnups higher than the design value can be achieved, costs will be reduced by a similar amount.

Other factors that could alter the predicted economic performance significantly are involved with fabrication development. In 
order to reduce the heat output in these high-axial-peaking-factor zones, a method must be developed for tapering the fuel to controlled dimensions at each end of the fuel element. While this should be successfully accomplished during the fabrication development, it is essential in order to . maintain the design specific power. Another requirement that must be met to maintain the high power capability of the element is successful coextrusion of the relatively large-diameter cylinder with a 0.100 -inch fuel thickness. Like the end taper situation, early fabrication-development effort should demonstrate achievement of this objective and could show that thinner cylinders are feasible. This development would permit an increase in the economic optimum specific power.

Some difficulty is encountered in adapting the thorium nested-cylinder design for operation in the UC-fueled HWOCR at its optimum economic performance because of the higher power capability of the cylinder geometry, as previously noted. However, some difficulty is inevitable when designs utilizing alternate fuel materials are adapted to a plant designed for fuels with significantly different properties and characteristics. The alternate designs usually suffer in capability, because physical characteristics of the plant dictate nonoptimum core designs. The degree to which each design is penalized, of course, depends on which are the controlling properties of the fuel material or geometry and on the flexibility inherent in the basic design. The design parameters and flexibility of the plant also are influential in determining the success of the efforts. While considerably more effort will be required to establish the best method of adapting the design to the AI-CE plant, all evidence indicates that it could be accomplished successfully once the plant design is more firmly established.

Development of the thorium metal nested-cylinder element would offer backup technology for the primary HWOCR program in conjunction with development of the thorium fuel cycle. Since the low-ductility SAP cladding has not been fully developed for operation at currently specified design conditions, adverse results could downgrade the projected performance of the HWOCR. Thus, establishment of the Zircaloy as a successful cladding, which is an inherent part of the nested-cylinder development, provides a valuable backup to the primary program. Developing the thorium metal fuel element would also complement the effort 
on advanced and dual-purpose HWOCR designs since annular geometries are being considered for these applications.

In summary, the thorium metal nested-cylinder fuel element has a number of inherently favorable characteristics, and development of this element would contribute to the primary HWOCR program by providing alternate materials and geometries as backup. At the same time, there are unfavorable aspects that could minimize the advantages. The performance analysis has allowed for these aspects, based on judgment and extrapolation of existing data. The adequacy of these allowances naturally depends upon the success of the development effort, and further definition of the achievable performance must await the accumulation of fabrication and operational data. While the current element differs somewhat from the design reviewed by ORNL, the following conclusion from the draft HWOCR Evaluation Report still summarizes the situation adequately: ${ }^{8}$

\footnotetext{
"The thorium metal nested tube fuel element appears to be well designed, and it should be operable at the heat ratings and temperature limits proposed. It represents a reasonable extrapolation of present technology, but additional testing is required to demonstrate that projected life and burnup can be achieved under reactor operating conditions. It must be shown that fuel element distortions resulting from the rmal gradients or fuel swelling do not adversely affect operation of large, closely spaced nested tubes, and also that the many factors affecting hydrogen pickup and hydride embrittlement can be controlled to ensure satisfactory life for fuel elements of this geometry."
}

\subsection{Thorium Oxide Core Designs}

2.4.1. Thorium-Optimized Core

\subsubsection{Core Description}

The thorium oxide clustered-pin core for the 1000-MWe Thorium HWOCR is described in this section. Design parameters are listed in Table 2-3.

The reactor complex arrangement for the clus tered-pin design is similar to that of the nested-cylinder core. Basically, the core consists of 758 pressure tubes or fuel channels on a square pitch 
of 9.5 inches, surrounded by $\mathrm{D}_{2} \mathrm{O}$ in a 26-foot, 7-inch-ID moderator tank. Each pressure tube has an ID of 4.030 inches and contains five fuel elements (equivalent active fuel length per element is 42.66 inches) stacked axially to form a total active fuel length of 17 feet, 9.4 inches. Each fuel element has 37 pins arranged on a triangular pitch. The pins are composed of SAP 895 cladding filled with Vipac $\mathrm{ThO}_{2}-\mathrm{UO}_{2}$ to $88 \%$ theoretical density.

A one-pass coolant system is utilized as in the nested-cylinder core. Coolant flow and refueling are bi-directional. The coolant flows in opposing directions in adjacent pressure tubes and flow is in the same direction as the fuel movement. Santowax coolant fluws through the core at the rate of $107.2 \times 10^{6} \mathrm{lb} / \mathrm{hr}$ at a total core pressure differential of $146 \mathrm{psi}$, including header and shield plug losses. The pressure drop across the active core is $92 \mathrm{psi}$; the total system pressure drop is $246 \mathrm{psi}$. The coolant transports $2936 \mathrm{MW}$ of heat while increasing its temperature from 560 to $721.4 \mathrm{~F}$. In addition to the heat transport in the coolant, the reactor generates $157 \mathrm{MWt}$ in the moderator and $10 \mathrm{MWt}$ in the shield for a total output of $3100 \mathrm{MWt}$. This output will producc $1076 \mathrm{MWe}$ at a net plant efficiency of $34.7 \%$.

\subsubsection{Mechanical Design}

Vipac sol-gel $\mathrm{ThO}_{2}-\mathrm{UO}_{2}$ fuel is well suited for remote fabrication to permit recycle of the $U-233$ produced in the reactor. Very little work has been done with the combination of SAP cladding and $\mathrm{ThO}_{2}-\mathrm{UO}_{2}$ fuel, but the nature of the vibratory-compacted fuel should preclude any incompatibility between the cladding and fuel that might be caused by thermal and irradiation growth.

SAP 895 was selected as the cladding material on the basis of the AI-CE work. Final establishment of the cladding thickness will be based on the cladding being free-standing and on its ability to withstand the internal and external pressure loading and the hydraulic and gravity loads that act on the fuel pin. The creep and stress-rupture properties of SAP 895 at operating conditions will govern the ability of the cladding to withstand these loads. Based on preliminary work and engineering estimates, the 0.022 and 0.017 -inch-thick cladding will meet the requirements; further evaluation is necessary, however. 
The fuel element has 37 fuel pins arranged on a triangular pitch in an array that has a circular outer boundary to fit inside a 4.030-inch-ID pressure tube (Figure 2-13). The 31 large fuel pins have a fin diameter of 0.631 inch, a 0.515 -inch clad OD, and a $0.022-$ inch wall thickness. Twelve fins, 0.058 inch in height by 0.030 inch thick, spiral on the outside of the clad with a $90 \% \mathrm{ft}$ helix pitch. The fins extend over the active fuel length. The six small pins have a fin diameter of 0.408 inch, a 0.332 -inch clad OD, and a wall thickness of 0.017 inch. Six spiral fins on the outside of the clad extend over the active fuel length. Two of the fins are 0.038 inch high by 0.030 inch thick, and four are 0.102 inch high by 0.030 inch thick. A machined cut on the two sides of the small pins gives the geometry shown in Figure 2-13. The overall element length is 44.82 inches, including an equivalent active fuel length of 42.66 inches. Void space is 1.300 inch in the large fuel pin and 0.430 inch in the small pins.

The 37 fuel pins are located and retained by two end grids. The Zircaloy end grids are circular ferrules, electron-beam welded or brazed in the arrays shown in Figure 2-13. The best method for joining the grid ferrules appears to be' electron-beam welding, but brazing will also be investigated to ensure the optimum compromise between structural integrity and economics. The ferrule-type grid has less metal in the core and greater flow area than the plate-type end fitting. It is presented as an alternate to the plate-type end fitting used in the AI-CE design.

The diameter of the ferrules has been increased by 0.002 inch (compared to the fin diameter on the fuel pins) to accommodate differential thermal growth and adverse tolerance bujldup (which would affect assembly of the element) and to reduce the clearance between the element and the pressure tube to cut down eccentric bypass flow. The diametral clearance at the end grids between the fuel element and the pressure tube amounts to 0.047 inch. At the midpoint of the element, the diametral clearance is 0.060 inch.

The 12 large-diameter fuel rods on the periphery of the element are fixed to each end grid by disc ferrules and Zircaloy cap scrcws. The 6 small-diameter fuel rods are retained by speciallyshaped ferrules in each end grid. The 19 inner fuel rods are positively 
positioned by dimple indentations on the inner ferrules. A projection on the bottom end cap of each fuel pin fits into a slot in each ferrule of the bottom grid t,o prevent rotation of the pin. A projection on the top end cap of each of the 19 inner fuel rods stops rod movement in that direction. The end caps are attached to the cladding by magnetic-force-resistance welding.

Five fuel elements are stacked vertically in a pressure tube. The axial pressure and weight loadings on each element are carried through column action by the 12 large and the 6 small pins on the periphery. AI-CE tests on a similar element indicate that pins in this diameter range do not need mid-element straps to prevent excessive vibration. Two spikes, which are an extension of the ferrules in the top grid of an element, mate with specially-shaped ferrules in the bottom grid of the axially adjacent element to index one element relative to another. The element is handled at the outer rim by lifting pawls on the AI-CE refueling machine. Some modifications will probably be required to ensure proper mating with the AI-CE equipment.

\subsubsection{Nuclear Design}

Table 2-3 summarizes the results of physics calculations for the economically optimum thorium oxide clustered-pin design. The physics methods are described in BAW-393-4.2 Results given in Table 2-3 include data for the U-233 idealized cycle, U-235 startup and recycle, and plutonium startup and recycle. (The idealized cycle is defined by an arbitrary fuel loading which is 94.5 wt \% U-233 and $5.5 \mathrm{wt} \%$ U-2.34.) Rerycle analyoes were made usling the tollowing ground rules: 180-day decay time for protactinium, $1.5 \%$ reprocessing losses, and a makeup mass sufficient to keep the same total mass of metal for the start of each cycle. The U-235 recycle assumes uranium that is 93 wt \% U-235 for both startup and makeup; the plutonium recycle assumes a plutonium mixture that is $52.8 \mathrm{wt} \% \mathrm{Pu}-239,28.8 \mathrm{wt} \% \mathrm{Pu}-240$, 12.7 wt \% Pu-24l, and 5.7 wt \% Pu- 242 (this being the calculated output from a uranium HWOCR plant) for both startup and makeup. Because of uncertainties in spectrum and cross sections, the plutonium recycle data are not as reliable as the U-235 recycle data.

Power peaking factors are included in Table 2-3; THERMOS-corrected, local radial power peaking factors are given for 
the idealized cycle at time zero. For U-235 startup, these peaking factors will be about 5 to 7\% higher (see Table 2-5); therefore, minor zoneloading would be required for the startup elements to achieve the idealized-cycle values. The results of RZ PDQ calculations of the local axial power peaking are shown in Figure 2-14. The increase in the axial peaking factor toward the center of the element is a function of the relative contribution of thermal neutrons from the $\mathrm{D}_{2} \mathrm{O}$ moderator and from the non-fuel region between the axially adjacent fuel elements. Since the resonance energy flux is flat, the slowing-down source from the nonfuel region does not diminish toward the center of the element; however, the thermal neutron supply from the $\mathrm{D}_{2} \mathrm{O}$ is sharply attenuated toward the center. Therefore, at the ends of the element, a higher fraction of the thermal neutrons supplied to the innermost fuel comes from the nonfuel region. The logical consequence is a more pronounced gradient near the ends of the element and higher axial peaking toward the center. Although the axial peaking factor at certain points in the center may be as high as 1.6, the total heat generation rate (including the local radial peaking factor) is less than the total in the outer fuel. Therefore, the high value of the axial peaking factor at the center of the element does not significantly affect the thermal performance of the clustered-pin design. Design changes can be made to reduce the local axial peaking factor. Reduced or non-enriched pellets at the ends of the fuel rods may bc used in the clustered-pin design. This is a common approach that has been successful in other reactors. A local axial peaking factor of 1.17 was conservatively selected for hot channel (outer fuel region) calculations.

Gross axial and radial power peaking factors of 1.3 and 1.17 were used in design analyses. These values are based on the analyses reported previously for the nested-cylinder core (section 2.3.1.3). Although detailed power peaking calculations remain to be done for the clustered-pin design, large variations in gross power shapes between the variuus cores arc not anticipated. The clustered-pin design possesses somc nuclear flexibility in that some control over both the axial and radial power peaking can be achieved through the use of such techniques as zone-loading, depleted fuel, etc. 
The validity of the standard lifetime physics model for determining the equilibrium cycle of a continuously refueled and recycled core has been tested with a more sophisticated mockup of continuous refueling; this is discussed in section 2.3 .1 .3 .

\subsubsection{Thermal Design}

Thermal and hydraulic parameters of the thorium oxide clustered-pin core are listed in Table 2-3. The hottest pressure tube in the core normally transfers $4.53 \mathrm{MWt}$ to the coolant. Including allowance for a 1.05 flux tilt, the maximum power capability is increased to $4.75 \mathrm{MWt}$. The average pressure tube fission power is 4.09 MWt. The coolant distribution through the 758 pressure tubes is controlled by orifices sized according to the radial power distribution to provide a mixed-mean reactor outlet temperature of 721.4 F-equal to that from the hot pressure tube.

To ensure adequate thermal performance of all fuel channels, the "hot channel" method was used to evaluate the thermal performance of the thorium oxide clustered-pin design. The hot channel is composed of the fuel pins and the associated channel in the pressure tube having the most restrictive thermal conditions with respect to geometry, nuclear power peaking, and engineering factors. The hot channel factors used to simulate these conditions are included in Table 2-3. An average power output of $10 \mathrm{kw} / \mathrm{ft}$ was used for the hot pin in the hot pressure tube. The GLOBS computer code (described in BAW-393-2 ${ }^{1}$ ) was used in calculating the flow and the associated pressure drop requircd to maintain the hot channel surface temperature at $830 \mathrm{~F}$. The appropriate fin efficiency and the effect of mixing were also incorporated; the efficiency of the fins is $92 \%$ because of the high aspect ratio 10.058 inch high/0.030 inch wide).

The MIX-l computer code was used to determine the effect of mixing between channels. An a (turbulence intensity factor) of 0.02 was used for the design analysis. This value of a is almost a factor of two below corresponding values obtained in tests of unwrapped rods. Because of mixing, the enthalpy rise is about $74 \%$ of what it would be for the hot channel without mixing of coolant from adjacent channels. Mixing, as defined by $\mathrm{AI}-\mathrm{CE},{ }^{9}$ is given by the following equation: 


$$
\% \text { mixing }=100 \frac{\Delta \mathrm{T}_{\mathrm{HC}}-\Delta \mathrm{T}_{\mathrm{HC}}^{\mathrm{M}}}{\Delta \mathrm{T}_{\mathrm{HC}}-\Delta \mathrm{T}_{\mathrm{A}}}
$$

where

$$
\begin{aligned}
\Delta \mathrm{T}_{\mathrm{HC}}= & \text { temperature rise of the fuel element hot } \\
& \text { channel without mixing } \\
\Delta \mathrm{T}_{\mathrm{HC}}^{\mathrm{M}}= & \begin{array}{l}
\text { temperature rise of the fuel element hot } \\
\text { channel with mixing }
\end{array} \\
\Delta \mathrm{T}_{\mathrm{A}}= & \begin{array}{l}
\text { overall temperature rise of the entire } \\
\text { fuel element }
\end{array}
\end{aligned}
$$

Using this definition, a 0.02 a gives $68 \%$ mixing for the 37 -pin thorium oxide design.

The resultant pressure drop obtained for the hot channel based on the hot channel factors, mixing effects, and the prefouling clad surface temperature of $830 \mathrm{~F}$ is used to determine the thermal and hydraulic performance of the hot pressure tube. The pin geometry, hot channel, and local radial peaking factors are shown in Figure 2-15. The temperature of the coolant out of the hot pressure tube is 721 F. Figures 2-16 and 2-17 show the calculated coolant and cladding temperatures for the hot channel and the calculated fuel temperatures for the hot pin. The critical heat flux or DNB ratio was calculated for the hot channel and is shown in Figure 2-18. The minimum DNB ratio is 2.6 occurring at $78 \%$ of the active channel length downstream of the inlet, based on a conservative saturation temperature of $850 \mathrm{~F}$. A much higher ratio would be obtained if actual pressure distribution along the length of the channel were considered. Critical heat fluxes were calculated using the correlation developed by Core and Sato, which is: ${ }^{10}$

$$
(Q / A)_{C}=100,000+408 \Delta T_{s i b}(V)^{2 / 3}
$$

where

$$
\begin{aligned}
(\mathrm{Q} / \mathrm{A})_{\mathrm{C}} & =\text { critical heat flux, } \mathrm{Btu} / \mathrm{hr}-\mathrm{ft}^{2} \\
\Delta \mathrm{T}_{\text {sub }} & =\text { saturation temp }- \text { bulk temp, } \mathrm{F} \\
\mathrm{V} & =\text { bulk velocity, } \mathrm{ft} / \mathrm{sec}
\end{aligned}
$$

Fission gas pressure in the hot pin based on release ratio from $\mathrm{UO}_{2}$ was calculated with TAFYA, a $\mathrm{B} \& W$ proprietary 
computer code. The results of this calculation are shown in Figure 2-19. The predicted fission gas release, which is a function of burnup and temperature as the element is moved through the core, is $23 \%$ of that generated. The calculation is based on a total burnup of 29,200 MWD/MT $\left(U^{\circ}+T h\right)$ in the hot pin and on the temperature distribution shown in Figure $2-17$.

2.4.2. AI-CE Design With Thorium Oxide Fuel Elements 2.4.2.1. Core Description

The preliminary design of a thorium oxide clustered-pin core for the 1000-MWe Uranium HWOCR is described in this section. Design parameters are listed in Table 2-4. As noted in section 2.3.2, the 1000-MWe Uranium HWOCR was defined by extrapolation of the 500-MWe Uranium Demonstration Plant described in AI-CEMEMO-25.4

By definition, thorium cores in the AI-CE plàt should produce the same power output as the uranium cores. Since the size and quantity of pressure tubes are also fixed, essentially identical power per pressure tube is required. A 55-pin oxide element is required to achieve this power level because of the limiting heat rating of the oxide fuel. The further requirement that the element fit inside the 4.03-inchID pressure tube fixes the pitch and (subject to small variations in fin height) the pin diameter. Thus each fuel element has an OD of 3.970 inches and consists of 55 pins arranged in a triangular pitch array. Each pin has six spiral fins integrally extruded with the clad. The pins are formed from SAP 895 cladding and are filled with Vipac $\mathrm{ThO}_{2}-\mathrm{UO}_{2}$ compacted to $88 \%$ of theoretical density.

Based on extrapolation of the 500-MWe Uranium Demonstration Plant, the core consists of 548 pressure tubes or fuel channels on a square pitch of 11.0 inches, surrounded by $\mathrm{D}_{2} \mathrm{O}$ in a 26-foot, 3-inch-ID moderator tank. Each pressure tube has an ID of 4.030 inches and contains five fuel elements (equivalent active fuel length of 42 inches per element) stacked axially to form a total active fuel length of 17 feet, 6 inches.

As in all the other cores, a one-pass coolant system with bi-directional flow in adjacent pressure tubes is utilized. 
Santowax coolant flows through the core at the rate of $121.7 \times 10^{6} \mathrm{lb} / \mathrm{hr}$ at a total core pressure differential of $227 \mathrm{psi}$, including headers. The pressure drop across the core is $173 \mathrm{psi}$, and the total system pressure drop is $327 \mathrm{psi}$. The coolant transports $3015 \mathrm{MWt}$ of heat while increasing in temperature from 560 to $706.5 \mathrm{~F}$. In addition to the heat transport in the coolant, the reactor generates $158 \mathrm{MWt}$ in the moderator and 10 MWt in the shield for a total output of $3183 \mathrm{MWt}$. This output produces $1076 \mathrm{MWe}$ at a net plant efficiency of $33.8 \%$.

At the design burnup of $20,000 \mathrm{MWD} / \mathrm{T}$, the idealized-cycle conversion ratio is 0.85 and the U-233 inventory is 1410 $\mathrm{kg}$.

\subsubsection{Mechanical Design}

A cross section of the basic element is shown in Figure 2-20. This element consists of 43 large pins, 12 small pins, and 6 flow blockers. The flow blocker is a circular segment, made of SAP 895, which extends the full length of the element. The small pins are offset toward the large pins as shown in Figure 2-20. Twelve large and ten small outer pins are attached to the ferrule end grid with cap screws to carry the hydraulic, drag, and weight loading. Indexing of one element to another (to prevent rotation) is done in the same manner as for the 37-pin oxide design.

Since the pins are smaller for the 55-pin design than for the 37-pin design, straps will be needed at the $1 / 3$ and $2 / 3$ points to prevent excessive vibration. These straps $(0.375$ by 0.020$)$ will be made of Inconel $X$ and will surround the element at the outer periphery.

The 43 large pins have a fin $O D$ of 0.501 inch, a clad OD of 0.381 inch, a 0.020-inch wall, and six spiral fins on the outside of the clad. The fins spiral with a helix pitch of 14.3 inches and are 0.060 inch in height by 0.030 inch wide. The 12 smaller pins have a fin $O D$ of 0.429 inch, a clad OD of 0.329 inch, a 0.020 -inch wall, and six spiral fins on the outside of the clad with a helix pitch of 14.3 inches. The small pin fins are 0.050 inch in height by 0.030 inch wide.

The overall effective element length is 44 inches with a 42-inch equivalent fuel length. The same type of Zircaloy end grids as used in the 37-pin design would be used here, modified by the pin geometry. 
The wall thickness of the SAP pressure tube in this 55-pin design has been increased to that of the AI-CE design in order to accommodate the larger core inlet pressure of the 55-pin design (310 psivs 229 psi for the 37-pin design).

\subsubsection{Nuclear Design}

Table 2-4 summarizes the results of physics calculations for the thorium oxide clustered-pin fuel element for the AICE core. Data given in the table are for the idealized cycle only as defined by an arbitrary fuel loading of $94.5 \mathrm{wt} \% \mathrm{U}-233$ and $5.5 \mathrm{wt} \% \mathrm{U}-234$. This design has been placed at a slight nuclear disadvantage compared to the thorium-optimized core (section 2.4.1) because of the lower volume fraction of fuel within the pressure tube. The lower fuel volume fraction is necessary to generate the same power per pressure tube as the AI-CE core; however, as indicated in BAW-393-4 $4^{2}$ and BAW-393-6, 3 the conversion ratio decreases with a decrease in the fuel volume fraction. The idealized-cycle conversion ratio for the 55-pin design is 0.85 compared with 0.91 for the 37 -pin optimized design.

\subsubsection{Thermal Design}

The same calculation methods as previously described were used for this design. An average power output of 10.24 $\mathrm{kw} / \mathrm{ft}$ was used for the hot pin in the hot pressure tube. The flow and the associated pressure drop required to maintain the hot channel surface temperature at $830 \mathrm{~F}$ were determined with the factors listed in Table 2-4 and with the effect of mixing applied to the hot channel. A 0.02 a (turbulence intensity factor) was used in the MIX-1 computer code. Because of mixing, the enthalpy rise is about $72 \%$ of what it would be for the hot channel without mixing of coolant from adjacent channels. On the basis of the AI-CE definition, mixing is $72.6 \%$.

The pin geometry and hot channel and local radial peaking factors are shown in Figure 2-20. The temperature of the coolant out of the hot pressure tube is $706.5 \mathrm{~F}$. Distribution of the flow through the 548 pressure tubes is controlled by orifices sized according to the radial power distribution to provide a mixed mean reactor outlet temperature equal to the outlet temperature $(706.5 \mathrm{~F})$ of the hot pressure tube. The hot pressure tube has a nominal power output of $6.43 \mathrm{MWt}$ to 
the coolant, and the average pressure tube has a fission power of 5.81 $\mathrm{MWt}$.

The calculated coolant and cladding temperatures for the hot channel are shown in Figure 2-21. The critical heat flux or DNB ratio calculated for the hot channel is shown in Figure $2-22$. The minimum DNB ratio is 2.25 occurring at $80 \%$ of the active channel length downstream of the inlet based on an $850 \mathrm{~F}$ saturation temperature.

\subsubsection{Evaluation of Thorium Oxide Designs}

The optimization studies indicate that the power costs are slightly higher for the 1000 MWe thorium oxide HWOCR than for the metallic nested-cylinder and the carbide pin designs under the design criteria and assumptions used in developing the designs. However, as previously noted, the design criteria and technical limits should be established carefully and evaluated critically to ensure that different designs can be compared on an equivalent basis. In addition, factors other than economic performance, which is predicted on the basis of a pre-established set of economic ground rules, should be considered in the comparative evaluation to select a reference design.

The principal factors that favor the oxide design are the irradiation stability of the fuel, the adaptability of the Vipac process to remote fabrication, and the relatively advanced stage of development. As a corollary to the requirement for less further development, there is probably less extrapolation and uncertainty involved in the predicted performance of the oxide than in that of the carbide or the metal designs. Although the power costs for the oxide design are greater than those for the other designs, the difference is relatively small and probably within the uncertainty band. However, there are inherent characteristics which are reflected as economic penalties. These characteristics are the limited pin heat rating and the cumulative effects of several factors that are minor when considered alone. Relative to the thorium metal ncsted-cylinder design, the most significant factors are the less efficient thermal performance of pin-type cores (as discussed in section 2. 3.3) and the limited power per pressure tube with thoria-urania pins. Likewise, the most important consideration in comparing the oxide with thorium monocarbide is the lower thermal conductivity of thoria- 
urania, which is reflected in higher fuel temperatures and fission gas release rates.

The performance of the thorium oxide design is limited by fission gas pressure buildup. The use of SAP cladding and the low external pressure on the fuel pins make fission gas pressure much more critical in the HWOCR than in previous applications of thorium oxide (e.g., Indian Point, which has stainless steel cladding and a 1500-psi operating pressure). Since the fission gas pressure buildup is dependent upon the pin heat rating and the burnup, $10 \mathrm{kw} / \mathrm{ft}$ (average in hot pin) and 20,000 MWD/T (average) were selected as a combination of values for near-optimum economic performance within fission gas pressure limitations,

The fuel temperature is a function of the linear heat rate $(\mathrm{kw} / \mathrm{ft})$ and the thermal conductivity. Therefore, thermal conductivity exerts its influence primarily by limiting the specific power. Economic performance depends not only on high specific power but also on the method of achieving the increase-by increasing pin heat rating or by reducing pin diameter. Both fuel cycle and plant capital costs decrease rapidly with increasing specific power when the increase is achieved by raising the pin heat rating. However, the low oxide conductivity in effect establishes the total length of fuel pins, which muct bc apprissindely $50 \%$ greater for oxide than for carbide and, to a large extent determines the reactor size. The reactor size and the specific power are also dependent, to some extent, on the fuel pin diameter and the assembly dimensions. Because fabrication costs increase and the conversion ratio decreases with a decrease in pin diameter, the fuel cycle cost is a minimum with pin diameters near $0.50 \mathrm{inch}$. In addition, pressurc tube radial peaking factors increase with increasing fuel element diameter and tend to reduce the diameter of the optimum pressure tube assembly. Thus the low heat rating, large optimum pin diameter, and small optimum pressure tube assembly lead to a thorium oxide core design with a large number of pressure tube assemblies. Since the reactor is larger, the capital costs for the thoria-urania pin cores are higher than those for the thorium carbide ( $\mathrm{ThC}$ ) clustered-pin or metallic nested-cylinder cores. 
Because of the importance of thoria-urania thermal conductivity, considerable effort was made to review and evaluate existing data. The results of this evaluation were applied in the design effort. However, $R \& D$ results are definitely required to confirm the values used or to define more clearly the limits on operation. While the possibility of favorable results from an $R \& D$ program exists, the probability of significant increases in pin heat rating (due to more precise thermal conductivity data) appears minimal. Assessment of power cost variations with pin heat rating indicates a change of about $0.01 \mathrm{mill} / \mathrm{kwhr}$ per percent for small changes in heat rating from the design value of $10 \mathrm{kw} / \mathrm{ft}$ (average in the hot pin). The rate of change decreases at higher heat ratings as indicated by the carbide pin performance.

In addition to its importance in establishing specific power in optimum pin sizes, the thermal conductivity affects the fuel cycle cost indirectly because of its part in limiting. the fuel burnup. For example, fuel cycle costs for the thoria-urania pin cluster design can be improved about $0.10 \mathrm{mill} / \mathrm{kwhr}$ by increasing the fuel-burnup to the economic optimum. As stated, the burnup limit of 20,000 MWD/T (average) for these designs is controlled by fission gas pressure buildup; consequently, it is dependent on fuel temperature, which is directly related to thermal conductivity of the fuel.

While the thermal conductivity data for Vipac thoriaurania fuel are inadequate for firm design, the fission gas release rates are even more uncertain. For example, $\mathrm{UO}_{2}$ release data and analytical models have been used in predicting fission gas pressure for design purposes. The few data points available from ORNL irradiations of thorium oxide indicate that physical changes which develop during irradiations and corresponding gas release rates will occur at heat ratings 10 to $40 \%$ higher than with $\mathrm{UO}_{2}$. Vibratory compacted $\mathrm{ThO}_{2}-\mathrm{UO}_{2}$ rods have been operated to $20,000 \mathrm{MWD} / \mathrm{T}$ at heat ratings up to $26 \mathrm{kw} / \mathrm{ft}$ with no evidence of swelling and with less than $30 \%$ fission gas release. These trends demonstra.te the irradiation stability of thoria-urania and indicate that the possibility of extending burnup beyond the specified 20,000 MWD/T is considerably greater for the oxide than for the other fuel materials. Demonstration of fission gas release characteristics more favorable than those assumed in the design would probably permit a $50 \%$ increase in 
burnup before other irradiation characteristics began to limit performance. Such an increase could improve the economic performance by 0.05 to $0.10 \mathrm{mill} / \mathrm{kwhr}$.

Another potential problem is the possibility that the SAP cladding cannot withstand the vibration required to attain the fuel density proposed by the Vipac process. However, should this potential problem materialize, it would be detected early in the development program and with minimum expense. Furthermore, alternate routes to use thoriaurania fuels are provided by the use of pellets. The remote fabrication costs would probably be somewhat higher, but such advantages as higher effective conductivity and lower fission gas release should partially offset any increase.

Naturally, minimized fouling and compatibility of the lowductility SAP clad with the organic environment must be demonstrated under HWOCR operating conditions. The AI-CE program should answer these questions satisfactorily. The performance of the SAP-clad Vipac thoria-urania fuel in an HWOCR environment should be verified by the program outlined in section 3.

As nuted in section 2.4.2, the oxide-pin element is basically compatible with the AI-CE HWOCR design, but pin diameters smaller than the economic optimum are required in a 55-pin element to equal the power output of the 37-pin uranium carbide fuel element. The requirement for a larger number of smaller pins dictates a somewhat different design from the AI-CE design, and some independent engineering tests will be required. Fabrication costs are also higher for the smaller-diameter pins.

In summiry, the economic performance of the thorium oxide core is slightly less favorable than the nested-cylinder core and about equal to that of the carbide element at the design conditions. How ever, the difference in power cost is small, and the uncertainty of performance predictions for the oxide core may be less than for the other designs. At the same time, the parameters most likely to be affected by $R \& D$ results-specific power or pin heat rating and fission-gas-limited burnup-are as important economically as the corresponding areas of concern in the nested-cylinder design-channel tolerances and fuel-swellinglimited burnup. 
Development costs for the thorium oxide core will be less than those for the other types of fuel materials, and the development can be completed on a shorter schedule. Most of the engineering test results from the UC clustered-pin fuel element should be applicable to the oxide element.

The conclusion from the draft HWOCR Evaluation Report ${ }^{8}$ provides an independent summary of the evaluation of a similar thorium oxide pin-type core: ${ }^{8}$

"The SAP-clad vibratory compacted element shows promise for HWOCR application; however, additional data and testing are required to show that the fuel element will operate satisfactorily under the proposed conditions. Particularly, experiments must be performed demonstrating that the effect of burnup in SAP-clad, vibratorily compacted fuel is not detrimental to the cladding. Also, it must be shown experimentally that SAP cladding is not adversely affected by the vibratory compaction operation."

\subsection{Thorium Carbide Core Design}

\subsubsection{Core Description}

The thorium carbide clustered-pin core design for the 1000-MWe HWOCR is described in this section. Table 2-5 lists design parameters. The thorium-optimized core is identical in size and configuration to the 1000-MWe HWOCR that B\&W extrapolated from the 500MWe HWOCR Demonstration Plant described in AI-CE-MEMO-25. Therefore, the thorium-optimized core and the thorium core for the AI-CE HWOCR are the same. The filel element has 37 pins in a 4.03 -inch-ID pressure tube: the pins are composed of SAP 895 cladding and filled with thorium-uranium monocarbide slugs.

The core has 548 pressure tubes on a square pitch of 11.0 inches, surrounded by $\mathrm{D}_{2} \mathrm{O}$ in a 26.25-foot-ID moderator tank. Each pressure tube has an ID of 4.030 inches and contains five fuel elements (equivalent active fuel length of 42.66 inches per element) stacked axially to form a total active fuel length of 17 feet, 9.4 inches.

Santowax coolant fluws through the core at the rate of 113 $\times 10^{6} \mathrm{lb} / \mathrm{hr}$ at a tolal core pressure differential of $209 \mathrm{psi}$ including header and shield plug losses. The pressure drop across the core is 155 psi, 
and the total system pressure drop is $309 \mathrm{psi}$. The coolant transports $2984 \mathrm{MW}$ of heat while increasing its temperature from 560 to $716.2 \mathrm{~F}$. In addition to the heat transferred to the coolant, the reactor generates $157 \mathrm{MWt}$ in the moderator and $10 \mathrm{MWt}$ in the shield for a total output of $3151 \mathrm{MWt}$. This output will produce $1076 \mathrm{MWe}$ at a net plant efficiency of $34.1 \%$. The power removal capability of an individual pressure tube is $6.69 \mathrm{MWt}$ with a flux tilt factor of 1.05 .

\subsubsection{Mechanical Design}

The pin-type carbide fuel element mechanical design is the same as the oxide design (described in section 2.4.1.2 and shown in Figurc 2-13) except for the following differences:

1. The large pin cladding $O D$ is 0.495 inch loxide is 0.515 ), the ID is 0.451 inch (oxide is 0.471 ), and the fins are 0.068 inch high (oxide is 0.058 ). Because linear heat ratings of the carbide pins are about $50 \%$ higher than those of the oxide pins, more flow area is required for adequate cooling; therefore the basic fin height for the carbide design is greater.

2. The fuel is ThC-UC in the form of slugs rather than Vipac $\mathrm{ThO}_{2}-\mathrm{UO}_{2}$.

3. The void length is 0.600 and 0.200 inch on the large and small pins (oxide is 1.3 and 0.43 ).

4. The overall element length is 44.12 inches loxide is 44.82). The reduced void space permits a shorter element.

5. Equivalent nonfuel length is 1.455 inches (oxide is 2.155). The reduced void space permits a shorter nonfuel length.

The fuel for this element is thorium-uranium monocarbide cast into slugs approximately 3 inches long. One end of the pellet is dished to a depth of 0.040 inch with a land width of 0.020 inch. The resultant density including gap, dish, and fabrication allowances is 10.1 $\mathrm{gm} / \mathrm{cm}^{3}$. The slugs are finish-ground to give a diametral clearance of 0.005 inch on both the large and 6 mall fuel pins. A tolerance of \pm 0.0005 inch on both the $O D$ of the slugs and the ID of the fuel tube gives a diametral clearance of 0.004 to 0.006 inch, which is sufficient to prevent 
adverse extension of the clad at operating conditions and which permits the pellets to be loaded in a standard manner. The ThC includes $5 \mathrm{wt} \%$ (nominal) carbon.

No work has been done with the combination of SAP clad-. ding and ThC-UC fuel, but based on UC performance, no incompatibility is expected between the cladding and the fuel as a result of thermal and irradiation growth. Since $\mathrm{ThC}$ is highly reactive with moisture, remote recycle fabrication will require a dry, inert atmosphere or the addition of a stabilizing agent to the fuel material.

\subsubsection{Nuclear Design}

Table 2-5 summarizes the results of physics calculations for the 37-pin thorium carbide fuel element in a 4.030-inch-ID pressure tube. The physics methods used are described in BAW-393-4. ${ }^{2}$ Results given in Table 2-5 include data for the U-233 idealized cycle and for U235 startup and recycle. THERMOS-corrected, local-radial power peaking ratios are given in Table $2-5$ for both the idealized cycle and the initial U-235 cycle at time zero. Plutonium startup calculations were not made for the carbide core. The following power peaking factors are as sumed on the basis of calculations for alternate core designs:

$$
\begin{array}{ll}
\text { Local axial } \mathrm{P} / \overline{\mathrm{P}} & 1.17 \\
\text { Gross radial } \mathrm{P} / \overline{\mathrm{P}} & 1.17 \\
\text { Gross axial } \mathrm{P} / \overline{\mathrm{P}} & 1.30
\end{array}
$$

Local radial peaking factors were calculated and the results are reported in Table 2-5.

The validity of the standard physics lifetime model for determining the equilibrium cycle of a continuously refueled and recycled core is discussed in section 2.3 .1 .3 .

\subsubsection{Thermal Design}

The thermal and hydraulic parameters for the 37-pin thorium carbide design are listed in Table 2-5. The calculation methods and hot channel factors described in section 2.4.1.4 were also used for this design. An average power output of $14.3 \mathrm{kw} / \mathrm{ft}$ was used for the hot pin. The flow and the associated pressure drop required to maintain the hot channel prefouling surface temperature at $830 \mathrm{~F}$ were based on the 
geometry, the local radial peaking factors, and the hot channel location shown in Figure 2-23.

The effect of mixing was applied to the hot channel, and a turbulence intensity factor (a) of 0.02 was used in the MIX- 1 computer code. Due to mixing, the enthalpy rise is about $77 \%$ of what it would be for the hot channel without mixing of coolant from adjacent channels. On the basis of the AI-CE definition, mixing is $66.1 \%$.

The high aspect ratio ( $0.068 \mathrm{inch}$ high/ $0.030 \mathrm{inch}$ wide) of the fins provides a fin efficiency of $87 \%$.

Due to insufficient data on thorium monocarbide properties and complete absence of information on irradiation performance, the fuel temperatures, fuel swelling, and fission gas release were based on uranium monocarbide data given in AI-CE-MEMO-25.4

The temperature of the coolant out of the hot pressure tube is $716.2 \mathrm{~F}$. The distribution of flow through the 548 pressure tubes is controlled by orifices sized according to the radial power distribution to provide a mixed mean reactor outlet temperature equal to the outlet temperature of the hot pressure tube $(716.2 \mathrm{~F})$. The hot pressure tube has a nominal power output of 6.37 . MWt to the coolant, and the average pressure tube has a fission power of $5.75 \mathrm{MWt}$.

The calculated coolant and cladding temperatures for the hot channel are shown in Figure 2-24. The critical heat flux or DNB ratio calculated for the hot channel is shown in Figure 2-25. The minimum DNB ratio is 2.34 occurring at $80 \%$ of the active channel length downstream of the inlet based on an $850 \mathrm{~F}$ saturation temperature. L.b.b. Evaluation of Thorium Carbide Core Design

The relative economic performance of the carbide pin design falls below that of the metallic nested-cylinder and slightly above that of the thoria-urania-pin designs. This position stems from the combination and basic characteristics of the fuel material, the coolant, and the reactor concept.

'The important design charactcristics of carbide fuel are its relatively high mass of thorium per unit volume and its high thermal conductivity. Compared with oxide fuel, the higher mass of fertile material contained in any given fuel element configuration leads to slightly 
higher conversion ratios. The higher thermal conductivity allows the fuel pin heat rating and the average specific power to be increased about $50 \%$ above the maximum design values using oxide fuel. The slightly higher conversion ratio reduces the burnup cost, and the higher specific power reduces both capital costs and inventory charges. Thus at first glance, it appears that power costs should be lower with carbide than with oxide cores. However, there are opposing trends that off et the potential advantages to a large extent.

In order to realize the advantage provided by high thermal conductivity, the carbide should be in solid form, rather than vibratory-packed powder. This requirement further complicates the remote fabrication and reprocessing that is essential for the long-term recycle of bred fuel. Consequently, fabrication and reprocessing costs are higher for carbide than for Vipac oxide fuel, offsetting at least to some extent the gain in inventory and burnup costs. This higher fabrication cost increases the economic optimum burnup, which may not be achievable because of fuel swelling and its effect on the low-ductility SAP cladding.

The higher allowable pin heat rating and specific power that provide the chief economic advantages for carbide also necessitate more stringent thermal-hydraulic performance than would be necessary for the lower-heat-flux oxide-pin design. Either larger coolant flow areas or much higher core pressure differential and coolant velocities are required to remove the higher-power-per-unit core volume. The larger coolant flow area naturally reduces the fertile material volume fraction and partially offsets the potentially higher conversion ratio capability. The use of additional fins to luwer the heat flux has the same effect.

The larger pressure differentials, together with lower outlet temperatures that result from higher heat fluxes, decrease the net plant efficiency and tend to reduce the initial benefits from a smallersize, lower-capital-cost core. Since a rather large reduction in core capital cost is required to offset a relatively small change in plant efficiency, the economic benefits of the smaller core, while real, are smaller than would at first be expected. Likewise, the fuel cycle costs are subject to similar offsetting effects. While the higher specific power 
reduces the carbide inventory cost, fabrication costs increase and essentially offset the saving in inventory: The higher specific power, together with the slightly larger coolant flow area required in the pressure tube, results in a conversion ratio about equal to that obtainable with the lowerpower-density oxide designs. Therefore, there is practically no saving in the burnup cost. Thus, with fuel cycle costs comparable to those of the oxide designs and capital costs comparable to those of the nestedcylinder designs, the economic performance of the carbide designs is intermediate between the other two.

As noted in section 4 , the fabrication cost is les sertain for the carbide fuel elements than for the other two fuel materials. This uncertainty is a result of the less-developed status of ThC in that the fabrication and reprocessing requirements have not been completely es tablished. Since the fabrication cost is based on remote operation of the UC fabrication plant, and reprocessing cust is based on oxide reprocessing cost, the values used are probably low, and at best, the fabrication cost estimate has a relatively large uncertainty.

The basic lack of sufficient data to adequately judge the potential of thorium carbide is a major deterrent to selection of this fuel material for the reference design. As noted in section 2. 5.4, the fuel temperature, fuel swelling, and fission gas release were assumed to be similar to those of UC fuel. While meager data. wnild support different values (as noted in section 3.4), there is not enough confirmed information to justify the additional design effort rcquired. Furthermore, if the use of UC properties did not lead to favorable performance, it is doubtfil that more effort to define the real properties would be productive.

The reactive iralure of lhl (also discussed in section 3.4) would lead to fabrication difficulties unless a stabilizing additive could be developed and proved. Lack of irradiation performance data is also of paramount concern. Thus, extensive fuel charactcrization would be required before acceptability of the ThC could be assured.

The ThC element is perfectly adaptable to the AI-CE plant, at least on the basis of the design assumptions; however, the changes that might be required as more precise information becomes available cannot be predicted quantitatively. In summary, lack of economic incentive, uncertain fuel fabrication-reprocessing cost, the reactive nature of $\mathrm{ThC}$, and the meager irradiation and properties data prohibit a factual evaluation of this design. 


\section{Reactor Data}

General

Moderator

$\mathrm{D}_{2} \mathrm{O}$

Coolant

Santowax OM-10\% HB

Fuel

Thorium-U-233 (low enriched)

Fission power, $\mathrm{MWt}$

Thermal power to coolant, MWt

3019

Thermal power to moderator, MWt

Net electric power, MWe

Number of coolant passes

Active fuel length, $\mathrm{ft}-\mathrm{in}$. $(5 \times$ active fuel length/element)

Active core length, ft-in. (fuel to fuel

for 5 elements)

Overall stack length, ft-in.

(end plate to end plate)

Maximum peak-to-average power ratios

Gross radial

1.17

Local radial

1.64

Gross axial

1.30

Loc al axial

1.10

Flux tilt

Pitch of fuel channel assemblies, in.

$\mathrm{D}_{2} \mathrm{O}$ inventory in calandria, lb

440,705

$\mathrm{D}_{2} \mathrm{O}$ cover gas

Helium

Fuel Channel Assembly

\begin{tabular}{|c|c|c|c|c|}
\hline . & $\begin{array}{c}\text { Inner } \\
\text { tube } \\
\text { (in-core } \\
\text { section) } \\
\end{array}$ & $\begin{array}{c}\text { Outer } \\
\text { tube } \\
\text { (in-core } \\
\text { section) }\end{array}$ & $\begin{array}{c}\text { Lower } \\
\text { fuel } \\
\text { channel } \\
\text { support } \\
\text { tube } \\
\end{array}$ & $\begin{array}{l}\text { Upper } \\
\text { fuel } \\
\text { channel } \\
\text { support } \\
\text { tube }\end{array}$ \\
\hline Material & SAP & $\mathrm{Zr}-2$ & SS & SS \\
\hline$O D$, in. & 5.262 & 6.130 & 7.340 & 7.340 \\
\hline Wall thickness, in. & 0.131 & 0.080 & 0.25 & 0.25 \\
\hline
\end{tabular}




\begin{tabular}{|c|c|c|c|c|}
\hline & $\begin{array}{c}\text { Inner } \\
\text { tube } \\
\text { (in-core } \\
\text { section) }\end{array}$ & $\begin{array}{c}\text { Outer } \\
\text { tube } \\
\text { (in-core } \\
\text { section) }\end{array}$ & $\begin{array}{l}\text { Lower } \\
\text { fuel } \\
\text { channel } \\
\text { support } \\
\text { tube }\end{array}$ & $\begin{array}{l}\text { Upper } \\
\text { fuel } \\
\text { channel } \\
\text { support } \\
\text { tube }\end{array}$ \\
\hline ength, $\mathrm{ft}$-in. & $21-4$ & $21-4$ & $3-7$ & $3-7$ \\
\hline
\end{tabular}

Overall fuel channel assembly length,

$\mathrm{ft}$-in.

Insulation between inner and outer tubes

Height of fuel channel as
above top shield, ft-in.

Height of fuel channel assembly extending below bottom shield, ft-in.

Total number of fuel channels in core Up \& down

Direction of coolant flow in fuel channels Up \& down

Direction of fuel flow in fuel channels

Method of refueling

On-line, by machine, frcm top \& bottom

How fuel channel is isolated Manually operated valves

Moderator Tank

Material

ID, $\mathrm{ft}$-in.

$21-7$

Wall thickness, in.

Inside shield length, ft-in.

Top shield height, ft-in.

Top shield diameter, $\mathrm{ft}$-in.

Bottom shield height, ft-in.

Bottom shield diameter, ft-in.

$\underline{\text { Piping }}$

Total number of pipes from fuel channel assemblies to header (each end)

Joint between fuel channel assemblies and pipes to headers 
Piping material

Carbon steel

Pipes to headers, size, in.

II. Fuel Element Data

General

Drawing number A30461 E

Figure 2-1

Fuel assemblies/fuel channel

Fuel assemblies/reactor

1620

Fuel cylinders/assembly

Refueling rate, assemblies/day@

20,000 MWD/T

Fuel content/assembly, kg $(U+T h)$

Fuel element weight, lb

Materials composition inside homogenized

fuel channel, vol \%

Fuel

Structural material (all $\mathrm{Zr}$ )

35.6

Coolant

Dimensions (Hot)

Active fuel length/assembly, in.

Cyl 1

Cyl 2

Cyl 3

Cyl 4

Overall length (effective), in.

$\mathrm{Zr}-2$ center moderator can diameter, in.

$\mathrm{Zr}-4$ cladding thickness, in.

(typical for all cylinders)

0.025

Fuel thickness, in.

Cyl 1

Cyl 2

0.242

Cyl 3

0.205

Cyl 4

0.150

0.100

Conlant gap thickness, in.

Cyl 1 - center can

Cyl 1 - 2

Cyl 2 - 3

0.110

0.150

0.150 
Cyl $3-4$

0.150

Cyl 4 - pressure tube

III. Thermal and Hydraulic Data

General

Core inlet temperature, F

560

Core mixed mean outlet temperature, F

708.4

Total coolant flow, lb/hr

$119.0 \times 10^{6}$

Core inlet pressure, psi

Total core pressure drop (including header), psi

Minimum ratio, critical flux to actual flux

2.4

Core

General

Number of pressure tubes

Power to coolant, MWt

Pressure drop, active core including head, psi

Pressure drop, headers, psi

Fission power/avg pressure tube, $\mathrm{MWt}$

9.8

Cylinders/element

Euel Tubes

Nominal Pressure Tube ${ }^{(a)}$

Power/pressure tube, MWt

Mixed mean outlet temp, F

\begin{tabular}{lll}
\multicolumn{4}{c}{ Cylinder } \\
\hline 1 & 2 & 3
\end{tabular}

Max surface temp, F

ID

OD

$\begin{array}{lll}772 & 776 & 781 \\ 773 & 777 & 782\end{array}$

779

$\begin{array}{llll}773 & 777 & 782 & 771\end{array}$

(a) Nominal pressure tube has nominal dimensions and nominal power peaking factors. 
Table 2-1. (Cont'd)

\begin{tabular}{llll}
\multicolumn{4}{c}{ Cylinder } \\
\hline 1 & 2 & 3 & 4 \\
\hline
\end{tabular}

Max heat flux,

$\mathrm{Btu} / \mathrm{hr}-\mathrm{ft}^{2} \times 10^{-5}$

ID

OD

Max fuel temp, $F$

Peak-to-average

power ratio
3.44

3.41

883

0.649
3.57

3.58

3.63

3.44

880

875

3.54

856
0.774
1.092
1.641

Hot Pressure Tube (b)

Power/pressure tube, MWt

Mixed mean outlet temperature, F

Cylinder
\begin{tabular}{llll}
1 & 2 & 3 & 4 \\
\hline
\end{tabular}

Max surface temp, F

ID

OD

Max heat flux,

Btu/hr $-\mathrm{ft}^{2} \times 10^{-5}$

ID

OD

Max fuel temp, F

Peak-to-average

power ratio
3.62

3.58

3.66

3.60

787

788

796

813

820

783

902

899.

3.78

3.71

4.00

3.88

909

911

0.672

0.801

1.033

1.567

(b) Hot pressure tube has maximum power peaking factors and worst tolerances for geometry and power generation. Dimensional variations caused by fabrication tolerances and fuel growth are incorporated in the fuel element geometry used in the thermal analysis. The outer cylinder is assumed to have a power generation factor of 1.05 . 
Table 2-1. (Cont'd)

Coolant Channels

Channel

$1 \quad 2 \quad 3 \quad 4 \quad 5$

Nominal Pressure Tube

Channel thickness,

in.

Channel flow, lb/hr $\times 10^{-3}$

Avg velocity, fps

Channel exit temp, F

Hot Pressure Tube

Channel thickness, in.

Channel flow, lb/hr $\times 10^{-3}$

Avg velocity, fps

Channel exit temp, F $\begin{array}{lllll}0.110 & 0.150 & 0.150 & 0.1365 & 0.0965\end{array}$

$\begin{array}{lllll}35.2 & 82.4 & 106.0 & 109.1 & 70.9\end{array}$

$38.1 \quad 46.0 \quad 46.0 \quad 44.0 \quad 35.5$

$\begin{array}{lllll}703 & 719 & 724 & 751 & 730\end{array}$

IV. Nuclear Data

U-235 Batch Recycle for Thorium Metal Nested-Cylinder Core

\begin{tabular}{|c|c|c|c|c|c|c|c|c|c|c|c|c|}
\hline & \multicolumn{2}{|c|}{ Cycle 1} & \multicolumn{2}{|c|}{ Cycle? } & \multicolumn{2}{|c|}{ Cycle 3} & \multicolumn{2}{|c|}{ Cycle 4} & \multicolumn{2}{|c|}{ Cycle 5} & \multicolumn{2}{|c|}{ Cycle 6} \\
\hline & In & Out & In & Out & In & Out & In & Out & In & Out & In & Out \\
\hline $\begin{array}{l}T h-232 \\
U-233 \\
U-234 \\
U-235 \\
U-236 \\
U-238 \\
P a-233 \\
P u-239, \text { Pu-241 }\end{array}$ & $\begin{array}{c}300.337 \\
-- \\
7.344 \\
-- \\
0.562 \\
-- \\
=-\end{array}$ & $\begin{array}{r}294.595 \\
2.893 \\
0.296 \\
2.281 \\
0.831 \\
0.520 \\
0.366 \\
0.013\end{array}$ & $\begin{array}{r}299.987 \\
3.206 \\
0.292 \\
3.397 \\
0.819 \\
0.599 \\
-- \\
--\end{array}$ & $\begin{array}{r}294.239 \\
3.860 \\
0.678 \\
1.109 \\
1.157 \\
0.554 \\
0.374 \\
0.014\end{array}$ & $\begin{array}{r}299.450 \\
4.167 \\
0.668 \\
2.242 \\
1.140 \\
0.633 \\
-- \\
--\end{array}$ & $\begin{array}{r}293.760 \\
4.150 \\
1.010 \\
0.825 \\
1.334 \\
0.587 \\
0.372 \\
0.015\end{array}$ & $\begin{array}{c}298.913 \\
4.450 \\
0.995 \\
1.963 \\
1.314 \\
0.665 \\
\ldots \\
\ldots\end{array}$ & $\begin{array}{r}293.281 \\
4.241 \\
1.277 \\
0.784 \\
1.471 \\
0.617 \\
0.369 \\
0.0115\end{array}$ & $\begin{array}{r}248.439 \\
4.537 \\
1.258 \\
1.922 \\
1.449 \\
0.695 \\
-- \\
--\end{array}$ & $\begin{array}{r}292.739 \\
4.270 \\
1.489 \\
0.801 \\
1.599 \\
0.645 \\
0.366 \\
0.016\end{array}$ & $\begin{array}{c}298.034 \\
4.563 \\
1.467 \\
1.939 \\
1.575 \\
0.722 \\
\ldots \\
\ldots\end{array}$ & $\begin{array}{r}292.308 \\
4.279 \\
1.654 \\
0.832 \\
1.724 \\
0.670 \\
0.363 \\
0.017\end{array}$ \\
\hline Total & $\overline{308.3}$ & & 308.3 & & 308.3 & & 308.3 & & 308.3 & & 308.3 & \\
\hline Eull powcr days & & 656 & & 636 & & 625 & & 627 & & 635 & & 638 \\
\hline MWD/T metal & & 20,214 & & 19,598 & & 19.259 & & 19,320 & & 19,567 & & 19.659 \\
\hline $\begin{array}{l}\text { C.R. } \\
\text { Makeup }\end{array}$ & & 0.7597 & & 0.8263 & & 0.8498 & & 0.8558 & & 0.8571 & & 0.8572 \\
\hline $\begin{array}{l}T h-232 \\
U-235 \\
U-238\end{array}$ & & & & & & & & & & & & \\
\hline
\end{tabular}

Notes: 1. Run at $9.5 \mathrm{MWt} / \mathrm{pressure} \mathrm{tube.} \mathrm{3.} 180$-day cooling for Pa decay.

$\begin{array}{ll}\text { 1. Run at } 9.5 \mathrm{MWt} / \mathrm{pressure} \text { tube. } & \text { 3. } 180 \text {-day cooling for Pa decay. } \\ \text { 2. Masses are } \mathrm{kg} / \mathrm{pres} \text { alire tube. } & \text { 1. Total lusses of } 1.5 \% \text { during recycle. }\end{array}$ 
Table 2-1. (Cont'd)

\section{Continuous Refueling of Thorium Metal Nested-Cylinder Core}

Batch No. Code $x / y$

$x=$ original batch No.

$y=$ times recycled

(i.e., \#11 is batch 10

after first recycle)

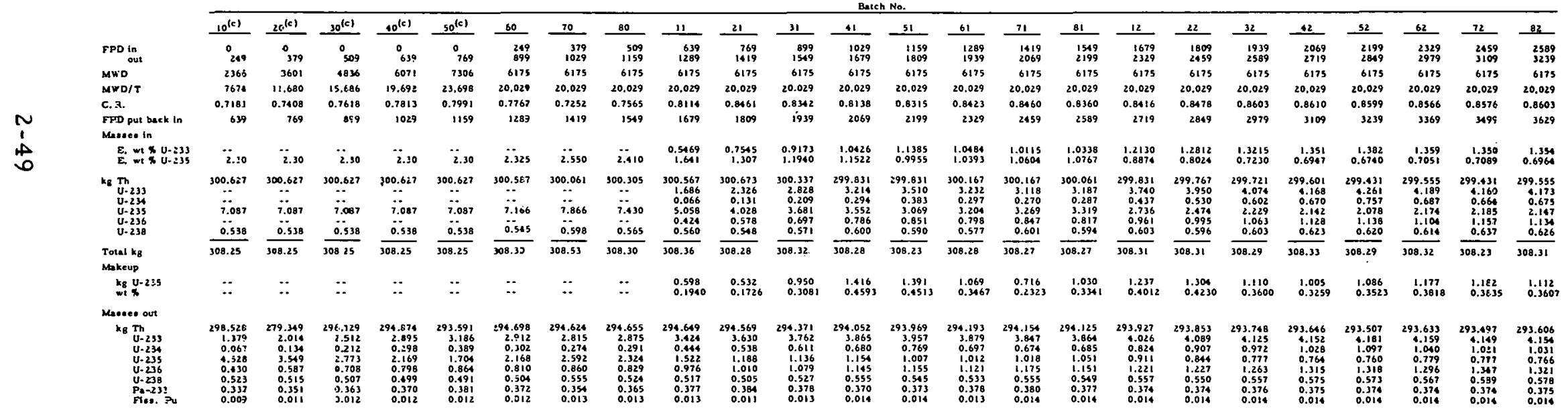

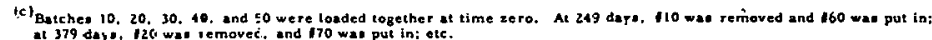

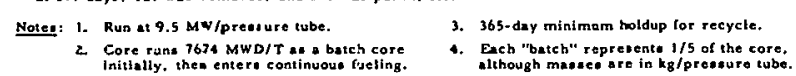


Table $2-1 . \cdot($ Cont'd)

Plutonium Batch Recycle of 4-Ring No. 5 Nested Cylinder Element

\begin{tabular}{|c|c|c|c|c|c|c|c|c|c|c|c|c|}
\hline & \multicolumn{12}{|c|}{ Mass balance, $\mathrm{kg} /$ pressure tube } \\
\hline & \multicolumn{2}{|c|}{ Cycle 1} & \multicolumn{2}{|c|}{ Cycle 2} & \multicolumn{2}{|c|}{ Cycle 3} & \multicolumn{2}{|c|}{ Cycle' 4} & \multicolumn{2}{|c|}{ Cycle 5} & \multicolumn{2}{|c|}{ Cycle 6} \\
\hline & In & Out & In & Out & In & Out & In & Out & In & _out & In & Out \\
\hline Th-232 & 298.525 & 294.231 & 297.500 & 293.013 & 297.500 & 293.017 & 297.393 & 292.634 & 297.393 & 292.742 & 297.163 & 292.434 \\
\hline$U-233$ & 年 & 2.461 & 2.717 & 3.739 & 3.977 & 4.245 & 4.484 & 4.444 & 4.684 & 4.503 & 4.746 & 4.522 \\
\hline $\mathrm{U}-234$ & -- & 0.200 & 0.197 & 0.484 & 0.477 & 0.764 & 0.753 & 1.027 & 1.012 & 1.242 & 1.223 & 1.421 \\
\hline $\mathrm{U}-235$ & ... & 0.022 & 0.022 & 0.081 & 0.080 & 0.145 & 0.143 & 0.207 & 0.204 & 0.258 & 0.254 & 0.300 \\
\hline $\mathrm{U}-23$ & $\therefore$ & 0.002 & 0.002 & 0.010 & 0.010 & 0.028 & 0.028 & 0.056 & 0.055 & 0.092 & 0.091 & 0.131 \\
\hline$P_{u-239}$ & 6.225 & 1.273 & 3.028 & 0.469 & 1.707 & 0.229 & 1.380 & 0.150 & 1.238 & 0.135 & 1.287 & 0.134 \\
\hline$P_{u-240}$ & 3.396 & 3.079 & 4.000 & 2.828 & 3.465 & 2.237 & 2.833 & 1.735 & 2.303 & 1.426 & 2.035 & 1.272 \\
\hline Pu-241 & 1.497 & 1.060 & 1.471 & 0.919 & 1.204 & 0.725 & 0.992 & 0.569 & 0.822 & 0.477 & 0.748 & 0.430 \\
\hline $\begin{array}{l}\mathrm{Pu}-242 \\
\mathrm{~Pa}-233\end{array}$ & $\begin{array}{l}0.672 \\
--\end{array}$ & $\begin{array}{l}1.163 \\
0.300\end{array}$ & 1.337 & $\begin{array}{l}1.799 \\
0.302\end{array}$ & 1.906 & $\begin{array}{l}2.228 \\
0.307\end{array}$ & $\begin{array}{l}2.320 \\
-.\end{array}$ & $\begin{array}{l}2.525 \\
0.314\end{array}$ & $\begin{array}{l}2.605 \\
--\end{array}$ & $\begin{array}{l}2.710 \\
0.318\end{array}$ & $\begin{array}{l}2.794 \\
-.\end{array}$ & $\begin{array}{l}2.847 \\
0.320\end{array}$ \\
\hline Total & 310.3 & & 310.3 & & $\overline{310.3}$ & & 310.3 & . & $3 \longdiv { 3 1 0 . 3 }$ & & 310.3 & \\
\hline Full power days & & 653 & & 656. & & 627 & & 650 & & 624 & & 634 \\
\hline MWD/T metal & & 19.991 & & 20,084 & & 19,195 & & 19.899 & & 19,103 & & 19,407 \\
\hline C.R. & & $0.71 \mathrm{Az}$ & & 0.7974 & & 0.8316 & & 0.0342 & & 0.8326 & & 0.8251 \\
\hline Makeup & & & & & & & & & & & & \\
\hline Th-232 & & & & & & & & & & & & \\
\hline$P_{u}-239$ & & & & & & & & & & & & \\
\hline $\begin{array}{l}P u-240 \\
P u-241\end{array}$ & & & & & & & & & & & & \\
\hline $\begin{array}{l}P_{u}-241 \\
P_{u}-212\end{array}$ & & & & & & & & & & & & \\
\hline
\end{tabular}

Note日: $1.9 .5 \mathrm{MWt} /$ tube.

2. I8v-day Pu decay, total losses are $1.5 \%$.
3. Pu feed is HWOCR discharge: Pu-239-0.528, $240-0.288,241-0.127,242-0.057$.

Thorium Metal Nested-Cylinder Core - Idealized Cycle

$\begin{array}{llll}\text { U-233, wt \% } & 1.75 & 1.80 & 1.875 \\ \text { keff } & 1.1245 & 1.1385 & 1.1584 \\ \text { Days } & 374 & 483 & 625 \\ \text { Tons } & 0.30755 & 0.30754 & 0.30773 \\ \text { MWD/T } & 11,553 & 14,920 & 19.295 \\ \text { C.R. } & 0.9232 & 0.9147 & 0.9034 \\ \text { MW/pressure tube } & 9.5 & 9.5 & 9.5 \\ \text { Fuel fraction } & 0.3500 & 0.3500 & 0.3500 \\ \text { Fuel/cell } & 0.0511 & 0.0511 & 0.0511 \\ \text { Watts/gram } & 30.89 & 30.89 & 30.89 \\ \text { Masses } & & & \\ \text { Time 0 } & & & \\ \text { Th } & & & \\ \text { U-233 } & 301.869 & 301.699 & 301.639 \\ \text { U-234 } & 5.382 & 5.536 & 5.769 \\ \text { Final } & 0.297 & 0.306 & 0.319 \\ \text { Th } & & & \\ \text { U-233 } & & & \\ \text { U-234 } & 298.185 & 296.991 & 295.647 \\ \text { U-235 } & 4.607 & 4.608 & 4.607 \\ \text { U-236 } & 0.639 & 0.732 & 0.844 \\ \text { Pa } & 0.074 & 0.097 & 0.127 \\ & 0.005 & 0.009 & 0.015 \\ & 0.393 & 0.391 & 0.387\end{array}$




\section{Table 2-1. (Cont'd)}

Thorium Metal (Optimized) Core Neutrón Balances

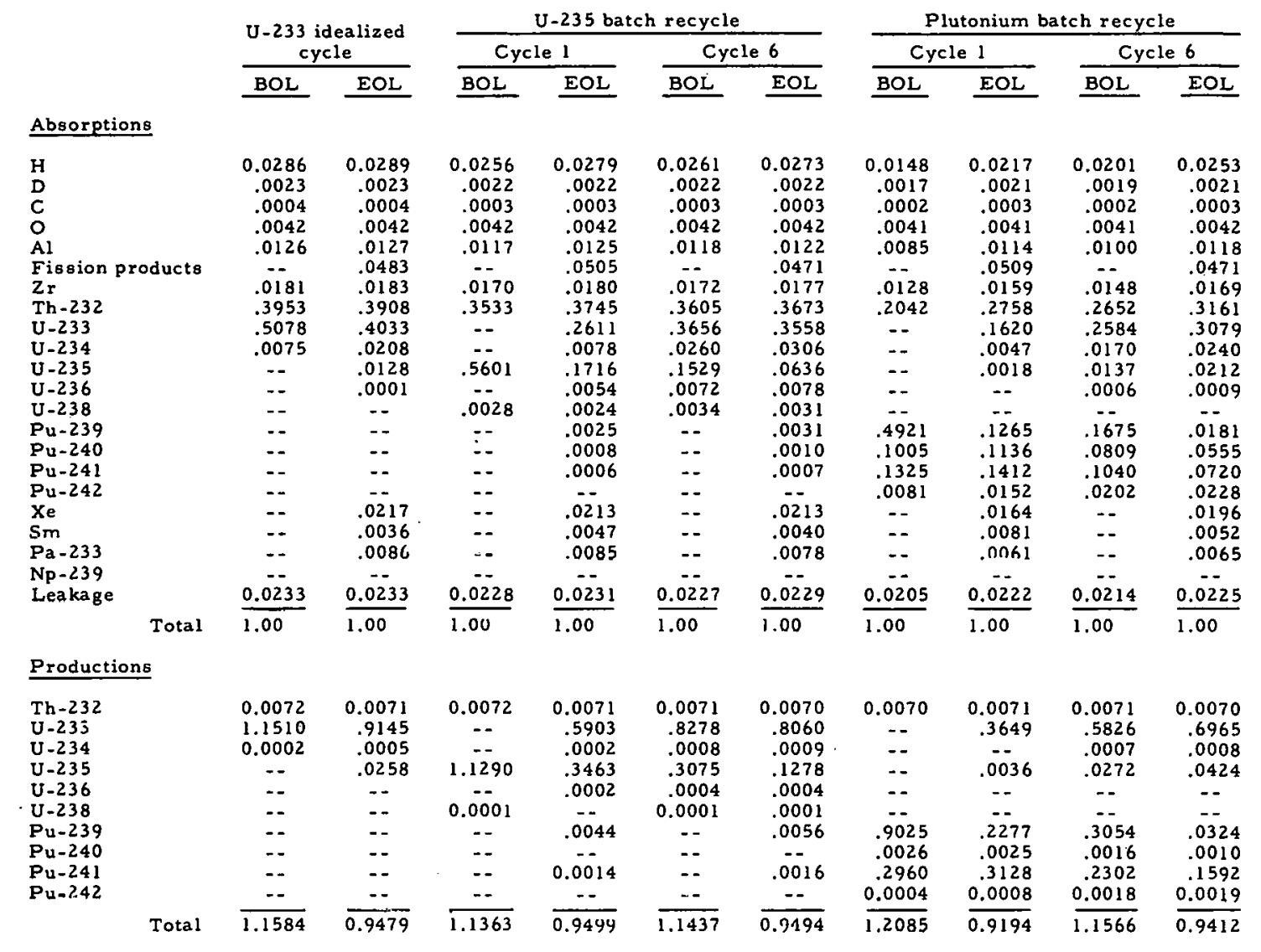


Table 2-2. Core Design Data for Five-Cylinder Thorium Metal Fuel Element in a 4.030-Inch-ID

Pressure Tube (AI-CE)

\section{Reactor Data}

\section{General}

Moderator

$\mathrm{D}_{2} \mathrm{O}$

Coolant

Santowax OM-10\% HB

Fuel

Thorium-U-233 (low enriched)

Fission power, $\mathrm{MWt}$

3209

Thermal power to coolant, $\mathrm{MWt}$

3039

Thermal power to moderator, $\mathrm{MWt}$

160

Net electric power, MWe

1076

Number of coolant passes

Active fuel length, ft-in. $(5 \times$ active fuel

length/element)

Active core length, ft-in. (fuel to fuel

for 5 elements)

$18-2.5$

Overall stack length, ft-in.

(end plate to end plate)

$18-3.8$

Maximum peak-to-average power ratios

Gross radial

1.17

Local radial

1.76

Gross axial

1.3

Local axial

1.1

Flux tilt

1.05

Pitch of fuel channel assemblies, in.

11.0

$\mathrm{D}_{2} \mathrm{O}$ inventory in calandria, $1 \mathrm{~b}-414$ pressure tubes

$498,87 \cap$

- 548 pressure tubes $\quad 642,768$

$\mathrm{D}_{2} \mathrm{O}$ cover gas

Helium

Fuel Channel Assembly

Material

\begin{tabular}{ccc}
$\begin{array}{c}\text { Inner } \\
\text { tube }\end{array}$ & $\begin{array}{c}\text { Outer } \\
\text { tube } \\
\text { (in-core } \\
\text { section) } \\
\text { section) }\end{array}$ & $\begin{array}{c}\text { fower } \\
\text { fuel } \\
\text { shanncl } \\
\text { support } \\
\text { tube }\end{array}$ \\
\cline { 1 - 2 } & $\frac{Z r-2}{\text { SS }}$ &
\end{tabular}

Upper

fuel channel support tube

OD, in.

4.274

4.992

6.35

SS

6.35 
Table 2-2. (Cont'd)

\begin{tabular}{|c|c|c|c|c|}
\hline & $\begin{array}{c}\text { Inner } \\
\text { tube } \\
\text { (in-core } \\
\text { section) }\end{array}$ & $\begin{array}{c}\text { Outer } \\
\text { tube } \\
\text { (in-core } \\
\text { section) }\end{array}$ & $\begin{array}{l}\text { Lower } \\
\text { fuel } \\
\text { channel } \\
\text { support } \\
\text { tube }\end{array}$ & $\begin{array}{c}\text { Upper } \\
\text { fuel } \\
\text { channel } \\
\text { support } \\
\text { tube }\end{array}$ \\
\hline Wall thickness, in. & 0.122 & 0.059 & 0.25 & 0.25 \\
\hline Length, $\mathrm{ft}$-in. & $20-0$ & $20-0$ & $3-7$ & $3-7$ \\
\hline
\end{tabular}

Overall fuel channel assembly length, $\mathrm{ft}$-in.

37-2 (414 PT's) 38-8 (548 PT's)

Insulation between inner and outer tubes

Carbon dioxide

Height of fuel channel assembly extending above top shield, ft-in.

5-10 (414 PT's) 6-7 (548 PT's)

Height of fuel channel assembly extending below bottom shield, ft

5-4 (414 PT's)

$6-1$ (548 PT's)

Direction of coolant flow in fuel channels

Up \& down

Direction of fuel flow in fuel channels

Up \& down

Method of refueling

On-line, by machine, from top \& bottom

Moderator Tank

Material

SS

ID, $\mathrm{ft}$-in.

23-1 (414 PT's)

26-3 (548 PT's)

Wall thickness, in.

Inside shield length, ft-in.

20-0

Top shield height, ft-in.

3-0

Top shield diameter, ft-in.

25-1 (414 PT's) 28-3 (548 PT's)

Bottom shield height, ft

Bottom shield diameter, ft-in.

Piping (for 548 PT's)

Total number of pipes from fuel channel assemblies to header (each end)

Piping material

Carbon steel 
Table 2-2. (Cont'd)

II. Fuel Element Data (for 414 PT's)

\section{General}

Figure number

$2-2$

Fuel assemblies/fuel channel

Fuel assemblies/reactor

Fuel cylinders/assembly

Refueling rate, assemblies/day @20,000 MWD/T

Fuel content/assembly, $\mathrm{kg}(\mathrm{U}+\mathrm{Th})$

52.1

Fuel element weight, ib

Materials composition inside homogenized fuel channel, vol \%

\section{Fuel}

Structural material (all Zr)

42.6 Coolant

Dimensions (Hot)

Active fuel length/assembly, in.

42.66

Overall length (effective), in.

$\mathrm{Zr}-2$ center flow blocker diameter, in.

0.280

$\mathrm{Zr}-4 \mathrm{cladding}$ thickness, in.

(Lypical for all cylinders)

0.025

Fuel thickness, in.

Cy 1

Cyl 2

Cy 13

Cyl 1

Cyls

0.284

0.240

0.175

0.128

0.090

Coolant gap thickness, in.

Flow blocker - cyl 1

0.11

Cyl 1 - 2

0.12 .5

Cyl 2 - 3

0.125

Cyl $3-4$

0.125

Cyl 4 - 5

0.125

Cyl. 5 - pressure tube

0.100 


\section{Thermal and Hydraulic Data (for $414 \mathrm{PT}^{\prime}$ s)}

\section{General}

Core inlet temperature, $F$

560

Core mixed mean outlet temperature, $F$

711

Total coolant flow, $1 \mathrm{~b} / \mathrm{hr}$

Core inlet pressure, psi

Total core pressure drop (including header), psi

Minimum ratio, critical flux to actual flux

\section{Core}

General

Number of pressure tubes

Power to coolant, $\mathrm{MWt}$

Pressure drop, active core including head, psi

Pressure drop, headers, psi

Fission power/avg pressure tube, $\mathrm{MWt}$

Cylinders/element

\section{Fuel Tubes}

Nominal Pressure Tube ${ }^{(a)}$

Power/pressure tube, $\mathrm{MWt}$

Mixed mean outlet temperature, F

Cylinder
$\begin{array}{lllll}1 & 2 & 3 & 4 & 5\end{array}$

Max surface temp, F

ID

OD

$\begin{array}{lllll}769 & 771 & 771 & 775 & 772 \\ 765 & 769 & 772 & 775 & 756\end{array}$

Max heat flux,

$\mathrm{Btu} / \mathrm{hr}-\mathrm{ft}^{2} \times 10^{-5}$

ID

OD
3.63

3.20
3.44

3.31
3.38

3. 34

(a) Nominal pressure tube has nominal dimensions and nominal power peaking factors. 
Table 2-2. (Cont'd)

\begin{tabular}{lllllll} 
& \multicolumn{6}{c}{ Cylinder } \\
\cline { 2 - 5 } & 1 & $\frac{2}{1}$ & $\frac{3}{8}$ & $\frac{4}{8}$ & 5 \\
$\begin{array}{l}\text { Max fuel temp, F } \\
\begin{array}{l}\text { Peak-to-average } \\
\text { power ratio }\end{array}\end{array}$ & 884 & 880 & 867 & 862 & 845 \\
& 0.523 & 0.623 & 0.854 & 1.220 & 1.759
\end{tabular}

Hot Pressure Tube ${ }^{(b)}$

Power/pressure tube, MWt

9.32

Mixed mean outlet temp, F

Cylinder

\begin{tabular}{|c|c|c|c|}
\hline 1 & 2 & 3 & 4 \\
\hline 782 & 784 & 784 & 795 \\
\hline 779 & 782 & 787 & 813 \\
\hline
\end{tabular}

Max heat flux,

$\mathrm{Btu} / \mathrm{hr}-\mathrm{ft}^{2} \times 10^{-5}$

ID

$O D$

Max fuel temp, F

Peak-to-average

power ratio
782

3.87

3.41

3.67

3.53

908

901

0.541

0.644
3.61

3.56

3.75

3.61

4.0

887

900

3.95

905

$0.882 \quad 1.139$

1.662

\section{Cuolant Channels}

Channel

$1 \quad 2 \quad 3 \quad 4 \quad 5 \quad 6$

Nominal Pressure Tube

Channel thick-

ness, in.

0.110

0.125

0.125

0.125

0.125

0.100

Channel flow,

$\mathrm{lb} / \mathrm{hr} \times 10^{-3}$

9.4

35.0

56.7

24.9

90.6

72.7

(b) Hot pressure tube has maximum power peaking factors and worst tolerances for geometry and power generation. Dimensional variations caused by fabrication tolerances and fuel growth are incorported in the fuel element geometry used in the thermal analysis. The outcr cylinder is assumed to have a power generation factor of 1.05 . 
Table 2-2. (Cont'd)

Avg velocity, fps

$\begin{array}{llllll}1 & 2 \\ 45.5 & \frac{3}{49.2} & \frac{4}{49.2} & \frac{5}{49.2} & \frac{6}{49.3} & 42.6\end{array}$

Channel exit

temp, F

$\begin{array}{llllll}703 & 715 & 717 & 719 & 720 & 680\end{array}$

Hot Pressure Tube

Channel thick-

ness, in.

$\begin{array}{llllll}0.11 & 0.125 & 0.125 & 0.125 & 0.112 & 0.087\end{array}$

Channel flow, $\mathrm{lb} / \mathrm{hr} \times 10^{-3}$

Avg velocity, fps

$\begin{array}{llllll}9.4 & 35.0 & 56.6 & 74.8 & 76.2 & 58.3\end{array}$

Channel exit

temp, $F$

45.549 .3

49.3

49.4

46.7

39.6

$712 \quad 726 \quad 727$

$733 \quad 763$

725

IV. Nuclear Data

Idealized U-233 Cycle

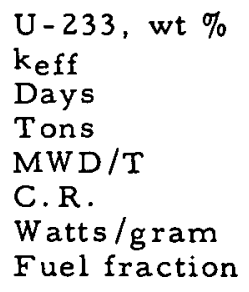

C. R.

Watts/gram

Fuel fraction

Masses

Time 0

$\mathrm{Th}$

U - 233

$\mathrm{U}-234$

Final

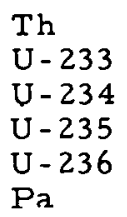

$\mathrm{P} / \overline{\mathrm{P}}$ Radial

$\begin{array}{rr}\text { Cyl } 1 & 0.521 \\ 2 & 0.622 \\ 3 & 0.852 \\ 4 & 1.219 \\ 5 & 1.757\end{array}$

$\begin{array}{ll}1.85 & 1.90 \\ 1.1541 & 1.1671 \\ 556 & 646 \\ 0.24660 & 0.24670 \\ 17.476 & 20,296 \\ 0.9132 & 0.9061 \\ 31.43 & 31.43 \\ 0.436 & 0.436\end{array}$

241.789

4.562

0.252

241.757

4.687

0.257

$\begin{array}{ll}237.389 & 236.695 \\ 3.732 & 3.736 \\ 0.638 & 0.692 \\ 0.090 & 0.104 \\ 0.010 & 0.014 \\ 0.319 & 0.318\end{array}$


Table 2-3. Core'Deșign Data for 37-Pin $\mathrm{ThO}_{2}$ Fuel Element in a 4.030-Inch-ID Pressure Tube

\section{Reactor Data}

General

Moderator

$\mathrm{D}_{2} \mathrm{O}$

Coolant

Santowax OM-10\% HB

Fuel

Fission power, $\mathrm{MWt}$ $\mathrm{ThO}_{2}+\mathrm{UO}_{2}$ Vipac pins

Thermal power to coolant, $\mathrm{MWt}$

Thermal power to moderator, $\mathrm{MWt}$

Net electric power, MWe

Number of coolant passes

Active fuel length, ft-in. ( $5 \times$ active fuel

length/element)

$17-9.4$

Active core length, ft-in. (fuel to fuel for

5 elements)

$18-6.0$

Overall stack length, ft-in. (end plate to end plate)

$18-8.1$

Peak-to-average power ratios

Gross radial

Local radial, effective

Gross axial

1.17

1.25

1.3

Local axial

1.17

Flux tilt

Pitch of fuel channel assemblies, in.

$\mathrm{D}_{2} \mathrm{O}$ inventory in calandria, $\mathrm{lb}$

624,854

$D_{2} \mathrm{O}$ cover gas

Helium

Fuel Channel Assembly

\begin{tabular}{|c|c|c|c|c|}
\hline . & $\begin{array}{c}\text { Inner } \\
\text { tube } \\
\text { (in-core } \\
\text { section) }\end{array}$ & $\begin{array}{c}\text { Outer } \\
\text { tube } \\
\text { (in-core } \\
\text { section) }\end{array}$ & $\begin{array}{l}\text { Lower } \\
\text { fuel } \\
\text { channel } \\
\text { support } \\
\text { tube }\end{array}$ & $\begin{array}{c}\text { Upper } \\
\text { fuel } \\
\text { channel } \\
\text { support } \\
\text { tube }\end{array}$ \\
\hline Material & SAP & $\mathrm{Zr}-2$ & SS & SS \\
\hline OD, in. & 4.248 & 5.127 & 6.43 & 6.43 \\
\hline Wall thickness, in. & 0.109 & 0.069 & 0.25 & 0.25 \\
\hline
\end{tabular}




\begin{tabular}{|c|c|c|c|c|}
\hline & $\begin{array}{c}\text { Inner } \\
\text { tube } \\
\text { (in-core } \\
\text { section) }\end{array}$ & $\begin{array}{c}\text { Outer } \\
\text { tube } \\
\text { (in-core } \\
\text { section) }\end{array}$ & $\begin{array}{l}\text { Lower } \\
\text { fuel } \\
\text { channel } \\
\text { support } \\
\text { tube }\end{array}$ & $\begin{array}{l}\text { Upper } \\
\text { fuel } \\
\text { channel } \\
\text { support } \\
\text { tube }\end{array}$ \\
\hline Length, $\mathrm{ft}$-in. & $20-4$ & $20-4$ & $3-7$ & $3-7$ \\
\hline
\end{tabular}

Overall fuel channel assembly length, $\mathrm{ft}$-in.

$40-11.2$

Insulation between inner and outer tubes

Carbon dioxide

Height of fuel channel assembly extending.

above top shield, ft-in.

$7-6.6$

Height of fuel channel assembly extending below

bottom shield, ft-in.

$7-0.6$

Total number of fuel channels in core

758

Direction of coolant flow

Up \& down

Direction of fuel flow

Up \& down

Method of refueling

On-line, from top \& bottom

How fuel channel is isolated

Manually operated valves

Moderator Tank

Material

304 SS

ID, ft-in.

26-7

Wall thickness, in.

Inside shield length, $\mathrm{ft}$-in.

$20-4$

Top shield height, ft-in.

Top shield diameter, $\mathrm{ft}$-in.

Bottom shield height, ft-in.

Bottom shield diameter, ft-in.

Piping

Total number of pipes from fuel channel

assemblies to header (each end)

Joint between fuel channel assemblies \& pipes to headers

Mechanical

Piping material

Carbon steel 
Table 2-3. (Cont'd)

II. Fuel Element Data

General

Drawing number A30471 E

Figure 2-13

Fuel elements/fuel channel

Fuel elements/core 3790

Fuel density, $\%$ of theoretical

88

Fuel element assembly weight, lb

$\mathrm{U}+\mathrm{Th} /$ fuel element assembly, $\mathrm{kg}$

Refueling rate, elements/day @ 20,000 MWD/T (avg)

Composition of homogenized fuel channel, vol \%

Fuel

43.46

Santowax

40.75

SAP

14.13

Zircaloy

0.53

Void

Individual Fuel Pins (Hot Dimensions)

Clad material

Clad $O D$, in.

Large pin/small pin

$0.515 / 0.332$

Cladding thickness, in.

Large pin/small pin

$0.022 / 0.017$

$\mathrm{U}+\mathrm{Th} /$ fuel rod, $\mathrm{kg}(31.6 / 37)$

0.855

Fuel rods/element

Large pin/small pin

$31 / 6$

Fuel rods/core

Large pin/small pin

$117,490 / 22,740$

Fins/fuel rod (spiral)

Lárge pin/small pin

Fin revolutions/ft of length

Large pin/small pin

$90^{\circ} / 90^{\circ}$

Height of fins, in.

Large pin/small pin

$0.058 / 0.038,0.102$

Width of fins, in.

0.030

Surface finish

Fission gas gap, in.

Large pin/small pin

$1.30 / 0.430$ 
Dimensions (Hot)

Pitch between fuel rods, in. (large pin)

Fuel element diameter, in.

Mid-section/ends

Diametral clearance between element \& inner tube (in-core), in.

Mid-section/ends

$0.060 / 0.047$

Fuel element length

Overall, in.

Overend plates, in.

Active fuel length (equivalent) per fuel element, in.

42.66

III. Thermal and Hydraulic Data

General

Core inlet temp, $F$

Core outlet temp, F

721.4

Outlet temp, hottest pressure tube, F

721.4

Coolant flow, lb/hr $\times 10^{-6}$

107.2

Core inlet pressure, psia

Pressure drop (including headers), psi

Avg linear heat rate (hot pin), $\mathrm{kw} / \mathrm{ft}$

Minimum burnout ratio

2.59

Core

General

Power to coolant, $\mathrm{MWt}$

Pressure drop, psi

Active core (excluding head)

Control valve and headers

Power/hot pressure tube, $\mathrm{MWt}$

Avg fission powe 1 /prcosure tube, $M W t$

4.09

Avg coolant flow/pressure tube, $1 \mathrm{~b} / \mathrm{hr} \times 10^{-5}$

Pressure Tube (Maximum Power)

Power, $\mathrm{MWt}$

Coolant flow, $\mathrm{lb} / \mathrm{hr} \times 10^{-5}$ 
Coolant outlet temp, F

721.4

Pressure drop, psi

Active core

Headers

Hot Nominal

condition condition

Unit Cell

Coolant outlet temp, F

Max surface temp, F

Max heat flux, Btu/hr-ft $\mathrm{ft}^{2} \times 10^{-5}$

Surface area (including fins), $\mathrm{ft}^{2}$

Max linear heat rate (hot spot), $\mathrm{kw} / \mathrm{ft}$

Coolant velocity, avg fps

762

746

830

804

2.23

2.09

4.26

4.26

15.66

14.68

Hot channel factors

Coolant temp rise, $F_{\Delta T}$

Film temp drop, $F_{\theta}$

Heat flux, Fq"

21.7

21.6

1.09

1.0

1.16

1.0

1.07

1.0

IV. Nuclear Data.

0

Fuel Loading/Fuel Channel (U + Th Mctal), kg

158.3

Fuel Volume Fraction of Homogenized Element Within Liner

0.43 .5

U-2331dealized Cycle

Burnup, MWD/tonne

Fuel enrichment, wt \% U-233

21,924

1.86

Conversion ratio

0.914

BOL mass balances, $\mathrm{kg} /$ pressure tube

$\mathrm{U}-233$

$\mathrm{U}-234$

Th- 232

2.945

0.173

$\underline{154.840}$

Total

157.958 
EOL mass balances, $\mathrm{kg} /$ pressure tube

$$
\begin{aligned}
& U-233 \\
& U-234 \\
& U-235 \\
& U-236 \\
& P a-233 \\
& T h-232
\end{aligned}
$$

\begin{tabular}{|c|c|}
\hline $\begin{array}{l}\text { Pin location } \\
\text { (Figure 2-3) }\end{array}$ & $\begin{array}{c}P / \bar{P} \\
\text { idealized cycle } \\
\end{array}$ \\
\hline 1 & 0.621 \\
\hline 2 & 0.680 \\
\hline 3 & 0.906 \\
\hline 4 & 1.412 \\
\hline 5 & 0.680 \\
\hline 6 & 0.818 \\
\hline 7 & 1.248 \\
\hline 8 & 0.818 \\
\hline 9 & 0.906 \\
\hline 10 & 1.248 \\
\hline 11 & 1.248 \\
\hline 12 & 1.412 \\
\hline
\end{tabular}

Total

$\underline{\text { Ratio of Power to Average Power }(\mathrm{P} / \overline{\mathrm{P}}) \text { at Time Zero }}$

Local axial $P / \bar{P}(B A W-393-6)$

1.17

Gross radial $\mathrm{P} / \overline{\mathrm{P}}$ (section 2.3 .1 .3 )

1.17

Gross axial $P / \bar{P}$ (section 2.3.1.3)

1.29 
Table 2-3. (Cont'd)

Mass Balances, U-235 Startup and Makeup

Mass balance per pressure tube, $\mathrm{kg}$

lsotope

$\mathrm{U}-233$

$\mathrm{U}-234$

$\mathrm{U}-235$

$\mathrm{U}-236$

$\mathrm{Pa}-233$

$\mathrm{Pu}-239, \mathrm{Pu}-241$

Th-232

Total

Cycle Conditions

E, wt \% U - 233

E, wt \% U-235

Power, MW

Full power days

Conversion ratio

\begin{tabular}{|c|c|c|c|}
\hline \multicolumn{2}{|c|}{ Cycle 1} & \multicolumn{2}{|c|}{ Cycle 2} \\
\hline BOL & EOL & BOL & EOL \\
\hline - - & 1.542 & 1.674 & 2.038 \\
\hline -- & 0.143 & 0.141 & 0.342 \\
\hline 3.656 & 1.075 & 1.621 & 0.492 \\
\hline - & 0.415 & 0.408 & 0.571 \\
\hline 0.279 & 0.260 & 0.298 & 0.277 \\
\hline-- & 0.159 & - & 0.163 \\
\hline -. & 0.006 & .. & 0.006 \\
\hline 154.378 & 151.398 & $154.160^{\circ}$ & 151.064 \\
\hline 158.313 & & 158.303 & \\
\hline
\end{tabular}

$2.166 \quad \frac{\text { DOL }}{2.175}$

158.303

$\begin{array}{rrrr}--31 & & 1.06 & \\ & & 1.02 & \\ & 4.09 & & 4.09 \\ & 730 & & 786 \\ & 20,152 & & 20,308 \\ & 0.7770 & & 0.8433\end{array}$

Cycle 3
BOL EOL

2.166
0.337

1.039
0.562

0.314

-.

153.895

$158.3^{6} 13$

2.175
0.509
0.371

0.509
0.371

0.371
0.650

0.293

0.162

0.007

150.878

Cycle 4
BOL $E O L$

BOL $\quad$ EOL

0.502

0.921

0.640

0.331

$--$

153.617

$158: 311$
1.37
0.66
4.09
764
0.738
19,738
0.8654

1.45
0.58

0.645

150.507

150.507

20,308 .
0.8433
0.351

0.715

0.307

0.161

\begin{tabular}{|c|c|}
\hline \multicolumn{2}{|c|}{ Cycle 5} \\
\hline BOL & EOL \\
\hline 2.339 & 2.228 \\
\hline 0.635 & 0.746 \\
\hline 0.893 & 0.368 \\
\hline 0.704 & 0.772 \\
\hline 0.342 & 0.320 \\
\hline -- & 0.159 \\
\hline - & 0.007 \\
\hline 153.395 & 150.372 \\
\hline 158.308 & \\
\hline
\end{tabular}

1.48

4.09

794
20.513

0.8709

0.56

4.09
778
20,100
0.8730

Cycle 6

BOL EOL

$2.348 \quad 2.231$

$0.735 \quad 0.822$

$0.902 \quad 0.384$

$0.759 \quad 0.827$

$0.355 \quad 0.332$

$\begin{array}{ll}-- & 0.158 \\ - & 0.007\end{array}$

$153.208 \quad 150.205$

158.307 .

1.48
0.57

4.09

778

20,100

0.8733

Recycle Masses After 180-Day Decay and 1.5\% Reprocessing Losses Plus Makeup Mass, kg

\begin{tabular}{|c|c|c|c|c|c|c|c|c|c|c|}
\hline Isotope & Recycle & Makeup & Recycle & Makeup & Recycle & Makeup & Recycle & Makeup & Recycle & Makeup \\
\hline $\mathrm{U}-233$ & 1.674 & - & 2.166 & -- & 2.300 &.- & 2.339 & - & 2.348 & - \\
\hline $\mathrm{U}-234$ & 0.141 & -. & 0.337 & -. & 0.502 & -- & 0.635 & -. & 0.735 & -. \\
\hline$U-235$ & 1.057 & 0.56 .2 & 0.485 & 0.554 & 0.365 & 0.556 & 0.346 & 0.547 & 0.362 & 0.540 \\
\hline $\mathrm{U}-236$ & 0.408 & -- & 0.562 & -. & 0.640 & -. & 0.704 & - - & 0.759 & -. \\
\hline$U-238$ & 0.256 & 0.042 & 0.273 & 0.041 & 0.289 & 0.042 & 0.302 & 0.040 & 0.315 & 0.040 \\
\hline Th-232 & 149.127 & 5.039 & 118.798 & 5.097 & 148.615 & 5.002 & 148.249 & 5.146 & 148.116 & 5.092 \\
\hline
\end{tabular}


Table 2-3. (Cont'd)

Mass Balances, Plutonium Startup and Makeup

Mass balance per pressure tube, $\mathrm{kg}$

$\begin{array}{ll} & \text { Isotope } \\ & \mathrm{U}-233 \\ \mathrm{U}-234 \\ \mathrm{U}-235 \\ \mathrm{U}-236 \\ \mathrm{Pu}-239 \\ \mathrm{Pu}-240 \\ \mathrm{Pu}-241 \\ & \mathrm{Pu}-242 \\ & \mathrm{~Pa}-233 \\ & \text { Th-232 } \\ & \text { Total } \\ \mathrm{G} & \text { Cycle Conditior: }\end{array}$

\begin{tabular}{|c|c|c|c|c|c|c|c|c|c|c|c|}
\hline \multicolumn{2}{|c|}{ Cycle 1} & \multicolumn{2}{|c|}{ Cycle 2} & \multicolumn{2}{|c|}{ Cycle 3} & \multicolumn{2}{|c|}{ Cycle 4} & \multicolumn{2}{|c|}{ Cycle 5} & \multicolumn{2}{|c|}{ Cycle 6} \\
\hline BOL & EOL & BOL & EOL & BOL & EOL & $\mathrm{BOL}$ & EOL & $\mathrm{BOL}$ & EOL & $\mathrm{BOL}$ & EOL \\
\hline _- & 1.335 & 1.446 & 1.976 & 2,077 & 2.232 & 2.330 & 2.314 & 2.414 & 2.335 & 2.438 & 2.335 \\
\hline - . & 0.097 & 0.095 & 0.241 & 0.237 & 0.391 & 0.385 & 0.523 & 0.516 & 0.626 & 0.616 & 0.722 \\
\hline$\ldots$ & 0.010 & 0.010 & 0.039 & 0.038 & 0.075 & 0.075 & 0.109 & 0.107 & 0.134 & 0.132 & 0.158 \\
\hline - - & 0.001 & 0.001 & 0.005 & 0.005 & 0.014 & 0.014 & 0.029 & 0.028 & 0.046 & 0.045 & 0.070 \\
\hline 3.078 & 0.500 & 1.420 & 0.176 & 0.859 & 0.081 & 0.664 & 0.054 & 0.602 & 0.052 & 0.611 & 0.036 \\
\hline 1.679 & 1.485 & 1.969 & 1.323 & 1.678 & 0.999 & 1.301 & 0.742 & 1.030 & 0.606 & 0.902 & 0.484 \\
\hline 0.741 & 0.522 & 0.737 & 0.445 & 0.603 & 0.338 & 0.473 & 0.257 & 0.385 & 0.216 & 0.347 & 0.176 \\
\hline 0.333 & 0.599 & 0.690 & 0.929 & 0.988 & 1.153 & 1.200 & 1.287 & 1.327 & 1.362 & 1.403 & 1.406 \\
\hline -. & 0.133 & -. & 0.133 & -- & 0.136 & $\ldots$ & 0.139 & - & 0.140 & $\ldots$ & 0.144 \\
\hline 152.779 & 150.546 & 152.260 & 149.914 & 152.146 & 149.631 & 152.185 & 149.622 & 152.218 & 149.772 & 152.136 & 149.308 \\
\hline$\overline{158.630}$ & & $\overline{158.678}$ & & $\overline{158.631}$ & & 158.627 & & $\overline{158.627}$ & & $\overline{158.630}$ & \\
\hline
\end{tabular}

$E$, wt $\% U-233$

E, wt \% Pu-239

$E$, wt \% Pu-241

Power, MW

Full power days

Conversion ratio

$\begin{array}{rrrr}-1.94 & & 0.91 & \\ 0.47 & & 0.90 & \\ & & 0.46 & \\ & 4.09 & & 4.09 \\ & 790 & & 786 \\ & 20,369 & & 20.266 \\ & 0.7278 & & 0.8100\end{array}$

$\begin{array}{rr}1.31 & \\ 0.54 & \\ 0.38 & \\ & 4.09 \\ & 810 \\ & 20,884 \\ & 0.8357\end{array}$

\begin{abstract}
1.47
0.42
0.42
0.30
\end{abstract}

1.52
0.38

0.24

4.09
7.50
19.337
0.8371

1.54

0.39

4.09
800
20,627

0.8404

0.8371

Recycle Masses After 190-Day Decay and 1.5\% Reprocessing Losses Plus Makeup Masses, kg

\begin{tabular}{|c|c|c|c|c|c|c|c|c|c|c|}
\hline Isotope & Recycle & Makeup & Recycle & Makeup & Recycle & Makeup & Recycle & Makeup & Recycle & Makeup \\
\hline$U-233$ & 1.446 & -- & 2.077 & - & 2.330 & -. & 2.414 & -- & 2.438 & -- \\
\hline$U-234$ & 0.095 & -- & 0.237 & -- & 0.385 & - - & 0.516 & -- & 0.616 & - - \\
\hline$U-235$ & 0.010 & -- & 0.038 & -- & 0.075 & -- & 0.107 & $\therefore-$ & 0.132 & -- \\
\hline$U-236$ & 0.001 & -- & 0.005 & $\cdots$ & 0.014 & -- & 0.028 & -- & 0.045 & -- \\
\hline$P u-239$ & 0.492 & 0.928 & 0.172 & 0.687 & 0.080 & 0.584 & 0.053 & 0.549 & 0.051 & 0.560 \\
\hline$P u-240$ & 1.463 & 0.506 & 1.304 & 0.374 & 0.983 & 0.318 & 0.731 & 0.299 & 0.597 & 0.305 \\
\hline $\mathrm{Pu}-241$ & 0.514 & 0.223 & 0.438 & 0.165 & 0.333 & 0.140 & 0.253 & 0.132 & 0.212 & 0.135 \\
\hline $\mathrm{Pu}-242$ & 0.590 & 0.100 & 0.914 & 0.074 & 1.137 & 0.063 & 1.268 & 0.059 & 1.343 & 0.060 \\
\hline$T h-232$ & 148.288 & 3.972 & 147.665 & 4.481 & 147.386 & 4.799 & 147.378 & 4.840 & 147.525 & 4.611 \\
\hline
\end{tabular}




\section{Reactor Data}

General

Moderator

$\mathrm{D}_{2} \mathrm{O}$

Coolant

Santowax OM-10\% HB

Fuel

Fission power, $\mathrm{MWt}$ $\mathrm{ThO}_{2}+\mathrm{UO}_{2}$ Vipac pins

Thermal power to coolant, $\mathrm{MWt}$

3183

Thermal power to moderator, MWt

3015

Net electric power, $\mathrm{MWe}$

Number of coolant passes

1076

Active fuel length, ft-in. ( $5 \times$ active fuel length/element)

Active core length, ft-in. (fuel to fuel

for 5 elements)

Overall stack length, ft-in. (end plate to end plate)

Peak-to-average power ratios

Gross radial

1.17

Local radial

1.37

Gross axial

1.33

Local axial

1.17

Flux tilt

Pitch of fuel channel assemblies, in.

$\mathrm{D}_{2} \mathrm{O}$ inventory in calandria, $1 \mathrm{~b}$

642,768

$\mathrm{D}_{2} \mathrm{O}$ snver gac

Helium

Fuel Channel Assembly

$\begin{array}{lcccc} & \begin{array}{c}\text { Inner } \\ \text { tube } \\ \text { (in-core } \\ \text { section) }\end{array} & \begin{array}{c}\text { Outer } \\ \text { tube } \\ \text { (in-core } \\ \text { section) }\end{array} & \begin{array}{c}\text { Lower } \\ \text { fuel } \\ \text { channel } \\ \text { support } \\ \text { tube }\end{array} & \begin{array}{c}\text { Upper } \\ \text { fuel } \\ \text { channel } \\ \text { support } \\ \text { tube }\end{array} \\ \begin{array}{l}\text { Material } \\ \text { OD, in. }\end{array} & \text { SAP } & \text { Zr-2 } & \text { SS } & \text { SS } \\ \text { Wall thickness, in. } & 4.274 & 4.992 & .6 .35 & 6.35 \\ & 0.122 & 0.059 & 0.25 & 0.25\end{array}$


Table 2-4. (Cont'd)

\begin{tabular}{|c|c|c|c|c|}
\hline & $\begin{array}{c}\text { Inner } \\
\text { tube } \\
\text { (in-core } \\
\text { section) } \\
\end{array}$ & $\begin{array}{c}\text { Outer } \\
\text { tube } \\
\text { (in-core } \\
\text { section) } \\
\end{array}$ & $\begin{array}{c}\text { Lower } \\
\text { fuel } \\
\text { channel } \\
\text { support } \\
\text { tube } \\
\end{array}$ & $\begin{array}{c}\text { Upper } \\
\text { fuel } \\
\text { channel } \\
\text { support } \\
\text { tube } \\
\end{array}$ \\
\hline ength, ft-in. & $20-0$ & $20-0$ & $3-7$ & $3-7$ \\
\hline
\end{tabular}

Overall fuel channel assembly length, ft-in.

$38-8$

Insulation between inner and outer tubes

Carbon dioxide

Height of fuel channel assembly extending

above top shield, ft-in .

Height of fuel channel assembly extending

below bottom shield, ft-in.

Total number of fuel channels in core

Direction of coolant flow

Direction of fuel flow

Method of refueling

\author{
$6-7$ \\ $6-1$ \\ 548 \\ 548 \\ Up \& down \\ Up \& down \\ On-line, from \\ top \& bottom
}

Moderator Tank

Material

304 SS

ID, $\mathrm{ft}$-in.

$26-3$

Wall thickness, in.

Inside stield length, ft-in.

20-0

Top shield height, ft-in.

3-0

Top shield diameter, ft-in.

$28-3$

Bottom shield height, ft-in.

Bottom shield diameter, ft-in.

$28-3$

Piping

Total number of pipes from tuel channel

assemblies to header (each end)

548

Piping material

Carbon steel 


\section{Fuel Element Data}

\section{Gentral}

Figure number

Figure 2-20

Fuel elements/fuel channel

Fuel elements/core 2740

Fuel density, \% of theoretical.

Fuej. element assembly weight, lb

$(\mathrm{U}+\mathrm{Th}$ )/fuel element assembly, kg

Refuejing rate, elements/day @ 20,000 MWD/T, avg

Cumposition of homogenized fuel channel, vol \%

Fue1

Santowax

43.24

SAP

19.90

Zircaloy

0.49

Void

1.05

Inconel-X

0.04

individual Fuel Pins (Hot Dimensions)

Clad material

SAP 895

Clad OD, in.

Large pin/small pin

$0.381 / 0.329$

Clad wall thickness, in. (large \& small pins)

0.020

$(\mathrm{U}+\mathrm{Th}) /$ fuel rcd, $\mathrm{kg}(25.2 / 55)$

0.458

Euel rods/element Large pin/small pin

$43 / 12$

Fuel rods/core Large pin/small pin

Spiral fins per fuel rod (large \& smalli)

Fin $r \in$ volutions / ft length. (large \& small)

Fin height, in.

Large pin/small pin

$0.060 / 0.050$

Fin width, in

0.030

Surfacc finish

Fission gas gap, in.

Large pin/small pin

$1.300 / 0.930$ 
Dimensions (Hot)

Pitch between fuel rods, in. (large pin)

Fuel element diameter, in. Mid-section/ends

Diametral clearance between fuel element and inner tube (in-core section), in.

Mid-section/ends

$0.060 / 0.042$

Fuel element length, in.

Overall/over end plates

$44.350 / 44.000$

Active fuel length (equivalent)/fuel element, in.

42.000

\section{Thermal and Hydraulic Data}

\section{General}

Core inlet temp, F

Core outlet temp, $F$

Hottest pressure tube outlet temp, F

Coolant flow, $1 \mathrm{~b} / \mathrm{hr} \times 10^{-6}$

Inlet pressure, psia

Pressure drop (including headers), psi

Avg hot pin linear heat rate, $\mathrm{kw} / \mathrm{ft}$

10.24

Minimum burnout ratio

\section{Core}

General

Power to coolant, MWt

Pressure drop, psi

Active core, excluding head

173

Headers

Max power/hot pressure tube, MWt

Avg fission power/pressure tube, MWt

Avg coolant flow/pressure tube, $1 \mathrm{~b} / \mathrm{hr} \times 10^{-5}$

Pressure Tube (Maximum Power)

Power, MWt

Coolant flow, $1 \mathrm{~b} / \mathrm{hr} \times 10^{-5}$

2.60

Coolant outlet temp, $F$

706.5 
Table 2-4. (Cont'd)

Pressure drop, psi

Active core

173

Headers

Hot

condition

Nominal

condition

Unit Cell

Coolant outlet temp, F

734.4

720.4

Max surface temp, $F$

830

802.9

Max heat flux, Btu/hr-ft $\mathrm{ft}^{2} \times 10^{-\mathrm{s}}$

3.88

3.63

Surface area (including fins), $\mathrm{ft}^{2}$

2.47

2.47

Max linear heat rate (hot spot), kw/f.t

16.06

15.01

Avg coolant velocity, fps

35.5

35.4

Hot channel factors

Coolant temp rise, $F_{\Delta T}$

Film temp drop, $F_{\theta}$

Heat flux, $F_{q^{\prime \prime}}$

1.09

1.0

1.16

1.0

1.07

1.0

IV. Nuclear Data

Fuel Loading/Fuel Channel

(U + Th Metal), kg

126.0

Fuel Volume Fraction of Homogenized

Element Within Liner

$\mathrm{U}-233$ Idealizied r.yclo

Burnup, MWD/tonne

Euel enrichment, wt \% U-233

19,291

2.04

Conversion ratio

0.853

BOL mass balances, $\mathrm{kg} /$ pressure tube

$\mathrm{U}-233$

$\mathrm{U}-234$

2.574

0.150

$\mathrm{Th}-232$

123.340

Total

126.064 
Table 2-4. (Cont'd)

EOL mass balances, $\mathrm{kg} /$ pressure tube

\begin{tabular}{lr}
$\mathrm{U}-233$ & 1.904 \\
$\mathrm{U}-234$ & 0.360 \\
$\mathrm{U}-235$ & 0.047 \\
$\mathrm{U}-236$ & 0.006 \\
$\mathrm{~Pa}-233$ & 0.224 \\
$\mathrm{Th}-232$ & 121.048 \\
\hline Total & 123.589
\end{tabular}

Ratio of Local Radial Power to Average Power (P/ $\bar{P})$ at Time Zero

\begin{tabular}{|c|c|}
\hline $\begin{array}{l}\text { Pin location } \\
\text { (Figure } 2-4 \text { ) }\end{array}$ & $\begin{array}{c}\mathrm{P} / \overline{\mathrm{P}} \\
\text { idealized cycle }\end{array}$ \\
\hline 1 & 0.602 \\
\hline 2 & 0.636 \\
\hline 3 & 0.768 \\
\hline 4 & 1.071 \\
\hline 5 & 0.636 \\
\hline 6 & 0.723 \\
\hline 7 & 0.936 \\
\hline 8 & 1.436 \\
\hline 9 & 0.723 \\
\hline 10 & 0.768 \\
\hline 11 & 0.936 \\
\hline 12 & 1.369 \\
\hline 13 & 0.936 \\
\hline 14 & 1.071 \\
\hline 15 & 1.436 \\
\hline 16 & 1.369 \\
\hline 17 & 1.436 \\
\hline
\end{tabular}




\section{Reactor Data}

\section{General}

Moderator

$\mathrm{D}_{2} \mathrm{O}$

Coolant

Santowax OM-10\% HB

Fuel

Fission power, $\mathrm{MWt}$

ThC + UC slugs

Thermal power to coolant, $\mathrm{MWt}$

Thermal power to moderator, $\mathrm{MWt}$

Net electric power, MWe

Number of coolant passes

Active fuel length, $\mathrm{ft}$-in. $(5 \times$ active fuel

length/element)

Active core length, ft-in. (fuel to fuel

for 5 elements)

$18-3.2$

Overall stack length, ft-in. (end plate

to end plate)

$18-4.6$

Peak-to-average power ratios

Gross radial

Local radial, effective

Gross axial

Local axial

Flux tilt

Pitch of fuel channel assemblies, in.

$\mathrm{D}_{2} \mathrm{O}$ inventory in calandria, $\mathrm{lb}$

642,768

$\mathrm{D}_{2} \mathrm{O}$ cover gas

Helium

Fuel Channel Assembly

\begin{tabular}{lcccc} 
Inner & $\begin{array}{c}\text { Outer } \\
\text { tube } \\
\text { (in-core } \\
\text { section) }\end{array}$ & $\begin{array}{c}\text { tube } \\
\text { (in-core } \\
\text { section) } \\
\text { channel }\end{array}$ & $\begin{array}{c}\text { Upper } \\
\text { support } \\
\text { tube }\end{array}$ & $\begin{array}{c}\text { channel } \\
\text { support } \\
\text { tube }\end{array}$ \\
\cline { 2 - 3 } & SAP & Zr-2 & SS & SS \\
OD, in. & 4.274 & 4.992 & 6.35 & 6.35 \\
Wall thickness, in. & 0.122 & 0.059 & 0.25 & 0.25
\end{tabular}


Table 2-5. (Cont'd)

Length, ft-in.

$\begin{array}{cccc}\begin{array}{c}\text { Inner } \\ \text { tube } \\ \text { (in-core } \\ \text { section) }\end{array} & \begin{array}{c}\text { Outer } \\ \text { tube } \\ \text { (in-core } \\ \text { section) }\end{array} & \begin{array}{c}\text { Lower } \\ \text { fuel } \\ \text { channel } \\ \text { support } \\ \text { tube }\end{array} & \begin{array}{c}\text { Upper } \\ \text { fuel } \\ \text { channel } \\ \text { support } \\ \text { tube }\end{array} \\ & \frac{3-7}{20-0} & & 3-7\end{array}$

Overall fuel channel assembly length, ft-in.

$38-8$

Insulation between inner and outer tubes

Carbon dioxide

Height of fuel channel assembly extending

above top shield, ft-in. $i$

6-7

Height of fuel channel assembly extending

below bottom shield, ft-in.

$6-1$

$T$ otal number of fuel channels in core

548

Direction of coolant flow

$U_{p}$ \& down

Direction of fuel flow

Up \& down

Method of refueling

On-line, from top and bottom

\section{Moderator Tank}

Material

304 SS

ID, $\mathrm{ft}$-in.

$26-3$

Wali thickness, in.

Inside shield length, $\mathrm{ft}$-in.

20-0

Top shield height, ft-in.

$3-0$

Top shield diameter, ft-in.

$28-3$

Bottom shield height, ft-in.

$3-0$

Bottom shield diameter, ft-in.

$28-3$

Piping

Total number of pipes from fuel channel assemblies to header (each end)

Piping material

Carbon steel 
Table 2-5. (Cont'd)

II. Fuel Element Data

General

Drawing number

Figure 2-23

Fuel elements/fuel channel

Fuel elements per core

Fuel density (including dish \& gap), \% of theoretical

94.26

Fuel element assembly weight, $1 \mathrm{~b}$

$\mathrm{U}+\mathrm{Th} /$ fuel element assembly, kg

36.12

Refueling rate, elements/day@ @20,000 MWD/T (avg)

Composition of homogenized fuel channel, vol \%

Fuel

Santowax

43.48

SAP

Zircaloy

14.76

Void

0.56

0.49

Individual Fuel Pins (Hot Dimensions)

Clad material

Clad OD, in.

Large pin/small pin

$0.495 / 0.332$

Cladding wall thickness, in.

Large pin/small pin

$0.022 / 0.017$

$\mathrm{U}+\mathrm{Th} /$ fuel rod, $\mathrm{kg}(36.12 / 37)$

0.976

Fuel rods/element

Large pin/small pin

$31 / 6$

Fuel rods/cnre.

Large pin/small pin

$84,940 / 16,440$

Fins/fuel rod (spiral)

Large pin/small pin

$12 / 6$

Fin revolutions/ft length

Large pin/small pin

$90 \% 90^{\circ}$

Height of fins, in.

Large pin/small pin

$0.068 / 0.038,0.102$

Width of fins, in.

0.030

Surface finish

Fission gas gap, in.

Large pin/small pin

$0.600 / 0.200$ 
Dimensions (Hot)

Pitch between fuel rods, in. (large pin)

Fuel element diameter, in.

Mid-section/ends

Diametral clearance between fuel element and

inner tube (in-core section), in.

Mid-section/ends

Fuel element length, in.

Overall/over end plates

$44.47 / 44.12$

Active fuel length (equivalent)/fuel element, in.

42.66

III. Thermal and Hydraulic Data

General

Core inlet temp, F

Core outlet temp, F

716.2

Outlet temp, hottest pressure tube, F

Coolant flow, $\mathrm{lb} / \mathrm{hr} \times 10^{-6}$

Core inlet pressure, psia

Pressure drop (including headers), psi

Avg linear heat rate (hot pin), kw/ft

Minimum burnout ratio

Core

General

Power to coolant, $\mathrm{MWt}$

Pressure drop, psi

Active core (excluding head)

Headers

Power/hot pressure tube, $\mathrm{MWt}$

Avg fission power/pressure tube, MWt

Avg coolant flow/pressure tube, $1 \mathrm{~b} / \mathrm{h} / \times 10^{-5}$

Pressure Tube (Maximum Power)

Power, MWt

Coolant flow, lb/hr $\times 10^{-5}$

Coolant outlet temp, F 
Pressure drop, psi

Active core

\begin{tabular}{cc}
$\begin{array}{c}\text { Hot } \\
\text { condition }\end{array}$ & $\begin{array}{c}\text { Nominal } \\
\text { condition. }\end{array}$ \\
\hline
\end{tabular}

Unit Cell

Coolant outlet temp, F

751.2

735.9

Max surface temp, $F$

830

803.6

Max heat flux; Btu/hr-ft $\mathrm{ft}^{2} \times 10^{-5}$

3.13

2.92

Surfacc area (including fins), $\mathrm{ft}^{2}$

4.35

4.35

Max linear heat rate (hot spot), $\mathrm{kw} / \mathrm{ft}$

22.41

20.94

Coolant velocity, avg fps

30.7

30.6

Hot channel factors

Coolant temp rise, $F_{\Delta T}$

Film temp drop, $F_{\theta}$

Heat flux, $\mathrm{F}_{\mathrm{q}^{\prime \prime}}$

1.09

1.16

1.07

1.0

1.0

1.0

\section{Nuclear Data}

Fuel Loading/Fuel Channel

(U +Th Metal), kg

180.6

Fuel Volume Fraction of Homogenized Element Within Liner

0.407

U-233Idealized Cycle

Burnup, MWD/tonne

Fuel enrichment, wt \% U-233

21,997

1.87

Conversion ratio

0.906

BOL mass balances, $\mathrm{kg} / \mathrm{pressure} \mathrm{tube}$

$\mathrm{U}-233$

3.376

$\mathrm{U}-234$

0.197

$\mathrm{Th}-232$

176.775

Total

180.348 
Table 2-5. (Cont'd)

EOL mass balances, $\mathrm{kg} /$ pressure tube

U -233

$\mathrm{U}-234$

2.647

$\mathrm{U}-235$

0.527

$\mathrm{U}-236$

0.080

$\mathrm{Pa}-233$

0.011

Th- 232

0.238

T otal

172.768

176.271

Ratio of Power to Average Power $(P / \bar{P})$ at Time Zero

Local radial $\mathrm{P} / \overline{\mathrm{P}}$

\begin{tabular}{ccc}
\hline $\begin{array}{c}\text { Pin location } \\
\text { (Figure 2-3) }\end{array}$ & Idealized cycle & U-235 cycle 1 \\
\cline { 1 - 2 } 1 & 0.555 & 0.486 \\
2 & 0.616 & 0.555 \\
3 & 0.880 & 0.846 \\
4 & 1.487 & 1.593 \\
5 & 0.616 & 0.555 \\
6 & 0.780 & 0.729 \\
7 & 1.293 & 1.348 \\
8 & 0.780 & 0.729 \\
9 & 0.880 & 0.846 \\
10 & 1.293 & 1.348 \\
11 & 1.293 & 1.348 \\
12 & 1.487 & 1.593
\end{tabular}

Local axial $P / \bar{P}(B A W-393-6)$

1.17

Grnss radial $P / \bar{P}$. (section 2.3 .1 .3 )

1.17

Gross axial $P / \overline{\mathrm{P}}$ (section 2.3.1.3)

1.30 
Table 2-5. (Cont'd)

Mass. Balances: U-235 Startup and Makeup

Mass balance per pressure tube, $\mathrm{kg}$

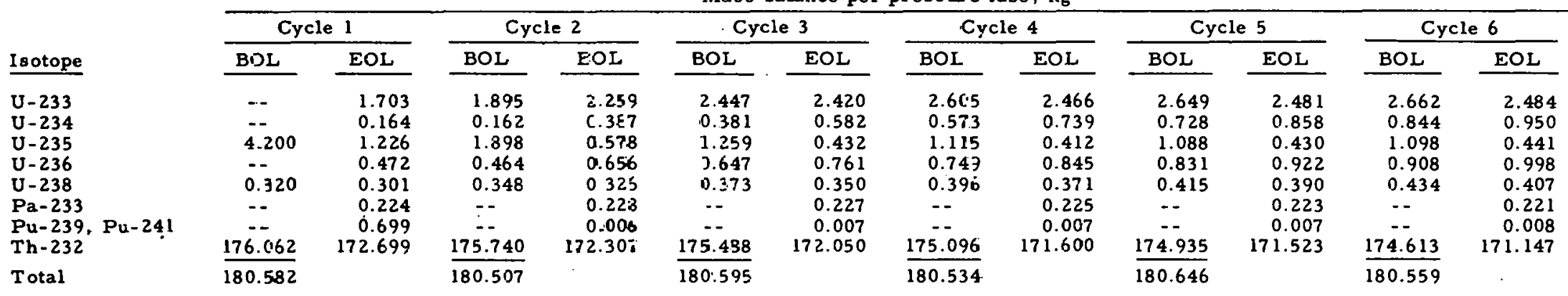

Cycle Conditions

E, wt \% U-233

E, wt \% U-235

$\overline{2.32}$

1.05

1.35
0.70

1.44

1.47
0.60

1.47

Fower, MW

MWD/tonne

5.8

5.8

624
0.050

20,299

20,050
0.3363

5.8

624

20,040
0.8524

5.8

640

20,562

0.8578

5.8
630

630

20,227
0.8591

5.8 .

0.687

20,687
0.8600

Recycle Masses After 180-Day Decay and 1.5\% Reprocessing Losses Plus Makeup, kg

\begin{tabular}{|c|c|c|c|c|c|c|c|c|c|c|}
\hline Isotope & Recycle & Makeup & Recycle & Makeup & Recycie & Makeup & Recycle & Makeup & Recycle & Makeup \\
\hline $\begin{array}{l}U-233 \\
U-234 \\
U-235 \\
U-236 \\
U-238 \\
T h-232\end{array}$ & $\begin{array}{r}1.895 \\
0.162 \\
1.209 \\
0.464 \\
0.296 \\
170.034\end{array}$ & $\begin{array}{l}-- \\
-- \\
0.689 \\
-- \\
0.052 \\
5.706\end{array}$ & $\begin{array}{r}2.447 \\
0.381 \\
0.570 \\
0.647 \\
0.321 \\
169.734\end{array}$ & $\begin{array}{l}-- \\
-- \\
0.689 \\
-- \\
0.652 \\
5.754\end{array}$ & $\begin{array}{r}2.665 \\
0.573 \\
0.425 \\
0.747 \\
0.344 \\
169.423\end{array}$ & $\begin{array}{l}-- \\
-- \\
0.689 \\
-- \\
0.052 \\
5.673\end{array}$ & $\begin{array}{r}2.649 \\
0.728 \\
0.406 \\
0.831 \\
0.364 \\
169.092\end{array}$ & $\begin{array}{l}-- \\
-- \\
0.682 \\
-- \\
0.051 \\
5.843\end{array}$ & $\begin{array}{r}2.662 \\
0.844 \\
0.423 \\
0.908 \\
0.383 \\
168.929\end{array}$ & $\begin{array}{l}-- \\
-- \\
0.675 \\
-- \\
0.051 \\
5.684\end{array}$ \\
\hline
\end{tabular}




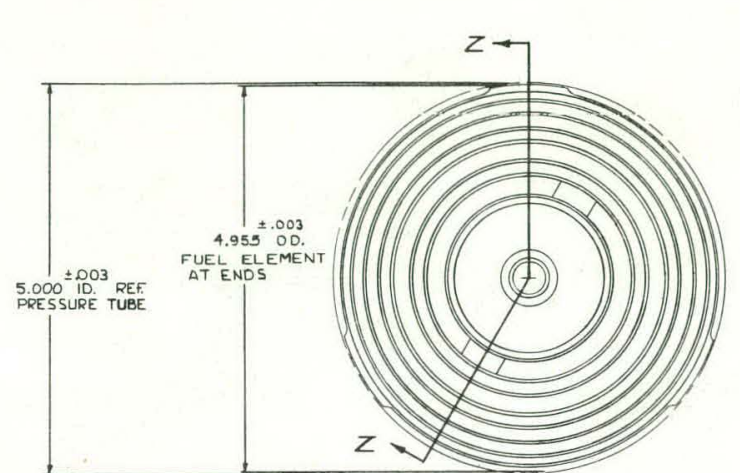

PLAN VIEW
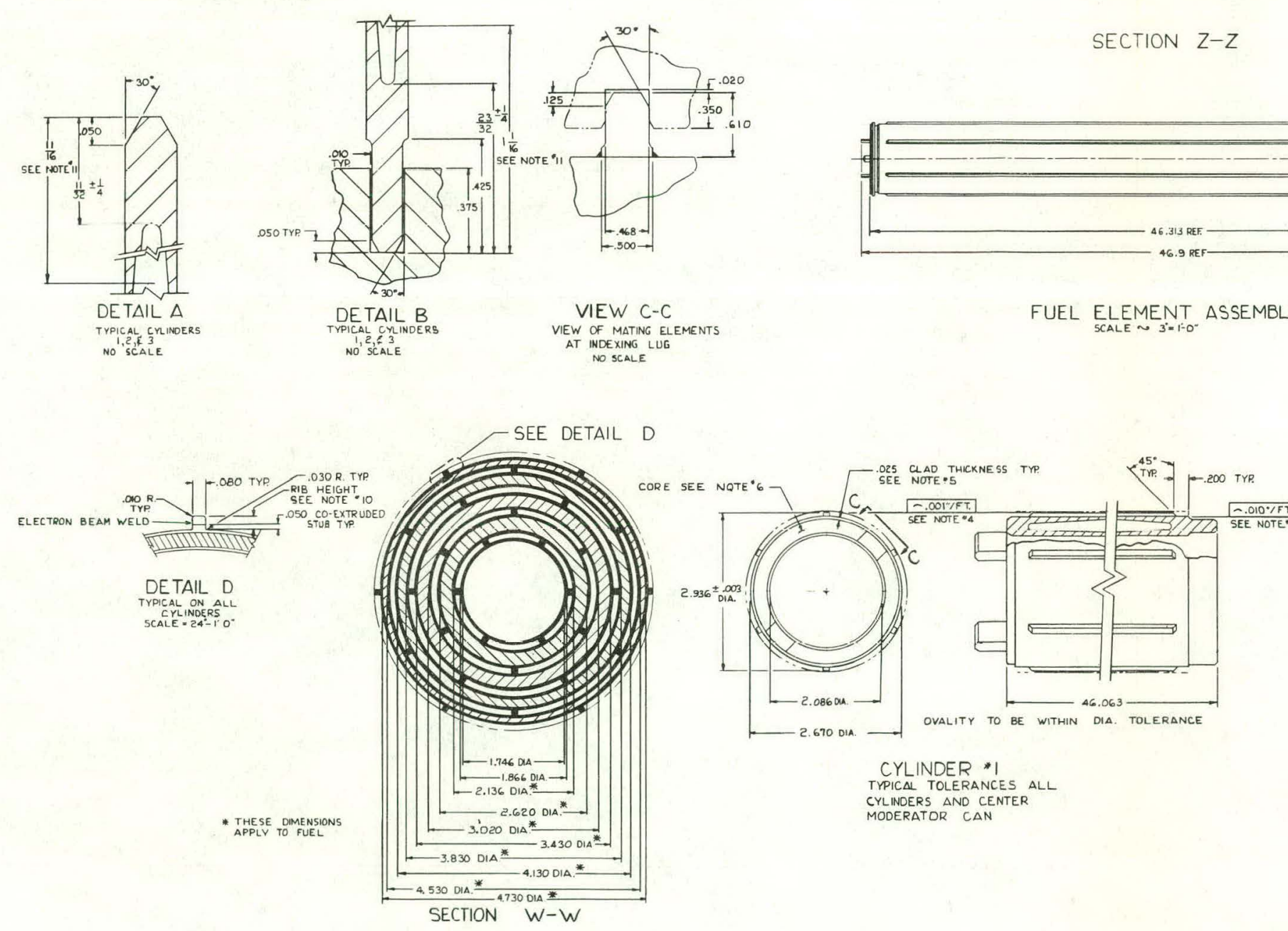

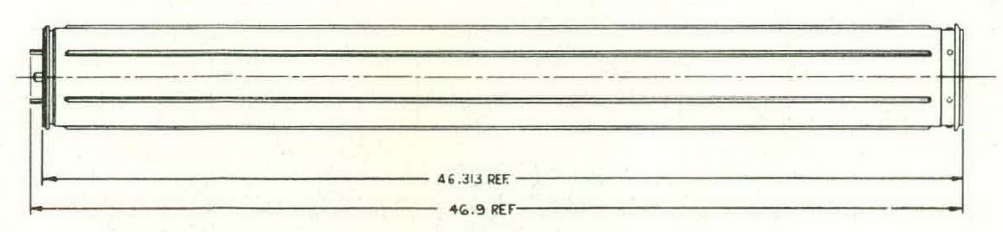

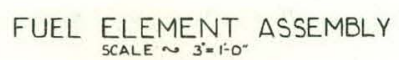

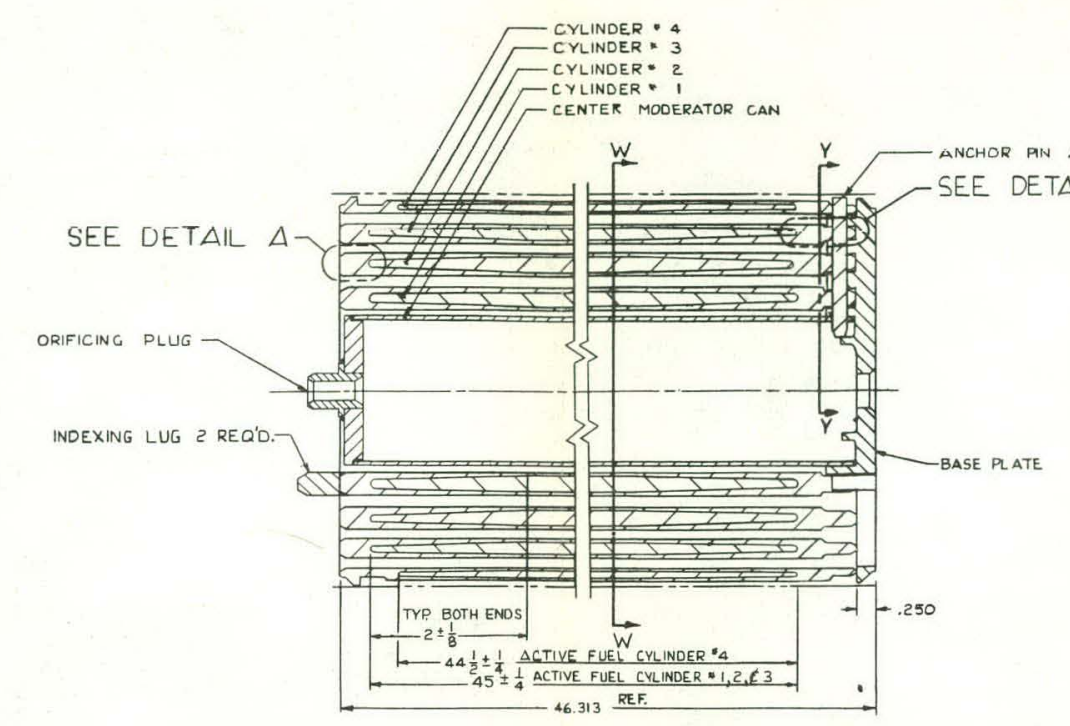

SECTION $Z-Z$

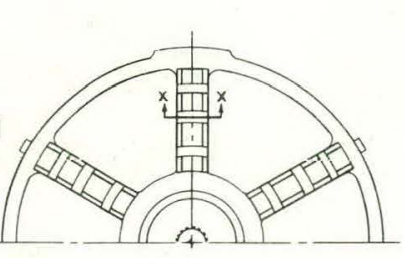

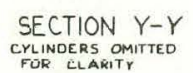

$\underbrace{.187} 7^{.0005}$

.

$\frac{3}{32} r \mathrm{rr}-1 .+2$

SECTION $X-X$
Figure 2-1. HWOCR 4-Cylinder Thorium Metal Fuel Element (With Center Moderator)
NOTES:

每

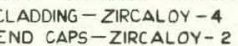

CAN-ZIRCALOY-

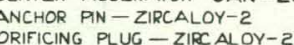

(2) ALL DIMENSIONS ARE HOT. COLD DMMENSIONS ARE SIGHTLY (3) WEIGHT LPPRDXXIMATELY ISPB LBS.

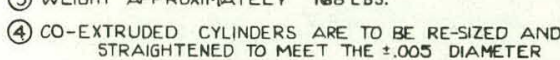

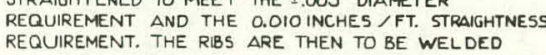
AND MACHINED TO THE. OOI NCHES/FT. BOW REQUUEEMENT AROM TIE O.D. OF THE CLAD $\triangle T$ TEACH END (5) CLADOING THICKNESS

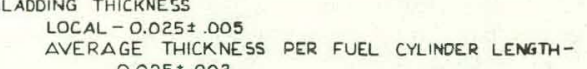
(6) CORE THEKKNSS

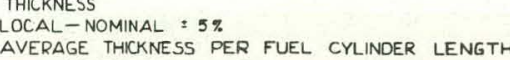

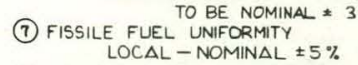

(6) BOTH THE INSIDE ANO THE OUTSIDE CYMMORICAL SURFACES DPFCTE

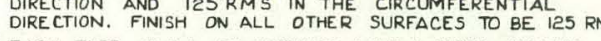
(9) EACH TUBE, SHALL BE MARK ED WITH A SERIAL RUMBER
ON THE TOP ENO CAP. FUEL ELEEMENT SERAL NUMBER TO

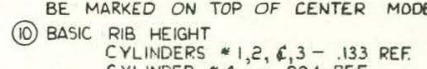

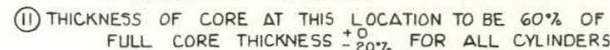


THIS PAGE

\section{WAS INTENTIONALLY LEFT BLANK}


Figure 2-2. Bow Condition Between Two Adjacent Cylinders

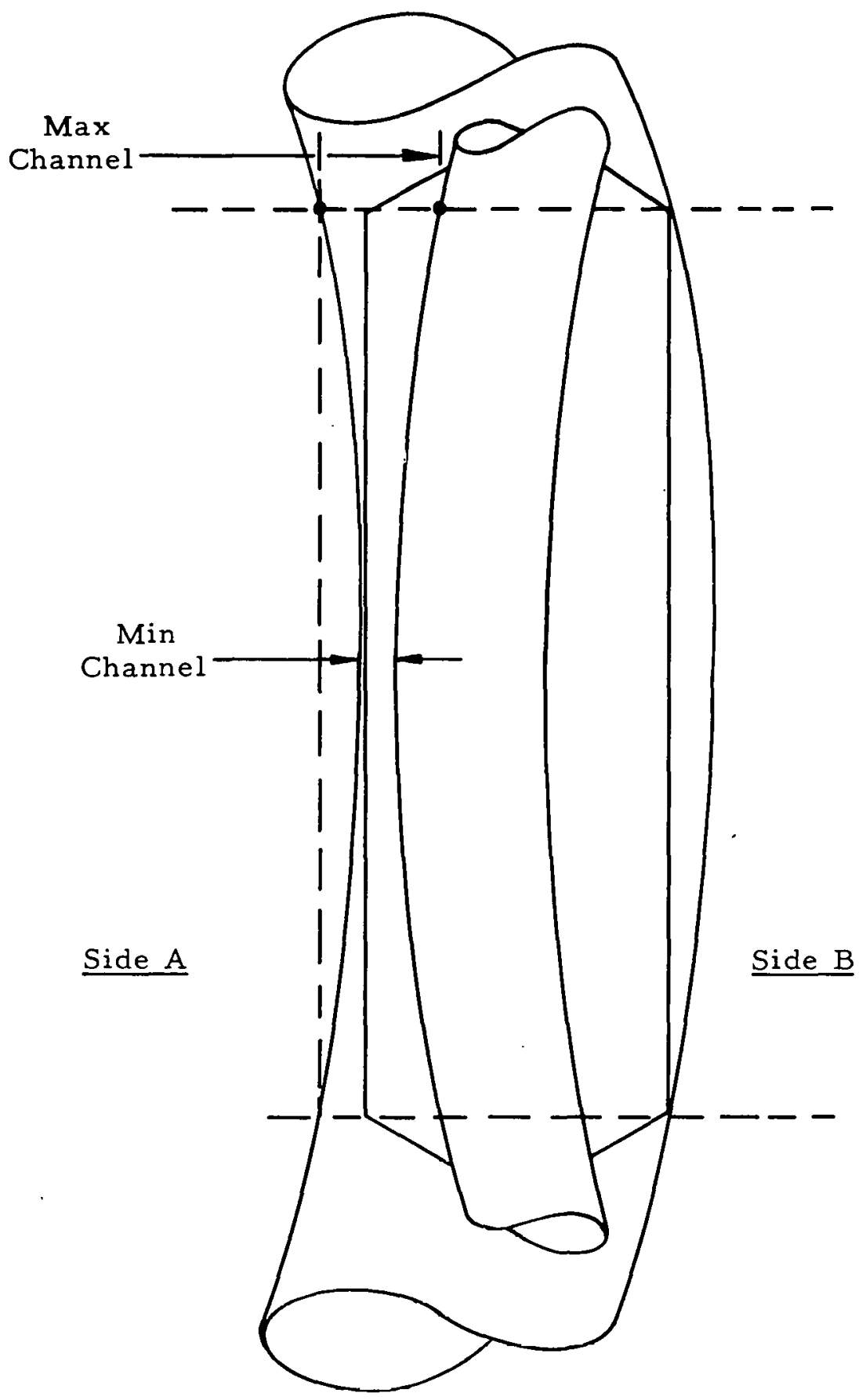


Figure 2-3. Gross Axial Power Distribution

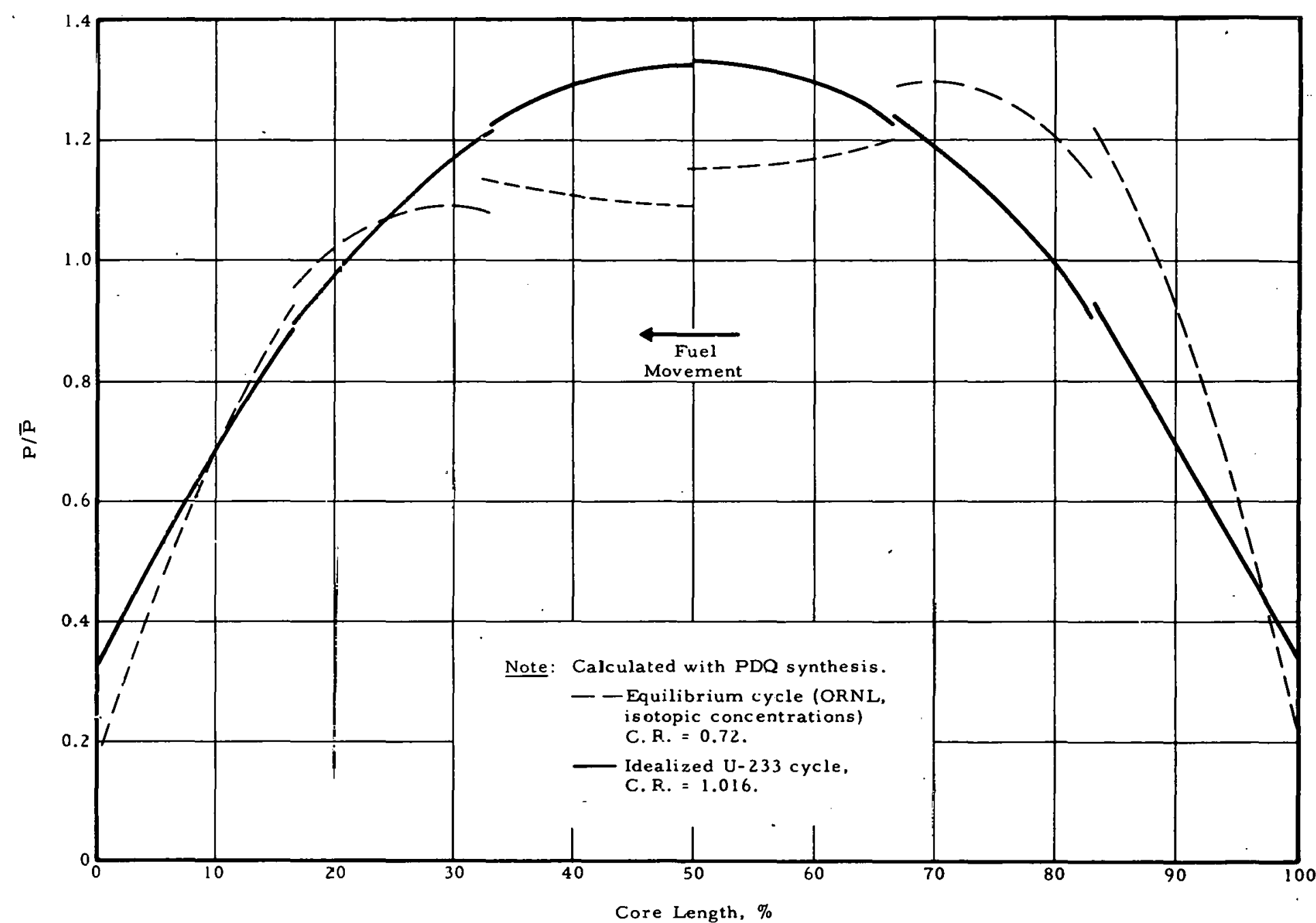


Figure 2-4. Radial Power Distribution

(Three Equal Volume Zones)

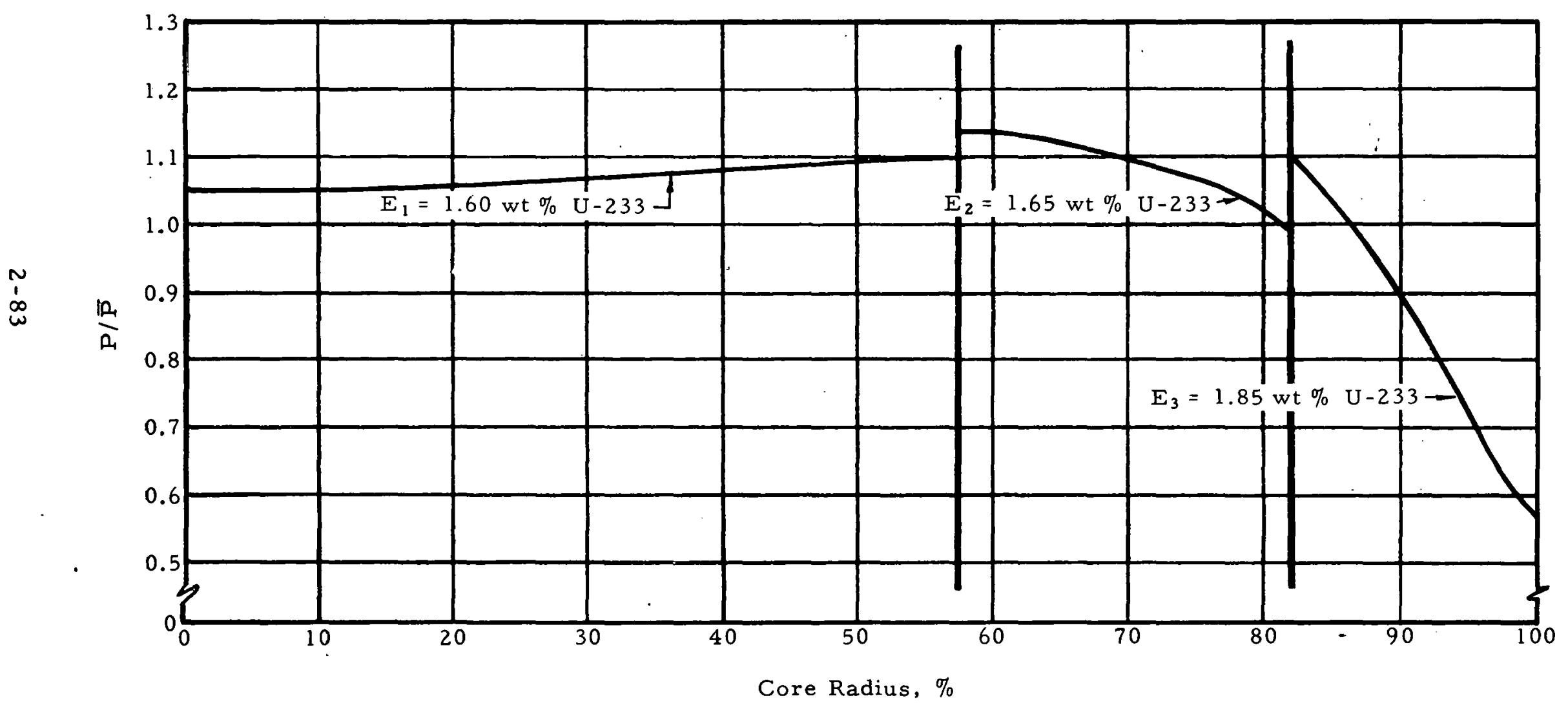


Figure 2-5. Axial Local Power Peaking $(P / \bar{P})$ in NestedCylinder Fuel Element
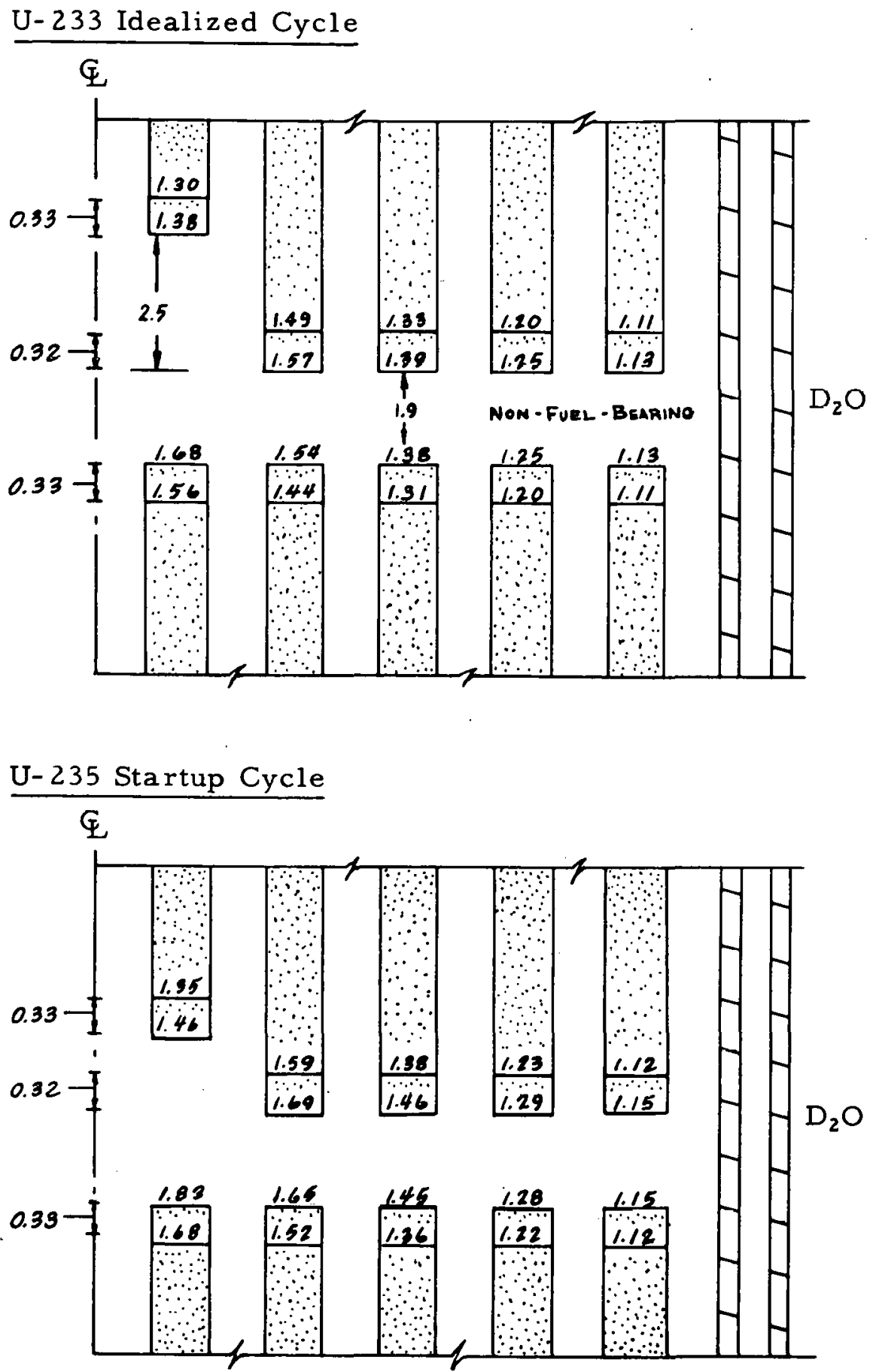

Note: All dimensions in $\mathrm{cm}$. 
Figure 2-6. Coolant, Cladding, and Fuel Temperature Vs Active Fuel Length (Hottest Cylinder and Coolant Channel - Nominal Conditions)

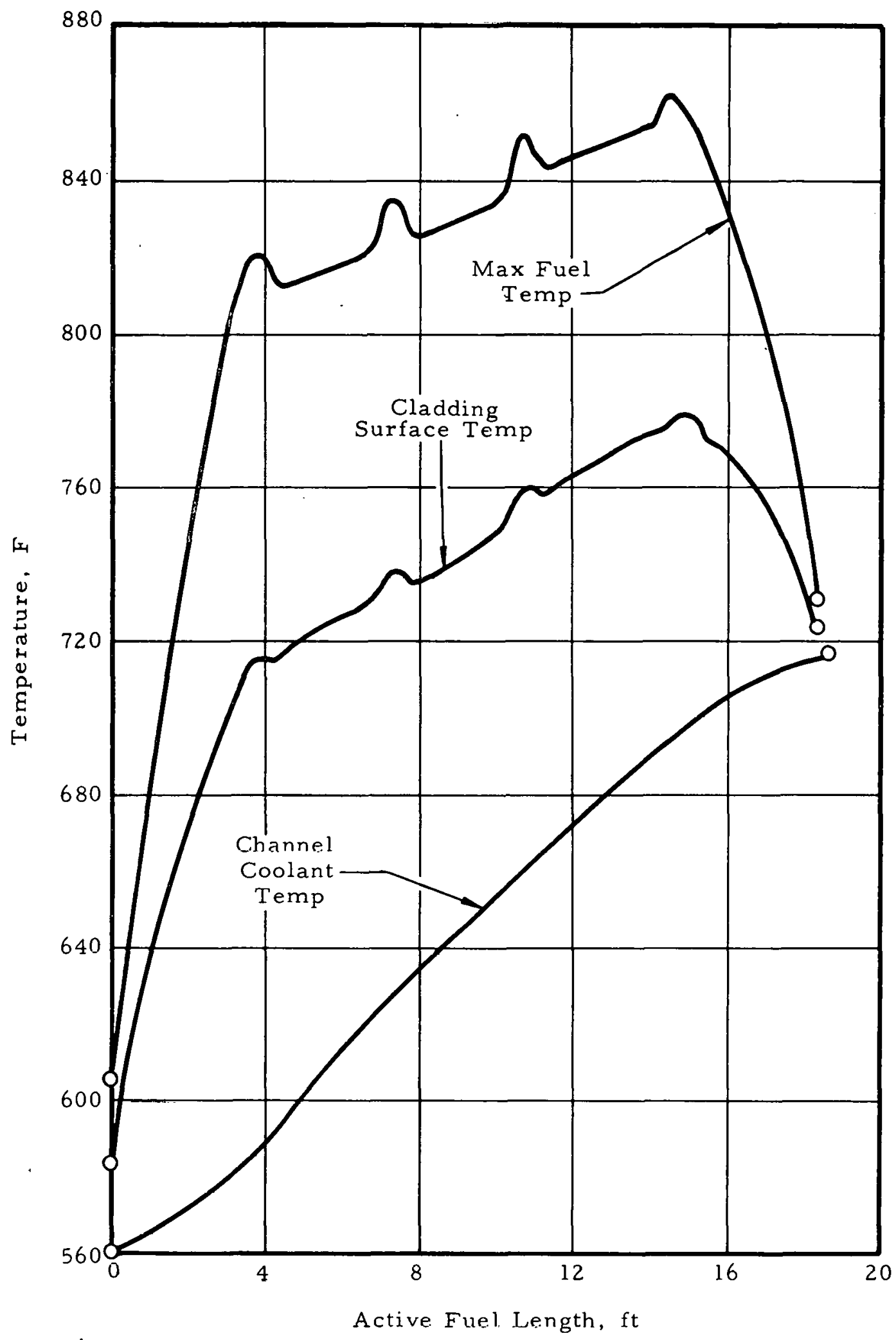


Figure 2-7. Coolant, Cladding, and Fuel Temperature Vs Active Fuel Length (Hottest Cylinder and Coolant Channel - Hot Channel Factors)

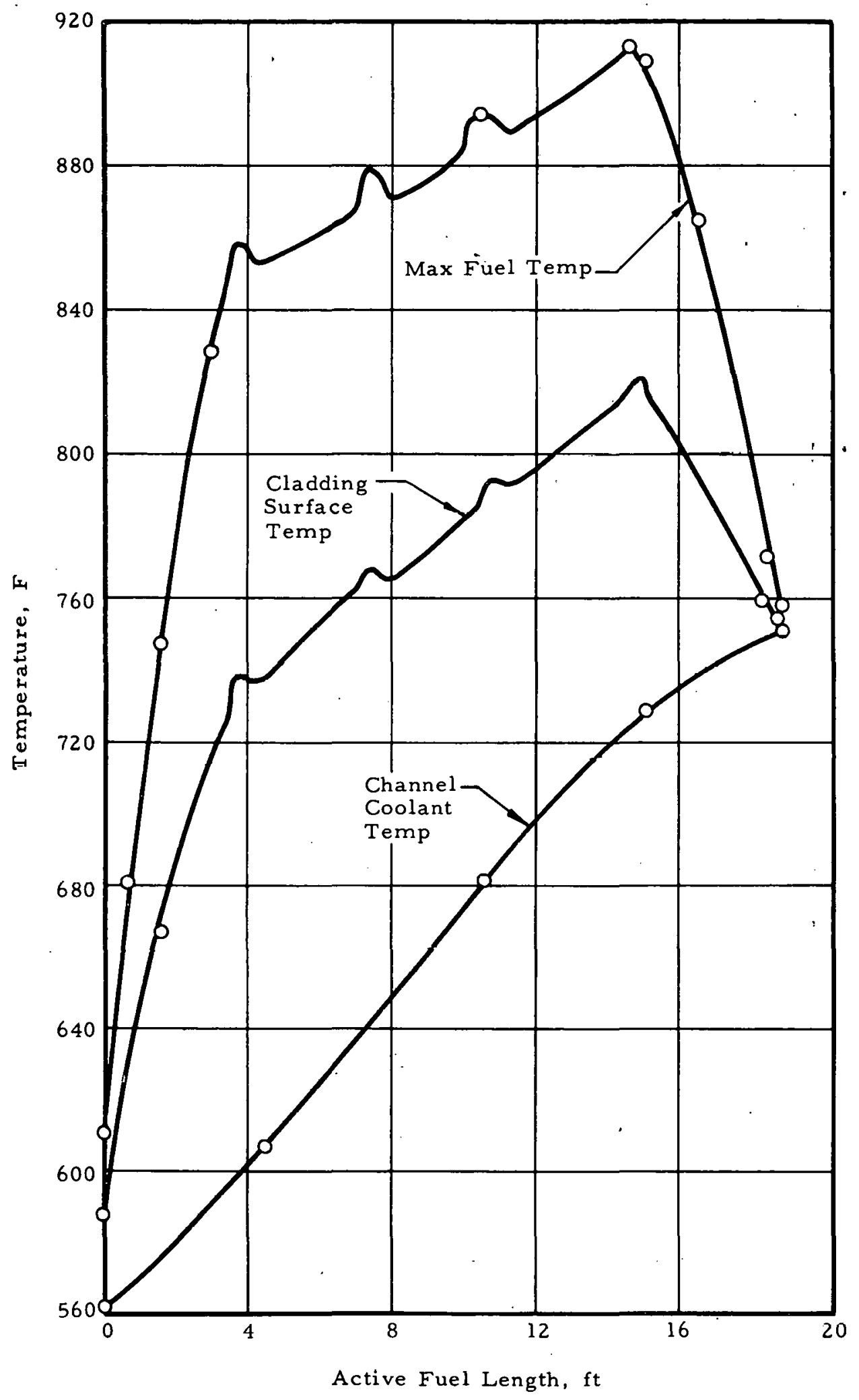


Figure 2-8. Ratio of Burnout Heat Flux to Actual Heat Flux, Based on Constant Saturation Temperature of $850 \mathrm{~F}$

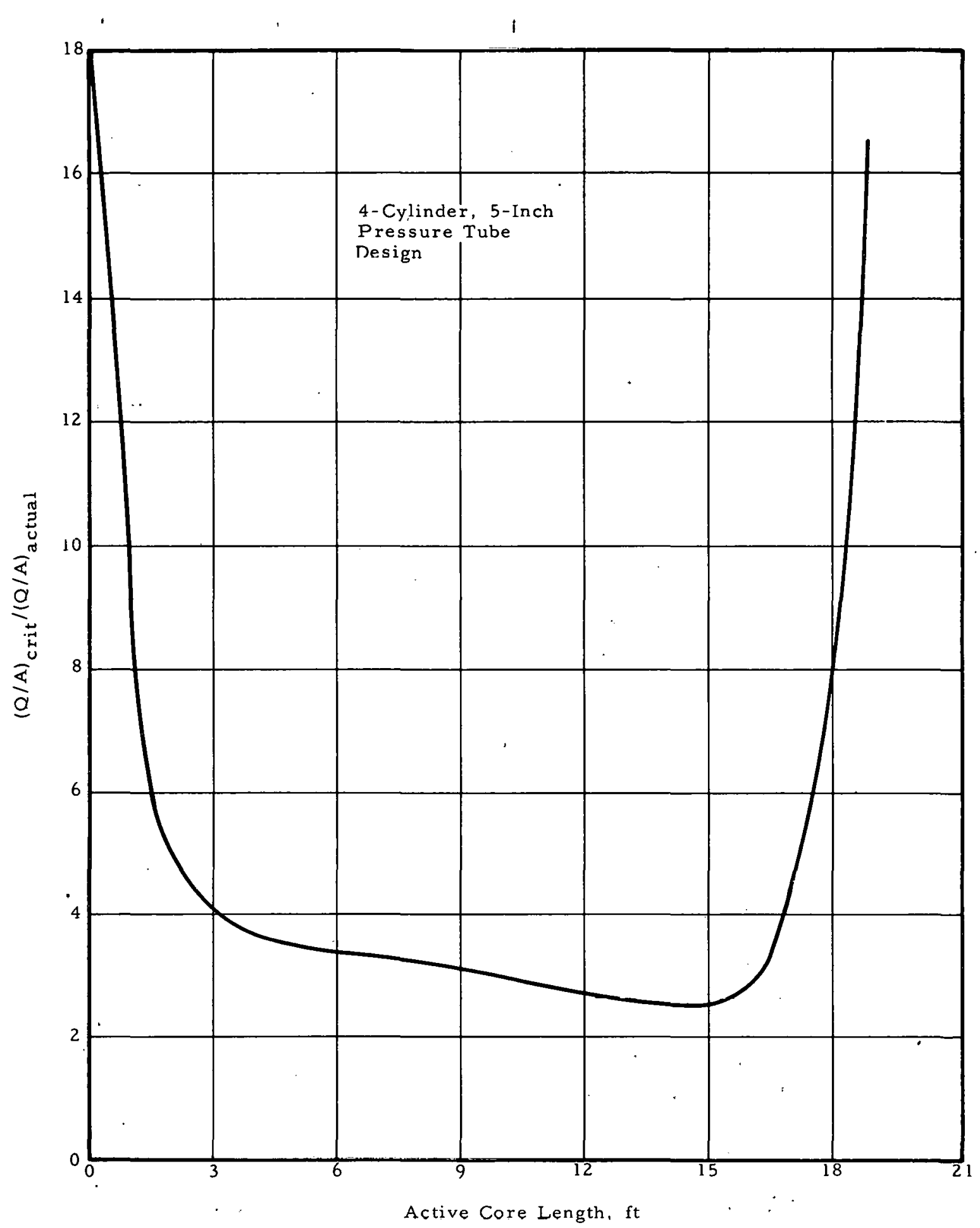


Figure 2-9. Five-Cylinder Thorium Metal Fuel Element, Cross Section

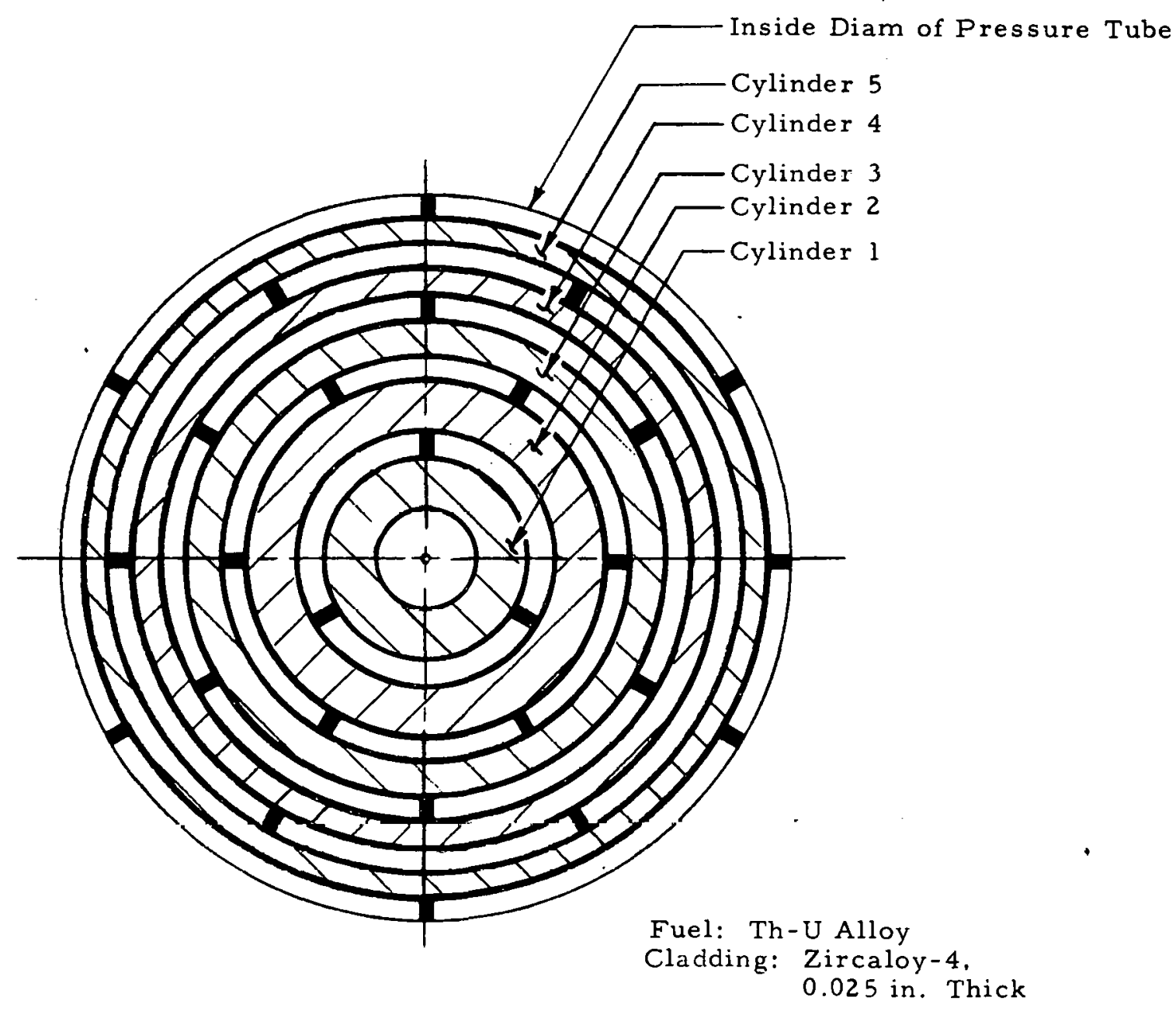


Figure 2-10. Coolant, Cladding, and Fuel Temperatures Vs Active Fuel Length (Hottest Cylinder and Coolant Channel - Nominal Conditions)

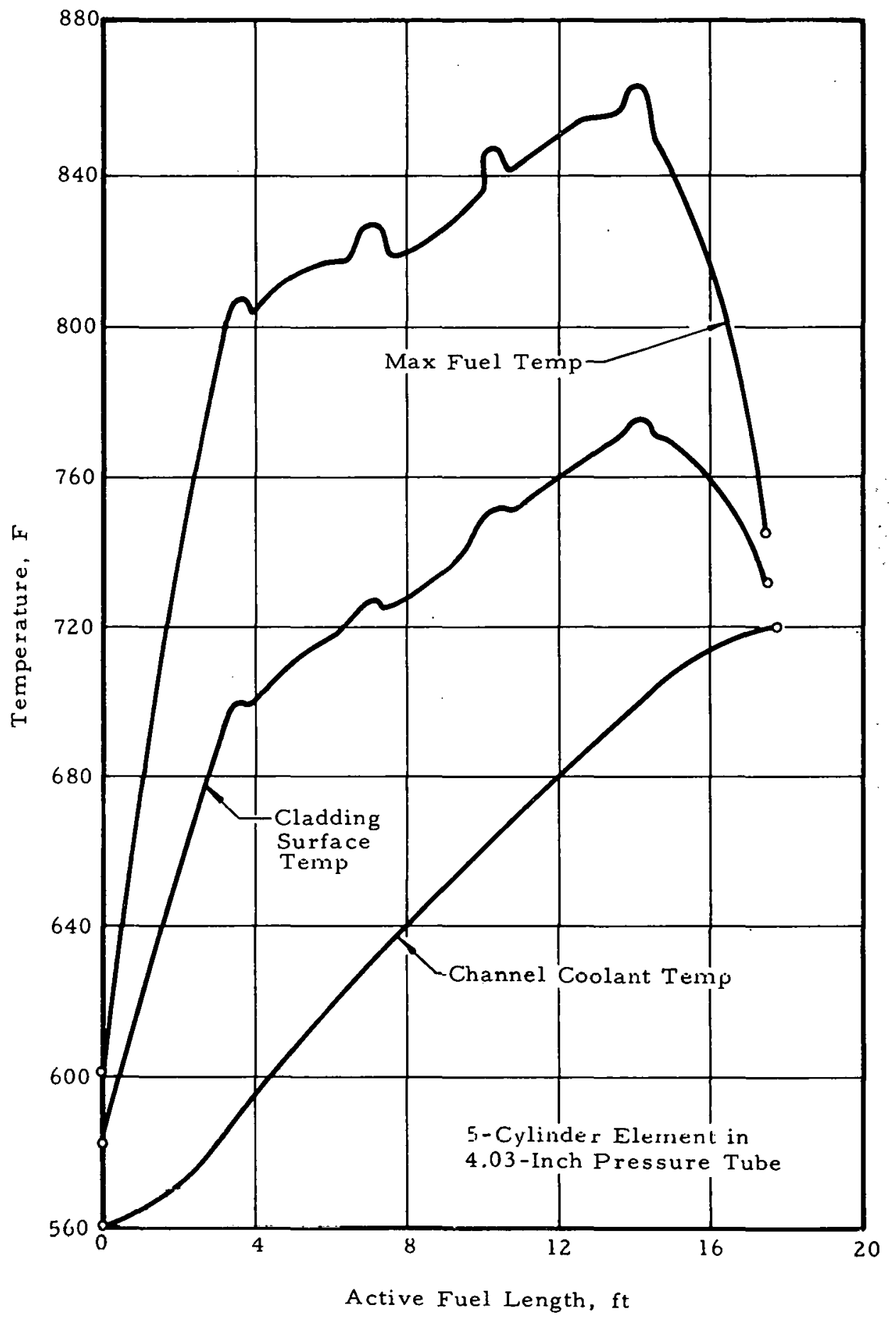


Figure 2-11. Coolant, Cladding, and Fuel Temperatures Vs

Active Fuel Length (Hottest Cylinder and Coolant Channel - Hot Channel Factors)

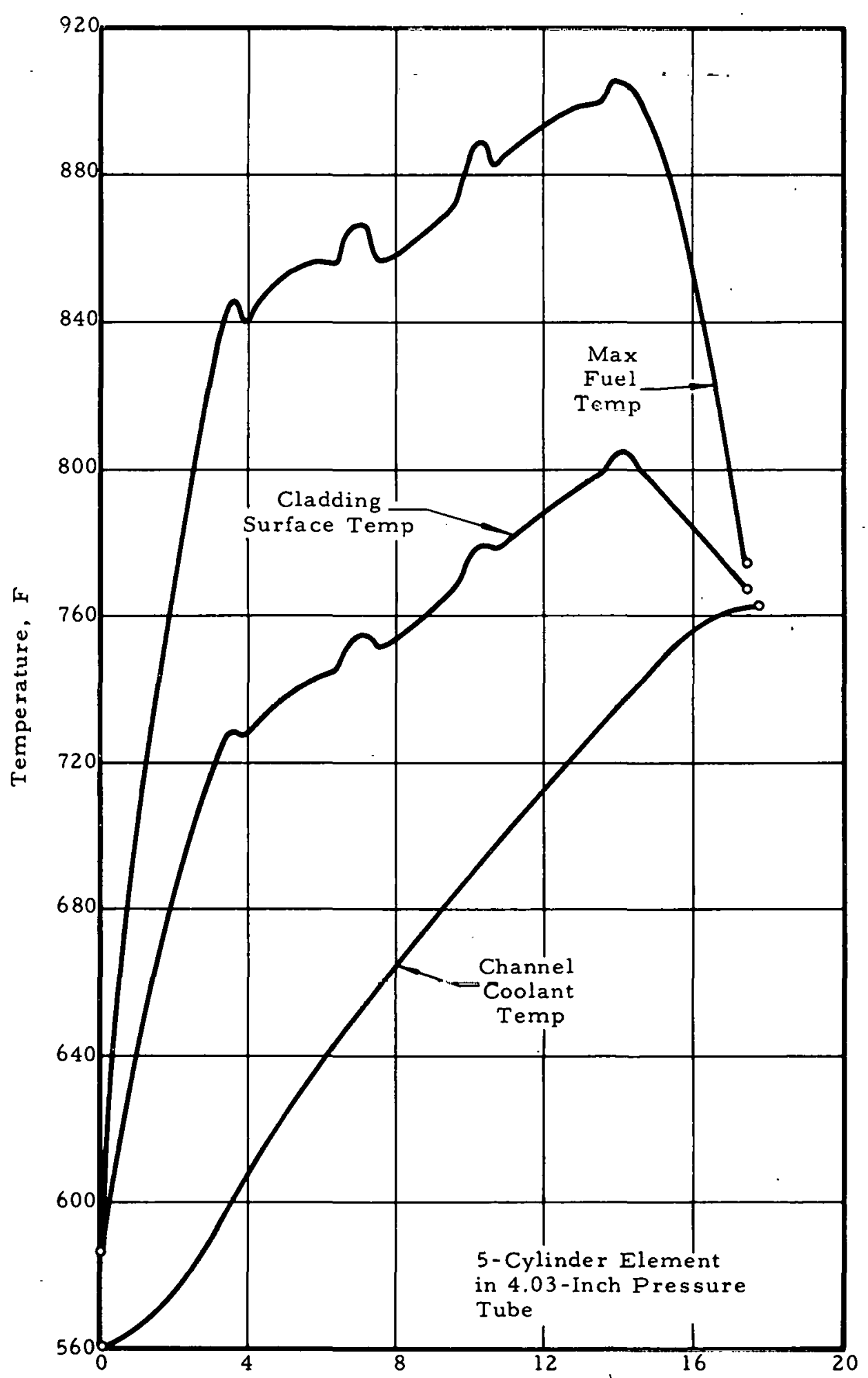

Active Fuel Length, ft

$2-90$ 
Figure 2-12. Ratio of Burnout Heat Flux to. Actual Heat Flux, Based on Constant Saturation Temperature of $850 \mathrm{~F}$

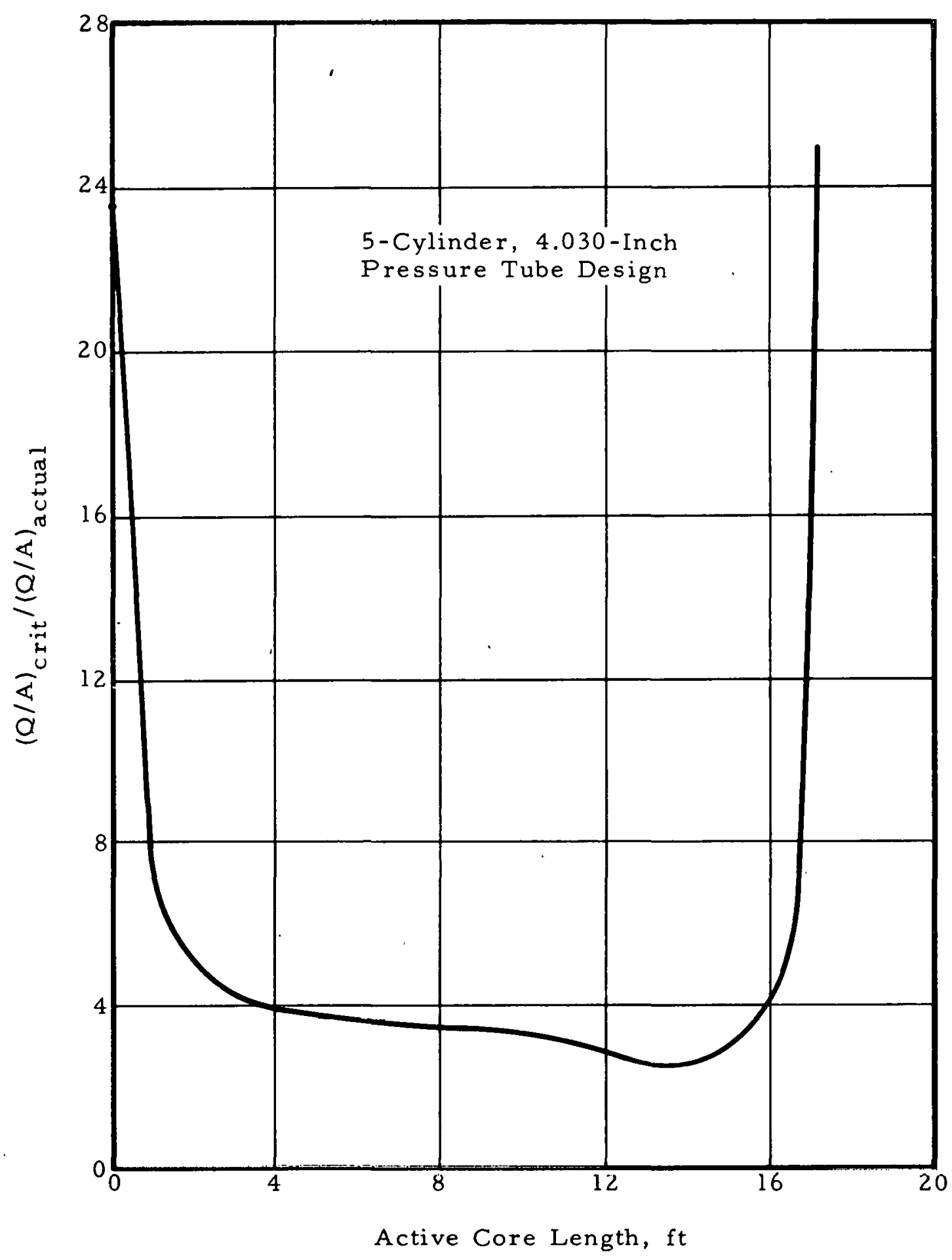


THIS PAGE

\section{WAS INTENTIONALLY LEFT BLANK}


Figure 2-13. HWOCR 37-Pin $\mathrm{ThO}_{2}$ Fuel Element
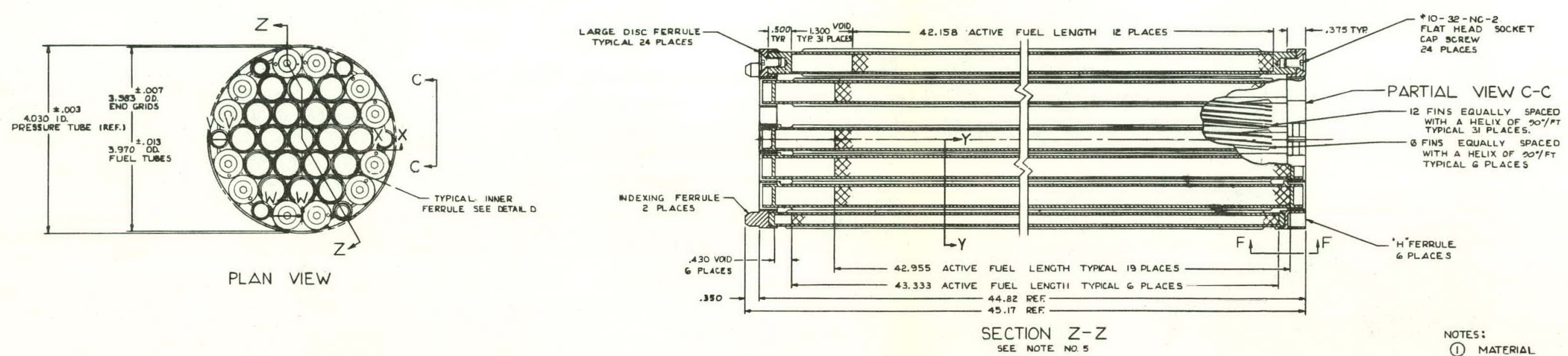

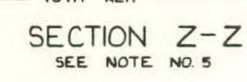
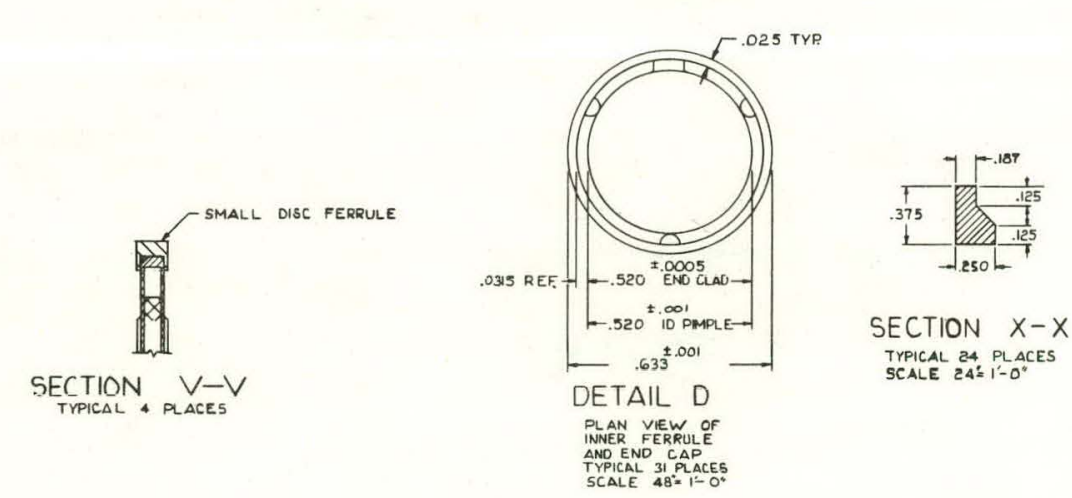

$\underset{\text { TYPICAL 24 PLACES }}{\text { SECTION }} X-X$

YCALE $24: 1=1^{\circ}$
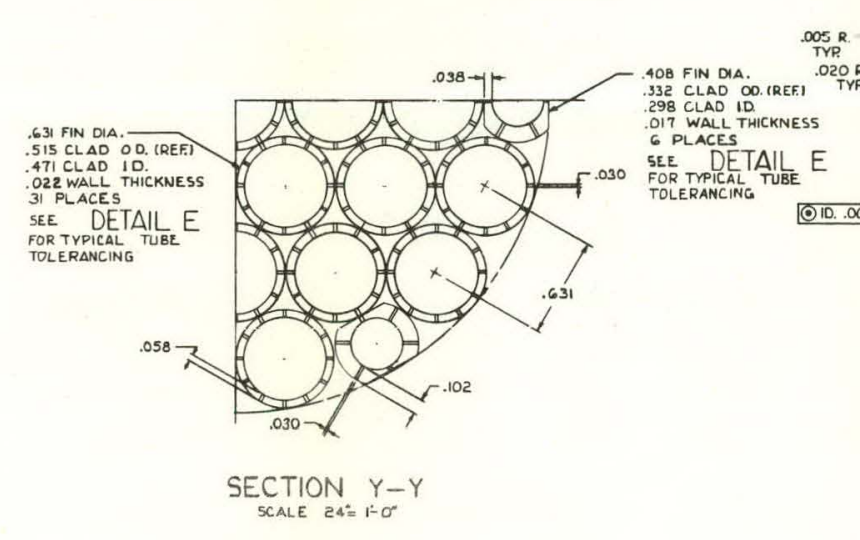

(1) MATERILI

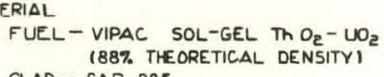

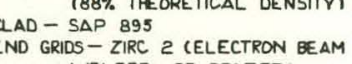

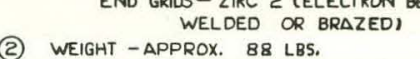
(3) ALL DMENSIONS ARE HOT. COLD

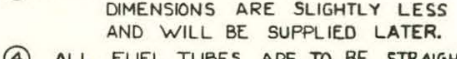
(4) ALL FUEL TUEES ARE TO BE STRALGHT (5) THE FNBSS TO TOED RUEL ELLEMENT MUST BE

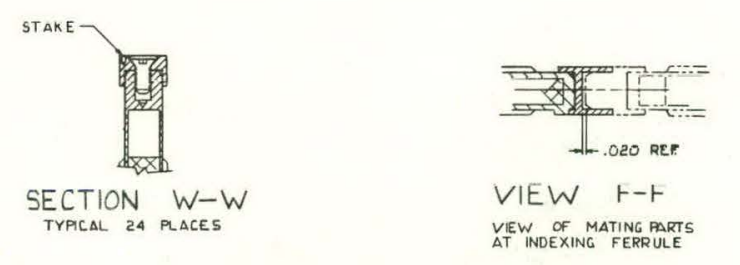


THIS PAGE

\section{WAS INTENTIONALLY LEFT BLANK}


Figure 2-14. Axial Local Power Peaking $(P / \bar{P})$ in Clustered-Pin Fuel Element

U-233 Idealized Cycle

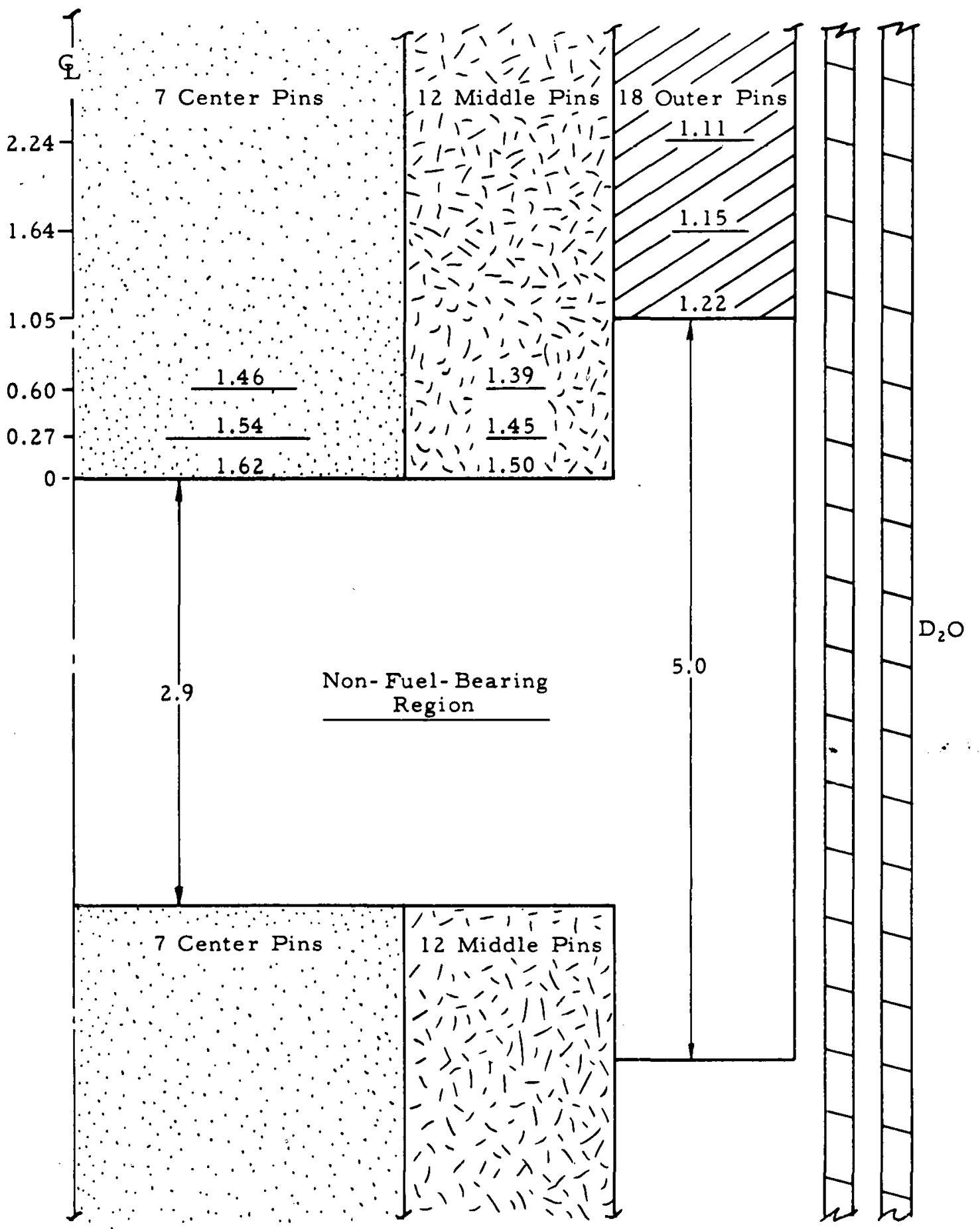

Note: All dimensions in $\mathrm{cm}$. 
Figure 2-15. Flow-Channel Designation, 37-Pin $\mathrm{ThO}_{2}$ Fuel Element

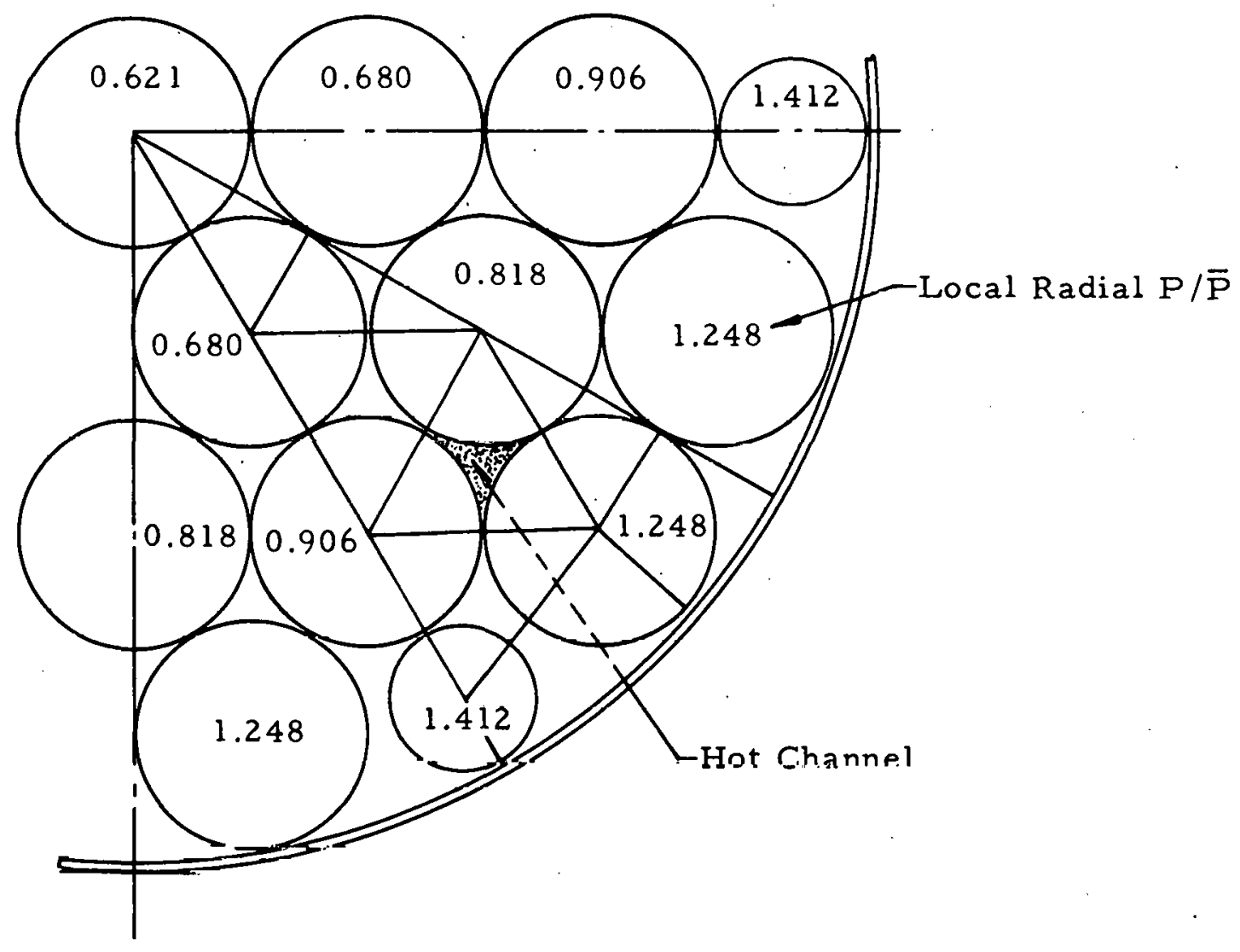


Figure 2-16. Hot Channel Coolant and Cladding Surface Temperature Vs Active Fuel Length

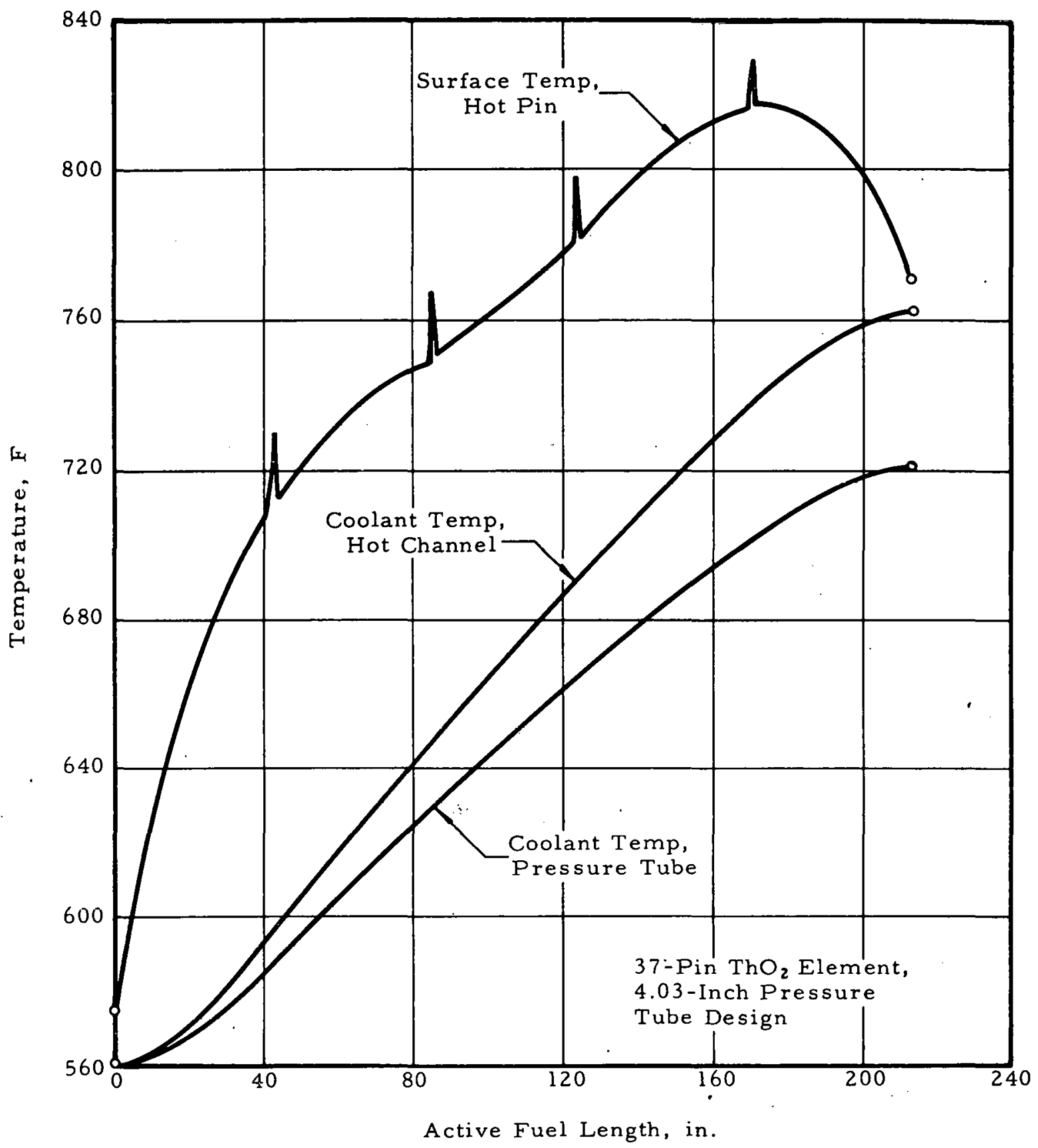


Figure 2-17. Hot Fuel Pin Temperature Vs Active Fuel Length

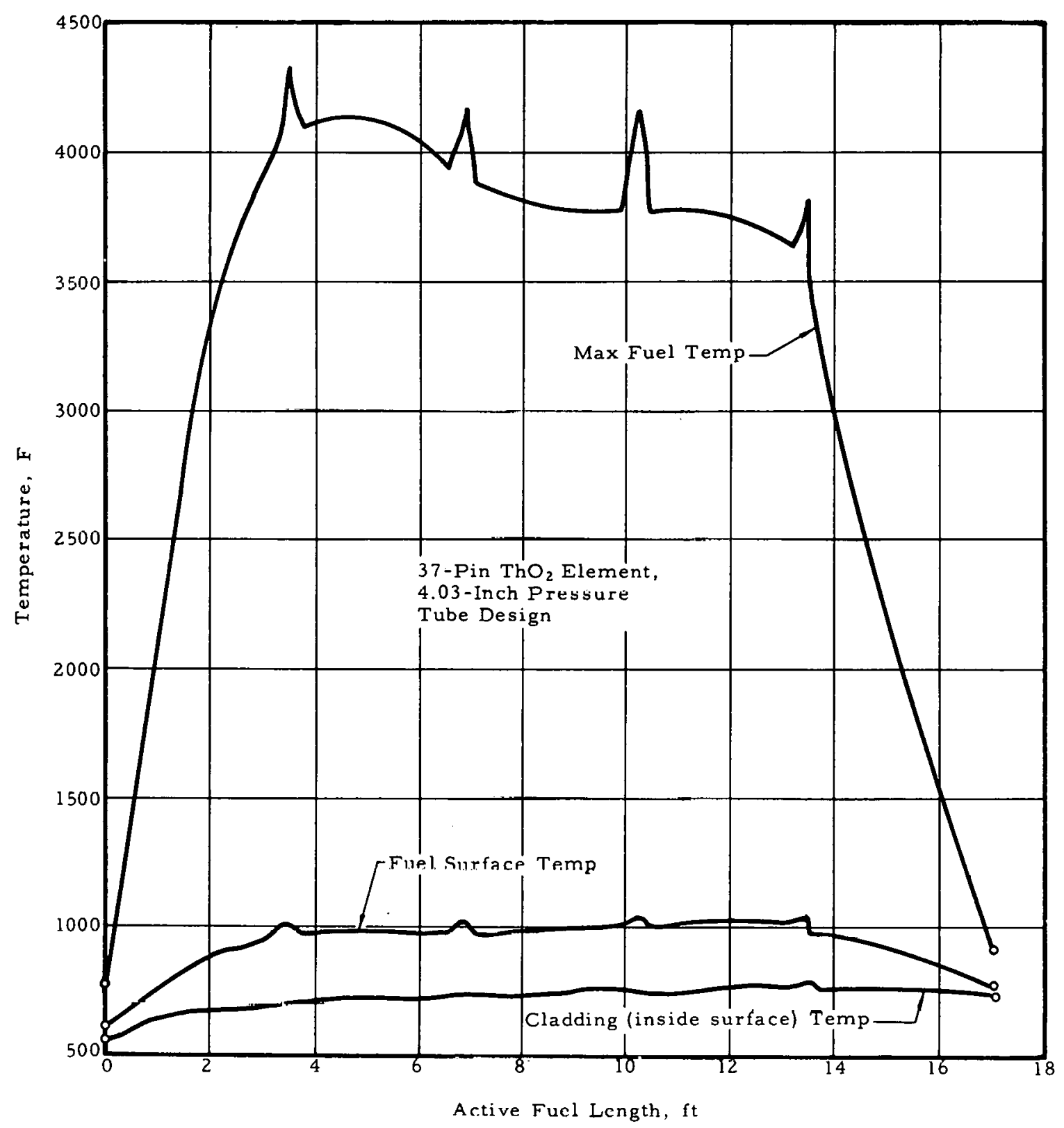


Figure 2-18. Ratio of Burnout Heat Flux to Actual Flux, Based on Constant Saturation Temperature of $850 \mathrm{~F}$

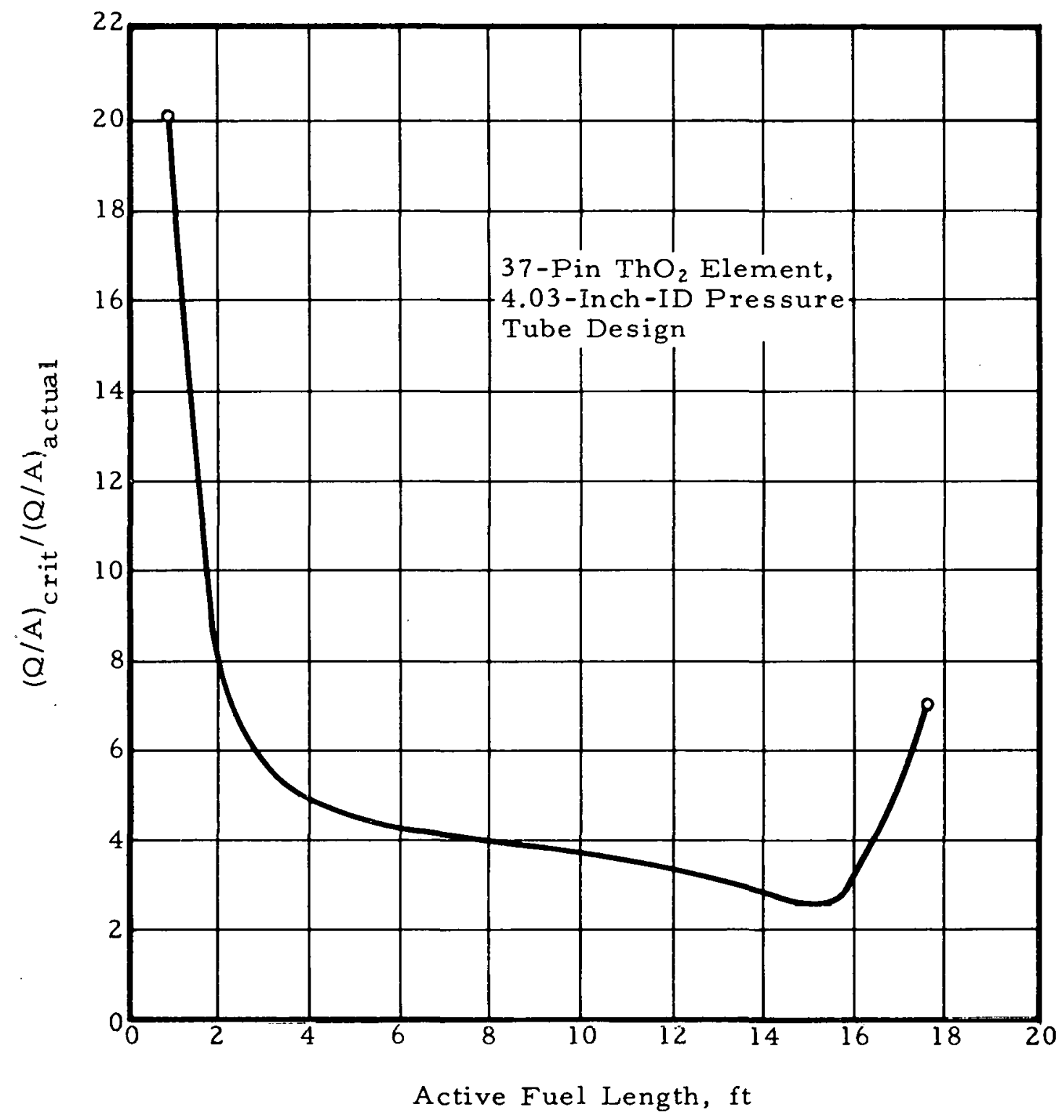


Figure 2-19. Fission Gas Pressure in Hot Pin Vs Full Power Days

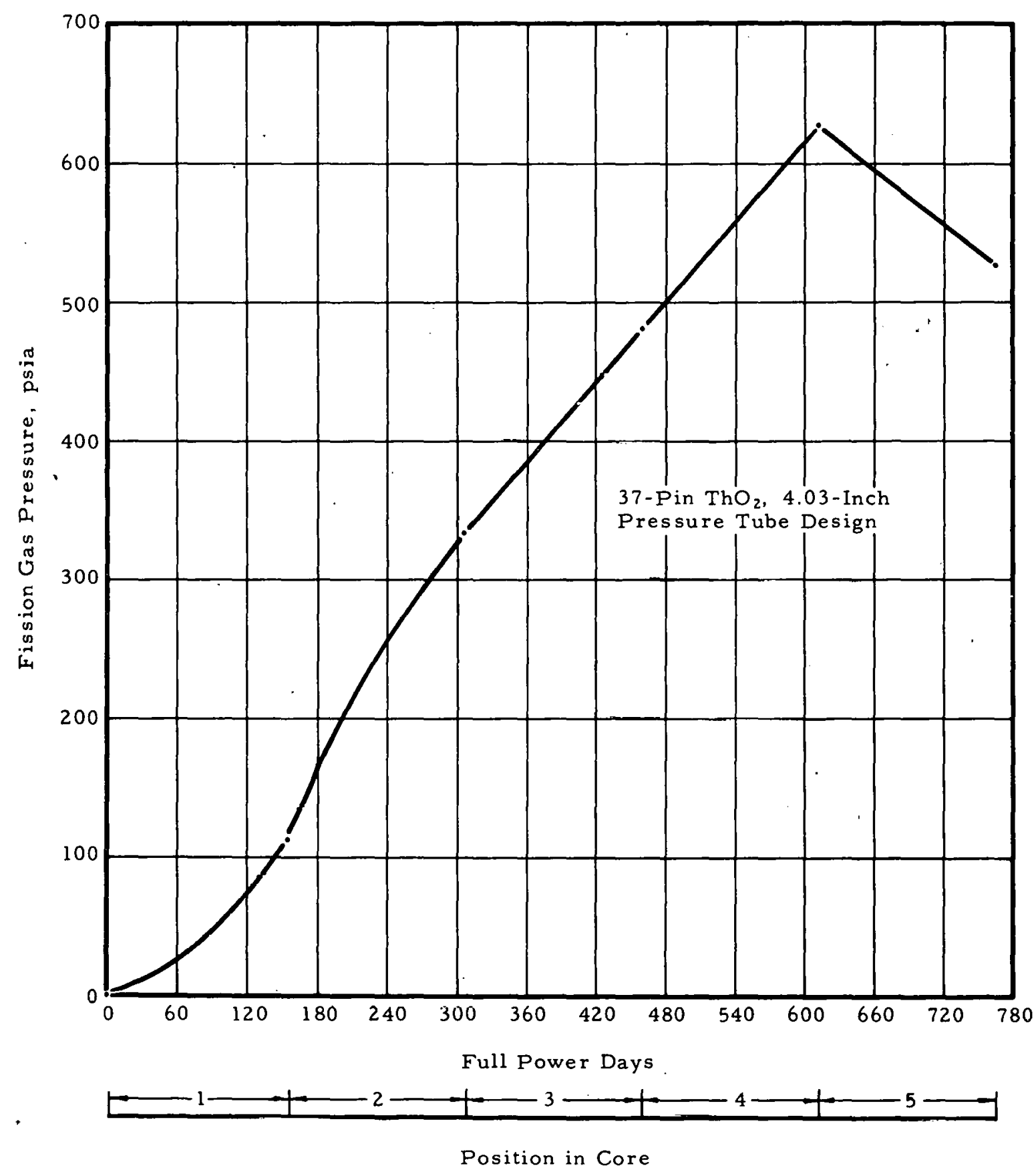


Figure 2-20. 55-Pin $\mathrm{ThO}_{2}$ Fuel Element, Cross Section

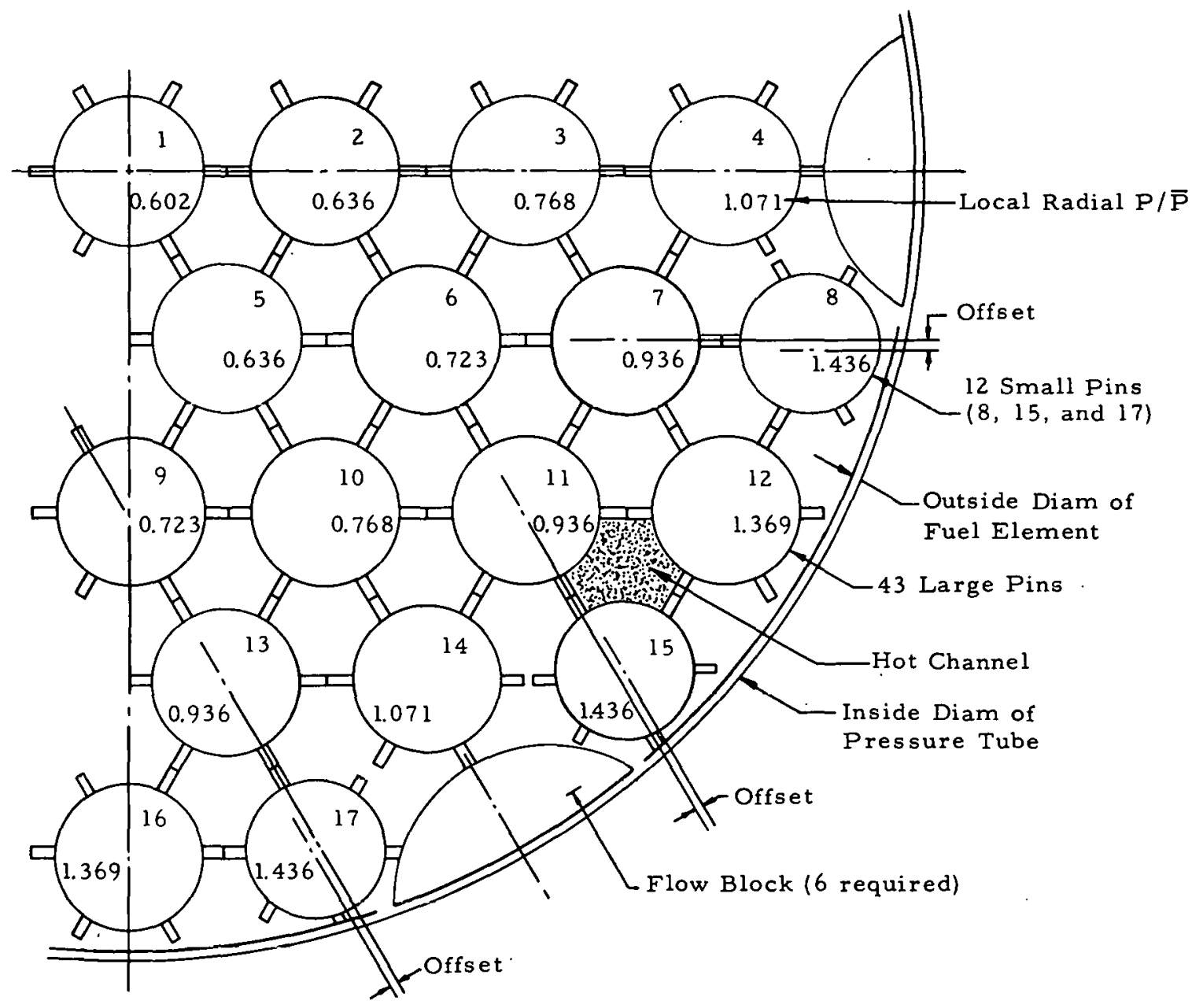


Figure 2-21. Coolant and Cladding Temperatures Vs Active Fuel Length, 55-Pin $\mathrm{ThO}_{2}$ Fuel Element in 4.030-Inch-ID Pressure Tube.

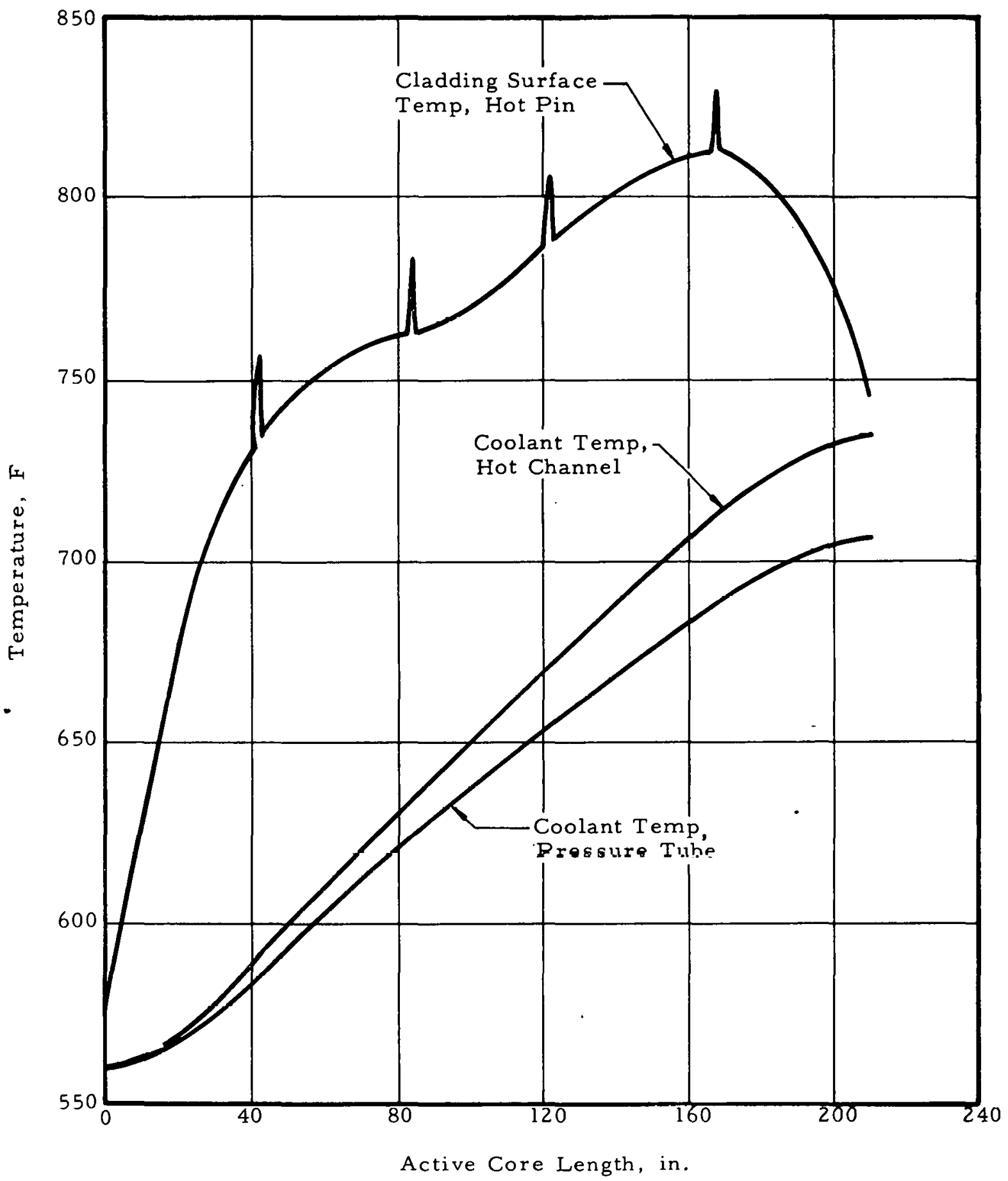


Figure 2-22. Ratio of Burnout Flux to Actual Flux, Based on Constant Saturation Temperature of $850 \mathrm{~F}$

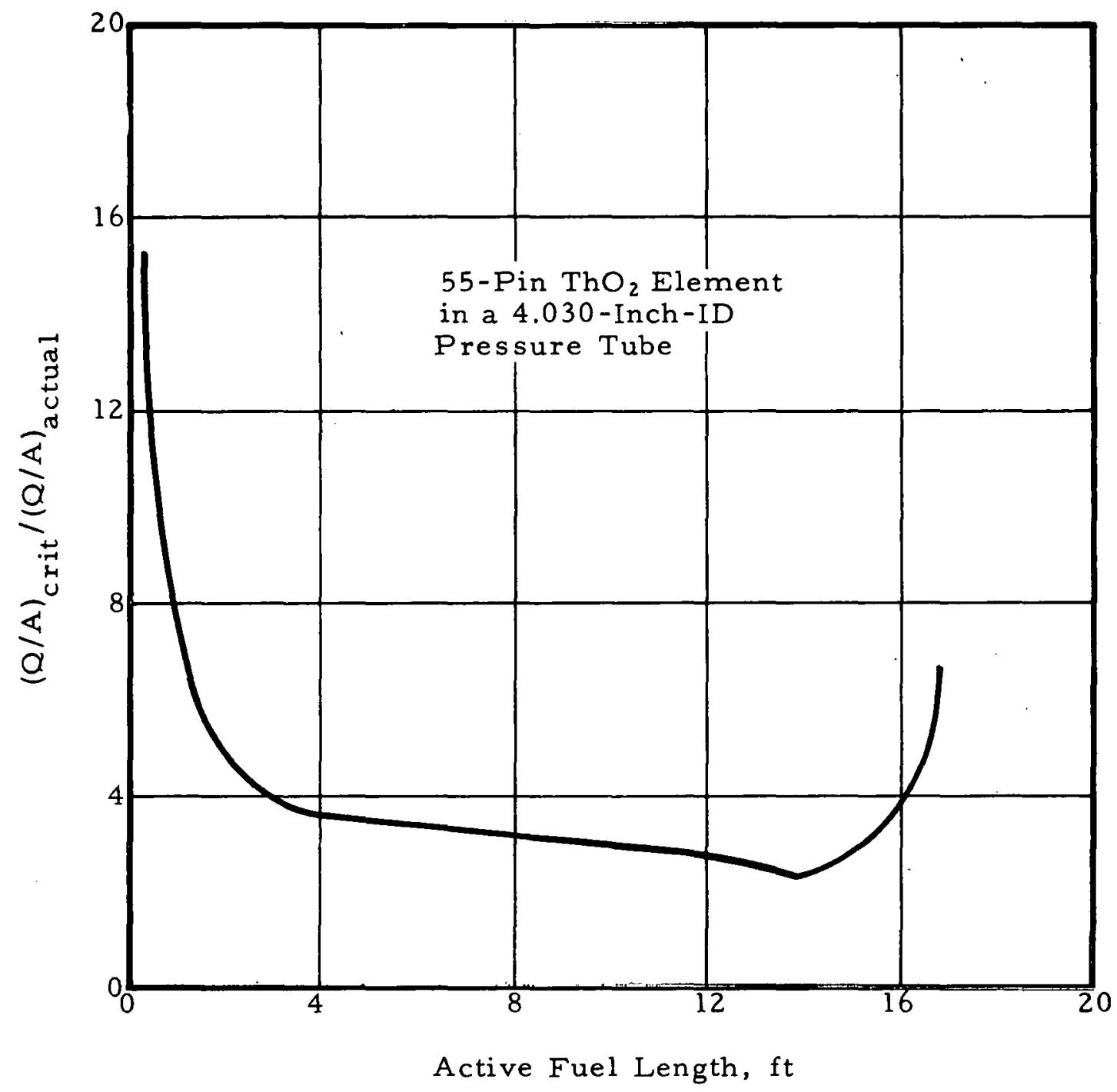


Figure 2-23. Flow-Channel Designation, 37-Pin Thorium Carbide Fuel Element

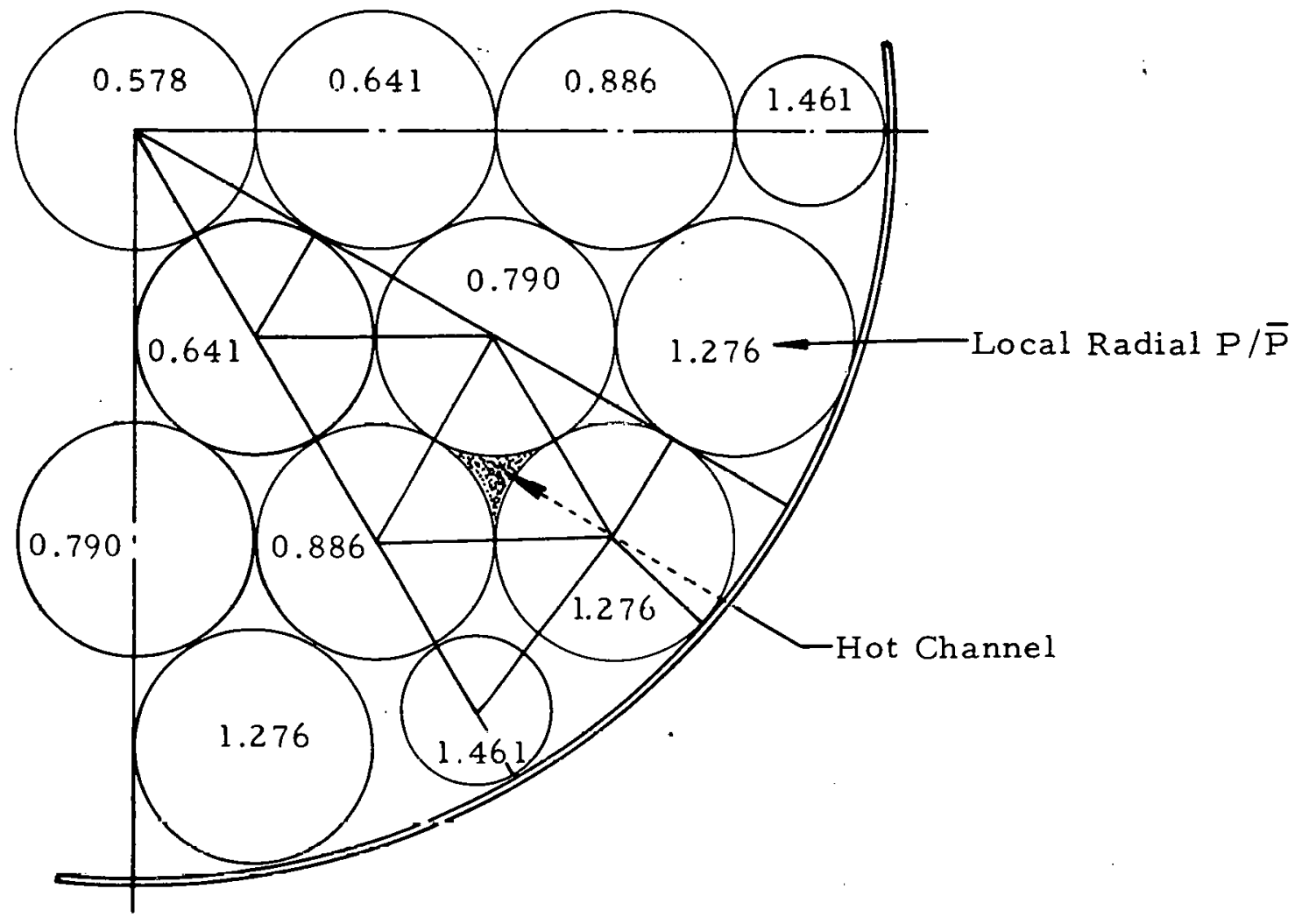


Figure 2-24. Coolant and Cladding Temperatures Vs Active Fuel Length, Thorium Carbide Fuel Element

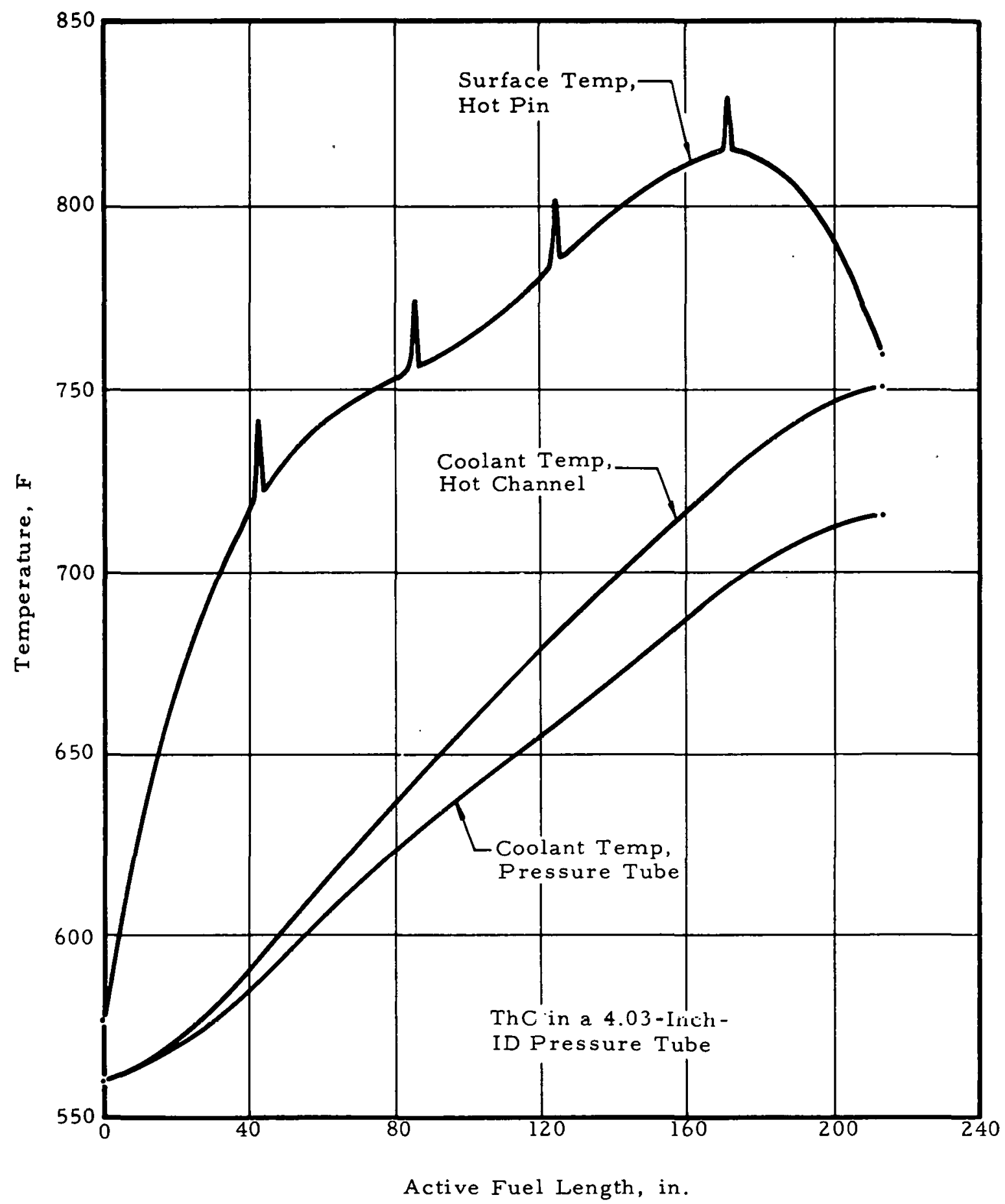


Figure 2-25. Ratio of Burnout Flux to Actual Flux, Based on Constant Saturation Temperature of $850 \mathrm{~F}$

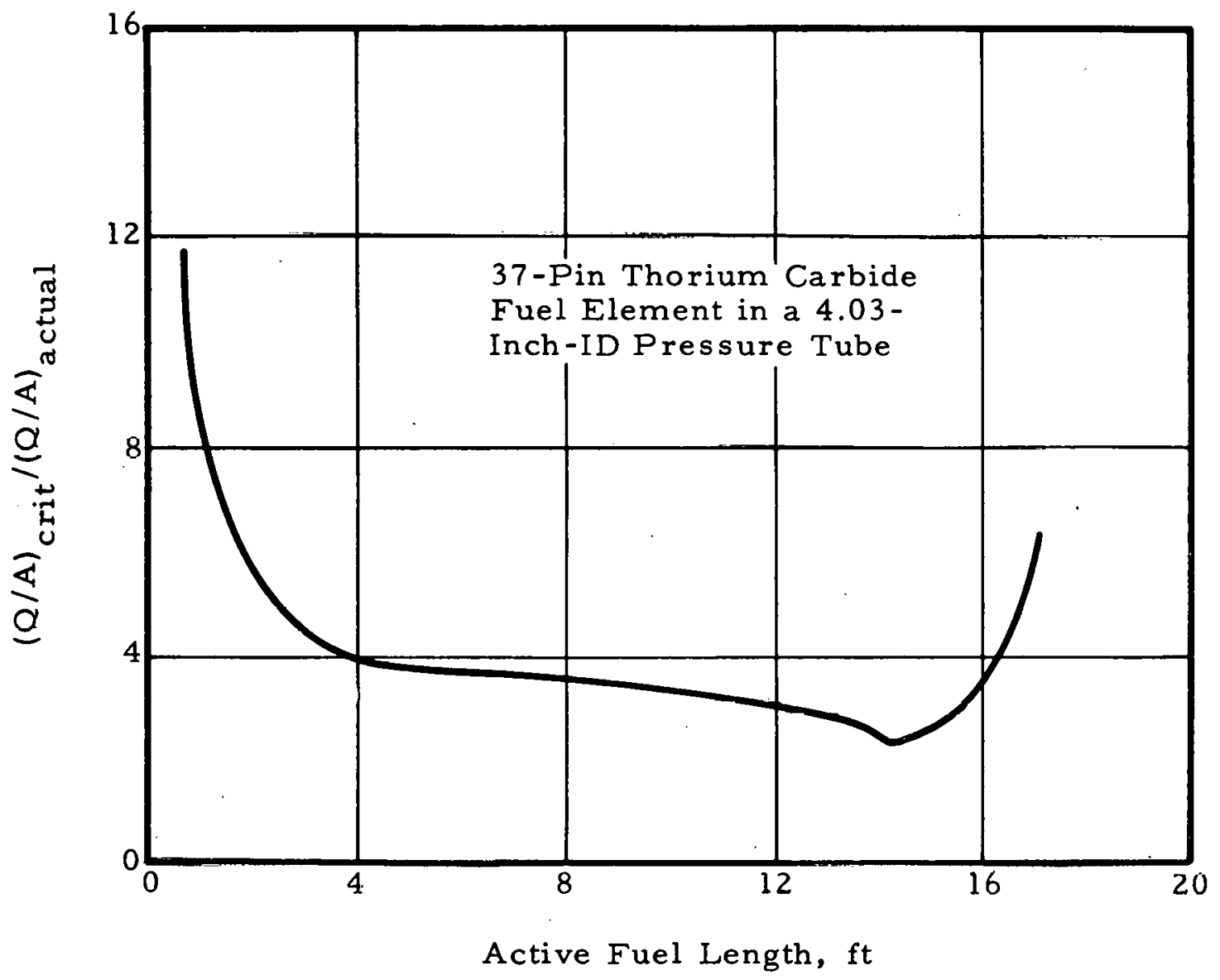


1 Thorium Fuel Cycle for Heavy Water Moderated Organic Cooled Reactors - Quarterly Technical Report No. 2, The Babcock \& Wilcox Company, BAW-393-2, Lynchburg, Virginia, April - June 1965.

2 Thorium Fuel Cycle for Heavy Water Moderated Organic Cooled Reactors - Technical Progress Report No.3, The Babcock \& Wilcox Company, BAW-393-4, Lynchburg, Virginia, July-December 1965.

3 Thorium Fuel Cycle for Heavy Water Moderated Organic Cooled Reactors - Technical Progress Report No. 4, The Babcock \& Wilcox Company, BAW-393-6, Lynchburg, Virginia, January - March 1966.

4 Heavy Water Organic Cooled Reactor, 500 MWe Nuclear Demonstration Plant Conceptual Design, Atomics International-Combustion Engineering, AI-CE-MEMO-25, Canoga Park, California, March 29, 1966.

5 Moncrief, E. C. and Schileo, G., Recycle of HWOCR Thorium Fuel, The Babcock \& Wilcox Company, BAW-393-3, Lynchburg, Virginia, March 1966.

6 Irradiation Tests of Uranium (Thorium) Metal Tubes for $\mathrm{D}_{2} \mathrm{O}$-Cooled Reactors, Savannah River Laboratory, SRL-DP-1019, February 1966.

7 Straub, R. V. and Cheatwood, W. C., TANC-1, Thermal Analysis of Nested Cylinders, The Babcock \& Wilcox Company, BAW-290, Lynchburg, Virginia, August 1965.

8 Kasten, Paul R。, et al., An Evaluation of Heavy-Water-Moderated, Organic-Cooled Reactors (preliminary rough draft), Oak Ridge National Laboratory, Oak Ridge, Tennessee, January 21, 1966.

9 Heavy Water Organic Cooled Reactor, 1000 MWe Nuclear Power Plant Conceptual Design, Atomics International-Combustion Engineering, AI-CE-MEMO-6, Canoga Park, California, October 1, 1965.

10 Organic Cooled, Heavy Water Moderated Reactor Power Plant Conceptual Design and Evaluation, CEND-175, March 1963. USAEC Contract No. $\operatorname{AT}(10-1)-1150$. 


\section{HWOCR THORIUM FUEL CYCLE DEVELOPMENT PROGRAMS}

\section{1. General}

The objective of the HWOCR Thorium Fuel Cycle Development Programs is to demonstrate the performance of thorium fuel elements in an HWOCR environment and to consider the requirements for recycling U-233 and thorium. A preliminary plan for achieving this objective has been developed for each of the candidate fuel elements (metal, oxide, and carbide). These preliminary plans help to guide the selection of a reference fuel element since they provide bases for evaluating the technical feasibility of the designs and the development costs in relation to expected power cost savings. Upon selection of a reference fuel element, the preliminary plan will be the starting point for preparing the detailed program plan to be submitted to the Commission.

The specific tasks of the HWOCR Thorium Program are Task 10 Reactor Engineering, Task 20 - Fuel Element, and Task 30 - Recycle Technology. Liaison will be maintained with AI-CE to obtain HWOCR technology related to pressure tubes, on-line refueling, reactor control, organic cooling, and major components and systems.

Task 10 - Reactor Engineering, is the coordinating technical task for the program. It includes methods development, optimization studies, fuel management studies, control and safety analyses, economic analyses, and the technical coordination necessary to ensure the compatibility of the thorium fuel elements with the AI-CE HWOCR design. The principal near-term task will be physics methods development, including the analysis of thorium physics experiments performed at BNL and SRL. The need for additional experimental physics data is discussed in section 3.5. The magnitude of work performed under Task 10 is not expected to be affected by the fuel element selected as the reference design. 
Task 20 - Fuel Element, is the principal task of the HWOCR Thorium Program. It has the following subtasks:

21. Preliminary Design.
22. Fabrication Development.
23. Fuel Characteristics.
24. Engineering Tests.
25. Fuel Element Assembly Irradiation Test.
26. $1000 \mathrm{MWe}$ Fuel Element Design.

Subtask 21 is part of a continuing effort to perfect and update the reference design by incorporation of the latest findings of the R\&D program. Concurrently, irradiation test fuel elements will be designed to demonstrate the features and pertormance of the reference design. Eubtask 26 covers the final design of a thorium fuel element for a 1000 MWe HWOCR and will incorporate the results of all related $R \& D$. The amount of effort required under these design subtasks is relatively independent of the fuel element. The development tasks $(22,23,24$, and 25), however, will significantly depend upon the fuel element chosen as the reference design. These tasks of the fuel element test program are described in relation to each type of fuel element in sections $3.2,3.3$, and 3.4; the costs and schedules for these test programs are compared in section 4.4 .

The objective of Task 30 - Recycle Technology, is to develop the reprocessing, feed materials preparation, and fabrication processes for the long-range condition of a mature industry and for the near-term condition of first plants on the line. The related research and development is discussed in section 3.5 .

In summary, the research and development required to resolve key technical problems for each type of fuel element is discussed in section 3.6. This information provides the basis for a comparative evaluation of the technical feasibility of the fuel element designs, as presented in section 4.

3. 2. Thorium Metal Fuel Element Test Program

3.2.1. Subtask 22 - Fuel Element Fabrication Development

3.2.1.1. Objective

The objective of this task is to develop the fabrication processes for the $1000 \mathrm{MWe}$ HWOCR thorium fuel element, 
including the necessary manufacturing procedures and inspection techniques.

\subsection{2. Course of Action}

Present technology will be extended to enable the manufacture of reliable large- and small-diameter fuel tubes for thorium nested-cylinder fuel elements. This task will encompass study and demonstration of extrusion methods, bonding of cladding to fuel, joining of end caps to cylinders, assembly of components, and nondestructive testing. The fabrication development work will provide specimens and fuel elements for fuel characterization and irradiation tests.

\subsection{3. Status of Technology}

Development of nested-cylinder fuel elements fabricated by the coextrusion of Zircaloy-clad thorium-uranium alloys at Hanford Laboratories (HAPO, now Pacific Northwest Laboratories, PNL) and Savannah River Laboratories (SRL) has resulted in the production of satisfactory elements. Nuclear Metals (NMI) cooperated in the SRL work.

Kemper et al. of $\mathrm{HAPO}^{1}$ described the fabrication procedures used to produce tubular fuel elements of thorium2.5 wt $\%$ uranium-1.0 wt \% zirconium clad with Zircaloy-2. These procedures included vacuum consumable arc melting, coextrusion, material evaluation, end closure joining, and cleaning.

The vacuum consumable arc process was used to prepare ingots by double melting. The problem of homogeneity was mitigated by the double melting, the low uranium content, and possibly the zirconium addition. The resulting ingots were 5.75 inches in diameter and weighed up to $200 \mathrm{lb}$. They were machined into extrusion billets by turning the surface and drilling an axial center hole. Zircaloy cladding and copper canning were solvent degreased, positioned in and around the billet, and electron beam welded.

Coextrusion was performed on a 2750-ton horizontal hydraulic press equipped with a heated extrusion container. The copper canned billet assemblies were appropriately lubricated with colloidal graphite and heated to $760 \mathrm{C}(1400 \mathrm{~F})$ for 4 hours. The billets were forward extruded from a 6.09-inch-diameter extrusion container 
heated to $427 \mathrm{C}(800 \mathrm{~F})$. The opening of the 90-degree cone die was 1.790 inches in diameter, and the mandrel was 1.050 inches in diameter, resulting in an extrusion ratio of 17:1. The extruded tubes, which were 18.5 and 22 feet long, exhibited good surface quality and no evidence of galling.

Dimensional control was found to be entirely satisfactory for HAPO reactor irradiation. Cladding thickness was uniform locally to approximately $\pm 0.005 \mathrm{inch}$ and averaged \pm 0.003 inch for the entire cylinder length. Local fuel thickness tolerance and fissile fuel uniformity were within $\pm 5 \%$, and straightness was within 0.010 inch per foot. ${ }^{2}$

Metallographic examination showed metallurgical bonding at the cladding-core interface; the fuel was partially recrystallized. Subsequent vacuum heat treatment of specimens for 1 hour at $750 \mathrm{C}(1380 \mathrm{~F})$, followed by furnace cooling, resulted in uniform diffusion at the interface and a total bond width of 0.0007 inch; the major portion of the bond on the Zircaloy- 2 side had the 85.6 atomic \% zirconium-thorium eutectoid composition, and the remainder changed linearly to the composition of the fuel alluy. The thorium alloy was almost completely recrystallized, greatly reducing the as-extruded fibrous structure. Random alpha-uranium precipitate was present as expected.

The end closure was made by vacuum brazing with $5 \mathrm{wt} \%$ beryllium-zirconium eutectic alloy, which melts at $980 \mathrm{C}$ $(1795 \mathrm{~F})$ and brazes at $1050 \mathrm{C}(1920 \mathrm{~F})$. Bonding to the thorium alloy was impaired by oxide formation, but was resolved by power brushing the thorium alloy surface with Zircaloy bristles before brazing.

'The tinal step in the manufacluse uf fuel elements consisted of a 72-hour exposure in deionized stedm at $400 \mathrm{C}$ (750 F) and $1500 \mathrm{psig.} \mathrm{The} \mathrm{assemblies} \mathrm{were} \mathrm{inspected} \mathrm{radiographically,} \mathrm{visu-}$ ally, and dimensionally, and the density was determined. It was concluded that coextrusion of thorium-2.5 wt \% uranium-1 wt \% zirconium clad with Zircaloy on the outside and inside tube surfaces is a practical operation. Reproducible, sound, nonporous, fully bonded braze joints are obtainable on the end closures, and the assembly is suitable for irradiation.

Larson and Huber of NMI and Gray et al. of $S R L^{2}$ described the fabrication procedure for thorium-1.4 wt \% uranium 
tubes clad with Zircaloy-2. The tubes were coextruded with a 14: l ratio and had the following dimensions:

$\begin{array}{ll}\text { OD } & 2.540 \text { inches } \\ \text { ID } & 1.830 \text { inches } \\ \text { Cladding } & 0.030 \text { inch } \\ \text { Length } & 9 \text { feet }\end{array}$

The alloy was vacuum induction melted, and $200 \mathrm{lb}$ ingots were bottom poured into bare graphite molds designed for rapid bottom-to-top solidification to reduce uranium inhomogeneity. The castings were machined into extrusion billets 6.59 inches in OD, 2.69 inches in ID, and 8 inches in length. The carbon content was high, approximately $1350 \mathrm{ppm}$; the carbon and uranium homogeneity was considered to be good. The fuel billet was enclosed internally and externally in Zircaloy-2 sleeves and end seals; the entire as sembly then was copper canned and lubricated with colloidal graphite. The billet assemblies were preheated to $775 \mathrm{C}$ (1425 F) for as much as 20 hours; 9 hours was stated as the preferred soaking time. Extrusion was accomplished in a 2750-ton press; 2000 tons of force was the maximum needed. From their data, the measured dimensions of the coextruded product were found to be typically as follows:

$\begin{array}{ll}\text { Wall thickness } & 0.353 \pm 0.005 \text { inch } \\ \text { Outer cladding } & 0.033 \pm 0.003 \text { inch } \\ \text { Inner cladding } & 0.033 \pm 0.003 \text { inch } \\ \text { Core } & 0.286 \pm 0.005 \text { inch }\end{array}$

Destructive rupture tests were employed, and it was concluded that the Zircaloy -2 cladding was adequately bonded to the fuel for irradiation. Ultrasonic inspection revealed no unbonded regions larger than $1 / 8$ inch, which was the lower limit of detectability for their instrumentation. Radiography was also used to confirm the quality of the coextrusion.

\section{2. 1. 4. Problem Areas}

The coextrusion conditions for small- and large-diameter fuel tubing have not been established. It will also be necessary to obtain the characteristics and dimensional tolerances of the product for cylinders of varying dimensions.

To provide adequate control of coolant channel gaps, spacers between fuel cylinders are required. Spacer designs 
generated in Task 21 (Fuel Element Preliminary Design) require proof of fabrication feasibility.

Although some development work on methods of applying end closures to coextruded fuel cylinders has been performed, more work is required to gain confidence that the end-closure technique is readily adaptable to production methods and that the end closures will perform satisfactorily at HWOCR operating conditions.

The reliability of present nondestructive testing techniques must be demonstrated to ensure the integrity of the tubular fuel element. Testing techniques are required to determine such items as the quality of bonding between cladding and fuel, the integrity of endclosure joints, and the homogeneity of fuel alloy. It may be necessary to develop new and improved testing techniques to determine these for cylinders having the $B \& W$ design.

\subsubsection{Technical Approach}

The development of the fabrication process for nested-cylinder fuel elements will include work on coextrusion development, end-closure development, spacer-rib development, and development of nondestructive test techniques. Detailed task descriptions must necessarily depend to some extent upon the experience and capabilities of the developer. The general requirements are as follows:

1. The coextrusion of thin-walled large-diameter fuel elements (up to approximately 4 inches in diameter and 100 mils in fuel thickness) for a $1000 \mathrm{MWe}$ HWOCR is required. The dimensional tolerances and other characteristics must be suitable for reactor operation. The anticipated requirements of HWOCR nested-cylinder fuel elements are compared with the characteristics of cylindrical fuel elements that have been produced, as follows:

\begin{tabular}{|c|c|c|c|}
\hline & Thorium HWUEK & 3RL/PJMAI & PNL \\
\hline Tube $O D$, in. & $\begin{array}{l}4.780 \text { (thorium-optimized-large) } \\
1.218 \text { (AI-CE-small) }\end{array}$ & 2.540 & 1.790 \\
\hline Tube ID, in. & $\begin{array}{l}4.480 \text { (thorium-optimized-large) } \\
0.550 \text { (AI-CE-small) }\end{array}$ & .830 & 1.050 \\
\hline $\begin{array}{l}\text { Cladding thickness } \\
\text { tolerance (averaged } \\
\text { over length), in. }\end{array}$ & \pm 0.003 & $\begin{array}{l} \pm 0.003 \text { (outer) } \\
-0.001 \text { to } \\
+0.005 \text { (inner) }\end{array}$ & \pm 0.005 \\
\hline $\begin{array}{l}\text { Fuel thickness tol- } \\
\text { erance (averaged } \\
\text { over length), \% }\end{array}$ & \pm 3 & \pm 3 & \pm 5 \\
\hline
\end{tabular}


Thus, IHOCR lolerances generally agree with previous production, but the sizes of the cylinders are not within the range of previous production. Suggested supplementary areas of evaluation to be performed under this task, after feasibility of producing the cylinders has been demonstrated, might include an evaluation of the two presently available melting techniques and their effect on subsequent fabrication and cost parameters. Both consumable electrode arc melting and vacuum induction melting would be investigated. The casting of large ingots of the fuel alloy and subsequent processing to produce an extrusion billet will be investigated to determine the feasibility of casting a hole in the middle of the ingot. Steps to reduce the amount of machining necessary on the outside and inside surfaces of the ingot will also be investigated since sizeable reductions in scrap production could be realized. Means of producing and controlling the oxide film between the Zircaloy and copper sheaths to prevent interaction during extrusion should also be investigated, as should the effect of carbon content in the fuel alloy upon extrusion characteristics. Integral end closures (see item 4 below) should also be investigated and evaluated.

2. The coextrusion of thin-walled small-diameter (approximately $l$ inch) fuel cylinders will be considered since the minimum sized cylinder for the AI-CE design (4.03-inch-ID pressure tube) is in this category, as noted above.

3. An important factor in the operational stability of fuel elements is the fuel-to-cladding bond. The maximum size of unbonded areas, thickness of the bond layer, and mechanical properties of the bond should be established. If necessary, this bond can be improved by heat treatment following extrusion. Such parameters as temperature and soaking time should be studied, therefore, to achieve the best practical bond as determined destructively by metallographic examination and mechanical property testing within the framework of the established requirements. As a further consideration, the dimensional tolerances should not be worsened by heat treatment.

4. The tube ends must necessarily be sealed and spaced relative to the abutting elements. This is accomplished with end caps which must be sealed to the cladding and preferably must be intimately 
bonded to the fuel. Development work will be required to determine the best end closure design. There are at least three possible designs: welded, brazed, and integral end caps. The welded or brazed end caps are inserted into the ends of a cut and carefully prepared extrusion. There are problems with surface preparation and braze joint integrity. The integral end caps are formed during extrusion and therefore are well bonded to fuel and cladding. There are problems with the fuel "tailing off" near the ends of the cylinder, which produces variations in fuel content.

5. Nondestructive testing is required to ensure that only reactor quality elements are released for operation. The degrees of bonding, fuel homogeneity, and freedom from defects may be determined by such methods as ultrasonic testing, radiography, autoradiography, gamma absorption, and surface replication. These inspection methods must be evaluated to determine their reliability and sensitivity, and where existing techniques are not suitable, they must be further developed or novel methods must be found to accomplish the required inspection. In those instances where standards are required, they must be fabricated and calibrated.

6. Concentric nesting of the tubular fuel elements of the reference design requires spacers between the elements to maintain the channel width. The spacers must be joined to the cladding, and the design of the spacers must enable the joint to be made and to function as required. The joint must cause only minimal problems in crevice corrosion, fouled organic buildup, fretting corrosion, and mechanical instabilities.

7. The components of the nested fuel element assembly must be designed to allow assembly without introducing undue stresses, elastic instability, blocking channels, or producing other abnormalities. The fuel element assembly must then be perfected by satisfying design requirements and minimizing fabrication costs.

8. The fuel elements fabricated in the course of this investigation shall be used as test specimens as required in other tasks. 


\subsubsection{Summary}

A program has been outlined to develop the fabrication processes for a $1000 \mathrm{MWe}$ HWOCR thorium metal fuel element. The experience of PNL and SRL/NMI will be considered in the manufacture and testing of the tubular fuel elements. Thin-walled tubing in the range of 1 to 5 inches in diameter will be coextruded with Zircaloy cladding. Methods for bonding of cladding to fuel, achieving proper end seals, joining spacers to the cladding, and assembling the components will be developed. Nondestructive testing techniques will be adapted to the needs of this program, and necessary standards will be fabricated and calibrated. The fuel elements manufactured in the course of this program will be used as test specimens in other tasks.

\section{2. 2. Subtask 23 - Thorium Alloy Fuel Characteristics}

\subsubsection{Objective}

The objective of this task is to characterize the thorium-uranium alloy fuel by inreactor and outreactor testing.

\subsubsection{Course of Action,}

Necessary fuel properties that are not adequately known will be determined or verified under conditions applicable to the HWOCR. The effect of hydrogen upon the mechanical properties of Zircaloy-4, the reference cladding material, is also of significant interest, but will not be treated in depth under this program. Applicable data from related AI-CE, AF,CL, and B\&W company-sponsored ${ }^{3}$ programs will be evaluated.

\subsubsection{Status of Technology}

\section{Introduction}

Thorium-uranium alloys have been studied at a number of laboratories, and a significant body of data exists on their preparation, properties, and behavior under neutron irradiation. Collection and comparison of the information revealed that the investigations were performed on many alloy compositions with differing (or unreported) impurity contents and that the test conditions were not uniform. However, there is sufficient directly applicable information to obviate the need for an extensive investigation. 


\section{Phase Equilibria}

The thorium-uranium equilibrium phase diagram in the thorium-rich region of interest to this program is disputed to some extent. Bentle of $\mathrm{AI}^{4}$ found that the solubility of uranium in thorium was less than 1 wt \% at room temperature and increased to about 7 wt $\%$ at $1270 \mathrm{C}(2320 \mathrm{~F})$. Bannister and Thoms on of UKAEA found the maximum uranium solubility to be 2.7 atomic $\%$ at $1343 \mathrm{C}(2450 \mathrm{~F})$. Since the reference fuel contains approximately $2 \%$ uranium and will not exceed $510 \mathrm{C}(950 \mathrm{~F})$, the dispute is essentially academic as far as this program is concerned. At that temperature, the microstructure consists of an alpha-thorium (tace-centered-culic) matrin with a small amount of precipitated alpha-uranium. The first allotropic change is at approximately $650 \mathrm{C}(1200 \mathrm{~F})$, where the orthorhombic alpha-uranium transforms to tetragonal beta-uranium. The effect of zirconium on the thorium-uranium system has been investigated by Badaeva and Alekseenko of the USSR Academy of Sciences. ${ }^{6}$ Their ternary diagram shows the lowest temperature "ternary" reaction to be a Class III peritectoid at $605 \mathrm{C}$ (1120 F); modest zirconium additions do not appreciably alter the thorium corner. Since these transformations are well beyond the maximum intended fuel temperature and since the system is probably characterized well enough to enable appreciation of microstructural changes likely to be observed, the performance of additional phase equilibrium studies as a part of this program is not anticipated.

\section{Corrosion}

In the event of a defect in the cladding, compatibility of fuel and coolant and more significantly cumpatibility of fuel and moderator become extremely important. The static corrosion tests of thorium and uranium in orthoterphenyl from 700 to $900 \mathrm{~F}$ reported by Pearlman of $\mathrm{AI}^{7}$ indicated that "no operating problem would result if there were a cladding failure, with almost any metal alluy fuel. "It was stated that the observed corrosion was due to air and/or water dissolved in the organic coolant; however, the amounts present were not given. Additional effort is required in this area.

Although the compatibility of thorium metal with organic coolant is high, the inability of thorium alloys coextruded 
with Zircaloy- 2 to survive catastrophic failure due to exposure to hightemperature water through a small defect in the cladding was reported by Kneppel of NMI. ${ }^{8}$ A more recent corrosion investigation was performed by Wang ${ }^{9}$ of ANL. He found that the water corrosion resistance of all thorium-uranium alloys from 5 to 40 wt $\%$ uranium was poor. The alloying addition of zirconium was beneficial at lower temperatures.

\section{Meclianical Pruperlies}

Roll of NMI, ${ }^{10}$ Bentle of $\mathrm{AI},{ }^{11}$ and Farkas of $B I^{12}$ reported the effect of uranium content upon the room temperature mechanical properties of thorium-uranium alloys. The strength increases and the ductility decreases as the uranium content is increased. Bentle 11,13 also investigated higher temperature tensile properties. The strength of the alloy at $500 \mathrm{C}(930 \mathrm{~F})$ is approximately $50 \%$ of the room temperature value. Cole of $\mathrm{ATL}^{\mathbf{1 4}}$ published the results of an extensive investigation wherein the strengthening effects of zirconium, niobium, molybdenum, carbon, aluminum, and beryllium on thorium-5 wt \% uranium and thorium-10 wt \% uranium alloy were explored. The effect of heat treatment, rationalized by microstructural studies, was also investigated, and the improvement of mechanical strength due to fine intragranular distribution of alpha-uranium was noted. Leggett of HAPO ${ }^{15}$ started the study of the effects of irradiation on the mechanical properties of thorium-uranium alloys with uranium contents to $5.4 \mathrm{wt} \%$. His principal effort with pure thorium ${ }^{16}$ expanded upon the earlier efforts of Bement of HAPO. ${ }^{17}$ Bement irradiated tensile specimens of two lots of thorium of differing carbon content to 0.1 atomic \% burnup $(\approx 1000 \mathrm{MWD} / \mathrm{MTM})$. The thorium having higher carbon content continued to possess higher strength and lower ductility after irradiation, since the strength properties increased significantly and the yield point decreased and eventually disappeared with increased exposure. Effective recovery from irradiation damage was obtained by annealing at $750 \mathrm{C}(1380 \mathrm{~F})$. Leggett described the mechanical properties of irradiated thorium tested in tension at 590 and $815 \mathrm{C}$ (1095 and $1500 \mathrm{~F})$. Irradiation to 0.06 atomic $\%$ burnup $(\approx 600 \mathrm{MWD} / \mathrm{MTM})$ doubled the yield strength and reduced the ductility; extensive reduction in area occurred at $590 \mathrm{C}(1075 \mathrm{~F})$, whereas little occurred at $815 \mathrm{C}(1500 \mathrm{~F})$. 
Creep of 5, 10, and $20 \mathrm{wt} \%$ uranium-thorium alloys was investigated by Farkas of BMI. ${ }^{12}$ He found that the creep resistance of thorium-uranium alloys decreases as the uranium content increases. This was ascribed to the concentration of alpha-uranium at grain boundaries and to the increasing intergranular flow at elevated temperatures. Cole of $\mathrm{ATL}^{14}$ also investigated creep of 5 and $10 \mathrm{wt} \%$ uranium-thorium. As noted above, the strengthening effect and dispersion hardness were explored; zirconium was the most effective additive in improving elevated-temperature mechanical properties.

\section{Irradiation Behavior}

Three irradiation experiments were conducted by Kittel of ANL. ${ }^{18}$ In the first experiment, wrought thorium and thorium-5 wt \% uranium irradiated to 1.5 atomic \% burnup ( $\approx 15,000 \mathrm{MWD} /$ MTM) showed isotropic growth and decreased in density at a rate of $1 \%$ per 1 atomic $\%$ burnup. In the second experiment, wrought thorium and thorium-0.1 wt \% uranium, thorium-1.4 wt \% uranium, and thorium-5.5 wt $\%$ uranium alloys irradiated to 0.3 to 3.6 atomic \% burnup $(\approx 3000$ to $36,000 \mathrm{MWD} / \mathrm{MTM}$ ) at irradiation temperatures in the range of 45 to $200 \mathrm{C}(110$ to $390 \mathrm{~F})$ showed isotropic growth while the densities decreased at rates near $1 \%$ per 1 atomic $\%$ burnup. In the third experiment, chill-cast thorium alloys containing from 10 to 31 wt \% uranium, irradiated from 0.16 to 10.1 atomic \% burnup ( $\approx 1600$ to $101,000 \mathrm{MWD} /$ MTM) at irradiation temperatures from 260 to $1000 \mathrm{C}(500$ to $1830 \mathrm{~F}$ ), showed no surface roughening when the uranium was below 25 wt \%. The rates of volume increase per 1 atomic $\%$ burnup were from $1 \%$ at lower temperatures to $2.5 \%$ at $6 b U \mathrm{C}(1 \angle U U \mathrm{~F})$ and $6 \%$ at $800 \mathrm{C}(1470 \mathrm{~F})$. These volume changes are significantly less than those reported for the most stable uranium base alloys. Kittel suggested that the excellent resistance to high-temperature swelling of the chill-cast thorium-uranium alloys was due to the very fine uranium particle dispersion, which allowed the fission recoils to escape from anisotropic alpha-uranium into the isotropic and less densely packed thorium matrix. Accelerated swelling was shown to start at about $550 \mathrm{C}(1020 \mathrm{~F})$. Ballif ${ }^{19}$ of AI irradiated thorium-5.4 wt \% uranium alloy and reported values substantially agreeing with Kittel's values. 
Neutron irradiation of tubular thorium-uranium alloy fuel elements was performed by PNL and SRL. The specimens and their fabrication are described in section 3.2.1.3.

Irradiation of the PNL specimens commenced in April 1963 in the high-temperature, high-pressure, water-cooled ETR-P7 facility. ${ }^{20}$ By March 1966 approximately 1.3 atomic \% burnup $(13,400 \mathrm{MWD} / \mathrm{T})$ had been achieved; the goal is 3 atomic \% burnup $(26,000$ $\mathrm{MWD} / \mathrm{T}$ ). The irradiation temperature varied from 460 to $585 \mathrm{C}$ (860 to $1085 \mathrm{~F})$, and the specific power varied from 46 to 69 watts/gram. The fuel volume increased $2.4 \%$ since the start, the first $1.7 \%$ being in a generally linear manner. and the remainder showing scatter. This gain is slightly less than the theoretical minimum volume expansion due to fission products.

The SRL irradiations were performed in the HWCTR from August to December 1964. ${ }^{21}$ A burnup of approximately 0.35 atomic $\%(\approx 3500 \mathrm{MWD} / \mathrm{MTM})$ was achieved at a maximum metal temperature of approximately $465 \mathrm{C}(870 \mathrm{~F})$. Comparison of dimensions before and after irradiation indicates that the volume change in the region of maximum exposure was about $0.8 \%$.

There is an extreme lack of gas release information. Hayward ${ }^{22}$ of AI reported gas release values for thorium-11 wt $\%$ uranium ${ }^{23}$ irradiated to 1.2 atomic $\%$ burnup $(\approx 12,000 \mathrm{MWD} / \mathrm{MTM})$. Fission gas release averaged about $0.5 \%$ for round specimens after burnups of 1.2 to 1.3 atomic \% (12,000 to 13,000 MWD/MTM) at about $595 \mathrm{C}$ $(1100 \mathrm{~F})$. This release was ascribed to diffusion and recoil; cracked specimens exhibited higher gas release.

\section{Physical Properties}

The influence of uranium addition upon the room temperature density of thorium was determined by Blumenthal of ANL. ${ }^{24}$ The density increased linearly and had a slope change at 1.4 wt \% uranium, the limit of solid solubility at room temperature. The $5.4 \mathrm{wt} \%$ uranium composition was irradiated by Ballif of $\mathrm{AI},{ }^{19}$ and the density was found to be unaffected up to 0.13 atomic $\%$ burnup $(\approx 1300$ MWD/MTM). Farkas of $\mathrm{BMI}^{25}$ also determined densities for varying compositions and reported small differences depending upon impurity content. All three investigations are in substantial agreement. 
Lamale of $\mathrm{BMI}^{26}$ determined the effect of neutron irradiation upon thermal expansion of thorium-11 wt \% uranium and found a 10 to $35 \%$ increase depending upon the test temperature (not the irradiation temperature). Wilson of $\mathrm{BMI}^{27}$ determined the mean thermal expansion coefficient of thorium-2 wt \% uranium by $X$-ray diffraction to 950,1150 , and $1325 \mathrm{C}(1742,2102$, and $2417 \mathrm{~F})$.

The thermal conductivity for eight compositions from pure thorium to $20 \mathrm{wt} \%$ uranium was calculated by Bentle of $\mathrm{AI}^{13}$ using electrical resistivity and the Wiedemann-Franz ratio. The thermal conductivities increased with temperature and decreased with increasing uranium content. The knowledge of thermal conductivity and expansion is considered insufficient for necessary fuel characterization.

\section{$\underline{\text { Plutonium }}$}

The use of plutonium in place of uranium as the fissionable material will probably not introduce new problems. Although the thorium-plutonium-uranium ternary has not been completely defined, work by Blumenthal of $\mathrm{ANL}^{28}$ indicates that, for the temperatures and composition under consideration for the HWOCR, the plutonium will be in solid solution rather than in new or liquid phases. Until uranium is bred into the alloy, the microstructure is monophasic alpha-thorium; upon achieving approximately 1.5 atomic \% uranium, gamma-uranium starts to precipitate. If the precipitate is fine and well dispersed, the behavior should be that of the comparable thorium-uranium alloy; however, if the uranium is present in larger aggregates, nonuniform swelling and gas bubbles may result.

\subsection{4. Problem Aréas.}

The irradiation experiments to date show thorium alloys to be highly resistant to swelling and other deleterious effects of irradiation, especially below $600 \mathrm{C}(1100 \mathrm{~F})$; however, data must be obtained for the specific composition and thermal conditions of the HWOCR reference thorium fuel. This added information is necessary to ensure adequate knowledge for optimization of core design. Similarly, thermal conductivity, thermal expansion, and compatibility with an organic coolant of varying moisture content must be definitely established. 


\subsubsection{Technical Approach}

The experimental program is divided into two parts, considered separately.

Fuel Alloy Irradiation Behavior

The specific swelling of thorium-uranium alloys as a function of temperature will be investigated. Experimental parameters will include chemical composition, impurity content, and burnup. Attention will also be given to the dispersion of the alpha-uranium phase. Six chemical compositions will be considered:

\begin{tabular}{ccc} 
Uranium, wt \% & Zirconium, wt \% & Thorium \\
\cline { 2 - 2 } 1.5 & -- & Balance \\
2 & -- & Balance \\
2.5 & -- & Balance \\
1.5 & 1.0 & Balance \\
2 & 1.0 & Balance \\
2.5 & 1.0 & Balance
\end{tabular}

According to Bentle's $\mathrm{s}^{4}$ equilibrium phase diagram for $1.5 \mathrm{wt} \%$ uranium, about 0.5 wt \% alpha-uranium should be present at equilibrium below $650 \mathrm{C}(1100 \mathrm{~F})$; at $2.0 \mathrm{wt} \%$ uranium about $1 \mathrm{wt} \%$ alpha-uranium should be present; at 2.0 wt \% uranium about $1.5 \mathrm{wt} \%$ alpha-uranium should be present. This selection of compositions, therefore, not only brackets the composition of interest, but also allows determination of the effects of varying quantities of alpha-uranium, which is precipitated in the alphathorium matrix. The carbon, nitrogen, and oxygen contents will be maintained at values representative of the typical level of contamination. Three temperatures in the range from 400 to $650 \mathrm{C}(750$ to $1200 \mathrm{~F})$ and three burnup levels, 0.5 to $0.6,1$ to 1.2 , and 2 to 2.4 atomic $\%$ (5000 to $6000,10,000$ to 12,000 , and 20,000 to $24,000 \mathrm{MWD} / \mathrm{MTM})$, will be achieved. It is estimated that the burnup ranges will require approximately 1,2 , and 4 calendar years of irradiation, respectively, in a typical thermal neutron flux provided by a materials test reactor. These specimens will be prepared from stock that has been extruded. The experiment should be performed three times to definitely establish the experimental results and could probably be accommodated in six irradiation 
capsules. The effect of irradiation on density and dimensional stability will be determined in this series of tests.

The second phase of the inreactor testing is to determine swelling of the fuel alloy restrained by cladding. The specific fuel swelling will be determined radially and axially on extruded cylinder specimens at various temperatures for various experimental parameters. The chemical composition will be maintained at thorium -2 wt \% uranium-1 wt \% zirconium. The impurities will be maintained at a constant, typical level. Temperature and burnup will range within the same limits used in the first phase, but only two temperatures and two burnups will be selected. The specimens will be coextruded cylinders approximately 1 to $1-1 / 2$ inches in diameter, 1/8 inch in fuel thickness, and 10 inches in length. Cladding thickness will be 0 (bare), 15, 20, and 30 mils. This experiment will probably be accomplished in eight capsules.

Physical and Corrosion Properties Outreactor

The mechanical properties are believed to be sufficiently well known for reactor design and need not be further explored at this time, except in conjunction with the normal preirradiation and postirradiation testing of irradiation specimens.

The thermal conductivity of the reference alloy has not been positively established by direct methods. The thermal conductivity will be determined as a function of temperature through the operating range, and the effect of compositional variation will also be investigated.

The thermal expansion must be determined for the operating temperature range and for the expected compositional variation.

The compatibility of the fuel alloy and cladding with the organic coolant has not been fully investigated. A survey experiment is therefore planned to establish this characteristic, which is important for hazards analysis. Specimens of the reference fuel alloy and cladding will be exposed outreactor to flowing organic coolant at temperatures of $150,260,370$, and $480 \mathrm{C}(300,500,700$, and $900 \mathrm{~F})$ for times ranging from a few hours to several weeks, depending upon 
the observed reaction. The experiment will be performed for organic coolant containing low, nominal, and high moisture content.' Analysis will be accomplished by metallographic examination and weight change measurements to determine the extent and nature of the reaction.

\subsubsection{Summary}

An experimental program to characterize the reference fuel has been outlined. The following investigations are proposed:

1. The specific swelling under neutron irradiation as a function of temperature will be determined. Experimental parameters will include chemical composition, impurity content, and burnup. The dispersion of alpha-uranium will be considered.

2. A related investigation is the determination of fuel swelling restrained by cladding. Extruded cylinders with varying thicknesses of cladding will be irradiated. The effects of temperature and burnup will be examined.

3. The thermal conductivity will be determined for temperatures through the operating range. The effect of compositional variation will be considered.

4. The thermal expansion will be determined for the operating temperature range.

5. The compatibility of fuel alloy and cladding with the organic coolant will be surveyed at various temperatures and moisture contents.

3. 2. 3. Subtask 24 - Fuel Element Engineering Tests

\subsubsection{Objective}

The objective of this subtask is to perform outpile engineering tests on the thorium metal nested-cylinder fuel element to obtain information for design optimization and to demonstrate the structural adequacy of the fuel element for operation in an HWOCR. The objective of each test is described below:

1. Thermal Cycling Test is to determine the ability of the fuel element cladding to withstand thermal strain caused by changes in fuel temperature. 
2. Hydraulic and Vibration Test is to determine the hydraulic and vibration characteristics of a nested-cylinder fuel element.

3. Structural Loading Test is to determine the adequacy of the fuel element to resist structural loads at reactor operating temperatures.

4. Full-Scale Flow Test is to demonstrate the adequacy of the $1000 \mathrm{MWe}$ HWOCR thorium metal nested-cylinder fuel element to withstand hydraulic and vibration effects.

\subsubsection{Course of Action}

Four basic engineering tests will be conducted:

1. Thermal Cycling Test. 'The Zircaloy cladding of the cylindrical thorium fuel element will experience thermal strain because of temperature gradients through the cylinder wall and differential expansion between the fuel and the cladding. Specimens will be thermally cycled until a predetermined number of cycles or fatigue failure occurs.

2. Hydraulic and Vibration Test. Flow testing of fuel elements (representing an interim design) will be performed in low-temperature and low-pressure water. Flow testing is required for fuel elements to be irradiated in WR-1. Information gained from these tests will also be used in the fuel element design (Subtask 21).

3. Structural Loading Test. A test will be performed at elevated temperatures to determine the effect of long-time column loads on the fuel cylinders.

$$
\text { 4. Full-Scale Flow Test. A flow test of the } 1000 \mathrm{MWe}
$$
HWOCR thorium fuel clement will be performed outpile in a hot organic loop.

\subsubsection{Status of Technology}

Limited testing of thorium nested-cylinder fuel, elements has been done at PNL and SRL. This test work has been aimed primarily at determining irradiation behavior. Tests similar to those proposed for the HWOCR have not been performed on thorium cylinders. The specific status of the tests is as follows: 
1. Thermal Cycling Test. For some time PNL has attempted to derive equations to analyze the effects of thermal cycling on the integrity of the junction between the end cap, the cladding, and the fuel. So far complete success has not been attained. To our knowledge, no testing has been performed in this area.

2. Hydraulic and Vibration Test and Full-Scale Flow Test. Some limited flow testing of thorium-uranium fuel assemblies. ( 10 feet long) has been performed at SRL (DP 943). The assemblies consisted of only one fuel cylinder and inner and outer housing tubes (not bearing fuel). Flow testing was accomplished in $260 \mathrm{C}$ water having a flow rate of $150 \mathrm{gpm}$. This flow rate is considerably lower than that expected in the thorium-fueled HWOCR, and results obtained from the SRL test may not be applicable to organic-cooled HWOCR fuel elements.

It is well known 29,30,31 that high-velocity coolant flow parallel to a fuel element assembly may induce vibrations in the assembly. This phenomenon is not well enough understood to satisfactorily determine vibratory response by using only analytical techniques; therefore, testing is considered essential. Unpublished B\&W-sponsored R\&D in this area further substantiates the need to investigate the phenomena of parallel-flow-induced vibration.

3. Structural Loading Test. Structural proof tests of the type proposed have not been performed on components of coextruded nested-cylinder fuel elements.

\subsubsection{Problem Areas}

Various mechanical, thermal, and hydraulic problems in the nested-cylinder design are better solved by experimentation than by analytical techniques. These problems are outlined below:

1. Thermal Cycling Test. Temperature gradients and thermal differential expansion in the end cap region of the cylindrical fuel element will cause thermal strains in the Zircaloy cladding. Because of power transients and reactor shutdowns, strain cycling will take place in the fuel element cladding. If the amplitude of the cycling is too severe or the number of cycles is too great, cladding failure may take place. Thermal strain limits must be known to design against failure. 
2. Hydraulic and Vibration Test and Full-Scale Flow Test. Hydraulic parameters of the thorium nested-cylinder fuel element are not established, and such items as flow distribution and pressure drops are required. Vibration of the fuel element components (individual cylinders) is not considered to be a problem if there is no backlash between nested cylinders. However, vibration of the fuel element assembly and the associated fretting and wear against the pressure tube may be a problem.

3. Structural Loading Test. Axial loads are imposed on the fuel elements by the weight of the fuel column, by hydraulic loads, and by a preload applied by the structural supports for the fuel assemblies within the pressure tube. Analysis has shown that it is desirable to carry the axial loads on the outer cylinders since they have the best structural integrity as a column. The effects of these long-time sustained loads on the creep buckling behavior of the fuel element need investigation.

\section{2. 3.5. Technical Approach}

Representative test fuel elements will be fabricated for use in the engineering tests. Suitable test facilities can be provided at $B \& W$ 's Alliance Research Center. Information gained from the tests will be used to ensure the adequacy of the fuel elements and to further refine the fuel element design.

1. Thermal Cycling Test. Coextruded cylindrical specimens, including end caps, will be thermally cycled (outpile) from 300 to $850 \mathrm{~F}$ until signs of cladding fatigue are detected or until the maximum feasible number of cycles has been accumulated. Time-dependent and irradiation effects will probably have a significant influence on the ability of the cladding to withstand thermal cycling. Therefore, some thermal cycle testing may be performed on cylinders fabricated to simulate as closely as possible the expected material effects of irradiation and time. Approximately six specimens will be tested. Different specimen sizes will be included in the total number of specimens to be tested; the actual sizes will be determined later. 
2. Hydraulic and Vibration Test. Fuel element assemblies will be tested in a water loop to determine the hydraulic and vibration characteristics of the interim fuel element design prior to ir radiation testing. A water loop will be used to simplify the testing and reduce the cost. Adequate extrapolation of water environment test results can be made to apply to the HWOCR organic coolant operating conditions.

Flow velocities in the range of 30 to $45 \mathrm{fps}$ and temperatures of about 180 to $200 \mathrm{~F}$ will be used. Later flow tests of the 1000 MWe HWOCR fuel element will be performed in organic coolant at reactor operating conditions. The axial load expected on the fuel element will be simulated in the test. The determination of the resonant frequency of individual fuel cylinders by bench testing or shaker testing is not presently contemplated for this type of fuel element. The test will determine the flow distribution between the various annuli, the entrance and exit losses for the fuel element, the pressure drop across the fuel element, the effect of the spacers, the degree of vibratory response of the assembly, and some fretting and wear characteristics of the fuel element and pressure tube combination. Two fuel elements will be required for testing.

3. Structural Loading Test. The need for this test will be based on the results of analytical investigations of the fuel element creep buckling characteristics and creep testing of the fuel material proposed for Subtask 23. If testing is necessary, one cylinder of the fuel assembly will be subjected to loads representative of those expected during reactor operation. The loaded cylinder will be heated to a temperature between 800 and $1000 \mathrm{~F}$ and maintained at this temperature for about 12 to 18 months. At the conclusion of this time, measurements will be made to determine the amount of creep buckling that has taken place in the fuel cylinder.

4. Full Scale Flow Test. Fuel element assemblies will be tested in a hot organic loop to determine the hydraulic and vibration characteristics of the $1000 \mathrm{MWe} \mathrm{HWOCR}$ fuel element design. An or ganic loop will be needed to confirm that the fuel element design is adequate for operation at simulated HWOCR conditions. Flow velocities in the range of 30 to $45 \mathrm{fps}$, temperatures of about 750 to $850 \mathrm{~F}$, and pressures of about 400 psi will be used. 
Engineering tests will be performed to obtain information necessary for design optimization and to demonstrate the adequacy of the fuel element for operation in a 1000. MWe HWOCR. Tests to be performed include the thermal cycling test, hydraulic and vibration test, structural loading test, and full-scale hydraulic flow test.

3. 2. 4. Subtask 25 - Thorium Alloy Fuel Element Assembly Irradiation Tests

\subsubsection{Objestive}

The objective of this subtask is to determine the operational behavior of the reference fuel element assembly under conditions closely simulating those of the HWOCR.

\subsubsection{Course of Action}

The fuel element assemblies will be irradiated in a succession of at least five experiments, progressively developing confidence in the behavior of thorium alloy nested-cylinder fuel elements for the HWOCR. The final step will be a proof test in the WR-1 under conditions as closely representative of the HWOCR as are reasonably attainable.

\subsubsection{Status of Technology \\ Prior irradiations of thoriumi-uranium alloy} cylinders are discussed in section 3.2.2. 3.

\subsubsection{Problem Areas}

The major problems that need to be investigated are (1) the dimensional stability of the fuel element during irradiation, (2) the mechanical and structural integrity of the fuel element during irradiation, and (3) the effect of organic fouling during irradiation on the thermal and hydraulic performance of the fuel element.

\subsubsection{Technical Approach}

A number of multicylinder fuel element assembly irradiation tests will be performed in the WR-1 reactor to obtain information on operational performance at simulated HWOCR conditions. 
A preliminary evaluation previously determined the feasibility of irradiating in the WR-1 an existing thorium-1.5 wt \% uranium fuel tube available from the HWCTR program at SRL. A more detailed evaluation will determine the practicality and desirability of ir radiating this tube, but this experiment is not considered an integral part of the test program discussed below.

The first irradiation experiment in the WR-1 reactor is a demonstration of the feasibility of the multicylinder design. This initial inreactor investigation will necessarily reflect the tubular designs developed at PNL and-NMI/SRL. The multicylinder design will have appropriate length and diameter for the WR-1. This fuel element will be designed for operation at reduced power. The operational characteristics will be studied and will provide design information for further testing. The specific information obtained will include power and temperatures achieved and dimensional stability. From destructive analysis, the gas release, corrosive effects (including the extent of hydriding of the cladding), and other physical and microstructural observations will be obtained.

The second irradiation experiment in the WR-1 reactor is similar to the first except that power will be increased and physical and functional design features applicable to the HWOCR will be incorporated. Information from the first experiment will be considered as it is received. Since the programs will overlap in time, the full benefit of experience with the first experiment will not be realized in the second.

The third irradiation experiment in the WR- 1 reactor is similar to those preceding except that the improved design will be based on the experiences of the first two experiments. The results of this experiment will help establish the prototypic design- parameters for the HWOCR.

The fourth irradiation experiment in the WR-1 reactor will test the operational performance of a near-prototypic fuel element modified in diameter to be accommodated in the WR-1. Defect testing is also planned.

The fifth irradiation experiment in the WR- 1 reactor will continue to test the operational characteristics of a reference 
design fuel element. Information obtained from the fourth ir radiation will be incorporated in this experiment. The results obtained will contribute to the design of the reference $1000 \mathrm{MWe}$ HWOCR thorium fuel element.

If the need for additional irradiation experiments is indicated, they will be further described in amendments to this document. It is presently not feasible to predict needs arising from future experimental work.

\subsubsection{Summary}

The planned irradiation program will determine the operational behavior of the reference fuel element assembly under conditions closely simulating those of the HWOCR. At least five irradiation experiments will be performed in the WR-1 reactor. They will start with initial irradiations of a multicylinder fuel element assembly based on current technology and culminate in the irradiation of a prototype of the reference fuel element assembly. The results obtained will contribute to the final design of the $1000 \mathrm{MWe} H W . O C R$ thorium fuel elerrent.

\section{3. Thorium Oxide Fuel Element Test Program}

3. 3. 1. Subtask 22 - Thorium Oxide Fuel Element Fabrication Development

\subsubsection{Objective}

The objective of this subtask is to develop the fabrication processes for the $1000 \mathrm{MWe}$ HWOCR thorium oxide fuel element, including the necessary manufácturing procedures and inspecllum techniques.

\subsubsection{Course of Action}

The present technology for thorium oxide is more advanced than that for thorium metal or monocarbide; therefore, less development effort will be required to produce acceptable oxide fuel elements. The work will be aimed primarily at fabricating fuel pins of the desired shape and size with acceptable and reproducible densities and fuel mass variations per unit length of fuel pin. The 
fabrication development will provide specimens and fuel elements for fuel characterization and irradiation tests.

\subsubsection{Status of Technology}

The vibratory compaction process has been investigated over the past few years at many laboratories, such as HAPO (now PNL), 32-35 GE at San Jose, 36,37 ORNL, 38-40 Combustion Engineering, ${ }^{41} \mathrm{SRL},{ }^{42}$ and B\&W. ${ }^{43-45}$ In addition, Euratom ${ }^{46}$ at several European laboratories has sponsored work involving the Vipac process; there have also been recent Japane $\mathrm{e}^{47}$ investigations into the Vipac process. Most workers have particular methods and innovations peculiar to their specific needs and equipment; therefore, correlation of results is often difficult. For this reason, the particular parameters of interest (for example, height and weight variations of the fuel column, density and fuel mass variations) must be established for the particular process, feed material, and fuel pin size and shape used.

Basically, fabrication of fuel pins by vibratory compaction consists of the following steps:

1. Feed material preparation including synthesis and sizing of the dense particles.

2. Introduction of fuel powder into the fuel tube with vibration.

3. Further compaction of the fuel column by vibration.

4. Measurement of fuel column height and weight.

5. Final end capping and nondestructive testing of weld integrity.

6. Nondestructive measurement of fuel mass variations per unit length of fuel pin.

7. Cleaning, final dimensional inspection, and identification.

8. Assembly of pins into fuel elements.

Fuel tubes having one end cap welded and inspected are introduced as one of the incoming components for the process.

Based on present procedures and fuel feed materials used at $B \& W$, it is anticipated that densities in the range of $87 \pm 1 \%$ of theoretical density could be maintained and that fuel mass 
variations (based on a 1 -inch scran length as the unit length) of $7 \pm 3 \%$ could be achieved. Fuel column height and weight variations commensurate with the density range would be on the order of \pm 1 inch and \pm 20 grams, respectively. All of these parameter ranges are based on experiments with fuel pins 10 feet long and 0.390 inch in inside diameter.

\section{3. 1.4. Problem Areas}

Work would consist of vibratory compacting an acceptable fuel feed material sized to an appropriate dimension for the particular HWOCR oxide pin size and shape and establishing the density and mass variation to a statistically dependable value. Irradiation specimens shorter than approximately 18 to 24 inches present a particular problem in fabrication since it is difficult to scale down the exact physical parameters that can be obtained in the larger pins; experimentation would therefore be necessary to establish the physical parameters in small capsule irradiation specimens. No major fabrication problems are expected as a result of using SAP cladding.

\subsubsection{Technical Approach}

This subtask, which can be performed at B\&W, is aimed at developing statistically reliable values for the various fabrication-related physical properties in the HWOCR fuel pins that affect reactor performance.' As previously discussed, these parameters are not anticipated to be greatly different from those established on fuel pins for pressurized water power reactors. The program can be subdivided into three parts: (1) preparation of suitable feed material, (2) optimization of physical parameters (density, mass variation, particle size distribution) in the full-sized HWOCR fuel pin (42 inches long by 0.447 inch in diameter by 0.020 inch of SAP cladding) produced by compaction, and (3) optimization of physical parameters in the small capsule irradiation specimens.

To achieve high fuel column densities, the feed material required for vibratory compaction must have a high particle density (greater than $98 \%$ of theoretical) and must not have excessive sorbed gas content. There are four possible techniques to obtain this type of material; arc fusion, crushed slugs, sol-gel, and pneumatic impaction. The latter three are the most economical; the sol-gel 
technique has the greatest technical advantage at the present time. It has been demonstrated ${ }^{40}$ that the sol-gel and vibratory compaction techniques can be successfully coupled in a semiremote facility. Recent $B \& W$ experience has shown that this process can also be used in a glovebox type of operation. A complete characterization of the fuel material, as produced for the HWOCR program, is necessary however. The sorbed gas content must be well known and low, and the uranium-to-thorium ratios and $O / M$ ratio must be very well known in the small quantity of powder produced for the irradiation experiments.

It will be necessary to obtain, on a statistical basis, routinely achievable characteristics such as bulk fuel density, mass variation, and column height and weight values and variations. These data will be used to realistically set future production variables. A pilot run of from 200 to 400 pins will be required.

When fabricating fuel pins less than 1 to 2 feet long by the Vipac process, difficulty is encountered in obtaining properties equivalent to those obtained in longer pins. The primary reason is that the zone of interaction, where the various powder particle sizes fit together into the proper packing, is generally longer than 8 to 10 inches. It is necessary that this zone be operable to achieve uniformly high densities. In shorter pins this zone is abbreviated to the point of having negligible effect, depending upon the length of the pin. Some work will be necessary to obtain properties for the small capsule irradiation specimens that would be equivalent to the properties for the longer, full-sized HWOCR fuel pins.

Fabrication of pins into fuel elements will require a regular mechanical assembly procedure utilizing applicable techniques developed under the AI-CE program. Additional fabrication development is not planned except as required to adapt assembly methods to equipment at $B \& W$.

Procedures developed in this subtask will be made compatible with recycle and remote handling methods (Task 30 ) and will permit expansion to full-core production quantities.

\subsubsection{Summary}

A program has been outlined for the development of thorium-dioxide-fueled, vibratory-compacted pins. Sol-gel 
material is considered to be most applicable. It will be vibratorily compacted in SAP tubes, and the necessary production variables will be established.

\section{3. 2. Subtask 23 - Thorium Oxide Fuel Characteristics}

\subsubsection{Objective}

The objective of this subtask is to characterize thoria-urania fuel by inreactor and outreactor testing.

\subsubsection{Course of Action}

Necessary fuel materials properties that are not adequately known will be determined or verified under conditions applicable to the HWOCR. Investigations of the SAP cladding material will be performed by AI-CE, except when specifically related to thoriaurania fuel.

\subsubsection{Status of Technology}

Thermal Conductivity

The thermal conductivity of thoria-based nuclear fuels has been investigated only to a limited extent, probably not sufficient for completely accurate design or reliable prediction for the reactor lifetime.

For thoria, or thoria with less than 15 wt $\%$ urania, the thermal conductivity has a relatively low value, characteristic of refractory oxide materials. ${ }^{48,49}$ The thermal conductivity up to the melting temperature has not been evaluated to date because of limitations in expcrimenting at high temperatures. Data obtained below about $1400 \mathrm{C}(2550 \mathrm{~F})$ have shown that thermal conductivity decreases with increasing temperature; 0.03 watt $/ \mathrm{cm}-\mathrm{C}(1.73 \mathrm{Btu} / \mathrm{hr}-$ $\mathrm{ft}-\mathrm{F})$ is a typical value at $1400 \mathrm{C}(2550 \mathrm{~F})$. The conductivity also de creases with increasing urania concentration and increasing bulk body porosity.

Some questions exist regarding the closeness to stoichiometric composition of the thoria-urania specimens utilized in some of the reported thermal conductivity investigations. For example, in Kingery's $\mathrm{s}^{5}$ work, the specimens were fabricated by air 
firing for several hours at $1540 \mathrm{C}(2805 \mathrm{~F})$. Kingery indicated the composition of his specimens as $\left(\mathrm{Th}_{0.9} \mathrm{U}_{0.1}\right) \mathrm{O}_{2}+\mathrm{x}$, showing oxygen content beyond the stoichiometric composition due to heating in air above $500 \mathrm{C}$ $(930 \mathrm{~F})$. Increased oxygen content lowers the thermal.conductivity. 51,52 The thermal conductivity of compacted powders, like that of presintered pellets, is the sum of heat transfer by lattice conduction and radiation. However, the lattice conduction contribution is reduced because of the loss of fuel lattice matrix continuity. Heat is transferred by gaseous conduction across the spacings between powder particles and directly at the points of particle contact. The gas is considered the continuous phase. At higher temperatures, the powder sinters to form a porous mass and undergoes microstructural alteration similar to that of presintered pellets at these higher temperatures; therefore, the effective thermal conductivities of the sintered "powder" and pellet are similar. However, the average integrated thermal conductivity of the powder fuel pin would remain lower in value than that of the pellet because of the insulating effect of the unsintered powder in lower temperature regions of the fuel pin.

In a study of the the rmal conductivity of powder, ${ }^{53}$ several theoretical models were considered. Excellent agreement was found between a model suggested by Godbe ${ }^{54}$ and experimental values for magnesia, alumina, and zirconia powders in air at atmospheric pressure and temperatures from 95 to $815 \mathrm{C}$ (200 to $1500 \mathrm{~F})$. However, this model is applicable only to a well characterized powder (having known bulk thermal conductivity and particle size, shape, and distribution) and to a gas system for which the physical constants are established.

The parameter, $\int_{T_{1}}^{T_{2}} \lambda d \theta$, known as the heat rating, has been used $d^{55}$ to describe the integrated thermal conductivity of $\mathrm{UO}_{2}$. (Thermal conductivity values are obtainable by differentiation of the heat rating with respect to temperature.) The integral limits (temperatures) can be obtained by noting the temperature required to cause observed microstructural changes. However, no definitive correlation has been established for thoria-urania, although a start has been made in this direction. ${ }^{56}$ Irradiation studies ${ }^{57}$ of presintered thoria-6.5 wt \% urania pellets indicate that the high-temperature thermal conductivity of 
thoria-urania is the sum of lattice conductivity and radiant energy transfer, similar to that observed for urania. This result was developed from the observation that the onsel of fuel-void redistribution (structural alteration by columnar grain formation) by a sublimation-condensation mechanism was indicated to have occurred at about $2400 \mathrm{C}$ $(4350 \mathrm{~F})$. It is interesting to note that Neimark ${ }^{52}$ calculated that the occurrence of this microstructural change in pure thoria was between 2150 and $2400 \mathrm{C}(3900$ and $4350 \mathrm{~F}$ ). He used vapor pressure data and the urania vapor pressure-sublimation model. 58

$\mathrm{RaO}^{59}$ of AECL has reported ${ }_{4 \mathrm{j}}^{\mathrm{m} n \mathrm{C}} \mathrm{cd \theta}$ values of 67 to 77 watts $/ \mathrm{cm}$ (26 to $30 \mathrm{kw} / \mathrm{ft}$ ) for $\mathrm{ThO}_{2}-5$ to $19 \mathrm{wt} \% \mathrm{UU}_{2}$ pellets having $95 \%$ of theoretical density. However, pellets of $\mathrm{ThO}_{2}-2.7 \mathrm{wt} \% \mathrm{UO}_{2}$ did not melt or form columnar grains at 72 watts $/ \mathrm{cm}(28 \mathrm{kw} / \mathrm{ft})$. Bain of AECL ${ }^{60}$ obtained an $\int_{400 \mathrm{c}}^{2150 \mathrm{c}} \mathrm{xd \theta}$ value of 57.5 watts $/ \mathrm{cm}(22 \mathrm{kw} / \mathrm{ft})$ for $\mathrm{ThO}_{2}-$ 2.2 wt $\% \mathrm{UO}_{2}$ pellets having $95 \%$ of theoretical density.

Based on these data, an ${ }_{0}^{\text {melt }}$ ido versus temperature plot was constructed by Gross and $\mathrm{Harbinson}{ }^{61}$ for $\mathrm{ThO}_{2}-2$ wt $\% \mathrm{UO}_{2}$ pellets. Kingery's $\mathrm{s}^{50}$ low-temperature thermal conductivity data were taken for the low-temperature lattice conduction component and expressed as $\int_{0}^{80 n c .} \lambda d \theta$. Bain's value of $\int_{400 \mathrm{C}}^{2150 \mathrm{C}} \mathrm{\lambda d}_{\mathrm{d}}$ was appropriately plotted on the $\int \lambda d \theta$ curve and was used to interpolate between 800 to $2150 \mathrm{C}$; the curve was then extrapolated to the melting temperature. This results in an $j_{0}^{\text {melt }} \lambda d \theta$ value of 148 watts $/ \mathrm{cm}$.

A further inferred analysis was performed to construct the $\int_{0}^{\text {melr }} \lambda \mathrm{de}$ curve for vibratory compacted $\mathrm{ThO}_{2}-\mathrm{UO}_{2}$ powders. A $50 \%$ reduction was made in the lattice conduction component up to $1900 \mathrm{C} \cdot(3450 \mathrm{~F})$, selected as the "sintering temperature;" beyond this temperature the pellet expression was used. This procedure was found to be satisfactory for urania ${ }^{62}$ and was therefore adopted for thoria-urania. This results in an $j_{0}^{m e l t}$ de value of 97 watts $/ \mathrm{cm}$.

Results of irradiation experiments with $\mathrm{ThO}_{2-}$

5 wt $\% \mathrm{UO}_{2}$ vibratory compacted powder conducted by Olsen et al. of ORNL ${ }^{63}$ tend to support the previous analysis. Test rods were operated at linear heat ratings of 1000 watts $/ \mathrm{cm}(30.5 \mathrm{kw} / \mathrm{ft})$ where $\int_{0}^{\text {center }} \lambda d \theta$ was 100 watts/cm without central melting. The linear heat rating was sufficient to produce central voids and columnar grain growth. Olsen ${ }^{64}$ also stated 
that a $40 \%$ higher power rating would be required to produce similar microstructural changes in $\mathrm{ThO}_{2}-5$ wt $\% \mathrm{UO}_{2}$ compared with. $\mathrm{UO}_{2}$. A typical value of $\int_{0}^{\text {melt }} \lambda d \theta$ for $\mathrm{UO}_{2}$ powder is 65 watts $/ \mathrm{cm} ; 62$ applying Olsen's $40 \%$ correction would increase $\int_{0}^{\text {melt }} \lambda d \theta$ to 91 watts $/ \mathrm{cm}$ for $\mathrm{ThO}_{2}-5 \mathrm{wt} \%$ $\mathrm{UO}_{2}$. Clearly, additional investigation is required.

Another problem in the understanding of the thermal conductivity of oxide fuels is the effect of porosity. Numerous relationships have been proposed ${ }^{65}$ to correct thermal conductivity of test specimens to that of theoretically dense material. A study is being pursued at Bettis Atomic Power Laboratory ${ }^{66}$ to quantitatively analyze the correction factor. The effects of such variables as pore shape, pore size, ánd orientation are being evaluated. Publication of this study is anticipated by the end of 1966.

\section{Fission Gas Release}

The only fission gas release data available for thoria-urania powder are from the ORNL sol-gel experiments reported by Olsen. ${ }^{63}$ Fuel pins containing sol-gel and arc-fused vibratorily compacted $\mathrm{ThO}_{2}-4.5 \mathrm{wt} \% \mathrm{UO}_{2}$ were irradiated to burnups of 12,000 to 81,000 MWD/MTM ( 1 to 6 atomic \%) at peak linear heat ratings of approximately 325 watts $/ \mathrm{cm}(10 \mathrm{kw} / \mathrm{ft}) ; \int_{0}^{\text {center }} \lambda d \theta$ was 32 to 38 watts $/ \mathrm{cm}$. Based on $\mathrm{Kr}-85$ analysis, slightly higher gas release is indicated for the sol-gel material than for the arc-fused material (17\% compared to $7 \%$ ). According to Olsen, the principal factor in gas release at these heat ratings is the time at temperature, which behavior is expected with a diffusion-controlled mechanism.

To study the effect of high heat ratings, ORNL irradiated vibratorily compacted $\mathrm{ThO}_{2}-5$ wt $\% \mathrm{UO}_{2}$ sol-gel powder fuel pins at peak linear heat ratings of 1000 watts $/ \mathrm{cm}(30.5 \mathrm{kw} / \mathrm{ft})$ where $\int_{0}^{\text {center }} \lambda d \theta$ was 100 watts $/ \mathrm{cm}$ to burnups beyond 20,000 MWD/MTM (1.3 atomic \%). The gas release values were less than $30 \%$. There were indications that the calcining atmosphere (in the preparation of the oxide powder) influences the release rates. Fuel that had been calcined in air showed a $39 \% \mathrm{Kr}-85$ release compared to $28 \%$ for material calcined in the standard atmosphere of argon and $4 \% \mathrm{H}_{2} \mathrm{O}$. The linear heat ratings were sufficient to produce central voids and columnar grain growth. 
Investigations are required to establish positively the fission gas release properties of thoria-urania powder and to determine the pressure buildup during reactor operation.

\section{Chemical Compatibility}

The chemical compatibility between $\mathrm{ThO}_{2}-2$ wt $\% \mathrm{UO}_{2}$ and SAP may be viewed as two separate problems. First, the alumina dispersed in the SAP and present as surface oxide film must be compatible with the oxide fuel. Second, the aluminum matrix must also be reasonably nonreactive with the fuel at the temperatures of interest. In the current fuel design the fuel surface temperature is approximately $650 \mathrm{C}(1200 \mathrm{~F})$ at $100 \%$ power, the cladding inner temperature being approximately $470 \mathrm{C}(880 \mathrm{~F})$. At these temperatures, solid-state reactions between the oxide phases are extremely unlikely and certainly are not indicated in existing equilibrium phase diagrams.67, 68

The HWOCR SAP Handbook' states that " $\mathrm{UO}_{2}$ has been shown to be compatible with XAP001 (ML57) at $1100 \mathrm{~F}$ for 5000 hours. ${ }^{1170}$ Considering this statement and the rather low concentration of $\mathrm{UO}_{2}$ in the reference oxide fuel, the $\mathrm{UO}_{2}$ constituent is not expected to present a compatibility problem. Reduction of $\mathrm{ThO}_{2}$ by aluminum to form alumina and thorium is energetically impossible at these temperatures (in straightforward solid-state reactions), since the free-energy change for the process is over $40 \mathrm{kcal} / \mathrm{mol}$ of $\mathrm{Al}_{2} \mathrm{O}_{3}$ (positive). ${ }^{71}$ At $\mathrm{SRL}^{72}$ a mixture of aluminum powder and $\mathrm{ThO}_{2}$ powder (or $\mathrm{UO}_{2}$ powder in other experiments) was baked for 16 hours at $575 \mathrm{C}(1065 \mathrm{~F})$ in a vacuum and was then extruded at $450 \mathrm{C}(840 \mathrm{~F})$ in an aluminum can. Although not specifically discussed in the report, macrophotographs shown do not reveal any signs of gross chemical attack or void formation due to melting or diffusion. However, Myrick and Folger of SRL, ${ }^{73}$ utilizing the results of Raleigh of $\mathrm{AI},{ }^{74,75}$ found that fine particles of aluminum and thoria were capable of reacting to form $\mathrm{ThAl}_{3}$ and alumina. In the solid state, the threshold temperature was given as near $560 \mathrm{C}$ (1040 F). For the situation existing in the HWOCR, where contact between the reactants is not nearly as intimate as that between the mixed powders and where the temperature upon contact is lower (the aluminum constitutes a heat sump for the fuel), the probability of the reaction occurring to any large extent is small. 
A critical evaluation of $\mathrm{ThO}_{2}-\mathrm{UO}_{2}$ phase equilibria studies ${ }^{76}$ by Hoekstra of ANL and Parker of NBS shows that the equilibrium phase is a solid solution over the entire composition range and that the lattice constant obeys Vegard's Law. The crystal structure is face-centered cubic.

\section{$\underline{\text { Plutonium }}$}

The use of plutonium dioxide in place of uranium dioxide as the fissionable material will probably introduce no new problems. Irradiation studies conducted at Hanford Laboratories (now $\mathrm{PNL})^{77}$ indicate that hydrogen-sintered $(\mathrm{Th}, \mathrm{Pu}) \mathrm{O}_{2}$ solid solution pellets in the composition range of interest for thermal reactor fuels (up to 5 wt $\% \mathrm{PuO}_{2}$ ) exhibited satisfactory irradiation performance to a burnup of $2.4 \times 10^{20}$ fissions $/ \mathrm{cm}^{3}(\approx 10,000 \mathrm{MWD} / \mathrm{MTM})$. During irradiation, (Th, $\mathrm{Pu}) \mathrm{O}_{2}$ recrystallized in the manner usually observed with $\mathrm{UO}_{2}$. Microstructures developed during irradiation were similar to those developed in $\mathrm{UO}_{2}$ and $\mathrm{UO}_{2}-\mathrm{PuO}_{2}$. It was deduced from a comparison of these structures that, in the low $(<5 \%) \mathrm{PuO}_{2}$ specimens, the power output would be 20 to $30 \%$ higher than that at the same fuel temperature in $\mathrm{UO}_{2}$. Further work will be directed toward determining gas release characteristics and fission product migration and identification. ORNL ${ }^{63}$ has ir radiated three fuel rods containing sol-gel $\mathrm{ThO}_{2}$ mixed with $\mathrm{PuO}_{2}$ before calcining. The rods were loaded by tamp packing. After exposure at linear heat ratings as high as 245 watts/cm to burnups of 29,000 MWD/ MTM, the fission gas release rates were less than $5 \%$ and the microstructures were similar to those of $\mathrm{ThO}_{2}-\mathrm{UO}_{2}$ exposed under similar conditions.

$\mathrm{PuO}_{2}$ and $\mathrm{UO}_{2}$ are isomorphous and otherwise chemically and physically similar. ${ }^{78}$ It would be expected that the substitution of plutonium dioxide for uranium dioxide in the thorium dioxide matrix in the concentrations required would not introduce substantial changes in the overall physical and chemical situation. The quaternary [(Th, $\left.\mathrm{Pu}, \mathrm{U}) \mathrm{O}_{2}\right]$ developed due to breeding in of uranium would probably behave as the ternary in the region of interest. 


\section{3. 2. 4. Problem Areas}

Further investigation is required to determine the thermal conductivity and gas release properties of the reference fuel and to determine the compatibility of fuel and cladding. The thermal conductivity investigation is particularly troublesome due to the possibility of large errors in the determination, the high temperatures that are necessary, and the added difficulty of working with powder. Internal gas pressure buildup is particularly important in the HWOCR because of the SAP cladding and the low external pressure on the fuel pin.

\subsubsection{Technical Approach}

Thermal Conductivity

The determination of the thermal conductivity of $\mathrm{ThO}_{2}-2$ wt $\% \mathrm{UO}_{2}$ vibralory compacted powder will require a comprehensive treatment if meaningful results are to be obtained. Inreactor and outreactor determinations, using both pellets and powder, will be necessary to firmly establish this property. Experimental determinations will be performed on two compositions, the reference composition and another composition having a greater uranium content.

Conventional thermal conductivity determinations will be performed on pellet material to $2000 \mathrm{C}(3630 \mathrm{~F})$ to establish the plot of thermal conductivity in this temperature range. This "pellet" curve will serve as a reference for the more difficult to establish "powder" curve: Outreactor thermal conductivity determinations will be performed on powder material to the highest attainable temperature. This will establish the plot of thermal conductivity in this temperature range for powder. Cognizance must be taken of sintering of the powder and the effect of irradiation upon conductivity in the application of these data.

Both pellet and powder fuel will be irradiated to central temperatures not exceeding $2000 \mathrm{C}(3630 \mathrm{~F})$. These specimens wiil be instrumented with thermocouples for temperature determination. Other specimens will be irradiated at sufficiently high power ratings to cause center melting, thereby producing a fiducial point. The radial location at which melting is first observed will be considered as operating at the melting point of the material. The radius of melting 
will be determined by metallographic observation of structure alteration and/or observation of melting in metal fuses properly located in the fuel body. Using burnup measurements, the heat rating $\left(\int \lambda \mathrm{d} \theta\right)$ will be obtained for the temperature of melting. This result is one point on the plot of heat rating versus temperature. The general shape of this plot may be obtained from consideration of uranium dioxide behavior. The outreactor thermal conductivity data expressed as heat rating will provide the lower end of the plot; gaps will be filled by interpolation. Differentiation of the curve of heat rating versus temperature will provide the curve of thermal conductivity versus temperature.

These irradiations will be brief, approximately three days, during which time the power levels of the specimens will be maintained as constant as practicable. This is necessary to minimize the error in calculating heat rating from fuel burnup determinations. It is anticipated that approximately 12 capsules will be required to accomplish the objectives of this experiment. Each capsule will contain approximately three specimens.

\section{Gas Release}

Internal pressure in a fuel element is a complex function of the initial fill gas introduced with the fuel, its removal by reaction with the fuel or cladding material, and the release and reaction of sorbed and fission gases during operation. The release of sorbed and fission gases is a function of temperature and the microstructure and macrostructure of the fuel. There are two areas of specific interest: (1) the internal pressure of the fuel versus time (dynamic gas release) and (2) the quantity and species of the released gas at a preselected burnup (static gas release). Both static and dynamic gas release experiments are required to obtain sufficient understanding of the process to confidently design for gas release throughout the core life.

The dynamic gas release experiment will, by inreactor monitoring, determine the internal gas pressures of a series of $\mathrm{ThO}_{2}-\mathrm{UO}_{2}$ fuel pins during reactor operation. Pressure determination will require pressure transducers capable of reliable operation in an irradiation environment; a mechanical null-balance diaphragm switch 
is proposed. Capsules will be irradiated for approximately 60 days. Gas pressure and neutron flux will be recorded as a function of time.

One set of specimens will be subjected to an initial high power to establish an altered grain structure. Another set of specimens will be subjected to a terminal high power to realter the grain structure after a substantial amount of fission gas has been generated. Gas release values of the two series of specimens will be compared to determine the significance of variations in power level over the operating life of a fuel element on the gas release characteristics of pellet and powder thoria-urania fuel. Power bursts will exceed normal power to the degree required for extensive recrystallization or center melting. It is anticipated that eight capsules, each containing one specimen, will be required for this experiment.

The static gas release experiment will produce data from postirradiation sampling to develop a relationship between gas release and heat rating $\left(\int \lambda \mathrm{d} \theta\right)$. Experimental parameters will be selected so that the operating heat rating varies up to that required for center melting. Both powder and pellets having two different $\mathrm{UO}_{2} \mathrm{com}-$ positions will be irradiated. Gas release data obtained from pellets will be used for correlation of the results of this experiment with those from other installations and to establish the general shape and magnitude of the curve representing the relationship between gas release and heat rating for these compositions.

The capsules for this subtask will be irradiated for at least 6 months-the time required for sufficient fission gas buildup to permit analysis with snme prerisinn. Capsule instrumentation will consist of neutron monitors and thermocouples where practicable. Approximately 10 capsules will be required to accommodate the specimens having powder and pellet form, two compositions, and perhaps four heat ratings. Postirradiation examination of the specimens will determine the relationship between gas release and heat rating for pellet and powder materials for the two urania compositions investigated. Analysis of characterization and operating data, gas sampling, and radiochemical, isotopic, and ceramographic examinations will be accomplished. 


\section{Compatibility of Fuel With Cladding}

The compatibility of thoria-urania powder with SAP will be considered from both mechanical and chemical viewpoints. A number of the specimens in the preceding gas release subtask will be SAP clad, thus providing information regarding chemical compatibility of the SAP with thoria-urania. By using varying wall thicknesses, the ability of SAF cladding to withstand gas pressure and its fuel restraint capability will also be determined.

\subsubsection{Summary}

An experimental program to characterize the reference thoria-urania fuel has been planned. The following investigations are proposed:

1. Thermal conductivity will be determined in a comprehensive treatment utilizing both inreactor and outreactor experiments. Powder and pellet materials will be examined; the "pellet" curve will serve as a reference for the "powder" curve, which is more difficult to establish.

2. Gas release will be studied by two procedures: determination of internal pressure (inreactor) versus time and determination of the quantity and species of the gas released at a preselected burnup.

3. Compatibility between fuel and cladding will be determined. Both chemical and mechanical compatibility in a neutron environment will be considered.

In all instances parameters will be selected to obtain information necessary for confident HWOCR core design.

\section{3. 3. Subtask 24 - Thorium Oxide Fuel Element} Engineering Tests

\subsubsection{Objective}

The objective of this subtask is to perform outpile engineering tests on the thorium oxide clustered-pin fuel element to obtain design and performance data to ensure the structural adequacy of the fuel element for operation in an HWOCR. 


\subsubsection{Status of Technology}

The basic engineering tests for the development of a SAP-clad clustered-pin fuel element are being performed under the AI-CE HWOCR program, including a SAP development program at ORNL. Successful prosecution of these tests will provide much of the basic information needed for the thorium oxide clustered-pin fuel element.

\subsubsection{Technical Approach}

Since it is expected that the major engineering development will be done under the AI-CE program, the types of tests are only outlined below:

1. Collapse Tests

Problem: Collapse strength at prolonged elevated temperatures.

Objective: Short-time and creep collapse data to provide optimum thickness of cladding.

Course of action: Short-time tests, longtime tests, analytical correlation, elevatedtemperature irradiated and unirradiated material properties.

\section{Burst Tests}

Problem: Internal pressure buildup.

Objective: Burst data to provide optimum thickness of cladding.

Course of action: Short-time tests, longtime tests at elevated temperature, irradiated and unirradiatod material properties.

\section{General Tests}

Problems: Creep, corrosion, fretting, and wear of the cladding.

Objective: Investigation of these problems to provide design information for the fullscalc flow test element and the production element.

Course of action: Outpile tests (on a component basis, as required, to provide design information) in a hot organic loop for long duration. 
4. Hydraulic and Vibration Test

Problems: Flow distribution, pressure drop, and vibration.

Objective: Hydraulic and vibration characteristics.

Course of action: Outpile flow test of fullsized interim fuel element at low temperature and pressure. Can be performed on a prototypic fuel element before irradiation testing in $\mathrm{WR}-1$.

5. Full-Scale Flow Test

Problems: Flow distribution including interchannel mixing effects, pressure drop, vibration, and axial loading.

Objective: Hydraulic (including mixing) and vibration characteristics.

Course of action: Outpile flow test of fullsized reference fuel element in a hot organic loop.

It is expected that all of these tests will be performed by AI-CE in developing their U.C element and that their information will be directly applicable to the B\&W 37-pin oxide element since the same number of pins are used in either element.and the pin sizes are approximately equal. The burst testing, however, must take into consideration the higher fission gas pressure buildup in the oxide pin.

Use of a 55-pin thorium oxide fuel element in an HWOCR designed for UC would require separate vibration and flow tests for the reference element. The flow and vibration characteristics of the 55-pin element may differ significantly from those of the 37-pin element.

\subsubsection{Summary}

Engineering tests for SAP-clad clustered-pin fuel elements are being performed under the AI-CE program. B\&W will use available data from this program. Additional engineering tests will be performed only to investigate areas peculiar to the thorium fuel element design. 


\section{3. 4. Subtask 25 - Thorium Oxide Fuel Element}

Assembly Irradiation Tests

\subsubsection{Objective}

The objective of this subtask is to determine the operational behavior of the thorium oxide fuel element assemblies under conditions closely simulating HWOCR conditions.

\subsubsection{Course of Action}

The fuel element assemblies will be irradiated in a succession of experiments. Thus, confidence in the behavior of thorium oxide fuel elements in an HWOCR environment will be progressively developed. The final step will be a proof test in the WR-l under conditions as closely representative of the HWOCR as reasonably attainable.

\subsubsection{Status of Technology}

The effects of irradiation on thoria-urania fuel are discussed in the description of Subtask 23.

\subsection{4. Problem Areas}

The overall problem is the need to demonstrate that the SAP-clad thorium oxide fuel element design is functionally adequate for operation in an organic coolant under HWOCR operating conditions. Among the items that need verification are (1) mechanical and structural integrity of the cladding and fuel combination during irradiation and (2) the effect of organic fouling during irradiation on the thermal performance of the fuel element.

\subsubsection{Technical Approach}

A number of fuel element assembly irradiation tests will be performed in the WR-1 reactor to obtain information on operational performance at simulated HWOCR conditions. Specific information obtained will include power and temperatures achieved, dimensional stability, extent of fretting wear, gas release, corrosive effects, and other physical and microstructural observations on both fuel and cladding. The largest bundle that can be accommodated, probably a 
19-pin cluster, will be irradiated. The pins will be highly instrumented with thermocouples in the fuel and cladding and with flux monitors.

The first irradiation experiment in the WR-1 reactor will operate at a relatively low power level. The second irradiation experiment will operate at a higher power level. The third irradiation experiment will have a greatly improved design because it will be based on the experience of the first experiment and possibly the second experiment.

Additional irradiation experiments in the WR-1 reactor will continue to test the operational characteristics of a reference design fuel element at successively higher power levels until a practical upper limit is achieved. Information obtained from prior irradiations will be incorporated in these experiments. The results obtained will contribute to the design of the $1000 \mathrm{MWe}$ HWOCR thorium dioxide fuel element. As the need for additional irradiation experiments is indicated, they will be further described in amendments to this document. It is presently not feasible to completely predict needs arising from future experimental work.

\subsubsection{Summary}

An irradiation program is planned to determine the operational behavior of the reference thorium oxide fuel element assembly under conditions closely simulating HWOCR conditions. A series of irradiation experiments are planned for the WR-1 reactor. They will start with initial irradiations of a cluster of oxide elements of current design operating at reduced power and culminate in the ixradiation of a fuel element assembly at operating conditions permitting a simulated performance of the reference design. The results obtained will contribute to the design of the $1000 \mathrm{MWe}$ HWOCR thorium fuel element.

\section{4. Thorium Monocarbide Fuel Element Test Program}

3. 4. 1. Subtask 22 - 'lhorium Monocarbide Fuel Element Fabrication Development

\subsubsection{Objective}

The objective of this subtask is to establish the $1000 \mathrm{MWe} H W O C R$ thorium-uranium monocarbide fuel composition 
and to develop the necessary fabrication and quality control processes.

\subsubsection{Course of Action}

Fabrication methods suitable for a commercial production facility will be developed. Efforts will be directed toward obtaining a fuel composition resistant to attack by moisture.

\subsubsection{Status of Technology}

As will be discussed in detail in the description of Subtask 23, thorium monocarbide is highly reactive with the moisture in air, rapidly hydrolyzing to form hydrocarbon gases and thoria. Abraham of Atomics International ${ }^{79}$ found that $1 \%$ zirconium had a definite stabilizing influence on $\left(\mathrm{Th}_{7} \mathrm{U}\right) \mathrm{C}$, rendering the material capable of being handled in air to some extent. Other stabilizers, such as molybdenum and niobium (columbium) were not as effective as zirconium was. Silicon presented some casting difficulties and was not thoroughly evaluated at AI; however, Battelle ${ }^{80}$ found that silicon was an effective stabilizing addition. Abraham prepared his compound by fusing the elemental components by arc melting with a nonconsumable graphite electrode. Drop casting was abandoned in favor of pouring from a skullmelt furnace since drop casting produced fuel slugs containing voids. The tilt-pour procedure produced sound castings having acceptable physical properties. The melt cycle for a 1000-gram charge was reported to require 2 to 4 minutes at 2000 to 3000 amperes and 32 to 38 volts under a static argon atmosphere at a pressure of $500 \mathrm{~mm} \mathrm{Hg}$.

In the BMI investigation, ${ }^{80}$ arc melting of the specimen material on a copper hearth was followed by drop casting of the specimens into a graphite mold. Satisfactory fuel slugs were so obtained.

At Brookhaven $(B N L)^{81,82}$ thorium monocarbide

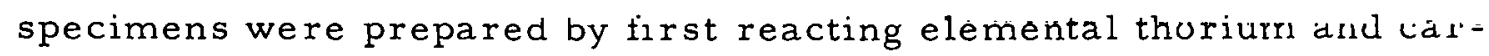
bon in a vacuum for 2 hours at $1800 \mathrm{C}(3270 \mathrm{~F})$, crushing to a powder, and then hot pressing the crushed powder in $\mathrm{Al}_{2} \mathrm{O}_{3}$ dies at 5000 psi at $1300 \mathrm{C}(2370 \mathrm{~F})$ in a vacuum. Material having a $\mathrm{C} / \mathrm{Th}$ ratio of 0.74 was at $95 \%$ of theoretical density after hot pressing, and the density increased to $97 \%$ after annealing at $1800 \mathrm{C}(3270 \mathrm{~F})$ for 10 hours. However, material having a $\mathrm{C} / \mathrm{Th}$ ratio of 0.96 was at only $80 \%$ of theoretical density. 
after hot pressing. The density increased after annealing to $90 \%$, but cracking of the pellets was observed.

Vitro Laboratories ${ }^{83,84}$ has a proprietary plasma-arc melting process for the manufacture of thorium monocarbide powder. The powder is in the shape of spherules, from 1/4-inch diameter to fines (particles finer than 40 mesh are perfect spheres and $100 \%$ dense). The larger particles are slightly flattened and contain some central porosity. The powder is recommended for vibratory compaction; however, if pellets are required, the recommended consolidation procedure is arc casting. Conventional pressing and sintering, according to Vitro, would not yield acceptable densities without the presence of free thorium.

Uranium monocarbide technology ${ }^{85}$ may be drawn upon as a guideline for thorium monocarbide fabrication development; however, this must be done cautiously and with the full realization that the two materials are not similar in all respects.

\subsection{4. Problem Areas}

The principal difficulty in fabricating thorium monocarbide is its reactivity with moisture. Because of this reactive tendency, thorium monocarbide must be stabilized by alloying, or dryprocessing techniques must be used. After the choice between stabilization and dry processing, casting, finishing, and inspection procedures will be established.

\section{4:1.5. Technical Approach}

It will be necessary to control the length and diametral dimensions, chemical composition, impurity content, density, and physical intactness to reasonably strict tolerances. The first phase of this investigation will be the development of a relatively stable thorium monocarbide fuel. Stabilizing amounts will be added to the monocarbide in varying proportions, and the pellets will be tested for hydrolysis in air. Although there are a number of possible stabilizing elements, initial work will be restricted to zirconium on the basis of previous success. If zirconium does not acceptably stabilize $\left(T_{h} U_{0.02}\right) C$, other elements or combinations of elements will be considered. A number of small pellets having 2,5 , and $10 \%$ zirconium will be arc cast. The 
cumulative weight gain in a controlled moisture content environment will then be determined as a function of exposure time. General observations will be made of the condition of the specimens. If an acceptable composition is found, casting, finishing, and inspection techniques will be developed; if an atmospherically stable composition is not found, dry-box processing procedures will be investigated.

Production methods suitable for full-core lots

will be developed. The methods will be compatible with recycle and remote fabrication procedures and will produce material of controlled quality.

\subsubsection{Summary}

An experimental program is planned for the fabrication procedures to obtain thorium monocarbide based fuel pellets. The principal difficulty is reactivity with the moisture in normal atmospheric air; this will be overcome by either chemical stabilization or is olated handling.

3. 4. 2. Subtask 23 - Thorium Monocarbide Fuel Characteristics

\subsubsection{Objective}

The objective of this subtask is to characterize thorium-uranium monocarbide fuel by inreactor and outreactor testing.

\subsubsection{Course of Action}

Necessary fuel materials properties that are not adequately known will be determined or verified under conditions applicable to the HWOCR. The SAP cladding material will be investigated by AI-CE, except for aspects specifically related to thorium fuel. The reference fuel composition will be determined in Subtask 22.

\subsubsection{Status of Technology \\ Phase Equilibria}

The thorium-carbon equilibrium phase diagram has not been indisputably established; however, the monocarbide region has been sufficiently well defined for the purposes of this subtask. From approximately 45 to 50 atomic \% (4 to $5 \mathrm{wt} \%$ ) carbon, the diagram shows thorium monocarbide to be a single phase (perhaps alpha thorium) existing 
without allotropic change to melting at approximately $2625 \mathrm{C}$ (4750 F).86,87 The crystal structure is cubic $\mathrm{NaCl}{ }^{88}$ The thorium-uranium-carbon equilibrium phase diagram has been determined at selected temperatures. Benesovsky and Rudy, ${ }^{89}$ Ivanov and Alekseeva, ${ }^{90}$ and Rosen ${ }^{91}$ obtained isothermal diagrams for 1700 and $1000 \mathrm{C}$ (3090 and $1830 \mathrm{~F}$ ), 1000 and $700 \mathrm{C}(1830$ and $1290 \mathrm{~F})$, and 950 and $400 \mathrm{C}(1740$ and $750 \mathrm{~F})$, respectively. There was substantial agreement that the monocarbides of thorium and uranium form a continuous series of solid solutions.

\section{Corrosion and Compatibility}

There are three considerations here:

1. Corrosion of the monocarbide by reaction with moisture in the air.

2. Compatibility of the monocarbide with organic coolant.

3. Compatibility of the monocarbide with SAP cladding.

These will each be discussed in turn.

Thorium monocarbide reacts with moisture in the air by hydrolysis. The reaction is fairly rapid, even at room temperature, forming hydrocarbon gases and thorium dioxide. The thorium dioxide exfoliates, leading to complete disintegration of the monocarbide specimen. ${ }^{92}$ The presence of moisture is imperative for this reaction as shown by Farkas et al. of BMI. ${ }^{80,93}$ They also performed oxidation tests in dry air at temperatures from $480 \mathrm{C}(900 \mathrm{~F})$ to $705 \mathrm{C}$ (1300 F), obtaining measurable weight gains after some hours of exposure. Chemical aspects of the hydrolysis reaction were studied by Kempter and Krikorian of LASL. ${ }^{94}$ Abraham of $\mathrm{AI}^{79}$ found that addition of approximately $1 \%$ zirconium to $\left(\mathrm{Th}_{7} \mathrm{U}\right) \mathrm{C}$ stabilized the monocarbide sufficiently to allow it to be processed in air; it still showed approximately eight times the weight gain of uranium monocarbide.

The investigation at $\mathrm{BMI}^{80,93}$ also included exposure of thoriurn monocarbide and thorium monocarbide alloyed with $10 \%$ uranium monocarbide to organic coolant (Santowax R) at $350 \mathrm{C}$ $(660 \mathrm{~F})$. Some slight reaction was found: however, this was not related to the moisture content of the coolant, which was not measured. Additional investigation of this reaction is required. 
The BMI investigation 80,93 also encompassed the compatibility of $\mathrm{ThC}$ and $\left(\mathrm{T} \mathrm{h}_{\mathrm{g}} \mathrm{U}\right) \mathrm{C}$ with aluminum (specifically, 3003 alloy). No reaction was found after exposure at $540 \mathrm{C}$ (1005 F) for 1000 hours in a helium atmosphere. By analogy with uranium monocarbide, 69 it might be postulated that the presence of $\mathrm{Al}_{2} \mathrm{O}_{3}$ on the surface of the aluminum prevents the formation of thorium aluminides and that the alumina is reduced at sufficiently high temperature, allowing the aluminide formation to proceed. As sufficient thermodynamic and kinetic data do not exist to evaluate this further, experimental studies are required.

\section{Physical and Mechanical Properties}

Thermal conductivity of thorium monocarbide was reported by Griesenauer et al. of $\mathrm{BMI}^{93}$ and Marchal and Trouve of $\mathrm{CEN} .{ }^{95}$ The $\mathrm{BMI}$ investigation on $\left(\mathrm{Th}_{9} \mathrm{U}\right) \mathrm{C}$ yielded values varying linearly from $0.0308 \mathrm{cal} / \mathrm{sec}-\mathrm{cm}-\mathrm{C}(7.447 \mathrm{Btu} / \mathrm{hr}-\mathrm{ft}-\mathrm{F})$ at $200 \mathrm{C}(390 \mathrm{~F})$ to $0.0442 \mathrm{cal} / \mathrm{sec}-\mathrm{cm}-\mathrm{C}(10.688 \mathrm{Btu} / \mathrm{hr}-\mathrm{ft}-\mathrm{F})$ at $1000 \mathrm{C}(1830 \mathrm{~F})$. The CEN work on pure ThC, however, produced much lower values, 0.02 $\mathrm{cal} / \mathrm{sec}-\mathrm{cm}-\mathrm{C}(4.8 \mathrm{Btu} / \mathrm{hr}-\mathrm{ft}-\mathrm{F})$ at $160 \mathrm{C}(320 \mathrm{~F})$ and $0.016 \mathrm{cal} / \mathrm{sec}-$ $\mathrm{cm}-\mathrm{C}(3.9 \mathrm{Btu} / \mathrm{hr}-\mathrm{ft}-\mathrm{F})$ at $365 \mathrm{C}(690 \mathrm{~F})$, which are extremely close to corresponding values for $\mathrm{UO}_{2}$. Further determinations at higher temperatures and with more refined techniques are required.

The thermal expansion of $\left(T h_{9} U\right) C$ was studied by Griesenauer et al. of BMI, ${ }^{93}$ and the thermal expansion of $\left(\mathrm{Th}_{7} \mathrm{U}+\mathrm{Zr}\right) \mathrm{C}$ was studied by Abraham of AI. ${ }^{79}$ The BMI study extended to approximately $1000 \mathrm{C}(1830 \mathrm{~F})$, and the AI work went to $1315 \mathrm{C}(2400 \mathrm{~F})$. The studies are in substantial agreement, showing thermal expansion that is approximately linear and results in a $0.7 \%$ increase in length at $1000 \mathrm{C}(1830 \mathrm{~F})$. Street and Waters of AERE ${ }^{96}$ found that the mean linear thermal expansion of pure ThC was $6.53 \times 10^{-6} /$ degree $C\left(3.62 \times 10^{-6} /\right.$ degrcc $\left.F\right)$ be tween room temperature and $841 \mathrm{C}(1545 \mathrm{~F})$, which is in fair agreement with the BMI value of $7.2 \times 10^{-6} /$ degree $C\left(4.0 \times 10^{-6} / \text { degree } F\right)^{97}$ for $(\mathrm{Th}, \mathrm{U}) \mathrm{C}$.

Mechanical strength was determined at BMI and AI. The BMI study ${ }^{93}$ found that compressive fracture stress decrcases from $123 \mathrm{ksi}$ at room temperature to $67 \mathrm{ksi}$ at $980 \mathrm{C}(1800 \mathrm{~F})$. The AI study ${ }^{79}$ found that tensile fracture stress was $15 \mathrm{ksi}$ at room temperature. 
As before, the BMI work was with $(\mathrm{Th}, \mathrm{U}) \mathrm{C}$, and the AI work was with $\left(\mathrm{Th}_{7} \mathrm{U}\right) \mathrm{C}+1 \%$ zirconium. BMI also qualitatively determined thermal shock resistance by quenching in oil from $1000 \mathrm{C}(1830 \mathrm{~F})$; no evidence of cracking was found. This suggests that the compounds possess a reasonable combination of thermal conductivity, thermal expansion, and strength characteristics, upon which thermal-shock resistance is dependent. The AI investigation also determined that Young's Modulus at room temperature was approximately $14 \times 10^{6} \mathrm{psi}$.

\section{Irradiation Characteristics}

A review of the technical literature has not revealed any information on the behavior of thorium monocarbide under neutron irradiation. A complete irradiation program is required to determine such properties as dimensional stability and gas release. Guidelines may be drawn from the irradiation experience with plutonium monocarbide and uranium monocarbide, but this must be done with the full realization that thorium monocarbide, although similar in many respects, is a different material, which may perform differently. In general, studies at ANL, ${ }^{98}$ AERE, ${ }^{99} \mathrm{UNC},{ }^{100}$ and other laboratories have shown that arc-fused monocarbides possess excellent radiation stability.

\section{$\underline{\text { Plutonium Compatibility }}$}

The use of plutonium monocarbide in place of uranium monocarbide as the fissionable material will probably not introduce new problems. Admittedly, there is very little data on ( $\mathrm{Th}$, $\mathrm{Pu}$ ) ; however, the monocarbide of thorium and plutonium is isomorphous and otherwise similar to UC physically and chcmically. Nevitt of $A N L^{101}$ found that the lattice parameters of UC in ThC and PuC in ThC were extremely similar and that both closely followed Vegard's Law. It would certainly be expected that the quaternary situation, $(\mathrm{Pu}, \mathrm{Th}, \mathrm{U}) \mathrm{C}$, for the concentrations here specified would not deviate markedly from the previously discussed ternary form, (Th, U)C.

\subsubsection{Problem Areas}

The principal need is for a determination of the effects of thermal neutron irradiation. Dimensional stability, 
chemical stability, and gas release must be determined. The compatibility of fuel and cladding and fuel and coolant must certainly be established. Thermal conductivity must also be positively determined at the operating temperatures.

\subsubsection{Technical Approach \\ Thermal Conductivity}

Outreactor thermal conductivity will be determined on cast pellet material to at least $2000 \mathrm{C}(3630 \mathrm{~F})$. The conductivity will be determined from thermal diffusivity measurements. Experimental determinations will be performed on four compositions having variations in carbon and uranium content of the reference material.

Some of the lower temperature irradiation experiments will be instrumented with thermocouples to determine the inreactor thermal conductivity and to determine the long-term effect of irradiation upon thermal conductivity.

\section{Compatibility}

The compatibility study will be divided into three independent areas of investigation as follows:

1. Reaction with moisture in the air. This will be determined in Subtask 22 as part of the fabrication development.

2. Compatibility of the monocarbide with organic coolant. Specimens of the reference fuel material will be exposed in an outreactor loop to flowing organic coolant at temperatures of 260,370 , and $480 \mathrm{C}(500,700$, and $900 \mathrm{~F})$ for times of 100 and 1000 hours. Reference organic coolant containing low, nominal, and high moisture content will be utilized. Subsequent analysis will include metallographic examination and determination of weight change data.

3. Compatibility of the monocarbide with SAP cladding. The compatibility between stoichiometric and hypostoichiometric fuel material and SAP cladding material will be determined using contactloaded diffusion couples. Both bare and anodized SAP surfaces will be tested; investigations will be conducted at temperatures of 425,540 , 650 , and $760 \mathrm{C}(800,1000,1200$, and $1400 \mathrm{~F})$ and times of 100,1000 , 
and 10,000 hours. The variables will be statistically arranged to minimize testing.

\section{Irradiation Performance}

A complete irradiation program is required to properly assess the performance of thorium monocarbide for HWOCR applications. Dimensional stability including swelling as a function of burnup and fracturing due to thermal stress, fission gas release, and compatibility of fuel and cladding under neutron irradiation are the areas of principal importance.

Dimensional stability will be determined by a series of capsule irradiation tests. Thorium monocarbide pellets, some of which will be clad in SAP, will be encapsulated and irradiated to the following burnups: 2500, 5000, 10,000, 20,000, and 25,000 MWD/MTM. These burnups would occur in approximately $1 / 2,1,2,4$, and 5 years of irradiation respectively in a typical test reactor thermal neutron flux. The fuel pins will have varying diametral gap and cladding thickness of 10,20 , and 25 mils to determine the effect of cladding restraint on irradiation stability.

\section{Gas Release}

Gas release experiments will produce data from postirradiation sampling to develop a "gas release versus heat rating $\left(\int_{T_{1}}^{T_{2}} \lambda d \theta\right)$ "relationship. Experimental parameters will be selected to vary the operating heat rating up to that required to approach center melting as closely as thermal conditions allow. The capsules will be irradiated for the time necessary to accumulate sufficient gas for reliable analysis. Capsule instrumentation will consist of thermocouples and flux monitors where practicable. In addition, the fuel pins irradiated in the dimensional stability subtask will be analyzed for gas release. Dynamic gas release experiments are not planned at this time. However, if there is a future indication that this information is needed, dynamic gas release experiments will be performed.

\section{Compatibility of Fuel With Cladding}

A number of the specimens in the dimensional stability and gas release experiments will be SAP clad. Thus, compatibility 
between SAP and thorium monocarbide will be determined under neutron irradiation.

\subsubsection{Summary}

An experimental program to characterize the reference fuel is planned. The following investigations are proposed:

1. The thermal conductivity will be determined for temperatures to $2000 \mathrm{C}(3630 \mathrm{~F})$. The effect of compositional variations will be considered.

2. The compatibility between fuel and organic coolant will be surveyed at various temperatures and moisture contents.

3. The compatibility between fuel and cladding will be determined using contact-loaded diffusion couples. Experimental variables will include carbon content and time and temperature of exposure.

4. Capsules of the reference fuel will be irradiated to determine dimensional stability, fission gas release, and the effect of neutron irradiation upon the rmal conductivity and compatibility with SAP cladding. Burnups will be from 2500 to 25,000 MWD/MTM.

3. 4. 3. Subtask 24 - Thorium Monocarbide Fuel Element Engineering Tests

The objective of this subtask is to perform outpile engineering tests on the thorium monocarbide clustered-pin fuel element to obtain additional design and performance data to ensure the structural adequacy of the fuel element for operation in an HWOCR.

The sante teshs 1 equired for the 37 pin thoring oxide element will be needed for the 37 -pin thorium carbide element (see section 3.3.3). AI-CE is expected to perform these tests in developing the 37-pin UC element, and the results will be directly applicable to the $B \& W$ carbide element since the number of pins is the same and the pin sizes are approximately equal.

3. 4. 1. Subtask 25 - Thorium Monocarbide Fuel Element Assembly Irradiation Tests

3.4.4.1. Objective

The objective of this subtask is to determine the operational behavior of the thorium monocarbide fuel element 
assemblies under conditions closely simulating HWOCR conditions.

\subsubsection{Course of Action}

The reference fuel element assemblies will be irradiated in a succession of experiments. The final step will be a proof test in the WR-1 under conditions closely representative of HWOCR ronditions

\subsubsection{Status of Technology}

There is no irradiation experience with thorium monocarbide.

\section{4. 4.4. Problem Areas}

The major problem is the need to demonstrate that the SAP-clad thorium monocarbide fuel element design is functionally adequate for operation in an organic coolant at HWOCR operating conditions. Among the items that need verification are (1) dimensional stability of the fuel element during irradiation, (2) mechanical and structural integrity of the cladding and fuel combination during irradiation, and (3) the effect of organic fouling during irradiation on the thermal performance of the fuel element.

\subsubsection{Technical Approach}

A number of fuel element assembly irradiation tests will be performed in the WR-1 reactor to obtain information on operational performance at simulated HWOCR conditions. Specific information obtained will include power and temperatures achieved, dimensional stability, extent of fretting wear, fission gas release, zorrosive effects, and other physical and microstructural observations on both fuel and cladding. As large a bundle as can be accommodated, probably a 19-pin cluster, will be irradiated. The pins will be instrumented with flux monitors and with thermocouples in the fuel and cladding.

The first irradiation experiment in the WR- 1 reactor will operate at a relatively low power level. The second ir radiation experiment will operate at a higher power level. The third irradiation experiment will be of improved design based on the experience of the first experiment and possibly the second experiment. 
Additional irradiation experiments in the WR-1 reactor will continue to test the operational characteristics of the fuel element at successively higher power levels until a practical upper limit is achieved. Information obtained from prior irradiations will be incorporated in these experiments. The results obtained will contribute to the design of the $1000 \mathrm{MWe}$ HWOCR thorium fuel element. As the need for additional irradiation experiments is indicated, they will be further described in amendments to this document. It is presently not feasible to completely predict needs arising from future experimental work.

\subsubsection{Summary}

An irradiation program is planned to determine the operational behavior of the thorium monocarbide fuel element assembly under conditions closely simulating HWOCR conditions. A series of irradiation experiments are planned to be performed in the WR-1 reactor. They will start with initial irradiations of a cluster of thorium monocarbide elements of current design operating at reduced power and will culminate in the irradiation of a fuel element assembly at operating conditions which simulate the performance of the reference design. The results obtained will contribute to the design of the reference $1000 \mathrm{MWe}$ HWOCR thorium fuel element.

\section{5. Additional R\&D Required for Commercial Acceptance}

Sections $3.2,3.3$, and 3.4 outline the test programs required to demonstrate the performance of prototypic thorium fuel elements in an HWOCR environment. The fuel element test program is the principal development task; however, additional $R \& D$ will be required to achieve commercial acceptance of the HWOCR thorium fuel cycle. Experimental physics data are required for confident design of a Thorium HWOCR. Thorium-U-233 recycle must be converted to practicality on technical and economic bases. A discussion of the $R \& D$ in these two areas follows.

\subsubsection{Experimental Physics}

The experimental physics program required to support the development of the thorium cycle for the HWOCR is based on an analysis of the nuclear design problems associated with that concept 
and an evaluation of the applicability of available information. The design features of the Thorium HWOCR's are described in section 2 of this report, and the available data have been reviewed before 101,102 Additional information on the thorium cycle has been obtained from experimental programs in progress at the Savannah River Laboratory (SRL) and Brookhaven National Laboratory (BNL), as will be discussed below.

The total experimental program can be separated into two phases. The first phase consists of basic experiments needed to develop analytical methods, substantiate the crucial features of the reference design, and provide a firm basis for evaluating the merits of the concept. The second phase is more design-oriented and includes those experiments needed to confirm the design and operational characteristics of the reference reactor. The experiments required for each phase are outlined in the following sections, although it must be recognized that additional work may be needed as the problems becomé better defined through further design and development studies. It should also be pointed out that there is no clean break between the phases. Depending on the development schedule, funding, incentives, and other factors, the sequence of experiments may be altered.

The program is based on the assumption that the demonstration of the Thorium HWOCR be initially with U-233 or U-235. A. decision to fuel the reactor with plutonium would require major revisions in the development program. It is also assumed that the physics experiments will be performed at SRL, although this work could be done at $B \& W$.

\subsubsection{Phase I}

The objective of Phase $I$ is to provide the integral physics data needed to confirm or normalize the analytical methods and cross sections that are used in the most crucial design calculations. The program incentives are based on the predictions of power cost and conversion ratio. However, as discussed in section 4 the error band in the economic evaluations resulting from uncertainties in the nuclear calculations alone is sufficiently broad that some experimental confirmation of their reliability-or narrowing of the error band-is absolutely 
essential at an early stage. Accurate cross sections are needed, but the principal problem is the reliability of the analytical model used to treat the complex and dissimilar geometrical features of close-packed rods and tubes. The conversion ratio and power distribution are particularly sensitive to the homogenization model used.

Phase I should also include any experiments needed to confirm the technical feasibility of the concept. However, at this stage in the design and development program, no go or no-go items have been identified. There may be some fundamental questions on safety. that should be included in Phase I, but this decision must await turther evaluation.

The experiments required in Phase $I$ are outlined below. They should be regarded as minimum requircments; earlier information on some of the problems relegated to Phase II would be desirable, but probably not absolutely essential.

\section{Task 1: Basic Integral Data}

Two sets of integral experiments (both exponentials) are essentially complete-one at SRL and one at BNL. SRL measured parameters for $\mathrm{U}-235-\mathrm{ThO}_{2}$ clusters and U-235-thorium metal nested cylinders. BNL has done a short but pertinent series of measurements with U-233-ThO 2 clusters. Data from these two programs are limited, but will provide the first real tests of the physics models. Considerably more experimental work is needed, however, if a high degree of confidence in the analytical calculations for these systems is to be achieved.

The broad objective of Task 1 is to obtalin basic integral cross section data needed to satisfy the objectives of Phase I. For the case of U-233, the data are obtained more easily and are more directly applicable if they are measured in lattice-type experiments, as will be discussed under Task 3. For Th-232, there are major uncertainties in both the thermal (non-l/v) and epithermal cross sections. The low energy range should be covered by detailed microscopic cross section measurements. Although such measurements are beyond the scope of the program proposed here, other laboratories (e.g., BNL) should be encouraged to undertake this work. 
The principal integral cross section to be measured in this task is the effective resonance integral of thorium. Since this parameter is geometry-dependent, effective resonance integral measurements are needed to confirm both the resonance parameters and the complexities of the analytical model. The case of clustered pins of $\mathrm{ThO}_{2}$ is fairly well established from direct resonance integral measurements as well as the SRL lattice experiments. Although no data are available for clustered pins of $\mathrm{ThC}$, the nuclear properties are similar enough to those of $\mathrm{ThO}_{2}$ pin clusters that the risk in omitting such measurements, in Phase I at least, is probably justifiable. However, the geometrical differences for the case of the nested metal tube fuel element are sufficiently large that, in the absence of any other confirmatory data, direct measurements of the effective resonance integral are necessary. The measurements can be made using well-established activation techniques and should cover a range of tube diameter, wall thickness, and number of tubes appropriate to the conceptual design of this fuel element.

The thermal scattering parameters for Santowax and Dowtherm (simulated coolant in exponential experiments) must be measured so that scattering kernels, required as input to computer programs such as THERMOS, can be derived. THERMOS or codes of equivalent sophistication are required for adequate calculations of effective thermal cross sections, flux and power distributions through the fuel elements, temperature coefficients, and other thermal phenomena.

\section{Task 2: Fuel Element Model Test}

Integral data are needed to test the theoretical models used to treat the geometrical features of the three alternate fuel element designs, so that the intercomparisons used to select the reference design are done on a firm basis. For the case of clustered $\mathrm{ThO}_{2}$ pins, the exponential experiments done at SRL should be adequate for the preliminary model test needed in Phase $I$, unless the analysis of results indicates serious discrepancies. The case of clustered $\mathrm{ThC}$ pins is probably not sufficiently different to require a separate preliminary model test. However, for the case of nested thorium metal tubes, 
the experiments at SRL do not appear to be sufficient to provide an equally strong test of the analytical methods, and additional work appears to be appropriate.

Experiments should be performed with nested tubes of U-235-thorium alloy, having dimensions and enrichments appropriate to the reactor design. To minimize fuel requirements, the use of the PCTR-technique is recommended, and the fuel elements fabricated for SRL can probably be used. The measurements should be made as a function of lattice pitch and number of tubes per nest; in most cases the coolant should be organic, but $\mathrm{H}_{2} \mathrm{O}, \mathrm{D}_{2} \mathrm{O}$, and air should also be used to provide additional checks on the analysis. The following are typical examples of the measurements that should be made:

1. Infinite medium multiplication factor $\left(\mathrm{k}_{\infty}\right)$.

2. Epithermal-to-thermal captures in $T h-232\left(\rho_{28}\right)$.

3. Epithermal-to-thermal fissions in U-235 $\left(\delta_{25}\right)$.

4. Epithermal-to-thermal fissions in U-233 $\left(\delta_{23}\right)$.

5. Modified conversion ratio (MCR).

6. Thermal disadvantage factor $\left(\bar{\phi}_{\mathrm{m}} / \bar{\phi}_{\mathrm{f}}\right)$.

7. Power distribution $[\mathrm{P}(\overline{\mathrm{r}})]$.

8. Thermal and epithermal neutron spectra $[\phi(E)]$.

In some cases, the spatial distribution of these parameters should be measured.

\section{Task 3: U-233 Experiments}

Experiments on U-233-fueled lattices are needed in Phase I to ensure the reliability of fuel cycle cost and conversion ratio calculations. The exponential experirnents in progress at BNL do not appear to be sufficient for this purpose, so additional experiments are recommended. By studying the $\mathrm{U}-235-\mathrm{Th}-\mathrm{D}_{2} \mathrm{O}$ system comprehensively and obtaining model and cross section tests separately (Tasks 1 and 2 ), the effect of U-233 can be isolated to a large extent, and U-233 experiments can be minimized. The experiments proposed parallel those of Task 2, except that the fuel contains about $2 \% \mathrm{U}-233$. To obtain a direct comparison between $\mathrm{U}-235$ and $\mathrm{U}-233$, the same range of parameters should be covered, and all of the measurements listed under Task 2 should be made. However, those 
measurements providing more insight into the neutron spectrum, effective eta, and conversion ratio should be emphasized. The coolant void coefficient should also be considered in more detail because of its role in nuclear safety.

\subsubsection{Phase II}

The objective of Phase II is to confirm the detailed design of the reference reactor and to determine its operational characteristics. At this stage, the range of variables (fuel element dimensions, lattice pitch, etc.) will have been narrowed. The experimental program should explore this range of variables.

\section{Task 4: Burnup Studies}

Data are needed to confirm design calculations of the core lifetime and integrated conversion ratio because of the importance of these parameters in the economic evaluation of the concept. The effect of fission products on the reactivity and conversion ratio and the changes in heavy-element composition (particularly $\mathrm{Pa}-233$ ) should be measured by irradiating samples of U-233-thorium and U-235-thorium fuel pins to 10,000 to $20,000 \mathrm{MWD} / \mathrm{T}$. The reactivity changes can be measured periodically using an RMF-type of facility, ${ }^{103}$ in which the neutron-producing and neutron-absorbing components can be separated. The fuel conversion ratio should also be measured by isotopic analysis.

\section{Task 5: Operating Coefficients}

The operating coefficients-moderator, coolant, and fuel temperature coefficients of reactivity-can be measured in a number of ways. The least complex way is to measure them in a zoned critical assembly or PCTR, using a heated central region. The moderator temperature coefficient can be measured by heating $\mathrm{D}_{2} \mathrm{O}$ to approximately $80 \mathrm{C}$ and observing the reactivity change. The same approach can be taken to obtain the coolant temperature coefficient, except that the temperature range is much higher and the fuel element must be insulated from the moderator. These experiments should be supplemented with total-coolant voiding measurements. The fuel, or Doppler, coefficient can also be measured in the same facility, using relatively standard activation or reactivity techniques. 
There are a number of important nuclear properties of the reference reactor that cannot be determined adequately in the small-scale experiments described above; therefore a relatively large critical assembly will be necessary to measure them. It should not be necessary to mock up the reference reactor in full size and exact detail; a large zoned system may be adequate. However, the degree of simulation cannot be specified until the reference HWOCR design is established and the performance requirements for the first thorium core are defined. It is assumed that the thorium core will be loaded in an existing HWOCR.

The following are typical examples of the measurements that should be made in the mockup assembly:

1. Power distribution. Measure the gross and local power distribution and power sharing if radial or axial zone loading is used.

2. Operating coefficients. Confirm the earlier measurements of moderator, coolant, and fuel reactivity coefficients.

3. Kinetics. Determine the zero-power transfer function. Develop experimental methods of studying stability, xenon oscillations, etc.

\section{Task 7: Startup and Operational Tcsts}

Although this task is beyond the scope of the dẹvelopment program, it is mentioncd for complctencss. If a fresh thorium core is loaded, the usual startup tests, safety measurements; and periodic checks of the nuclear parameters throughout core lite will be made. However, if thorium fuel elements are loaded by on-line refueling methods, the principal measurements will be aimed at determining the perturbations introduced by the thorium fuel in the UC core.

\subsubsection{Recycle Technology}

The flow sheets selected for the recycling of thoriumuranium alloy and thorium-uranium oxide fuels are presented in BAW 393-3 (section 2). ${ }^{104}$ A flow sheet for the recycling of thorium-uranium carbide has not previously been presented. However, basic assumptions concerning the problem areas in the processing of all three fuel types 
in a TRIP (Thorium Recycle Integrated Plant) facility are discussed in this section.

The major philosophy governing the TRIP facility flow sheet and process equipment selection was the use of established reprocessing, conversion, and fabrication techniques. This does not require that each technique be proven with the specific fuel for which it is chosen in order to merit consideration. This is not possible with the present state of thorium technology. However, novel concepts, no matter how promising they may appear to be, are excluded from consideration unless they have been previously applied successfully on an industrial scale. Thus, the flow sheets which evolved for the alloy and the oxide fuels, though somewhat unique, are a balance between optimum economics and minimum risk. Where possible, the selection of the carbide fuel processes is handled in an identical manner.

In order for the TRIP recycle concept to attain commercial acceptance, a considerable amount of development work is required. A study has been made to determine the areas requiring additional research and development. As a result the problem areas (to permit commercial acceptance of the TRIP design) have been arranged into two categories:

1. Those chemical and metallurgical problems which must be solved to make the TRIP facility operable as conceptually envisoned in BAW-393-3 for oxide and metal (similarly for carbide).

2. Those problems which need to be solved in order to design a TRIP facility today based on BAW-393-3 flow sheets employed current state-of-design technology.

Those problem areas related to category 1 are listed in Table 3-1, and those problem areas related to category 2 are listed in Table 3-2.

\subsection{Summary}

Selection of a reference fuel element for future development will be based primarily on the following factors: economics, fuel utilization, compatibility with AI-CE design (including R\&D spinoff), and technical feasibility (including development costs and schedule). The preceding discussion of $R \& D$ requirements, therefore, provides important input 
and background for the comparative evaluation presented in section 4 . The test program plan for the selected fuel element will be used as the starting point for preparing a detailed work program to be submitted to the Commission.

Table 3-1. Chemical and Metallurgical Uncertainties in Thorium-Uranium Fuel Processing

Item

Choice of dissolution operation (e.g., chemical decladding versus simultaneous dissolution)

Effect of cladding dispersion material $\left(\mathrm{Al}_{2} \mathrm{O}_{3}\right)$ on dis solution cycle

Effect of organic degradation films on dissolution cycle

Practicality and sequence of heel type dissolution with HWOCR fuel

Effect of fluoride ion concentration on feed adjustment

Other feed adjustment requirements

Off-gas problems during core dissolution

Effect of soluble hydrolysis products on extraction system operation

Complications produced by the addition of zirconium to the fuel mixture

Choice of solvent extraction flow sheet

Minimum extraction requirements for remote recycling of fuel

Nitration reaction during product concentration

Acceptability of steam denitrated thoria as an intermediate reactant

Pyrophoricity or reactivity of intermediate or final fuel material

Atmospheric requirements in processing steps

Choice of fuel preparation method

Ability to meet purity specification

Fuel homogeneity

Fuel stabilization

Interaction of fuel and cladding
Fuel type

\begin{tabular}{|c|c|c|}
\hline $\begin{array}{l}\mathrm{ThO}_{2}-\mathrm{UO}_{2} \\
\text { (XAP clad) } \\
\end{array}$ & $\begin{array}{c}\text { Th-U alloy } \\
\text { (Zr clad })\end{array}$ & $\begin{array}{c}\text { ThC-UC } \\
\text { (XAP clad) } \\
\end{array}$ \\
\hline$x$ & $x$ & $\mathrm{x}$ \\
\hline$x$ & & $\mathbf{x}$ \\
\hline$x$ & $x$ & $x$ \\
\hline \multicolumn{3}{|l|}{$x$} \\
\hline & $\mathbf{x}$ & \\
\hline \multirow[t]{4}{*}{$x$} & $\mathrm{x}$ & $x$ \\
\hline & & $x$ \\
\hline & & $\mathrm{x}$ \\
\hline & $\dot{x}$ & $x$ \\
\hline$x$ & $x$ & $x$ \\
\hline$x$ & $x$ & $\mathbf{x}$ \\
\hline \multirow[t]{9}{*}{$x$} & $x$ & $x$ \\
\hline & $x$ & $x$ \\
\hline & $x$ & $x$ \\
\hline & $x$ & $\mathrm{X}$ \\
\hline & & $x$ \\
\hline & $x$ & \\
\hline & $x$ & \\
\hline & & $\mathrm{x}$ \\
\hline & $x$ & \\
\hline
\end{tabular}


Table 3-2. Uncertainties in Design of Thorium-Uranium Fuel Processing Equipment

Item

Proper dissolver design for the accommodation of desired operation sequence and criticality safety

Fuel element disassembly procedure

Choice of type of contactors to use in extraction plant

Adaptation of feed preparation steps to continuous operation

Adaptation of feed preparation steps to remote operation

Methods of reducing sorbed gases in fuel

Fuel fabrication method

Satisfactory joining techniques for cladding

Adaptation of element fabrication to remote operation

\begin{tabular}{lcc}
\multicolumn{3}{c}{ Fuel type } \\
\hline $\mathrm{ThO}_{2}-\mathrm{UO}_{2}$ & $\mathrm{Th}-\mathrm{U}$ alloy & $\mathrm{ThC}-\mathrm{UC}$ \\
(XAP clad) & (Zr clad) & (XAP clad) \\
\hline
\end{tabular}

$\mathbf{X}$

$\mathrm{x}$

$\mathrm{X}$

$\mathrm{X}$

$\mathbf{X}$

$\mathbf{X}$

$\mathbf{X}$

$\mathrm{X}$

$\mathrm{X}$

$\mathrm{X}$

$\mathrm{X}$

$\mathrm{X}$

$\mathrm{x}$

$\mathrm{X}$

$\mathrm{X}$

$\mathrm{X}$

$\mathrm{X}$

$\mathbf{x}$

$\mathrm{X}$

$\mathrm{X}$ 


\section{REFER ENCES}

(Section 3)

1 Kemper, S., et al., Fabrication of Zircaloy-2 Clad Thorium-Uranium Alloy Fuel Elements, HW-79843, March 1964.

2 Nemeth, S. R. (editor), Thorium-1.4 wt \% Uranium Metal Fuel Tubes - Fabrication and Irradiation in HWCTR, DP-943, Supplement, April 1965.

3 Harbinson, E. N. and Baroch, C. J., Mechanical Properties of Zircaloy-4 After Irradiation at 90, 650, and $750 \mathrm{~F}$, presented at ASTM Annual Meeting, Atlantic City, New Jersey: June 1966.

4 Bentle, G. G. , Study of the Thorium-Uranium Alloy System, Paper 706 from Second Conference on the Peaceful Uses of Atomic Energy, Geneva, 1958.

5 Bannister, G. H. and Thomson, J. R., "The Body-Centred-Cubic to Face-Centred-Cubic Transformation in Thorium and Some ThoriumRich Alloys", J. Nuclear Materials 12, pp 16-23 (1964).

6 Badaeva, T. A. and Alekseenko, G. K. , Structure of Alloys of the Thorium-Zirconium-Uranium System, Paper from AEC-tr-5834, July 1963, pp 376-394.

7 Pearlman, H., Corrosion of Uranium, Thorium, and Uranium Alloys in Sodium and Organics, Paper from Fuel Elements Conference, Paris, November 1957, TID-7546, Book 2, pp 565-590.

8 Kneppel, D. S., Aqueous Corrosion of Thorium Alloys and ZircaloyClad Thorium Alloys, NMI-1226, March 1960.

9 Wang, Y. Y. N., Corrosion of Experimental Thorium-Base Alloys, ANL-7006, February 1965.

10 Roll, I. B., "Thorium and Its Alloys", Ch. 5 from Nuclear Reactor Fuel Elements, Metallurgy and Fabrication, edited by Kaufman, A. R. , Interscience, New York, 1962.

11 Bentle, G. G., "Study of the Thorium-Uranium Alloy System", Ch. 1-2 from Progress in Nuclear Energy, Series V. Metallurgy and Fuels, 
Vol. IV. Basic Materials and Phenomena, Pergamon, New York, 1961.

12 Farkas, M. S., Bauer, A. A., and Dickerson, R. F., Development of Thorium-Uranium and Thorium-Uranium Base Alloys for Breeder Applications, Paper IV-20 from TID-7650, Book 11, 1962.

13 Bentle, G. G., A Physical Metallurgical Study of Thorium-Rich, Thorium-Uranium Alloys, NAA-SR-2069, January 1958.

14 Cole, R。 H. and Wilkinson, L。 E., Development of High Strength Ternary and Quarternary Thorium-Uranium Base Alloys, ATL-A-128, November 1961 .

15 Leggett, R. D. , Mastcl, B., and Weber, J。W., Swelling of Irradiated Fissionable Materials, Sect. from HW-77954, July 1963.

16 Leggett, R. D., Physical Property Changes in Thorium Post-Irradiation Annealed to $950 \mathrm{C}$, BNWL-24, January 1965.

17 Bement, A. L., Jr., Tensile Properties of Irradiated Thorium, HW-66693, September 1960.

18 Kittel, J. H. et al., Effects of Irradiation on Thorium and ThoriumUranium Alloys, ANL-5674, April 1963.

19 Ballif, J. L., Hayward, B. R., and Walter, J. W., Engineering Evaluation of a Mixed Alloy Fuel Element Irradiated at Elevated TemPeratures in the SRE, NAA-SR-3888, Junc 1960.

20 Kemper, R. S., PNL, private communication, and Marshall, R。 K., Irradiation Testing of Thorium-Uranium Fuel Elements, Section frum HW-84609, December 1964 .

21 Nemeth, S. R. (editor), Thorium-1.4 wt \% Uranium Metal Fuel Tubes - Fabrication and Irradiation in HWCTR, DP-943, Supplement, April 1965 .

22 Hayward, B. R. and Wilkinson, L。 E. Radiation Behavior of Metallic Fuels for Sodium Graphite Reactors, NAA-SR-3411, August 1959.

23 Gates, J. E., Lamale, G. E., and Dickerson, R. F., The Examination and Evaluation of Irradiated Thorium-11 w/o Uranium Specimens, BMI-1334, April 1959. 
24 Blumenthal, B., Density Measurements in Gloveboxes, with Density Data on Monobrómobenzene, Cast Uranium, Thorium-Uranium, and Thorium-Plutonium Alloys, ANL-6671, September 1963.

25 Farkas, M. S., Bauer, A. A., and Dickerson, R. F., Development of Thorium-Uranium-Base Alloys, BMI-1428, March 1960.

26 Lamale, G. E., Eldridge, E. A., and Dean, H. W., SRE Fuel Materials, Section from BMI-1324, March 1959.

27 Wilson, W. B., Austin, A. E., and Schwartz, C. M. , The Solid Solubility of Uranium in Thorium and the Allotropic Transformation of Thorium-Uranium Alloys, BMI-1111, July 1956.

28 Argonne National Laboratory, Annual Report for 1963, Metallurgy Division, ANL-6868, p 120.

29 Burgreen, D, Byrnes, J. J., and Benforado, D. N., "Vibration of Rods Induced by Water in Parallel Flow", "Transactions of ASME, July 1958.

30 Quinn, E. P., Vibration of Fuel Rods in Parallel Flow, GEAP 4059, APED, GE, San Jose, California, USAEC Div. of Technical Information.

31 Kiefer, R. J. and Sparks, T. R., Advanced HTGR Fuel Element Vibration Tests, GAMD 6145.

32 Merker, L. G., et al., Battelle-Northwest Fuel Fabrication Experience with High-Exposure Plutonium, BNWL-27, January 1965.

33 Bloomster, C. H., Fabrication Costs for Plutonium Fuel Elements; Part A: Variable Costs of Fabricating $\mathrm{UO}_{2}-\mathrm{PuO}_{2}$ Fuel Rods for the Plutonium Recycle Critical Facility, BNWL-131A, September 1965.

34 Bloomster, C. H. , Fabrication Costs for Plutonium Fuel Elements, Part B: Variable Costs of Fabricating $\mathrm{UO}_{2}-\mathrm{PuO}_{2}$ Fuel Rods for the Experimental Boiling Water Reactor, BNWL-131B, September 1965.

35 Bloomster, C. H. , Fabrication Costs for Plutonium Fuel Elements, Part D: Variable Costs of Fabricating $\mathrm{UO}_{2}-\mathrm{PuO}_{2}$ Fuel Rods for the Plutonium Recycle Test Reactor, BNWL-131D, October 1965. 
36 Slosek, T. J. and Weidenbaum, B., Irradiation and Examination of Vibratory Packed $\mathrm{UO}_{2}$ High Burnup Program Fuel Elements, GEAP3108 (Part 2), February 1960.

37 Lyons, M. F., et al., "Molten $\mathrm{UO}_{2}$ Fuel Rod Irradiations to High Burnup", ANS Transactions 7, (November 1964), p 411.

Oak Ridge National Laboratory, Metals and Ceramics Division Annual Progress Report for Period Ending June 30, 1964, ORNL-3670, October 1964.

39 Oak Ridge National Laboratory, Status Report for October 1964, ORNL-3729.

40 Hawes, C. C., et al, Summary of the Kilorod Project. A Semiremote 10-Kg/Day Demonstration of $233 \mathrm{UO}_{2}-\mathrm{ThO}_{2}$ Fuel-Element Fabrication by the ORNL Sol-Gel Vibratory-Compaction Method, ORNL3681, August 1965.

41 Chernock, W. P., et al., The Development and Testing of $\mathrm{UO}_{2}$ Fuel Systems for Water Reactor Applications, CEND-2863-243, June 1965.

42 Babcock, D. F。 and Hood, R. R. (compilers), Heavy Water Moderated Power Reactors Progress Report, March - June 1965, DP-975, August 1965.

43 Kerr, J. M. , Bensiek, W. F., and Boyer, R. L., Statistical Determination of Physical Properties of Vibratory Compacted SSCR-Type Fuel Rods, BAW-227, March 1964.

44 Kerr, J. M. and Barnes, L. D., Centi-rod Vibratory Compaction Pilot Run, BAW-271, April 1965.

45 Barnes, L. D. and Kerr, J. M., Vibratory Compaction Process Development, BAW-297, December 1965.

46 Societe Belge pour l'Industrie Nucleaire and Centre d'Etude 1'Energie Nucleaire, Use of Plutonium as Fuel in Nuclear Reactors. Quarterly Report No. 12, July 1 to September 30, 1963, EURAEC-954, November 1963.

47 Japan - US Research Newsletter No. 3, August 1964. 
48 Kingery, W. D., et al., "Thermal Conductivity: S, Data for Several Pure Oxide Materials Corrected to Zero Porosity", J. Amer. Cer. Soc. 37, (1954) pp 107-110.

49 Young, R. C., Thermal Conductivity of Thoria and Thoria-Urania Fuel Elements for the Consolidated Edison Reactor, B\&W Research Center Report No. 7230, November 1959, (Company Confidential).

50 Kingery, W. D., "Thermal Conductivity: XIV, Conductivity of Multicomponent Systems", J. Amer. Cer. Soc. 42, (1959), pp 617-627.

51 Hawkings, R. C. and Bain, A. S., The Effect of Oxygen: Uranium Ratio on the Thermal Conductivity of Uranium Oxide During Irradiation in Pellet Rod Mark V, AECL-1790, May 1963.

52 Neimark, L. A., "Recrystallization in $\mathrm{ThO}_{2}-\mathrm{UO}_{2}$ During Irradiation", Trans.ANS 5, (1962), pp 226-228.

53 Gross, L. B. and DeBoskey, W. R., A Survey of Theoretical and Experimental Thermal Conducitvity of Powders as Applied to Uranium Dioxide, BAW-229, March 1964.

54 Godbee, H. W., "Thermal Conductivity of Magnesia, Alumina, and Zirconia Powders in Air at Atmospheric Pressure from $200 \mathrm{~F}$ to 1500 $F^{\prime \prime}$ Ph. D. Thesis, Georgia Institute of Technology, July 1963.

55 Robertson, J. A. L., $\int k d \theta$ in Fuel Irradiations, AECL-807, April 1959.

56 Irradiation Performance of Thoria-Urania Fuel Materials, Final Report, BAW-3376-4, September 1965.

57 DeBoskey, W. R., "Irradiation Testing of Thoria-Urania Fuel for the Indian Point Reactor", Proceedings of the Thorium Fuel Cycle Symposium, Gatlinburg, Tennessee, December 1962, TID-7650, 1963, pp 630-642.

58 Lawson, V. B. and MacEwan, J. R., Thermal Simulation Experiments with a $\mathrm{UO}_{2}$ Fuel Rod Assembly, AECL-994, March 1960.

59 Rao, S. V. K. , Investigation of $\mathrm{ThO}_{2}-\mathrm{UO}_{2}$ as a Nuclear Fuel, AECL1785, July 1963.

60 Bain, A. S., AECL, private communication. 
61 Thorium Fuel Cycle for HWOCR. Technical Progress Report No. 3, BAW-393-4, July - December 1965.

62 Harbinson, E. N. and Anderson, R. H., Jr., Evaluation of Swaged Fuel Rods Irradiated in Capsule C, BAW-199, December 1962.

63 Olsen, A. R., et al., Irradiation Behavior of Thorium-Uranium Alloys and Compounds, ORNL-TM-1142, June 1965.

64 Olsen, A. R., et al., Current Status of Irradiation Testing of Thorium Fuels at ORNL, presented at 2nd International Thorium Fuel Cycle Symposium, Gatlinburg, Tennessee, May 2 - 6, 1966.

65 Robertson, J. A. L., et al., "Temperature Distribution in $\mathrm{UO}_{2}$ Fuel Elements", J. Nucl. Mat. 7, (1962), pp 225-262.

66 Gross, L. B. and Harbinson, E. N., "B\&W Trip Report No. LBG-8/ ENH-66-1', May 3, 1966.

67 Levin, E. M., Mc Murdie, H. F., and Hall, F. P., Phase Diagrams for Ceramists, American Ceramic Society, 1956.

68 Levin, E. M. , Robbins, C. R., and McMurdie, H. F., Phase Diagrams for Ceramists, American Ceramic Society, 1964.

69 Heavy Water Organic Cooled Reactor - SAP Handbook, AI-CE-MEMO24, March 23, 1966.

70 Harlow, R. A., Interim Report on the Compatibility Between Thorium Dioxide and Aluminum Powder Metallurgy Alloys, TID-7637, October $1,1962$.

71 Wicks, C. E. and Block, F. E., "Thermodynamic Properties of 65 Elements - Their Oxides, Halides, Carbides, and Nitrides", Bureau of Mines Bulletin 605, 1963.

72 Marsh, H. G., Coextrusion of Powder-Compact Slugs, DP-443, April 1960.

73 Myrick, R. E. and Folger, R. L., "Fabrication of Targets for Neutron Irradiation of Neptunium Dioxide", I \& EC Process Design and Development 3 (1964), pp 309-313.

74 Raleigh, D. O., "Prepare Thorium-Aluminum Alloys by Direct Reduction", Industrial and Engineering Chemistry 53 (1961), pp 445-448. 
75 Raleigh, D. O., "Equilibrium Studies in the Reduction of Thorium Oxide by Aluminum", J. Electrochem. Soc. 109, (1962), pp 521-525.

76 Hoekstrá, H. R. and Parker, H. S., "Binary Oxide Systems", Section 6.6 from Uranium Dioxide: Properties and Nuclear Applications, USAEC, 1961 .

77 Hanford Atomic Products Operation, Ceramics Research and Development Operation, Quarterly Report, October - December 1964, $\mathrm{HW}$ 81603, p 2.11 .

78 DeBoskey, W. R. and Gross, L. B., Operating Characteristics and Physical Properties of $\mathrm{PuO}_{2}$ and $\mathrm{PuO}_{2}-\mathrm{UO}_{2}, \underline{\mathrm{BAW}-233,}$ March 1964.

79 Abraham, L., "Thorium-Uranium Monocarbide Fuel Development", Proceedings of the Thorium Fuel Cycle Symposium, Gatlinburg, Tenn., December 1962, TID-7650, 1963, pp 498-518.

80 Farkas, M. S., Bauer, A. A., and Dickerson, R. F., Evaluation of Thorium and Thorium-Uranium Compounds as Thermal Breeder Fuels, BMI-1568, February 1962.

81 Auskern, A. B., et al., "Electrical Properties of Thorium Carbides", J. Phys. Chem. Solids 27 (1966), pp 613-615.

82 Auskern, A., Aronson, S., and Sadofsky, J., Preparation and Characterization of Nonstoichiometric Thorium Carbide, presented at American Ceramic Society Annual Meeting, Washington, D. C., May $11,1966$.

83 Weissert, L. R., "B\&W Trip Report No. LRW-65-1", April 26, 1965.

84 Gross, L. B. and Kerr, J. M., "B\&W Trip Report No. LBG-6/JMK28', April 13, 1966.

85 Russell, L. E., et al., (editors), Carbides in Nuclear Energy, Vol. 2, Preparation and Fabrication; Irradiation Behavior, MacMillan, 1964 .

86 Hansen, M. and Anderko, K. , Constitution of Binary Alloys, Second Edition, McGraw-Hill, (1958) pp 381-383.

87 Elliott, R. P., Constitution of Binary Alloys, First Supplement, Mc Graw-Hill, (1965) pp 231-232. 
Wilheim, H. A. and Chiotti, P., "Thorium-Carbon System"!, Transactions ASM 42, (1950), pp 1295-1310.

Benesovsky, F. and Rudy, E., Studies of the Uranium-ThoriumCarbon System, AEC-TR-5175, 1961, or Phase Equilibrium and Thermodynamic Studies of Carbide Systems Related to High Reactors, DP-Report-132, January 1963.

90 Ivanov, O. S. and Alekseeva, Z. M. , Investigation of the ThoriumUranium Monocarbide System, AEC-TR-5834, July 1963 (original 1961), pp 409-418.

91 Rosen, S., Nonstoichiometry in the Actinide Monocarbides, section from ANL Metallurgy Division Annual Report for 1962, ANL-6677, pp 265-268,

92 Lawrence, J. J. and $\mathrm{O}^{\prime}$ Conner, D. J., "Hydrolys is of Thorium Carbides", J. Nucl. Mat. 5, (1962) pp 156-157.

93 Griesenauer, N. M., Farkas, M. S., and Rough, F. A., Thorium and Thorium - Uranium Compounds as Potential Thermal Breeder Fuels, BMI-1680, July 1964.

94 Kempter, C. P. and Krikorian, N. H., "Some Properties of Thorium Monocarbide and Dicarbide", J. Less Com. Mat. 4, (1962) pp 244-251.

95 Marchal, M. and Trouve, J., Study of the System Carbon-UraniumThorium. Fourth Quarterly Report. October 1 to December 31, 1961, AEC-TR- 5174 .

96 Street, R. S. and Waters, T. N., The Thermal Expansion of ThC and ThN, AERE-M1115, 1962 .

97 Endebrock, R. W. (editor), Properties of Fuels for High Temperature Reactor Concepts, BMI-1598, November 1962.

98 Neimark, L. A., Kittel, J. H., and Crothers, C. C., "Irradiation of Pu-C and (UPu)-C", Carbides in Nuclear Energy, MacMillan, 1964, pp $864-878$.

99 Bradbury, B. T., et al., "Irradiation Effects in U-C and (UPu)-C Fuel Pellets", Carbides in Nuclear Energy, MacMillan, 1964, pp 879-895. 
100 Crane, J. and Grodon, E., "Effect of Fabrication and Composition on the Irradiation Stability of Uranium Carbide", Carbides in Nuclear Energy, MacMillan, 1964, pp 896-918.

101 Proposal to USAEC for a Thorium Fuel Cycle Development Program for Heavy Water Reactors, The Babcock \& Wilcox Company, September $30,1964$.

102 Long Range Development Programs for Thorium Fueled HWOCR, The Babcock \& Wilcox Company, April 20, 1965.

103 DeBoisblanc, D. R., et al., Second UN International Conference on Peaceful Uses of Atomic. Energy, A/Conf 15/P/1842, Vol. 13, p 75, Geneva,, 1958 .

104 Moncrief, E. C. and Schileo, G., Recycle of HWOCR Thorium Fuel, The Babcock \& Wilcox Company, BAW-393-3, Lynchburg, Virginia, March 1966. 


\section{COMPARATIVE EVALUATION OF THORIUM FUELS}

Section 2 describes fuel element designs for the thorium fuel forms under consideration, and section 3 outlines test programs for developing the fuel elements. With this background established, section 4 summarizes the characteristics of each design in a head-on comparison with respect to the principal evaluation factors.

\section{1. Economics}

\section{1. 1. Ground Rules and Methods}

\subsubsection{Economic Ground Rules}

The economic analyses presented here are based on two representative methods of utility financing; investor-owned and publicly-owned reactors. The principal economic factors for these methods of financing are as follows:

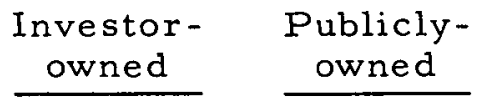

Fixed charges on plant capital, \%/yr

12

7

Fixed charges on nondepreciated assets, including $\mathrm{D}_{2} \mathrm{O}$ and fuel

investment, \%/yr

10

5

Present worth discount rate, $\% / y r$

6

Annual plant factor
0.8

0.8

These economic parameters are representative of one of several 1000-MWe units committed for on-line service in the 1970 's; the se units are forerunners in a growing HWOCR economy. Accordingly, the economic parameters related to fuel cycle costs are based 
on large-scale fabrication and processing geared to service an expanding HWOCR economy. Additional economic ground rules are as.follows:

1. The reactor will begin operation in the period $1970-1980$.

2. The plant lifetime is 30 years.

3. The thorium system is initially fueled with $\mathrm{U}-235$, and the uranium produced is recycled to the core in the reference cases. Plutonium startup and recycle are also considered.

4. For capital cost estimates, all components are fully developed, and first-of-a-kind engineering has been done. (The Thorium HWOCR will use the AI-CE overall plant design and capital cost data where practical.)

5. Fuel is privately owned.

6. The reactor plant and recycle facilities are operating in a mature industry of 15,000 MWe.

7. The reference values of materials are:

$\begin{array}{lr}\mathrm{U}-233, \$ / \mathrm{gm} & 14 \\ \mathrm{ThO} & 5 \\ \mathrm{U}_{3} \mathrm{O}_{8} \text { (nitratlo form), } \$ / 1 \mathrm{~b} & 8 \\ \mathrm{Separative} \text { work, } \$ / \mathrm{kg} & 30 \\ \mathrm{D}_{2} \mathrm{O}, \$ / \mathrm{lb} & 20 \\ \text { Fissile plutonium, } \$ / \mathrm{gm} & 10\end{array}$

\subsubsection{Capital Cost Methods}

Since the major effort on the Thorium HWOCR system is concentrated on core designs, the plant design data are insufficient for establishing independent overall capital cost estimates. However, some consideration of plant capital cost variations is required to optimize for economic power, since design changes that reduce one component of the power cost may increase another. Accordingly, reactor hardware cost curves and secondary system heat transfer equipment costs based on data from the ORNL evaluation of the HWOCR ${ }^{1}$ were developed as. reported in BAW - $393-6,{ }^{2}$ and used to estimate capital costs of the reference designs. Other variable costs, such as primary pump and driver and instrumentation, were included. The effect of design parameters on net plant efficiency was also estimated, and the capital costs for the three designs reflect these variations in efficiency. 


\section{1.1.3. Fuel Cycle Cost Methods}

The fuel cycle economic evaluation considers all costs associated with fuel, from the time the initial fuel loading is purchased for fabrication to the end of reactor lifetime when fuel is discharged from the reactor at some value. The costs include fabrication, reprocessing, shipping, and fuel depletion (direct costs), and working capital charges on investments, either material of value (inventory) or services of value (fabrication and reprocessing).

Economic evaluation of nuclear fuel cycles can be complicated, since many factors vary during the lifetime of a nuclear plant; therefore a method of evaluation that properly accounts for the time value of money is required. Many investor-owned electric utilities in the United States use the present worth of future revenue requirements as the criterion of economic choice. This method, based on minimizing the cost of energy to the customer, can be readily applied to fuel cycle evaluation. The appropriate economic criterion is the levelized fuel cycle cost which is derived by applying the present worth to annual fuel cycle revenue requirements. This method, incorporated into one of the Company's confidential computer programs, has been used to obtain the nuclear fuel costs in this analysis. The levelized fuel costs are defined as follows:

1. Let $M=$ levelized fuel cost (mills/kwhr) that satisfies fuel-cycle revenue requirements during a period of $n$ years.

2. Let $\mathrm{K}_{1}=\mathrm{kwhr}$ generated in the first year, $\mathrm{K}_{2}=\mathrm{kwhr}$ generated in the second year, and so on.

3. Let $P_{1}=$ present worth of $\$ 1$ received one year hence, $P_{2}$ two years hence, etc.

4. Let $R_{1}=$ revenue requirements in the first year, $R_{2}$ in the second year, etc.

5. Since $M$, by definition, makes receipts satisfy the revenue requirements, it is given by

$$
M=\frac{P_{1} R_{1}+P_{2} R_{2} \cdots \cdots P_{n} R_{n}}{K_{1} P_{1}+K_{2} P_{2} \cdots \cdots K_{n} P_{n}} \times 10^{3}
$$

Levelized fuel costs for a 30-year period are calculated for the 1000-MWe Thorium HWOCR conceptual designs based 
on physics data from recycle analysis. In the recycle analysis, lifetime calculations are made for a pressure tube unit cell and include a correction for total core leakage as noted in section 2 . The fuel exposure history of a fuel element is calculated by batch core techniques modified to simulate continuous on-line refueling by allowing the batch cores to run to a lifetime exactly double the normal lifetime. The basis for this simulation is that the fuel exposure of the discharged fuel is about twice the average exposure in the core. The validity of this method was tested and found to be adequate for survey calculations, but inadequate for es tablishing an optimum startup cycle. Consequently, most of the fuel cycle costs are not based on the startup core, but on the first fuel element of the second core. This fuel element, which displaces one of the six original elements in a pressure tube, is discharged from the cure at the same burnup as the equilibrium cycle fuel burnup. The startup core fabrication cost is included in the fuel cost of the first cycle calculated.

The optimum startup cycle will have a lower average fuel exposure than will the equilibrium cycle; therefore, the fabrication component of the startup cycle fuel cost will be greater than the value calculated by including the startup core in the first-cycle fuel cost analysis. However, the fuel enrichment of the startup core will be lower than that of the first-cycle core-a fact that will compensate for the disparity in fabrication cost. Detailed fuel management calculations have not been made to optimize the startup cycle, but a startup method was considered for the nested-cylinder core, as explained in section 2. 3. 1, to verify the assumption that fucl cycle costs based on the batch core nuclear analysis approximate those for a true startup method.

Although the components of the fuel cycle cost and the method of computation are adequately established throughout the power industry, the corrcct working capital charges on fuel inventory in recycled cores are not clearly defined. This is due partially to differences in accounting methods by various utilities and designers and partially to the uncertainty of the worth of bred fuel.

Several methods of computing fissile material inventory charges have been considered. In the reference calculations, a value of $\$ 14 / \mathrm{gm}$ is assigned to $U-233$, and working capital charges on 
fissile material are calculated on an average fuel worth during each cycle. Fabrication charges are linearly depreciated to zero value at the end of core life. Reprocessing and shipping charges, which occur at the end of the cycle, are capitalized from the beginning of the cycle and hence are negative costs.

Initial core fabrication financing charges are based on an equivalent fabrication rate of 0.5 tonne/day, an average value during the fabrication period equal to one-half the initial core value and a rate of $6 \%$ and $4 \%$, respectively, for investor-and publiclyowned plants. These financing charges are added to the fabrication cost of the first core loading. The pre-and post-irradiation times used in computing the fuel cycle costs are 90 and 210 days.

Fabrication-reprocessing costs are a significant portion of the fuel cycle cost. To minimize the uncertainty in this component, B\&W evaluated the fabrication and reprocessing requirements in detail for both thorium metal nested-cylinder and Vipac oxide pin fuel element designs. Cost estimates were developed based on both thorium and uranium recycle in a heavily shielded, remotely operated integrated plant, the TRIP facility, and the results were published in BAW $-393-3 .^{6}$

Personnel at ORNL also calculated fabrication and reprocessing costs for the same designs to aid in their design evaluation effort, and provided cost information from a computer program on several other designs to assist $B \& W$ in the optimization studies. The fabrication-reprocessing values used in the fuel cycle cost calculations are as follows:

\begin{tabular}{|c|c|c|c|}
\hline & $\begin{array}{l}\text { Nested } \\
\text { cylinder }\end{array}$ & Oxide pin & Carbide pin \\
\hline Fabrication and conversion & 40.30 & 42.00 & 51.20 \\
\hline Reprocessing and shipping & 27.10 & 29.00 & 29.00 \\
\hline
\end{tabular}

The fissile material charges account for the change in fuel value from the initial worth, due to fuel depletion (makeup) and losses in processing. All losses (1.5\%) and protactinium decay $(98.95 \%)$ are assumed to occur at the end of core life. 


\section{1.2. Economics of 1000-MWe Thorium-Optimized HWOCR's}

\subsubsection{Fuel Cycle Costs}

Table 4-1 summarizes the fuel cycle costs of all three designs for both investor-owned and publicly-owned utility financing, based on U-235 startup and batch recycle of U-235 and bred U-233. The fuel costs for plutonium startup are given in Table 4-2.

In general, the U-235 startup fuel cycle costs are between 1.19 and $1.23 \mathrm{mills} / \mathrm{kwhr}$ for all designs at 20,000 $\mathrm{MWD} / \mathrm{T}$ under investor-owned utility financing. Under publicly-owned utility financing, the fuel cycle costs vary from 0.94 to $1.00 \mathrm{mill} / \mathrm{kwhr}$. The costs are lowest for the nested-cylinder design and highest for the carbide pin design, but the difference is within the estimated uncertainty. band. It is also noteworthy that the fuel cycle costs based on batch recycle and those based on semi-continuous refueling methods (see section 2.3.1) are about equal.

Based on the same thermal performance as the U-235 case, the use of plutonium priced at $\$ 10 / \mathrm{gm}$ as startup fuel with recycle of plutonium and bred $U-233$, gives fuel cycle costs essentially identical to those for U-235 startup fuel at $\$ 12 / \mathrm{gm}$. These results may be altered appreciably when one considers the variation in power production over the life of the fuel element that occurs when highcross-section plutonium is burned and low-cross-section uranium is produced. At least, a reoptimization of the design or zone loading would be required to compensate for this effect.

\section{1.2.2. Capital, $\mathrm{D}_{2} \mathrm{O}$, and Maintenance Costs}

The estimated capital, $\mathrm{D}_{2} \mathrm{O}$, and operating costs for each of the three reference designs are summarized in $\mathrm{Table}$ 4-3. Capital costs for investor-owned financing conditions a re $\$ 119 \times 10^{6}$ for the nested-cylinder design and $\$ 126.4 \times 10^{6}$ for the oxide pin design. Indirect costs were determined using the same percentages as used in the advanced converter study. ${ }^{3}$ These costs compare with $\$ 120.9 \times 10^{6}$ estimated by ORNL for the uranium design and $\$ 115.3 \times 10^{6}$ for the thorium metal design in the HWOCR Evaluation Report. 1 Including the $\mathrm{D}_{2} \mathrm{O}$ cost and a constant value of $0.3 \mathrm{mill} / \mathrm{kwhr}$ for operation and maintenance, 
the power costs, exclusive of the fuel cycle, vary from 2.36 to 2.51 mills/kwhr. Corresponding values under publicly-owned financing conditions are $1.46 \mathrm{mills} / \mathrm{kwhr}$ for the nested-cylinder design and 1.55 mills/kwhr for the oxide pin design.

\section{1.2.3. Power Costs}

The fuel cycle costs have been combined with the other costs to obtain the following total power costs.

$\underline{U}-235$ startup fuel

Investor financing

Public financing

$\underline{\text { Plutonium startup fuel }}$

Investor financing Public financing

*Not calculated.

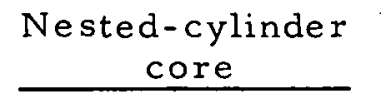

3.54

2.40

3.54

2.40

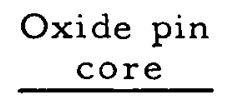

3.73

2.49

3.73

2.50
Carbide pin core

3.71

2.52 
plutonium fuels. Thus, these values serve more to indicate the potential for the use of plutonium in the Thorium HWOCR rather than to provide accurate power costs with this fuel.

4. 1. 3. Fuel Cycle Costs - 1000-MWe AI-CE HWOCR With Thorium Fuel Elements

The preliminary thorium-fuel-element designs described in sections 2.3.2 and 2.4.2 were developed for operation in a 1000-MWe HWOCR defined by extrapolation of the 500-MWe HWOCR demonstration plant described in AI-CE Memo 25.4 Since the optimized thorium carbide core described in section 2.5 is designed to operate in the AI-CE HWOCR plant, two separate carbide designs are not required.

The batch fuel cycle cost based on "idealized" cycle nuclear calculations are shown in Table 4-4 and Figure 4-1 for these three designs, along with corresponding results for the reference Thorium HWOCR designs. Although the optimum and the thorium carbide core for the AI-CE plant are identical, the "idealized" batch fuel cycle costs are presented for comparison with those for the oxide pin and nestedcylinder designs.

As shown in Figure 4- 1 the fuel cycle costs for the 55pin thorium oxide core in the AI-CE plant are about $0.1 \mathrm{mill} / \mathrm{kwhr}$ higher than those for the 37-pin optimized thorium oxide design. This difference is primarily due to the design requirements which dictate pin diameters in the 55-pin fuel element of about 0.38 inch, which is below the economic optimum primarily because of the increased fabrication cost in $\$ / \mathrm{kg}$. In addition, the resultant lower volume fraction of thorium decreases the conversion ratio and increases the burnup cost to essentially offset the savings from lower fuel inventory. Thus, with oxide fuels, either the diameter or the quantity of pressure tubes must be increased for minimum fuel cycle costs.

As noted in section 2.3.2, it was assumed that the pressure tubes in the $A I-C E$ plant that are not required for the thorium metal nested-cylinder core will not be used. Modifications to make the core and plant more compatible while maintaining the advantageous higherpower-capability would definitely be required, but the results illustrate the potential of the nested-cylinder element. Table 4-4 shows that the batch "idealized" fuel cycle costs for the thorium metal nested-cylinder 
core in the AI-CE plant are essentially identical to those for the optimized design. Thus, the favorable economics of the thorium-optimized nestedcylinder design is due to reduced capital and $\mathrm{D}_{2} \mathrm{O}$ cost rather than to the fuel cycle cost.

\section{1.4. Major Uncertainties}

\section{1. 4.1. Fabrication and Reprocessing Cost} Uncertainties

Unit processing costs were estimated by $B \& W$ and ORNL for the thorium-optimized fuel element designs described in section 2 (see Table 4-5). All costs are based on a burnup of 20,000 MWD/T, which corresponds to a recycle plant capacity of about 2.6 tonnes/day.

The ORNL costs were compiled from two sources. The costs for reprocessing, shipping, and conversion are from ORNL's HWOCR evaluation. ' To these costs were added more recent ORNL $\operatorname{costs}^{5}$ for fabricating the optimum fuel designs mentioned above.

The B\&W estimates for oxide and alloy were made by adjusting the TRIP facility's ${ }^{6}$ recycle costs for recent changes in the pin and nested-cylinder designs. Data from reference 5 and other sources ${ }^{7}$ were used to adjust these costs.

$\mathrm{B} \& \mathrm{~W}$ carbide costs were estimated by adding the ORNL costs for reprocessing, conversion, fabrication, and shipping after making these adjustments:

1. A $10 \%$ cost increment was added to the ORNL unit reprocessing cost for oxide to give the carbide recovery cost under the $B \& W$ single-cycle concept. This incremental cost to handle carbide was considered valid by SRP perșonnel. ${ }^{8}$

2. A $20 \%$ cost increment was added to the ORNL carbide fabrication cost to cover flow sheet uncertainties (to expedite estimation ORNL assumed the same fabrication flow sheet for $\mathrm{ThC}$ as was used previously for UC).

3. The total adjusted unit cost based on the ORNL estimates was then decreased by $10 \%$ for integrated processing (credit to the TRIP recycle concept). 
The agreement between the estimates in Table 4-5 is extremely good, although perhaps fortuitous. While the maximum difference between estimates is only about $10 \%$ (for the alloy fuel), the potential error in the absolute costs may be 20 to $25 \%$. Nuclear fuel. cycle cost estimates are seldom performed in sufficient breadth to permit assignment of statistically evaluated error bands. Normally, when several estimates are used to cost the same process, the technical approach and assumptions vary considerably between estimates. In this case, the error band assigned to the cost by each estimator generally reflects his opinion of the error based on his overall knowledge of the problem. Such is the case in the estimates of the unit processing costs given in Table 4-4.

Two contributions should be considered in evaluating the total error associated with $B \& W ' s$ HWOCR unit processing cost estimates: (1) an error as sociated with the level of effort expended on the design, and (2) an error dependent on the technological unkrowns inherent in each fuel recycle flow sheet. These error bands are estimated to be $15 \%$ and $10 \%$ for the most-proven fuel type (oxide). Greater uncertainties are possible for the metal and carbide cases.

Since unit processing costs constitute about $40 \%$ of the HWOCR fuel cycle cost, ${ }^{2}$ a potential error of $25 \%$ in the unit processing cost can result in about a $0.1 \mathrm{mill} / \mathrm{kwhr}$ uncertainty in the total power cost. Thus, a total power cost difference of $0.1 \mathrm{mill} / \mathrm{kwhr}$ between candidate fuels falls within the possible uncertainty band. Therefore the final choice of fuel should be based on careful consideration of other factors in addition to economics.

\section{1.4.2. Fuel Exposure Limits}

As noted in the evaluation of each design (section 2) the exposure limit of $20,000 \mathrm{MWD} / \mathrm{T}$ is not the economic optimum. Figure 4- 1 illustrates typical power cost variations with $M W D / T$ and indicates that fuel cycle costs vary about $0.01 \mathrm{mill} / \mathrm{kwhr}$ per $1000 \mathrm{MWD} / \mathrm{T}$ change in exposure for small changes from the reference value. In general, an increase to the economic optimum of 25,000 to $35,000 \mathrm{MWD} / \mathrm{T}$ would decrease fuel cycle cost of each design about 0.05 to $0.10 \mathrm{mill} / \mathrm{kwhr}$. At burnup less than the design value the rate of change in fuel cycle cost 
with $\mathrm{MWD} / \mathrm{T}$ is increasingly greater. A reduction to $10,000 \mathrm{MWD} / \mathrm{T}$ would increase the cost 20 to $25 \%$.

The value of $20,000 \mathrm{MWD} / \mathrm{T}$ established for the oxide design is limited by fission gas pressure and represents a compromise between two economically important parameters-MWD/T and specific power or pin heat rating. Should development efforts produce favorable fission gas release results, exposures could probably be increased at least $50 \%$ before other irradiation characteristics begin to limit performance.

The nested-cylinder exposure of 20,000 MWD/T average is based on maximum fuel swelling of about $7 \%$ at the rate of 2 volume \% per atomic \% burnup. This swelling rate is probably conservative, judging from PNL results. Furthermore, the change in volume at design conditions would not be limiting unless the structural integrity of the fuel element were jeopardized. Since this situation demands engineering judgment, an attempt was made to establish reasonably conservative limits, and favorable development results could demonstrate that economically optimum exposure is achievable.

No irradiation data are available for thorium monocarbide. The design value of $20,000 \mathrm{MWD} / \mathrm{T}$ is assumed on the basis of uranium monocarbide data, but cannot otherwise be justified.

\section{1.4.3. Conversion Ratio Uncertainty}

The conversion ratio in any reactor is primarily determined by two factors: the net number of neutrons produced per absorption in fissile material $(\eta-1)$, and the ability of the fertile material to compete with other neutron-absorbing atoms and losses. Since each of these items has associated with it some degree of uncertainty, the conversion ratio computed from the nominal values must also have an associated range of uncertainty. Statistical analysis based on the assignment of a numerical uncertainty to each variable can be used to determine a confidence level for various degrees of uncertainty in the conversion ratio. This approach has not been applied to the Thorium HWOCR, so a true numerical confidence level cannot be assigned to the calculated conversion ratio. It is possible, however, to identify the significant factors influencing the conversion ratio and to evaluate their importance. 


\section{$\underline{\eta \text { (Neutrons Produced/Fissile Absorption) }}$}

The high conversion ratio potential of the thorium system lies mostly in $\eta$ of $U-233$. Averaged over the reactor spectrum to $10 \mathrm{Mev}, \eta$ of $U-233$ is about 2.26 compared to about 2.03 for $\mathrm{U}-235$. Considering data uncertainties and difficulties in computing the thermal spectrum, a plus or minus 0.02 is not unreasonable for $\eta$ of U-233. Since thorium absorbs about $70 \%$ of the excess neutrons during core life, this would lead to approximately 0.014 uncertainty in conversion ratio. A second problem concerned with $\eta$ arises from the use of U-235 as a startup fuel. Conversion ratios of successive cycles on the approach to equilibrium follow the average $\eta$ and therefore depend on the rate of transition from U-235 to U-233. Thus, the conversion ratio of cycle 2 depends on that of cycle 1 , etc. If cycle 1 has a low conversion ratio for some reason, the makeup U-235 to cycle 2 will be higher, the average $\eta$ in cycle 2 will be lower, and the U-236 buildup during cycle 2 will be greater. All these factors lead to the conclusion that a reduction in the initial conversion ratio (say on addition of neutronabsorbing structural material) may compound itself and have a greater effect on subsequent cycles. It is not clear what the effect would be on the true equilibrium cycle, however, since it is independent of method of approach. Calculations have not been made to evaluate the effect of compounding errors on conversion ratio, and a numerical estimate would be conjecture at this time.

\section{Thorium Cross Section}

In addition to the high $\eta$ of $U-233$, the thorium system has the advantage of a fertile material thermal cross section nearly two and one-half times higher than that of $U-238$. This is an obvious advantage in competition for the excess neutrons and contributes to the high conversion ratio. Thorium's thermal cross section, however, is not well known in the range of 0.1 to $20 \mathrm{ev}$. Measurements are required to fill in this gap. Thorium's self-shielded resonance integral is known to about $10 \%$. The best estimate of the total uncertainty in the thorium cross section is 5\%. An error of $5 \%$ would be roughly equivalent to about 0.015 in conversion ratio. 
The use of low-cross-section structural materials in the HWOCR reduces the effect of the uncertainty in these cross sections. The buildup of fission products and heavy isotopes is more significant and has a larger associated uncertainty. A typical core loses about $25 \%$ of its excess neutrons to parasitic absorption over life. A $10 \%$ variation in these losses would be equivalent to about 0.021 in conversion ratio.

\section{Reactor Leakage}

Leakage is small in the HWOCR even though core calculations account for increased leakage due to power shaping. The effect of an uncertainty in the computed leakage would be minor compared to other effects. A $10 \%$ error in leakage translates into about 0.004 in conversion ratio.

\section{Lifetime Calculation Technique}

Although the HWOCR has bi-directional refueling, calculations have been based on a simple one-dimensional approximation which was tested against a three-dimensional synthesis model. As described in section 2.3.1.3, this method was also checked against a more refined one-dimensional model closely resembling ORNL's TONG code. Any error in this process would show up primarily in an incorrect matching of feed enrichment and discharge burnup, which would be equivalent to computing the wrong average $\mathrm{k}_{\mathrm{eff}}$ as a function of time. A $1.5 \%$ error in $k_{\text {eff }}$ due to the model would change the conversion ratio by about 0.03 .

\section{$\underline{\text { Reactivity Control }}$}

All calculations have assumed a just-critical reactor. In reality, some excess reactivity must be carried for control of power shape and maneuvering. The vertical control system described in AI-CE Memo $6^{9}$ is worth about $0.003 \Delta \mathrm{k}$. Assuming that the available reactivity for control averages $50 \%$ in the core, a loss of 0.003 in conversion ratio would result. 


\section{Other Effects}

The aforementioned items would be expected to play the largest roles in conversion ratio uncertainty, but other factors should be considered to some degree. Pa-233 losses are still small at present specific powers, and reasonable uncertainties in this cross section would not be a problem. Thorium fast-fission will be affected somewhat by the geometry, but will not be a strong factor. Nonuniform discharge burnups will also affect the conversion ratio, but no attempt to estimate these effects has been made.

Proper combination of these error estimates

is difficult because they are interdependent. Considering the estimated errors to be standard deviations, the estimated uncertainty for the first cycle is \pm 0.043 ; allowing for factors not considered, an uncertainty of about 0.05 is reasonable. The uncertainty in the conversion ratio for subsequent cycles may be slightly greater, perhaps \pm 0.06 to 0.07 .

\section{1. 4. 4. Specific Power Limits}

The specific power and associated pin heat rating are key parameters in establishing the economic performance of a design. As noted in section 2.4.3, the relatively low heat rating for the oxide design, which is limited primarily by fission gas release, penalizes the economic performance. It affects both fuel cycle and plant capital costs. For small changes from the design value of pin heat rating, the power cost changes about $0.005 \mathrm{mill} / \mathrm{kwhr}$ per percent change in $\mathrm{kw} / \mathrm{ft}$. However, higher heat ratings necessarily require more stringent thermal-hydraulic performance. The associated higher core pressure differentials and lower outlet temperatures decrease the net plant efficiency and thereby lead to an economic optimum heat rating. An increase of $25 \%$ to $12.5 \mathrm{kw} / \mathrm{ft}$ average in the hot pin would reduce the power cost of the oxide design by about 0.10 to $0.15 \mathrm{mill} / \mathrm{kwhr}$, and this heat rating would probably be within $0.05 \mathrm{mill} / \mathrm{kwhr}$ of the economic optimum. Further increases in the carbide pin heat rating would not significantly affect power cost.

Since the optimum design of the nested-cylinder fuel element has the maximum heat flux on all fuel element surfaces, the maximum specific power is dependent on the pressure tube radial power 
distribution and the allowable heat flux. Therefore, the specific power can be altered by a change in the power profile or in the allowable heat flux. The radial power peaking is the factor most likely to be altered by the fuel element test program. The economic effect of specific power changes for the nested-cylinder design is similar to that for the clusteredpin cores.

\section{1.4.5. Value of Fissile Material}

The value of fissile material obviously plays a major role in determining the fuel cycle cost in any reactor. For thorium fuel cycles, which require fully enriched fuel and a relatively large fuel inventory, the fuel value is the prime determinant. For example, burnup and inventory charges, which are directly related to fissile material value, constitute 50 to $70 \%$ of the Thorium HWOCR fuel cycle cost. Thus, relatively small changes in such predominant factors can significantly alter the results.

The reference values for the Thorium HWOCR evaluation given in section 4.1 . 1 define the $U-233$ value at $\$ 14 / \mathrm{gm}$. An alternate value of $\$ 18 / \mathrm{gm}$ with a penalty of $\$ 12 / \mathrm{gm} \mathrm{U}-236$ was suggested by ORNL. Both of these values were considered in evaluating the fuel cycle costs of the reference designs. In addition, calculations were performed in which the dollar value of the core at the start of each batch was a constant. The value at the end of the batch life was equal to the initial value minus the U-235 makeup cost at the reference value of $\$ 12 / \mathrm{gm}$. Fuel cycle costs were also obtained with U-233 valued at zero and $\$ 7 / \mathrm{gm}$ to indicate the effect of variation in value of the bred fuel.

The 30-year levelized results for the nested-cylinder core based on recycle of fissile and fertile materials are as follows:

\section{U-233 Value, $\$ / \mathrm{gm}$}

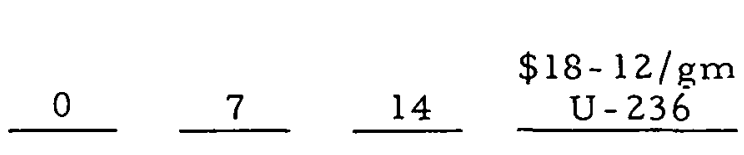

Variable to maintain constant core value

Fuel cycle cost

Investor-owned

1.028

1. 108

1.189

1.237

1. 192

0.916

0.945

0.966 
In general, the results show that the $\$ 18 / \mathrm{gm}$ U-233 with a $\$ 12 / \mathrm{gm} U-236$ penalty produces the highest fuel cycle cost and that the $\$ 14 / \mathrm{gm} U-233$ leads to costs essentially identical to those obtained with the core value held constant at the start of each batch loading. The trends are similar for all three designs. For investor-owned conditions the fuel cycle costs may be expressed as a function of U-233 value by the equation

fuel cycle cost in mills $/ \mathrm{kwhr}=1.028+0.0115(\$ / \mathrm{gm} \mathrm{U}-233)$.

The value of startup and makeup fissile material (U-235 or plutonium) has a greater effect on fuel cycle cost than does the value of bred fuel alone, since the $U-233$ price is currently established by the U-235 value. Although costs of $\$ 8 / \mathrm{lb}$ for $\mathrm{U}_{3} \mathrm{O}_{8}$ (yellow cake) and $\$ 30 / \mathrm{kg}$ for separative work have been used as the reference values, lower costs are anticipated in the near future which will reduce the value of fully enriched U-235 below $\$ 12 / \mathrm{gm}$. In addition, the value of plutonium may be partially determined by future technological developments and may differ from the reference value of $\$ 10 / \mathrm{gm}$. Calculations were made to assess the variation in Thorium HWOCR fuel cycle costs with decreasing startup fissile material values. Typical results are tabulated below. In obtaining these results for the nested-cylinder core, U-233 was held at $14 / 12$ the value of $U-235$ for $U-235$ startup cases and at $\$ 14 / \mathrm{gm}$ for plutonium startup cases. Comparable results for the oxide pin core with plutonium startup are shown in Figure 4-2.

\begin{tabular}{|c|c|c|c|c|}
\hline & \multicolumn{4}{|c|}{ Startup fuel, $\$ / \mathrm{gm}$} \\
\hline & $\underline{y}-235$ & $\mathrm{U}-235$ & $\mathrm{Pu}$ & $\mathrm{Pu}$ \\
\hline & 12 & 6 & 10 & 0 \\
\hline & \multicolumn{4}{|c|}{ Fuel cycle cost, mills/kwhr } \\
\hline Investor-owned & 1.189 & 0.808 & 1.1818 & 0.5982 \\
\hline Publicly-owned & 0.945 & 0.684 & 0.9408 & 0.4453 \\
\hline
\end{tabular}

In general, the results for the investor-owned case indicate that fuel cycle costs decrease $0.064 \mathrm{mill} / \mathrm{kwhr}$ for each dollar per gram decrease in value of $U-235$. The results are defined by the equation: 
fuel cycle cost in mills $/ \mathrm{kwhr}=0.427+0.0636(\$ / \mathrm{gm} \mathrm{U}-235)$

Under publicly-owned financing rates, the variation is $0.044 \mathrm{mill} / \mathrm{kwhr}$ per unit change in $\mathrm{U}-235$ value. Thus, at $\mathrm{U}_{3} \mathrm{O}_{8}$ (yellowcake) and sepa-

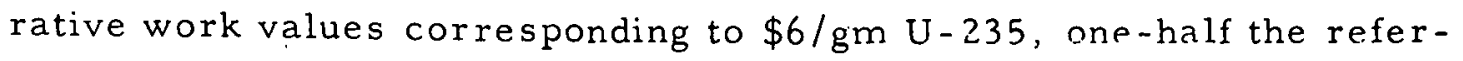
ence value, fuel cycle costs for the thorium nested-cylinder design are $0.81 \mathrm{mill} / \mathrm{kwhr}$ at a $10 \%$ financing rate and $0.68 \mathrm{mill} / \mathrm{kwhr}$ at a $5 \%$ rate. Comparable values at one-half the reference value of plutonium are 0.890 and $0.693 \mathrm{mill} / \mathrm{kwhr}$, as shown above. Although changes in value of this magnitude are unlikely to occur, some changes from the reference conditions are expected. These results indicate approximate changes in the Thorium HWOCR fuel cycle cost with modified fuel material values.

\subsubsection{Film Fouling}

For the purposes of the design evaluation, the maximum allowable prefouling surface temperature was set at $830 \mathrm{~F}$ for the clustered-pin designs and $820 \mathrm{~F}$ for the nested-cylinder design. (The nested-cylinder value is less because of the greater allowable heat flux.) A change in surface temperature will significantly modify the thermal performance, as indicated in Figure 4-3. The improved thermal characteristics, in turn, will increase the net plant efficiency, reduce the reactor size, and significantly improve the economic performance. A 50-F increase in surface temperature would modify the operating parameters extensively and reduce the power cost by about 0.05 to $0.10 \mathrm{mill} / \mathrm{kwhr}$. By contract, $\mathrm{B} \& W$ is dependent on $\mathrm{AI}-\mathrm{CE}$ for coolant technology; $\mathrm{AI}-\mathrm{CE}$ is conducting an experimental program to investigate film fouling and resolve this uncertainty.

\subsubsection{Conclusions of Econornic Studies}

Thirty-year levelized fuel cycle costs are essentially identical for all three reference designs; under investor-owned financing conditions the variation is only $0.04 \mathrm{mill} / \mathrm{kwhr}$. The fuel cycle costs are about $1.2 \mathrm{mills} / \mathrm{kwhr}$ for investor-owned financing and $0.95 \mathrm{mill} / \mathrm{kwhr}$ for publicly-owned financing for either U-235- or plutonium-fueled cores at reference materials values. The fuel-management method selected to check the validity of the fuel cycle cost, which are primarily based 
on batch recycle nuclear data, confirmed the general accuracy of the batch recycle economics results.

i1:

The value of materials, the financing rate, and the technical limits all influence the fuel cycle cost. The more important technical limits are fuel exposure or burnup, specific power, and clad surface temperature; the economic effects of these limits have been evaluated. The fuel cycle costs decrease about $0.05 \mathrm{mill} / \mathrm{kwhr}$ for each percentage decrease in the financing rate. Fuel material values are major determinants of fuel cost. Under publicly-owned conditions with fuel material at one-half the reference value, fuel cycle costs as low as $0.68 \mathrm{mill} / \mathrm{kwhr}$ could be realized.

Plant capital, operation and maintcnance, and $\mathrm{D}_{2} \mathrm{O}$ costs constitute approximately two-thirds of the total power costs under investor-owned conditions; the percentage of these costs is slightly smaller under publicly-owned conditions. Capital and $\mathrm{D}_{2} \mathrm{O}$ costs for the nestedcylinder design are about $0.15 \mathrm{mill} / \mathrm{kwhr}$ lower than these costs for the clustered-pin designs. This differential is the major factor in the favorable economic position of the nested-cylinder design. Power costs for the three reference designs are in the range of 3.5 to $3.7 \mathrm{mills} / \mathrm{kwhr}$ under investor financing and 2.4 to $2.5 \mathrm{mills} / \mathrm{kwhr}$ under public financing. Since the power cost differentials fall within the uncertainty band, other factors must be given careful consideration in selecting a fuel element design for future development.

\subsection{Fuel Utilization}

The term, fuel utilization, is normally considered a measure of the efficiency of the use of natural resources of fissionable material. In this respect, the Thorium HWOCR has excellent fuel utilization characteristics. In addition, there are strong incentives to exploit the vast energy resources latent in thorium. The Thorium HWOCR is the most practical vehicle for achieving wide-scale utilization of thorium.

For evaluating the fuel utilization of the HWOCR, AI-CE uses the Dynamic Utilization as the figure of merit. The following definitions and equation are taken from AI-CE MEMO-6.9 Assuming the nuclear power industry is growing at an exponential rate characterized by a doubling time, $T_{d}$, the defined quantities are: 
1. The Exponential Investment (E.I.) of natural uranium is the ratio of the number of tons of natural uranium as $\mathrm{U}_{3} \mathrm{O}_{8}$ fed into the industry up to any time, $t$, for both burnup and inventory, to the number of megawatt years of electric energy produced up to the time, $t$. Obviously, the value of the E.I. depends upon the doubling time. An appropriate doubling time is necessary to determine an E.I. value that has a meaningful relationship to the fuel supply problem.

2. The Dynamic Utilization (D. U.) of natural uranium is the reciprocal of the E.I. The D.U. is proposed as the figure of merit, evaluated for a suitably selected doubling time.

$$
\text { Assuming } e^{0.693 \mathrm{t} / \mathrm{T}_{\mathrm{d}}}>1 \text {, the E.I. can be calculated with the }
$$
following equation:

$$
\text { E.I. }=\frac{N}{W}=B+\frac{0.693 S}{F T_{d}}
$$

where

$$
\begin{aligned}
\mathrm{S}= & \text { specific inventory including outcore require- } \\
& \text { ments = tons of } \mathrm{U}_{3} \mathrm{O}_{8} \text { required to provide the } \\
& \mathrm{U}-235 \text { for } 1 \mathrm{MW} \text { of installed reactor capacity } \\
\mathrm{F}= & \text { plant factor } \\
\mathrm{B}= & \text { specific makeup for burnup in equivalent tons } \\
& \text { of } \mathrm{U}_{3} \mathrm{O}_{8} \text { per megawatt-year of electric energy } \\
& \text { produced } \\
\mathrm{W}= & \text { total electric energy produced from } \mathrm{t}=0 \text { to } \\
& \mathrm{t}=\mathrm{T} \\
\mathrm{N}= & \text { total natural uranium, as tons of } \mathrm{U}_{3} \mathrm{O}_{8}, \text { put } \\
& \text { into the system for burnup plus inventory } \\
& \text { from } \mathrm{t}=0 \text { to } \mathrm{t}=\mathrm{T}
\end{aligned}
$$

Two trends may be observed from the foregoing equation:

1. The D.U. is sensitive to the assumed doubling time of the nuclear economy. Generally, a short doubling time favors reactors with low specific inventory, such as the Uranium HWOCR. Long doubling times are more favorable to a reactor with low specific burnup, such as the high-conversion-ratio Thorium HWOCR.

2. The D.U. considers the number of tons of $\mathrm{U}_{3} \mathrm{O}_{8}$ fed into the industry up to any time, $t$. It does not consider, however, the tons 
committed for operation of the reactors beyond time $t$; e.g., all reactors going on the line at time $t$ require an ore commitment for 30 years of operation. Therefore, the D. U. favors the low-inventory reactor rather than the good converter.

The D.U. does provide one basis for comparing the relative fuel utilization characteristics of the thorium-optimized 1000 MWe HWOCR's. Examination of Table 4-6 shows only slight differences in the $D$. U. for the three designs. The differences are within the accuracy of the calculations, so that no single design has a conclusive advantage in $D . U$. Similarly, the conversion ratios for all three reactors are essentially the same $(0.86$ to 0.87$)$, which seems to indicate that designs optimized for economics have about the same conversion ratio. The uncertainties in the conversion ratio were discussed in section 4.1 .

Available data on the "idealized" cycle conversion ratios of the Thorium HWOCR designs have been correlated against the important design variables. The following equation was found to predict the conversion ratio from the "idealized" cycle nuclear calculations for clustered-pin cores:

$$
\text { C.R. }=0.86+0.352 \mathrm{~V}_{\mathrm{f}}-2.6 \times 10^{-6}(\mathrm{MWD} / \mathrm{T})-1.4 \times 10^{-3}(\mathrm{w} / \mathrm{gm})
$$

where

$$
\begin{aligned}
C \cdot R . & =\text { conversion ratio } \\
V_{f} & =\text { volume fraction of thorium metal in the pressure tube }
\end{aligned}
$$

The correlation of oxide and carbide conversion ratio data is shown in Figure 4-4.

The conversion ratio is less sensitive to the fuel volume fraction in the nested-cylinder design than it is in the clustered-pin corcs. The variation of conversion ratio with volume fraction in the nested-cylinder designs is also shown in Figure 4-4. These results can be expressed by the following equation:

$$
\text { C.R. }=0.944+0.21 \mathrm{~V}_{\mathrm{f}}-2.6 \times 10^{-6}(\mathrm{MWD} / \mathrm{T})-1.4 \times 10^{-3}(\mathrm{w} / \mathrm{gm})
$$

This difference in sensitivity is probably due to the different methods of changing volume fractions in the two designs. Fuel is added or removed uniformly over the pressure tube area by changing the pin pitch or fuel pin diameter in the clustered-pin elements. In contrast, the 
nested-cylinder fuel volume fraction is changed by adding or removing fuel preferentially toward the center of the element to maintain a thermally optimum design. Consequently, the fuel fraction is changed in a relatively low flux region, near the center of the element, while the fuel fraction remains constant in the outer, higher flux region of the pressure tube. These results indicate that the effect of fuel volume fraction on conversion ratio is flux dependent and that for the same fuel volume fraction the removal of fuel to incorporate a center moderator is not as detrimental to conversion ratio as is the removal of fuel uniformly over the pressure tube area. Therefore, the optimization studies have generally shown that higher conversion ratios can be more readily achieved in a thorium metal nested-cylinder core than in the pin cores.

The correlations also indicate that the conversion ratio decreases with increasing burnup and specific power, but the decrease is slow enough to permit economic optimization without large penalties in the conversion ratio. It is significant that the conversion ratio is sufficiently sensitive to the volume fraction of thorium that a near-optimum design requires a relatively high-inventory, high-pressure-drop core for good economy and fuel utilization.

Another fuel utilization aspect of the Thorium HWOCR is the ability to use plutonium for startup and makeup. The availability of low-cost $\because$ plutonium and the late development of the fast breeders would make the plutonium-thorium system especially attractive. The use of plutonium in place of uranium as fissionable material will probably not introduce significant problems, as discussed below and in greater detail in section 3 .

In the metallic fuels, plutonium is in solid solution at the temperatures and composition under consideration for the HWOCR. The microstructure is monophasic alpha-thorium until uranium is bred into the alloy; upon achieving $1.5 \%$ uranium, the precipitation of gamma-uranium commences. This alloy should operate as the comparable thorium-uranium alloy operates.

In the oxide fuel, the operation of $\mathrm{PuO}_{2}$ is expected to be similar to the operation of $\mathrm{UO}_{2}$, as evidenced by irradiation experiments. $\mathrm{PuO}_{2}$ and $\mathrm{UO}_{2}$ are isomorphous and otherwise chemically and physically similar. 
The quaternary, ( $\mathrm{Th}, \mathrm{Pu}, \mathrm{U}) \mathrm{O}_{2}$, developed by the breeding in of uranium would probably behave as the ternary behaves in the region of interest.

In the monocarbide fuel, although there is very little data on (Th, Pu)C, there is no reason to suspect aberrant behavior. ThC, PuC, and UC are isomorphous and similar in chemical and physical properties. The quaternary, $(\mathrm{Pu}, \mathrm{Th}, \mathrm{U}) \mathrm{C}$, in the concentrations of interest for the HWOCR would not be expected to deviate the behavior markedly from the $(\mathrm{Th}, \mathrm{U}) \mathrm{C}$ ternary.

On the basis of the preceding discussion, all three of the thorium fuel forms offer excellent fuel utilization potential, but no one form has a clear-cut superiority over the others.

\subsection{Compatibility of Thorium Fuel Elements With AI-CE HWOCR}

\section{3. 1. Relative Performance}

As discussed in section 2, all three thorium fuel element types are basically compatible with the $1000 \mathrm{MWe}$ Uranium HWOCR. However, varying economic penalties are incurred in adapting the elements to the HWOCR design, depending on the fuel material and the assumptions or methods used in making the adaptation. By definition, the governing thorium carbide properties are similar to those of uranium carbide, and the thorium monocarbide fuel element is specifically designed for the Uranium HWOCR.

The nested-cylinder design can be adapted to the 1000 MWe HWOCR without imposing an economic penalty on fuel cycle cost provided the full power capability of the element is utilized. The thorium metal nested-cylinder fuel element does have a capability for more power output per unit of volume than a uranium carbide fuel element does. Therefore, not all of the pressure tubes in the AI-CE HWOCR are needed to achieve the same power output with nested-cylinder fuel elements. If the secondary equipment were sized for a "stretch" capability, the use. of thorium metal nested-cylinder fuel elements in the AI-CE HWOCR would allow an increase in the station power rating and would improve the economic performance.

The thorium oxide fuel element has a relatively low linear heat rate in comparison with the uranium carbide fuel element. The thorium oxide element can be adapted to the AI-CE HWOCR by using 55 pins instead of 37 pins, as noted in section 2. 4. However, the smaller pin 
size required is less than the optimum and imposes a fuel cycle cost penalty of about 0.10 mill per kwhr.

Thus, the thorium fuel materials and both pin and nestedcylinder geometries are basically compatible with the AI-CE HWOCR design. Additional effort to define the best method of achieving the necessary modifications could further reduce the already small economic penalties.

\section{3.2. R\&D Spinoff}

Information on the selection, specification, procurement, fabrication, properties, characteristics, and irradiation behavior of SAP will necessarily be obtained from AI-CE if thorium dioxide or monocarbide is selected as the fuel material. Similarly, engineering tests performed by AI-CE will be generally applicable to the clustered-pin thorium fuel elements.

If thorium monocarbide is chosen, AI-CE's fabrication experience with uranium monocarbide will provide a useful reference basis for $B \& W$ 's investigations. Specifically, knowledge of methods of casting, finishing, and inspecting pellets will be required.

AI-CE's experience with WR- 1 irradiations will also prove beneficial to the $B \& W$ program. Applicable aspects are design and hazards evaluation of the experiment, fabrication of the bundle, and working arrangements with AECL/WNRE.

The R\&D spinoff is reflected in the development cost es timates given in section 4.4 .

\section{4. Technical Feasibility}

The test programs are discussed in section 3. To enable direct comparison, this section briefly summarizes the key technical problems and the probability of their solution, and the preliminary schedules and cost estimates for the development programs.

\section{4. 1. Key Technical Problems}

\subsubsection{Thorium Metal}

As to the fabrication of fuel elements, the coextrusion conditions for large-diameter, thin-walled cylinders have not been fully established. The process will require development to ensure dimensional reliability and security of the end-closure. The control of 
coolant channel gaps with spacing devices poses another problem, which cannot be fully assessed until irradiation testing is performed. Proof testing is also required to determine the effect of irradiation on the dimensional stability of the coolant channel.

\section{4. 1.2. Thorium Dioxide}

Further investigation is required to determine the thermal-conductivity and gas-release properties of the dioxide in both pellet and powdered forms. The thermal conductivity investigation is particularly troublesome because of the possibility of large errors in the determination, the high temperatures that must be achieved, and the added difficulty of working with powder. The buildup of gas pressure within the low-ductility SAP cladding could cause clad rupture and will require careful surveillance.

\section{4. 1.3. Thorium Monocarbide}

The principal difficulty in fabricating thorium monocarbide is its reactivity with moisture. Therefore, thorium monocarbide must be stabilized by alloying, or dry-processing techniques must be used. After establishing the best route, casting, finishing, and inspection procedures must be developed. Since no neutron irradiation of thorium monocarbide has been reported, the dimensional and chemical stability and gas release properties must be established.

4. 4.2. Probability of Successful Development

4.4.2.1. Thorium Metal

The fabrication unknowns probably can be resolved within the time allowed. However, the effect of irradiation on the coolant channel gaps will require extensive testing to determine whether a problem exists; if there is a problem, a long and costly procedure may be required to solve it. We feel that the technology to be developed in the proposed development program would help solve such a problem.

\subsubsection{Thorium Dioxide}

The thermal conductivity may not be conclusively determined in this program because the techniques and methods of interpretation are controversial. In any case, the program should 
make a significant contribution to the overall solution and make available working values for reactor designers. The gas-release and pressurebuildup problem will be fully appreciated only after irradiation testing; any existing problems probably could be solved by introducing additional plenum space, using less gaseous feed material (may require development), or by using pellets instead of powder (introduces other difficulties). It is felt that current technology can provide the ultimate solution.

\section{4.2.3. Thorium Monocarbide}

Owing to the low uranium content of the monocarbide, we may not be able to achieve stabilization without excessive alloying. However, this point can be readily determined, and dry-box procedures can be used if necessary. There should be no irradiation problems other than those arising from the use of uranium monocarbide. There is still a great deal of uncertainty associated with this material, and the large economic penalty imposed by dry-box procedures and the unknown effect of neutron irradiation reduce the chance of using monocarbide successfully.

\section{4. 3. Development Costs and Schedules}

The fuel element test programs are defined in section 3 . Preliminary cost estimates for these programs are summarized in Table 4-7, and schedules are shown in Eigures 4-5, 4-6, and 4-7. All the test programs are scheduled for completion in FY-1972. Initial WR- 1 irradiations of thorium-oxide and thorium-metal (multicylinder) fuel elements could begin in 18 months, considering USAEC FY-1967 budgeting restraints. Thorium monocarbide irradiation could begin in two years. The total cost estimates for the fuel element test programs through FY-1972 are $\$ 5,005,300$ for thorium oxide, $\$ 7,366,300$ for thorium metal, and $\$ 7,123,800$ for thorium monocarbide. These estimates are preliminary and are primarily intended to show the relative costs of developing these fuel elements as a factor in the selection of a reference design.

As discussed in section 3.5, some $R \& D$ (not included in the fuel element test programs) in the areas of experimental physics and recycle technology will be required to realize commercial acceptance of the HWOCR thorium fuel cycle. 
The total experimental physics program outlined in section 3.5 is estimated to cost approximately $\$ 1.8$ million and to require three to five years. There is no appreciable difference in cost among the three fuel element types being considered. It is assumed that the physics work will be done at the Savannah River Laboratory.

Relative costs only were estimated for recycle technology development. These estimates are based on two major assumptions:

1. The TRIP facility process flow sheets to be developed are those reported in $\mathrm{BAW}-393-3^{6}$ for metal and oxide; the carbide flow sheet is similar for reprocessing, but uses essentially pellet technology in canning cast monocarbide slugs.

2. Except for the problem areas listed in section 3. 5, the current state-of-design technology is adequate to allow the TRIP facility to be designed today with a reasonable probability of success.

Based on these assumptions, the relative development costs were evaluated for each major phase of fuel recycle and are tabulated below.

Relative recycle development cost

\begin{tabular}{lccc}
\cline { 3 - 4 } Fuel type & Reprocessing & Conversion & Fabrication \\
\cline { 3 - 4 } Oxide & $\mathrm{X}$ & $\mathrm{Y}$ & $\mathrm{Z}$ \\
Metal & $\mathrm{X}$ & $2 \mathrm{Y}$ & $5 \mathrm{Z}$ \\
Carbide & $2 \mathrm{X}$ & $5 \mathrm{Y}$ & $3 \mathrm{Z}$
\end{tabular}

To arrive at final récycle develupment costs, a wcighting was assigned to the separate steps of recycle. This weighting was 0.35 for reprocessing, 0.15 for conversion, and 0.50 for fabrication. Applying this weighting to the values just given, the final relative development costs are:

$\begin{array}{lr}\text { Oxide } & X \text { (dollars) } \\ \text { Metal } & 3 X \text { (dollars) } \\ \text { Carbide } & 3 X \text { (dollars) }\end{array}$


The stability characteristics of the HWOCR should be similar to those of other large $\mathrm{D}_{2} \mathrm{O}$-moderated reactors except that the use of neutron-absorbing organic coolant leads to positive. void coefficients. It is assumed that the control system designed by AI-CE for the Uranium HWOCR will be applicable to the thorium system. Thorium, because of its higher cross section, tends to provide a more stable system; conversely, the poison control material has less reactivity effect in controlling an oscillation in the thorium system than in the uranium system. Preliminary two-dimensional control studies indicate that the Thorium HWOCR will respond well to a control system similar to that proposed by AI-CE. The question of $\mathrm{Pa}-233$ decay to $\mathrm{U}-233$ during a shutdown and the corresponding additional load placed on the control system is recognized, but has not been evaluated yet. (A 30-day shutdown would decay about half the protactinium and inject approximately $1.5 \% \Delta \mathrm{k} / \mathrm{k}$ into a typical core.)

A basic question arises as to whether any one of the three thorium fuel element designs is better suited to the HWOCR because of safety or control considerations. At this stage, no grounds have been established that would allow us to assume that any reactor dynamic characteristic will be sufficiently magnified or suppressed to cause the selection or rejection of a design on the basis of control or safety. This is not to say that all three fuel element types have the same coefficients or transient response, but that there are not enough differences to influence the choice of a design for further development. Conductivity differences among the three fuel matrices will yield varying Doppler coefficients. The nested-cylinder design was not expected to have a Doppler coefficient comparable to those of the clustered-pin designs because of the high metal conductivity; however, ORNL calculations showed that the Doppler coefficient of the metallic cylinder is more effective than that of the others.

Relative isolation of the coolant channels in the nested-cylinder element will undoubtedly produce void reactivity characteristics that are different from those of the open-lattice clustered-pin element with associated interchannel coolant mixing. Contributions external to the pressure tube, however, will affect all fuels in much the, same manner, that is, they will affect $D_{2} \mathrm{O}$ purity, $\mathrm{D}_{2} \mathrm{O}$ voiding, $\mathrm{D}_{2} \mathrm{O}$ temperature, 
leakage, control material insertion, etc. Only a detailed study of a given design will ascertain the dynamic characteristics and the suitability of a fuel element for HWOCR application. Such information is not now available for any design and, therefore, cannot be used as a factor in the evaluation. Safety studies of this type are planned for FY-1967.

\subsection{Commercial Acceptance}

The prime consideration of the electric utility industry in the United States in evaluating fuels is the power generation cost. In this respect, based on a reasonable extrapolation of existing technology, thorium metal fuel elements in a 1000-MWe HWOCR will provide power cost savings of about $0.15 \mathrm{mill} / \mathrm{kwhr}$ over oxide or carbide. This savings, if realized in commercial practice, is clearly sufficient to justify utility preference for thorium metal.

However, the United States' nuclear economy is geared to the $\mathrm{UO}_{2}$ fuel cycle. To reach a similar commercial position, wide-scale acceptance of thorium fuels by the electric utility industry is necessary. Such acceptance will require proven performance of the fuel cycle. In this respect, the transferability of $\mathrm{UO}_{2}$ experience makes $\mathrm{ThO}_{2}$ the most likely thorium candidate to win commercial acceptance in the United States market.

In foreign countries having no enrichment facilities, the prime objective of a thorium reactor would be to achieve minimum fissile material requirements. Therefore, the goal is a thorium breeder or near-breeder. As discussed in section 4.2, the conversion ratio is strongly dependent on the fuel volume fraction within the pressure tube. The designs optimized for economics have about the same converston ratio; however, optimization studies indicate that near-breeder performance can be most readily achieved with the thorium metal nestedcylinder design. Commercial application of a thorium inetal fuel cycle, including recycle, in a foreign country would face difficulties similar to those expected in the United States.

\subsection{Summary}

The three thorium fuel element types have been evaluated according to the factors that are pertinent to the objectives of the HWOCR Thorium Fuel Cycle Development Program. The lack of data in many 
areas of thorium technology makes it difficult to reach sound conclusions. Therefore, the uncertainties in the results have also been evaluated. The conclusions reached for individual evaluation factors provide the bases for weighing alternate courses of action as reported in section 5 .

Table 4-1. 30-Year Levelized Fuel Cycle Cost, u. U-235 Startup Fuel

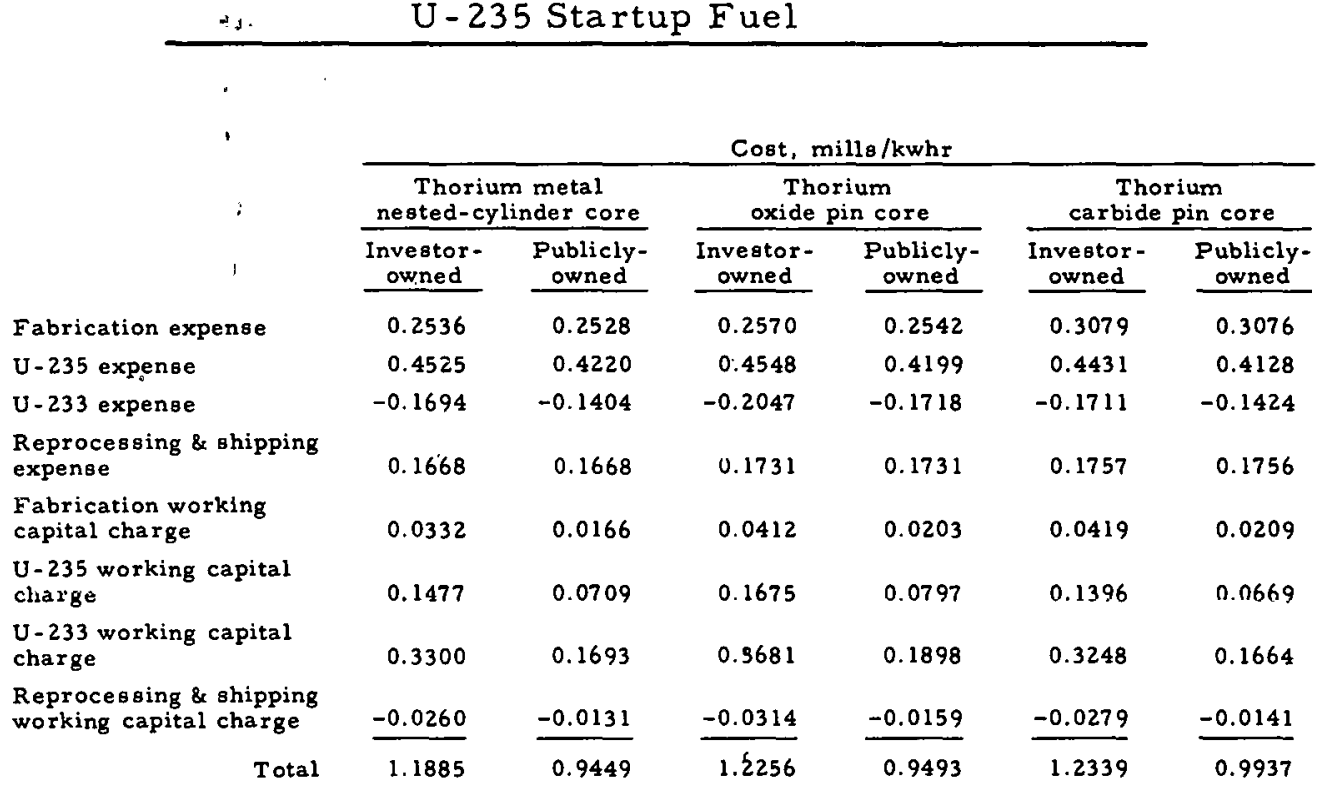

Table 4-2. 30-Year Levelized Fuel Cycle Cost, Plutonium Startup and Recycle

\begin{tabular}{|c|c|c|c|c|c|}
\hline & & & Cost, $n$ & lls/kwhr & \\
\hline & t. & Oxide & in core & Nested-c & nder core \\
\hline & t & $\begin{array}{l}\text { Investor- } \\
\text { owned }\end{array}$ & $\begin{array}{l}\text { Publicly- } \\
\text { owned }\end{array}$ & $\begin{array}{l}\text { Investor - } \\
\text { owned }\end{array}$ & $\begin{array}{l}\text { Publicly- } \\
\text { owned }\end{array}$ \\
\hline & Fabrication expense & 0.246 .0 & 0.2464 & 0.2456 & 0.2457 \\
\hline & $U-235$ expense & 0.4819 & 0.4520 & 0.4706 & 0.4434 \\
\hline & U-233 expense & -0.2166 & -0.1854 & -0.1888 & -0.1611 \\
\hline & $\begin{array}{l}\text { Reprocessing \& shipping } \\
\text { expense }\end{array}$ & 0.1706 & 0.1706 & 0.1661 & 0.1662 \\
\hline & $\begin{array}{l}\text { Fabrication working } \\
\text { capital charge }\end{array}$ & 0.0394 & 0.0196 & 0.0324 & 0.0162 \\
\hline & $\begin{array}{l}\text { U- } 235 \text { working capital } \\
\text { charge }\end{array}$ & 0.1527 & 0.0720 & 0.1338 & 0.0636 \\
\hline & $\begin{array}{l}\text { U- } 233 \text { working capital } \\
\text { charge }\end{array}$ & 0.3796 & 0.1974 & 0.3479 & 0.1799 \\
\hline & $\begin{array}{l}\text { Reprocessing \& shippinf } \\
\text { working capital charge }\end{array}$ & -0.0307 & -0.0155 & -0.0259 & -0.0131 \\
\hline$\quad \therefore$ & Total & 1.229 & 0.9572 & 1.1818 & 0.9408 \\
\hline
\end{tabular}




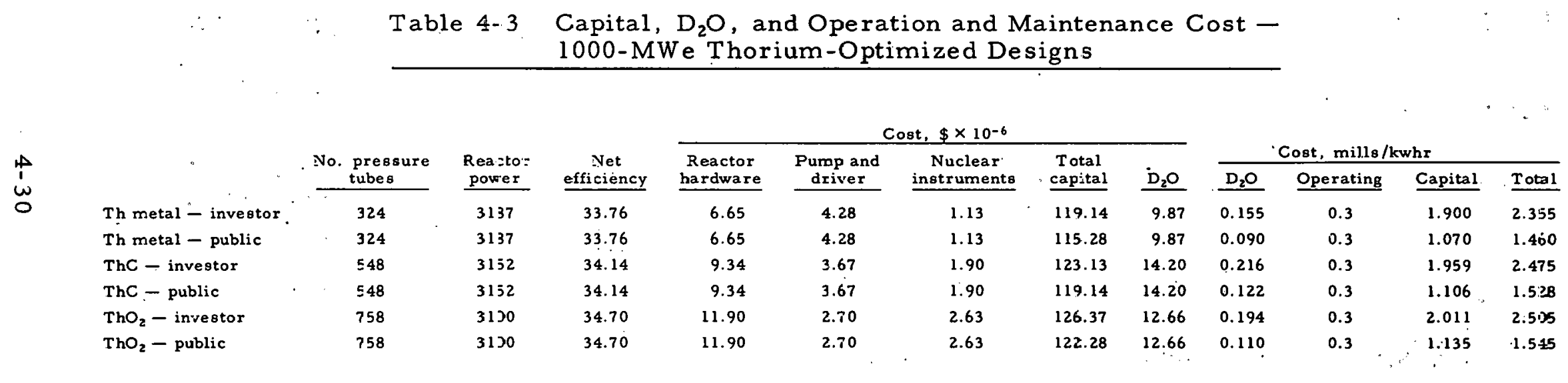




\section{Table 4-4. Batch 'Idealized" Cycle Fuel Cycle Costs}

\begin{tabular}{|c|c|c|c|c|c|c|c|}
\hline \multirow{2}{*}{\multicolumn{2}{|c|}{ 100-MWe Th-optimized design, $\mathrm{MWD} / \mathrm{T}$}} & \multicolumn{3}{|c|}{ Nested cylinder } & \multirow{2}{*}{$\frac{\text { Carbide pin }}{22,000}$} & \multicolumn{2}{|c|}{ Oxide pin } \\
\hline & & 11,550 & 14,920 & 19,300 & & - & 22,450 \\
\hline & Fuel cycle cost, mills/kwhr & & & & & & . \\
\hline \multirow{4}{*}{$\begin{array}{l}\stackrel{\oplus}{1} \\
\omega \\
\omega\end{array}$} & Investcr-owned & 1.199 & 1.121 & $\begin{array}{l}1.067 \\
0.853\end{array}$ & 1.083 & -- & $=1.070$ \\
\hline & $\begin{array}{l}\text { Thorium core for AI-CE } 1000-\mathrm{MWe} \\
\text { HWOCR, MWD/T }\end{array}$ & 17,500 & 20,300 & -- & 22,000 & 16,360 & 19,300 \\
\hline & Fuel cycle cost, mills/kwhr & & & & & & \\
\hline & $\begin{array}{l}\text { Investor-owned } \\
\text { Publicly-owned }\end{array}$ & $\begin{array}{l}1.102 \\
0.881\end{array}$ & $\begin{array}{l}1.075 \\
0.857\end{array}$ & -- & $\begin{array}{l}1.083 \\
0.879\end{array}$ & $\begin{array}{l}1.265 \\
1.089\end{array}$ & $\begin{array}{l}1.200 \\
1.031\end{array}$ \\
\hline
\end{tabular}


Table 4-5. Comparative Unit Processing Costs for ThoriumOptimized HWOCR Fuel Elements

Fuel type

Alloy nested-cylinder ${ }^{(b)}$

Oxide pin (c)

Carbide pin ${ }^{(\mathrm{d})}$
Total unit processing cost, $\$ / \mathrm{kg}^{(\mathrm{a})}$

ORNL estimates compiled at B\&W

$\underline{B \& W}$ estimates

67

73

74

70

81

(a) Includes reprocessing, conversion, fabrication and shipping.

(b) Four-cylinder, center moderator, 5-inch-ID préssure tube.

(c) 37-pin, 0.510-inch ID, 4.03-inch pressure tube.

(d) 37-pin, 0.493-inch ID, 4.03-inch pressure tube:...

Table 4-6. Comparison of Dynamic Fuel Utilization

Thorium HWOCR

\begin{tabular}{lcc}
\hline 4-cylinder & $37-$ pin & 37 -pin \\
Thmetal & Th oxide & Th carbide \\
\hline
\end{tabular}

Specific inventory,

tons $\mathrm{U}_{3} \mathrm{O}_{8} / \mathrm{MWe}$

0.74

0.85

0.71

Specific burnup,

tons $\mathrm{U}_{3} \mathrm{O}_{8} / \mathrm{MWe}-\mathrm{yr}$

0.052

0.047

0.054

Dynamic fuel utilization, $\mathrm{MWe}-\mathrm{yr} /$ ton $\mathrm{U}_{3} \mathrm{O}_{8}$, for

nuclear economy doubling time:
$5 \mathrm{yr}$
5.5
5.2
5.6
$7 \mathrm{yr}$
7.0
6.0
7.0
$10 \mathrm{yr}$
8.5
8.3
8.7 
$\because$
$\cdots$
$\because$
-

Table 4-7. Fuel Element Test Program Preliminary Cost Estimate Summary (\$)

1. Thorium Metal Nested-Cylinder Fuel Element

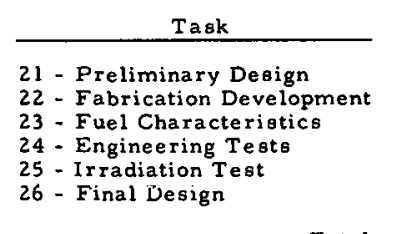

Total

\begin{tabular}{|c|c|}
\hline 67 & 68 \\
\hline $\begin{array}{l}150,000 \\
257,100\end{array}$ & $\begin{array}{l}110,000 \\
635,600\end{array}$ \\
\hline -. & 431,100 \\
\hline-- & 175,000 \\
\hline 74,600 & 274,100 \\
\hline$\therefore$ & $\therefore$ \\
\hline 481,700 & $1,625,800$ \\
\hline
\end{tabular}

Fiscal year

\begin{tabular}{|c|c|c|c|c|}
\hline 69 & 70 & 71 & 72 & Total \\
\hline $\begin{array}{c}110,000 \\
625,800 \\
537,100 \\
229,000 \\
476,500 \\
\ldots\end{array}$ & $\begin{array}{r}60,000 \\
422,800 \\
476,900 \\
224,000 \\
276,000 \\
175,000\end{array}$ & $\begin{array}{c}177,800 \\
357,600 \\
- \\
523,100 \\
300,000\end{array}$ & $\begin{array}{c}- \\
\cdots \\
76,600 \\
-- \\
65,600 \\
145,000\end{array}$ & $\begin{array}{r}430,000 \\
2,119,100 \\
1,879,300 \\
628,000 \\
1,689,900 \\
620,000\end{array}$ \\
\hline 978,400 & $1,634,700$ & $1,358,500$ & 287,200 & $7,366,300$ \\
\hline
\end{tabular}

2. Thorium Dioxide Clustered-Pin Fuel Element

Fiscal year

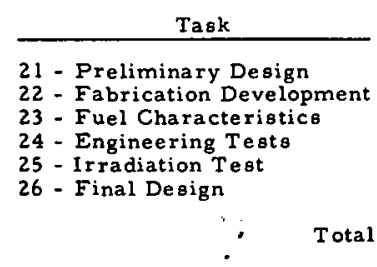

Fiscal year

\begin{tabular}{|c|c|c|c|c|c|c|}
\hline 67 & 68 & 69 & 70 & 71 & 72 & Total \\
\hline $\begin{array}{l}150,000 \\
220,900\end{array}$ & $\begin{array}{r}110,000 \\
85,900\end{array}$ & $\begin{array}{r}110,000 \\
35,000\end{array}$ & 60,000 & $\because$ & -- & $\begin{array}{l}430,000 \\
341,800\end{array}$ \\
\hline$\cdots$ & 467,800 & 763,700 & 403,100 & 62,700 & -- & $1,697,300$ \\
\hline-- & - & 42,000 & 124,000 & $65 ; 000$ & -- & 216,000 \\
\hline 82,100 & 154,300 & 361,100 & 321,800 & 467,300 & 298.600 & $1,685,200$ \\
\hline-- & -- & - & 175,000 & 300,000 & 145,000 & 620,000 \\
\hline 453,000 & 818,000 & $1,311,800$ & $1,083,900$ & 895,000 & 443,600 & $5,005,300$ \\
\hline
\end{tabular}

3. Thorium Monocarbide Clustered-Pin Fuel Element

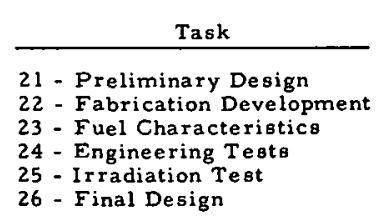

Total

\begin{tabular}{|c|c|c|}
\hline 67 & 68 & 69 \\
\hline $\begin{array}{l}150,000 \\
207,800\end{array}$ & $\begin{array}{l}110,000 \\
667,200\end{array}$ & $\begin{array}{l}110,000 \\
625,000\end{array}$ \\
\hline-- & 387,700 & 529,600 \\
\hline$=$ & $\therefore$ & 42,000 \\
\hline 131,300 & 333,700 & 356,400 \\
\hline$\therefore$ & $\ldots$ & -- \\
\hline 489,100 & $\overline{1,498,600}$ & $1,663,000$ \\
\hline
\end{tabular}

Fiscal year

\begin{tabular}{|c|c|c|c|}
\hline 70 & 71 & 72 & Total \\
\hline $\begin{array}{r}60,000 \\
650,000 \\
292,200 \\
124,000 \\
505,900 \\
175,000\end{array}$ & $\begin{array}{c}-- \\
194,100 \\
50,000 \\
589,800 \\
300,000\end{array}$ & $\begin{array}{c}- \\
88,100 \\
299,000 \\
145,000\end{array}$ & $\begin{array}{r}430,000 \\
2,150,000 \\
1,491,700 \\
216,000 \\
2,216,100 \\
620,000\end{array}$ \\
\hline & $1,133,900$ & 100 & 800 \\
\hline
\end{tabular}


Figure 4-1. Fuel Cycle Cost Vs Fuel Exposure

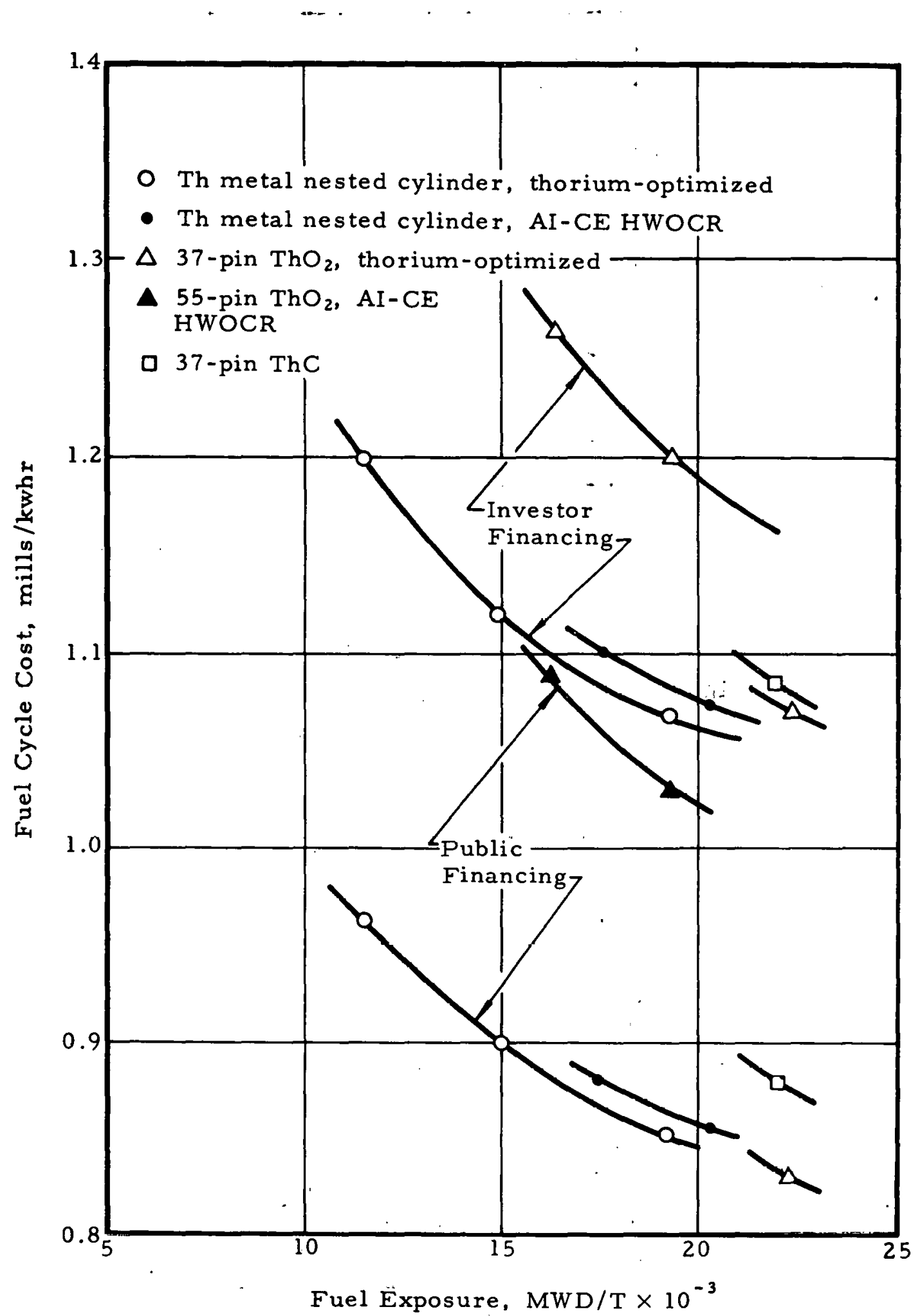


Figure 4-2. Fuel Cycle Cost Vs Plutonium Value (Oxide Core)

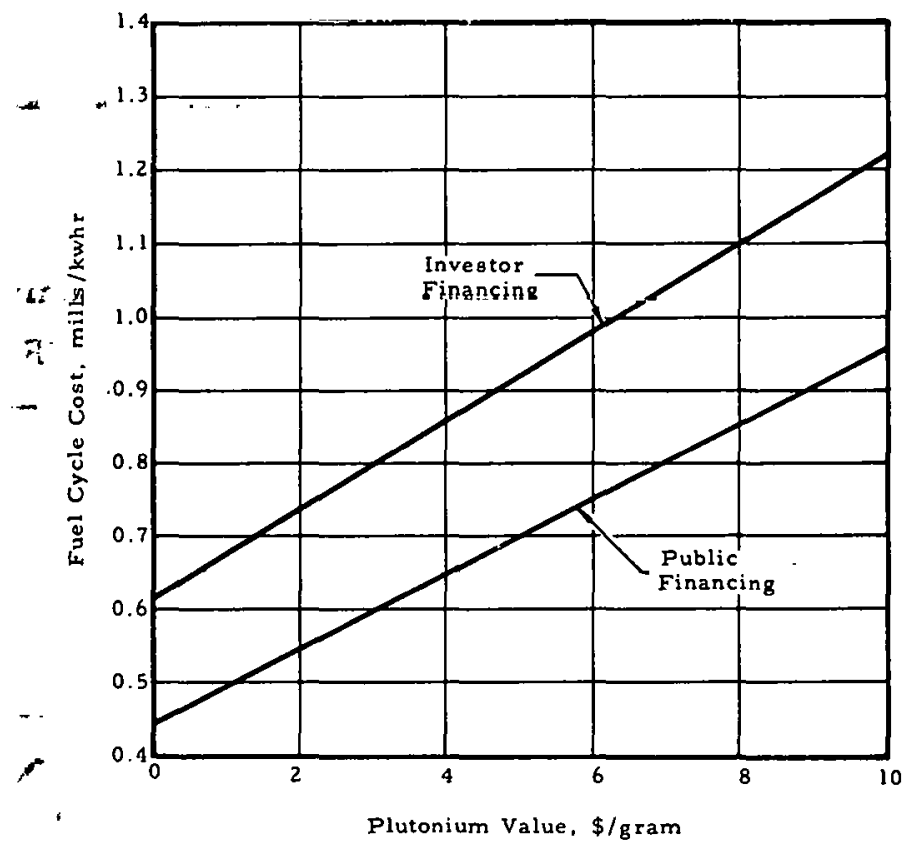

Figure 4-3. Effect of Allowable Cladding Surface Temperature on Core Pressure Drop and Coolant Outlet Temperature.

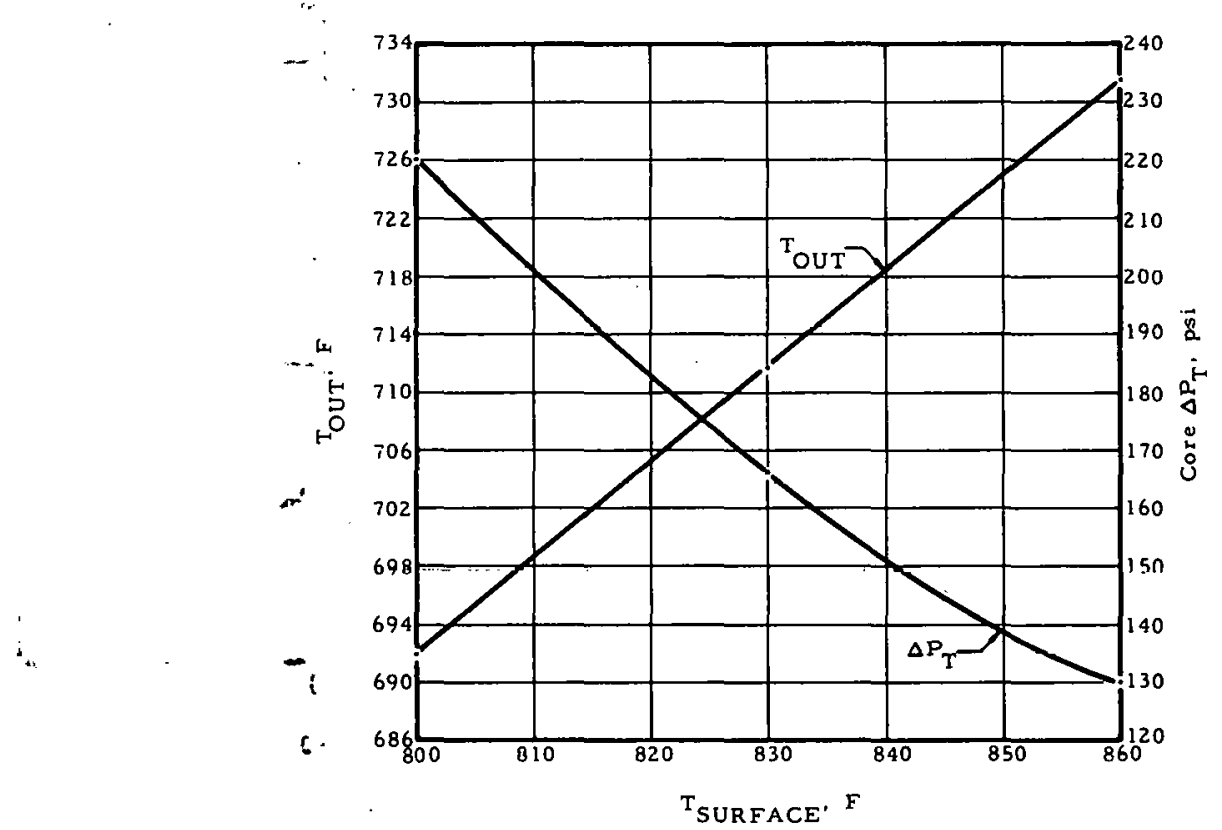


Figure 4-4. Thorium Fuel Elements: Conversion Ratio Factor Vs Fuel Volume Fraction

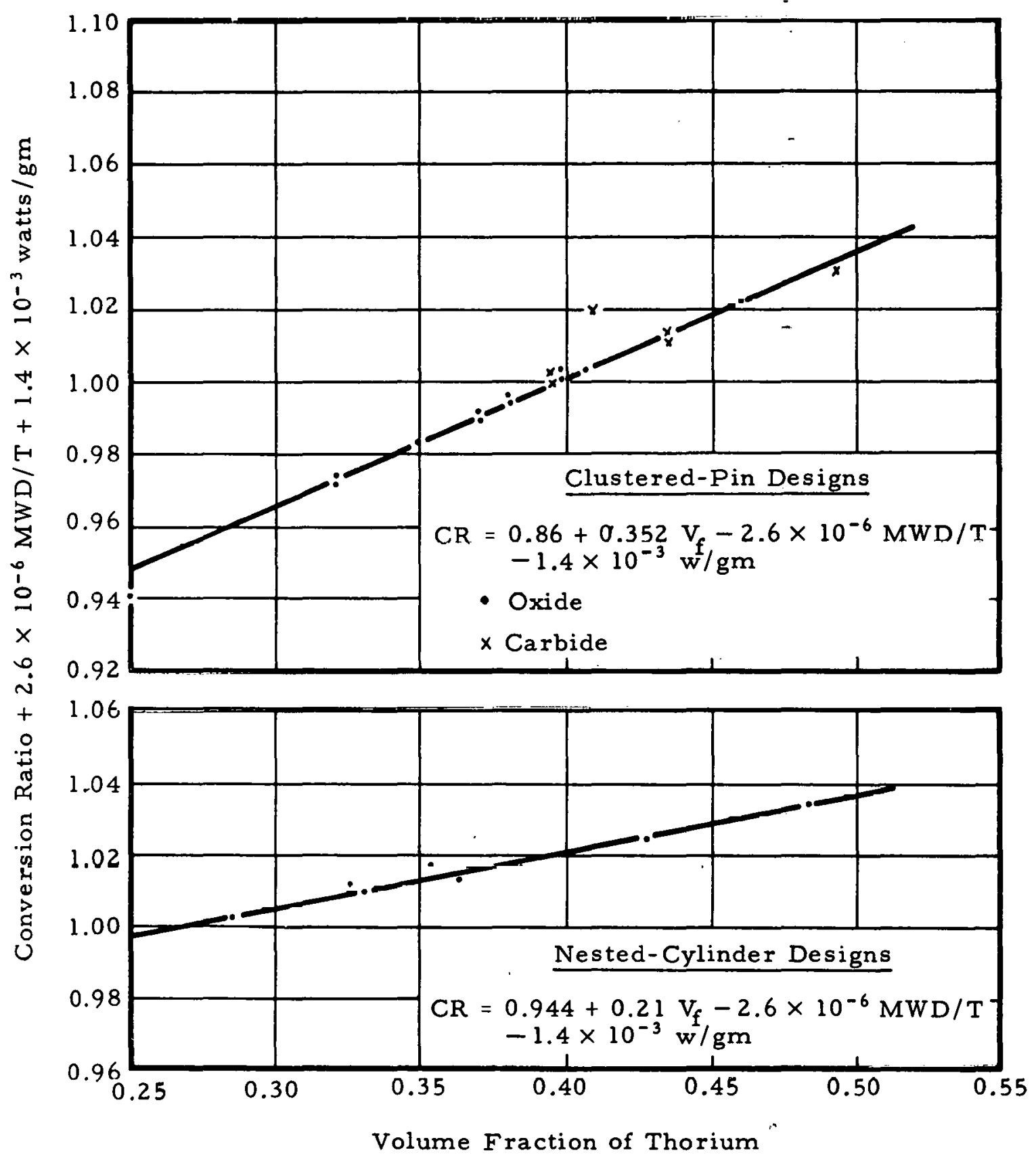


Figure 4-5. Preliminary Schedule for Thorium Metal Nested-Cylinder Fuel Element Test

Program

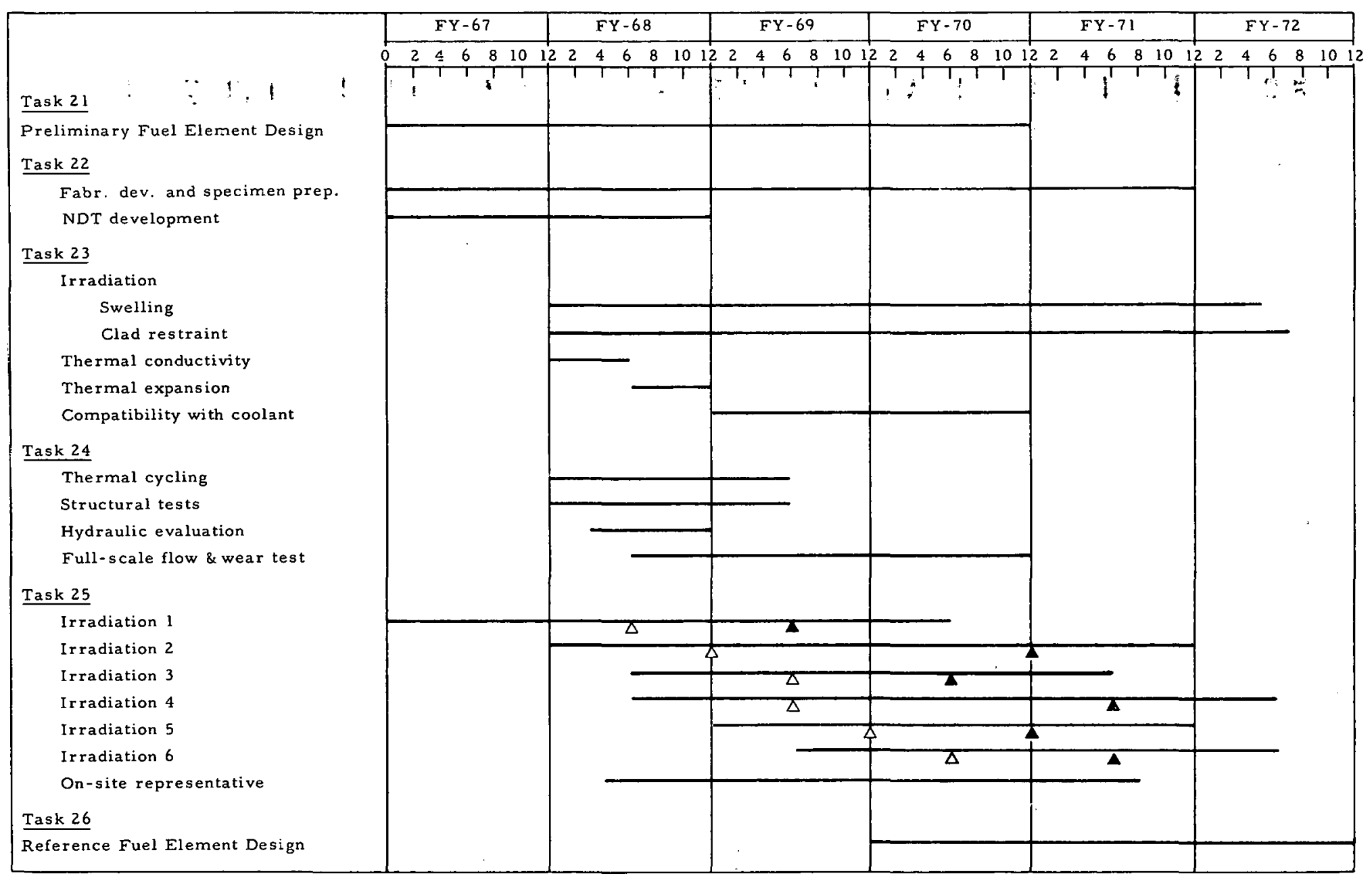

$\Delta \quad$ Enter WR-1

- Leave WR-1 
Figare 4-6. Preliminary Schedule for Thorium Oxide Clustered-Pin Fuel Element Test Program

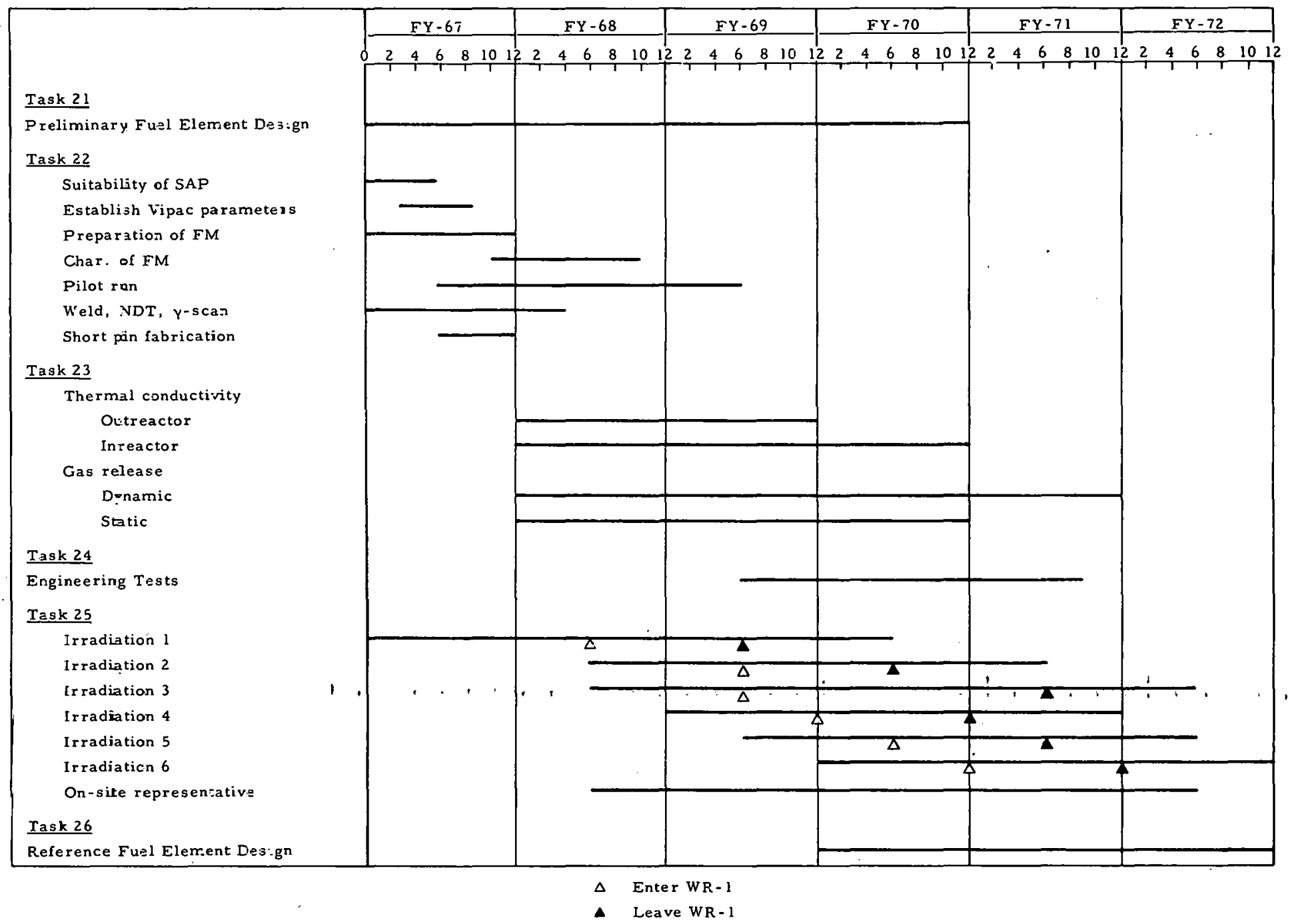


Figure 4-7. Preliminary Schedule for Thorium Monocarbide Clustered-Pin Fuel

Element Test Program

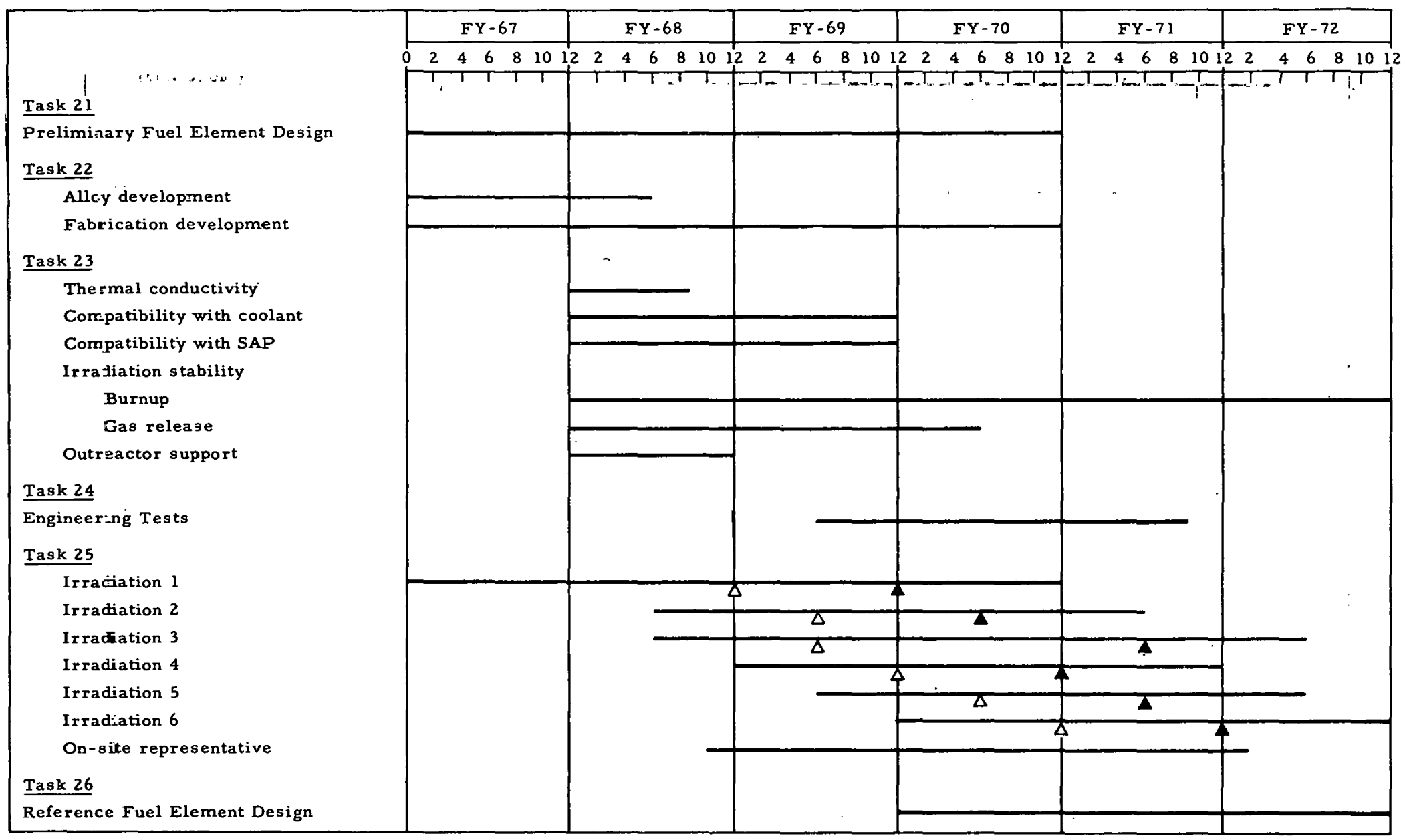

$\triangle \quad$ Enter WR-1

- Leave WR-1 
1 Kasten, P. R., et al. An Evaluation of Heavy-Water-Moderated, Organic Cooled Reactors (preliminary rough draft), Oak Ridge $\mathrm{Na-}$ tional Laboratory, Oak Ridge, Tennessee, January 21, 1966.

2 Thorium Fuel Cycle for Heavy Water Moderated Organic Cooled Reactors, Technical Progress Report No. 4, The Babcock \& Wilcox Company, BAW-393-6, Lynchburg, Virginia, January - March 1966.

3 Rosenthal, M. W., et al. , A Comparative Evaluation of Advanced Converters, USAEC ORNL-3686, Oak Ridge National Laboratory, 1965.

4 Heavy Water Organic Cooled Reactor 500 MWe Nuclear Demonstration Plant, Conceptual Design, AI-CE MEMO 25, March 29, 1966.

5 Washburn, T. N., Oak Ridge National Laboratory, Oak Ridge, Tennessee, private communications, March 2, 1966.

6 Moncrief, E. C., and Schileo, G., Recycle of HWOCR Thorium Fuel, The Babcock \& Wilcox Company, BAW-393-3, Lynchburg, Virginia, March 1966.

7 Washburn, T. N., and Douglas, D. A., Controlling Factors in Determining Fabrication Costs of Metal-Clad Oxide Fuel Elements, Trans. Amer. Nuc. Soc., Vol 8, No. 1, 1965.

8 Burkart, C. A., and Moncrief, E. C., The Babcock \& Wilcox Company, Trip Report to Savannah River Plant, January 14, 1966.

9 Heavy Water, Organic Cooled Reactor - $1000 \mathrm{MWe}$ Nuclear Power Plant Preliminary Conceptual Design, Combustion Engineering, Inc. , and Atomics International, AI-CE MEMO 6, October 1, 1965. 


\section{RECOMMENDATION}

The advantages and disadvantages of developing each type of fuel element are summarized in Table 5-1. A review of these factors leads to a recommendation.

The most obvious conclusion is that there is little incentive for developing thorium monocarbide. The lack of thorium monocarbide data required the assumption of uranium monocarbide characteristics in many areas. On this basis, the thorium monocarbide has about the same economic and fuel utilization performance as thorium oxide. In addition, the thorium monocarbide is at least an order of magnitude more reactive in air than uranium monocarbide. Therefore, ThC must be handled in a dry, inert atmosphere, or it must be alloyed with a stabilizing agent. Considering the potential development problems and the probable lack of economic or fuel utilization advantages, there is no justification for recommending the development of the thorium monocarbide fuel element.

On the basis of our studies, the thorium metal nested-cylinder fuel element offers the best potential for low cost power and efficient fuel utilization. The economic potential is based on the predicted thermal performance, which allows more power output per unit volume and a consequent improvement of about $0.15 \mathrm{mill} / \mathrm{kwhr}$ in capital and $\mathrm{D}_{2} \mathrm{O}$ costs, in comparison with the thorium oxide core. The principal questions in the predicted performance are whether or not the large thin-wall, multicylinder fuel elements can be built economically to the required tolerances and can maintain dimensional stability under long-term $(20,000$ MWD/T average) exposure in an HWOCR environment. These questions cannot be resolved without a development program.

As stated, the economically optimum thorium oxide HWOCR has predicted capital and $\mathrm{D}_{2} \mathrm{O}$ costs about $0.15 \mathrm{mill} / \mathrm{kwhr}$ higher than those for the thorium metal HWOCR. However, the fuel cycle costs and the conversion ratios of the two designs are essentially equal. The pin heat rating (kw/ft), which is primarily responsible for the capital cost 
differential, is limited by fission gas pressure buildup in the low-ductility SAP cladding combined with a relatively low external pressure. Resolution of the fission gas pressure problem could lead to higher pin heat ratings and longer fuel exposures, both of which would improve the economics of the thorium oxide HWOCR.

In general, the technology of thorium fuels is inadequate to draw firm conclusions. Our recommendation must be based ón analytical. studies using existing data. From a technical standpoint, the logical development program will carry both thorium oxide and thorium metal fuel elements through several phases of irradiation testing aimed at determining the dimensional stability of the thorium metal cylinders and the fission gas pressure limits of the thorium oxide pins. With this specific HWOCR-oriented test data available, the correct decision can be made with a high degree of confidence. The two-pronged test program would be a compromise between the separate programs outlined in section 3 and would emphasize obtaining the necessary irradiation performance data in a minimum time.

If practical considerations require the selection of a single fuel element for development, our recommendation is thorium oxide. The power cost difference between the oxide and the metal casses is within the uncertainty band, and the oxide costs can be predicted with more confidence than the metal costs can. The conditions under, which thorium will be used in the HWOCR are also uncertain. The development of a thorium oxide fuel element offers the shortest and cheapjest route and the best probability of success for putting the United States in a position to use thorium in the HWOCR when conditions are favorable. The thorium oxide fuel will require the least initial investment during the buildup of a thorium economy, and the fabrication process has the most flexibility to meet changing conditions (e.g., changes in the value of plutonium that may favor the Thorium HWOCR). In conclusion, the thorium oxide fuel element has the best chance of gaining large-scale application at a minimum development cost. 


\section{Table 5-1. Evaluation of Alternate Courses of Action}

\section{Advantages}

1. Best economic potential of thorium HWOCR's. Estimated total power cos of $3.55 \mathrm{mills} / \mathrm{kwhr}$ is $0.15 \mathrm{mill} / \mathrm{kwhr}$ better than cost of oxide or carbide.

2. Best thermal performance capability. Has more power output per unit volume than clustered-pin fuel element. Therefore, provides a "stretch" capability for AI-CE HWOCR with thorium fuel elements.

3. Good potential for near breeder. High fuel density and adaptability for high fuel volume fraction make high conversion ratio attainable.

4. Different geometry and cladding from AI-CE HWOCR fuel element. Provides a backup fuel element that is not dependent on success of SAP development.

5. Annular fuel elements are being considered as advanced designs for AI- CE HWOCR for desalting application. Th metal fuel element development would be beneficial to development of annular uranium fuel element.

\section{Disadvantages}

1. More design uncertainties than for oxide fuel element. Principal uncertainties are fabrication tolerances and irradiation stability of large thinwall, multicylinder elements.

2. Higher development cost than for oxide. Fuel element test program cost is about $\$ 3$ million higher. Development cost of recycle technology is higher by a factor of about 3 .

3. Commercial acceptability will be hampered by lack of existing economy for metallic fuels and annular geometry.

4. Changes in pressure tube power distribution with fuel burnup will require downgrading of optimum design since each cylinder is designed for maxistartup, but is with Pu startup. Cylinders are more difficult to zone load than pins.

5. Full potential of cylinders cannot be realized in AI- CE HWOCR unles some pressure tubes are blocked off or unless a stretch capability is built into the secondary system equipment.

6. Optimum cylinder design has 5-inch-ID pressure tube. Additional development and testing would be required for.this size pressure tube since AI-

Develop Thorium Oxide Clustered-Pin Fuel Element

Advantages

1. Most advanced stage of development, which means

a. Best probability of success.

b. Less time to demonstrate compatibility of thorium and uranium sys-

c. More certainty in cost estimates.

2. Most likely route for commercial acceptance of thorium fuel cycle because

a. Least initial investment during buildup of thorium economy.

b. Transferability of experience from $\mathrm{UO}_{2}$ economy.

3. Good transferability of technology between following programs :

a. USAEC Thorium Utilization Program.

b. Seed and Blanket (Thorium Breeder) Reactor Program.

c. Canadian Heavy Water Program $\left(\mathrm{ThO}_{2}\right.$ is only form compatible with $\mathrm{H}_{2} \mathrm{O}$ or $\mathrm{D}_{2} \mathrm{O}$ coolant).

d. SAP Development and Engineering Tests from AI-CE Program.

4. Flexibility in fabrication process as follows:

a. Adaptable to Pu startup fuel.

b. Adaptable to enrichment variations and zone loading.

Develop Thorium Monocarbide Clustered-Pin Fuel Element Advantages

1. Maximum spinoff from AI-CE Program as follows:

a. Same geometry.

b. Same cladding.

c. Same basic manufacturing process (note disadvantage 2 ).

2. All R\&D will contribute to basic ThC technology.
Disadvantages

1. Low pin heat rating $(\mathrm{kw} / \mathrm{ft}$ ) which means

a. Higher capital costs than for Th metal core.

b. 55-pin fuel element in AI-CE HWOCR. Smaller diameter pins impose fabrication cost penalty (approximately $0.1 \mathrm{mill} / \mathrm{kwhr}$ ).

2. Uncertainty of fission gas pressure buildup (in SAP-clad pins with low external pressure) limit's performance.

3. Achieving near-breeder performance is more difficult with $\mathrm{ThO}_{2}$ than with higher density Th metal. 